Supporting Information for

\title{
Finite-length models of carbon nanotubes based on Clar sextet theory
}

\author{
M. Baldoni, A. Sgamellotti and F. Mercuri
}

S2: $\quad$ FLCC planar models

S13: Electronic properties of CNTs not discussed in the text

S20: Optimized geometries 


\section{FLCC planar models}

Schematic planar representation of FLCC models used in calculations discussed in the text. Models constituted by three Clar cells (highlighted in black) are superimposed to the hexagonal network corresponding to an infinite-length CNT (in grey). The unit cell is highlighted in green. Equivalent hexagons are shadowed. To build up 3D models cut along the edges and superimpose hexagons labelled with the same letters. When they differ (see text), models originating both from the canonical Clar cell and from our particular choice are shown. 
$(6,6), \mathrm{R}=0$

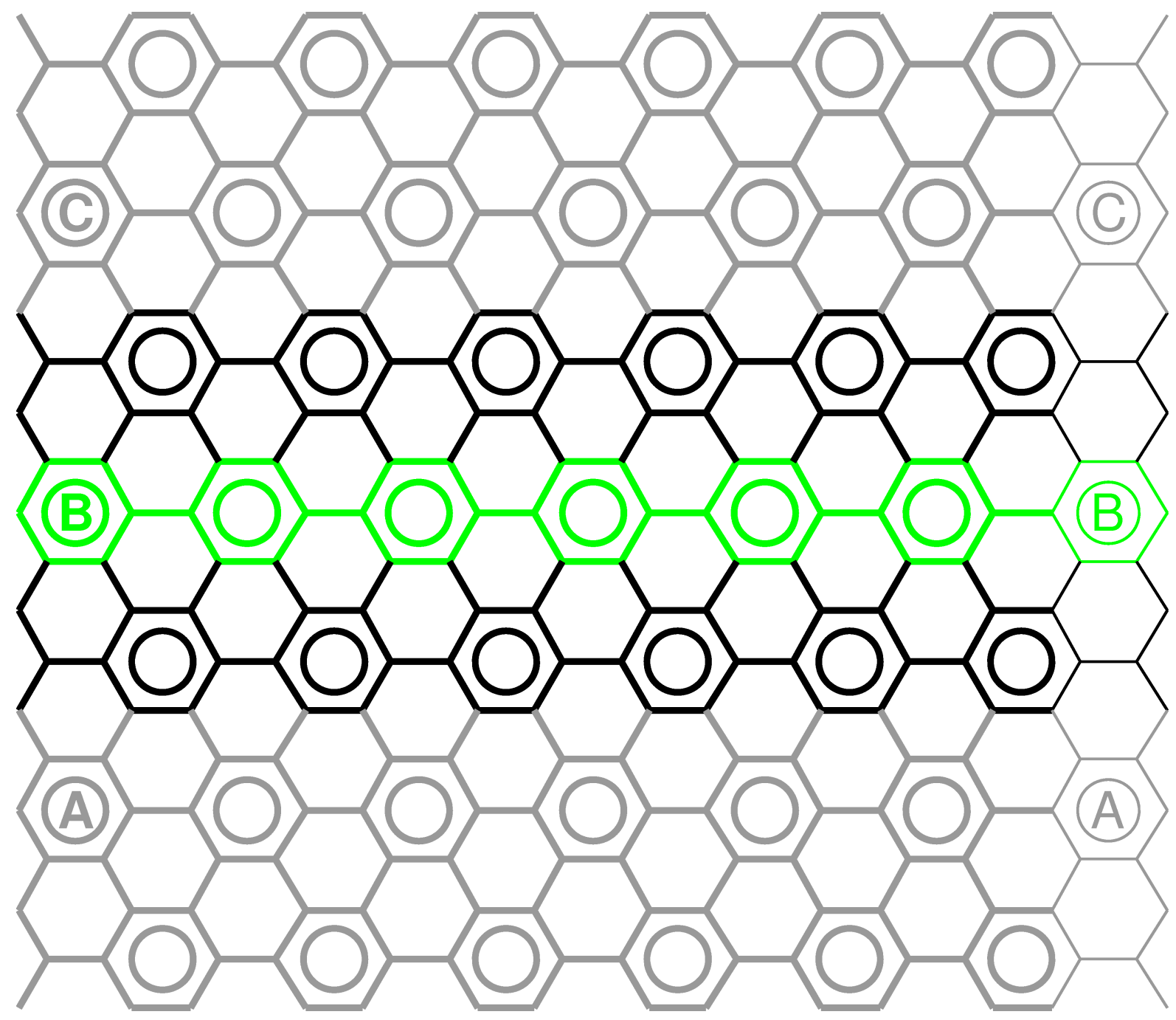


$(9,0), \mathrm{R}=0$ (canonical Clar cell)

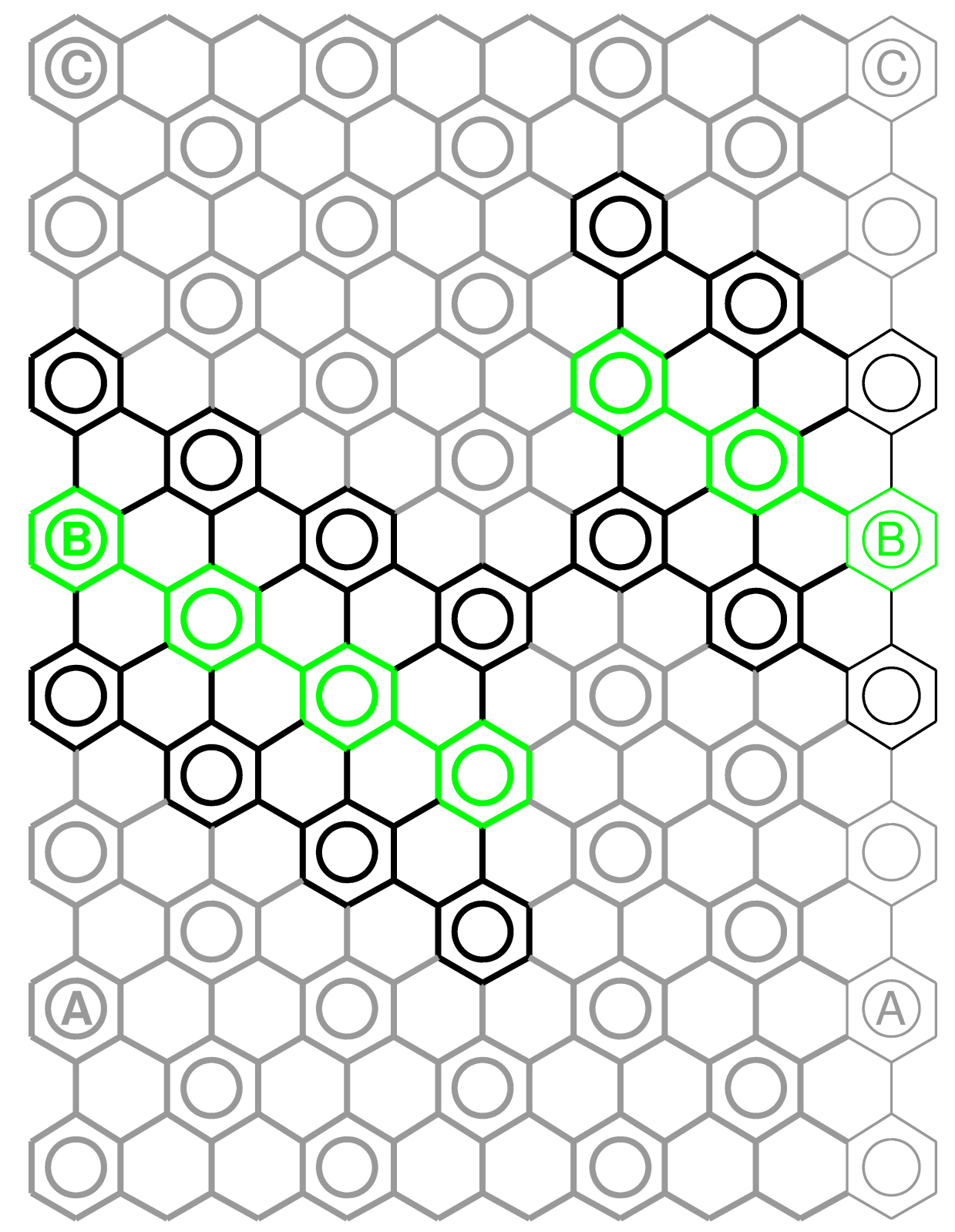


$(9,0), \mathrm{R}=0$ (cell used in calculations)

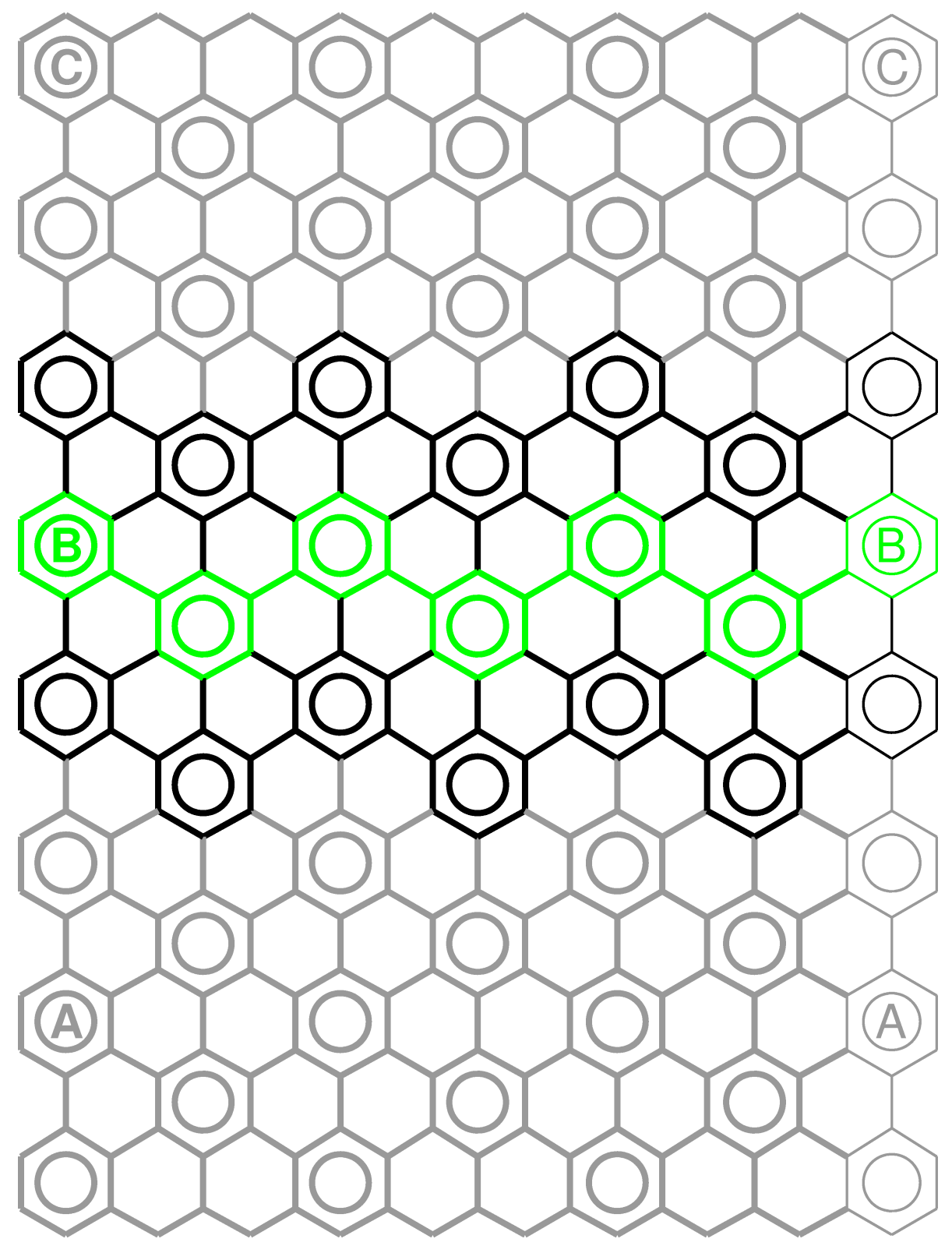




$$
(6,5), \mathrm{R}=1
$$

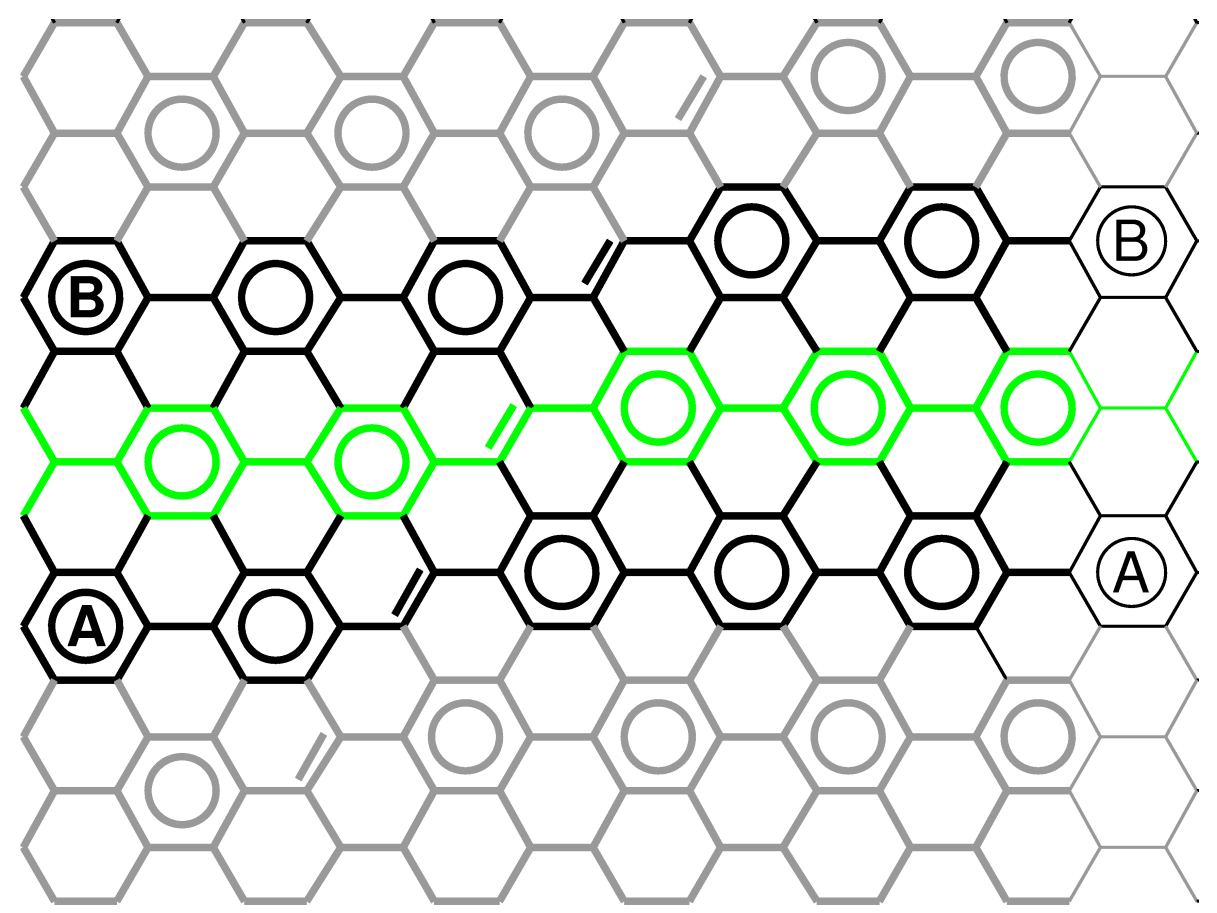


$(7,0), R=1$ (canonical Clar cell)

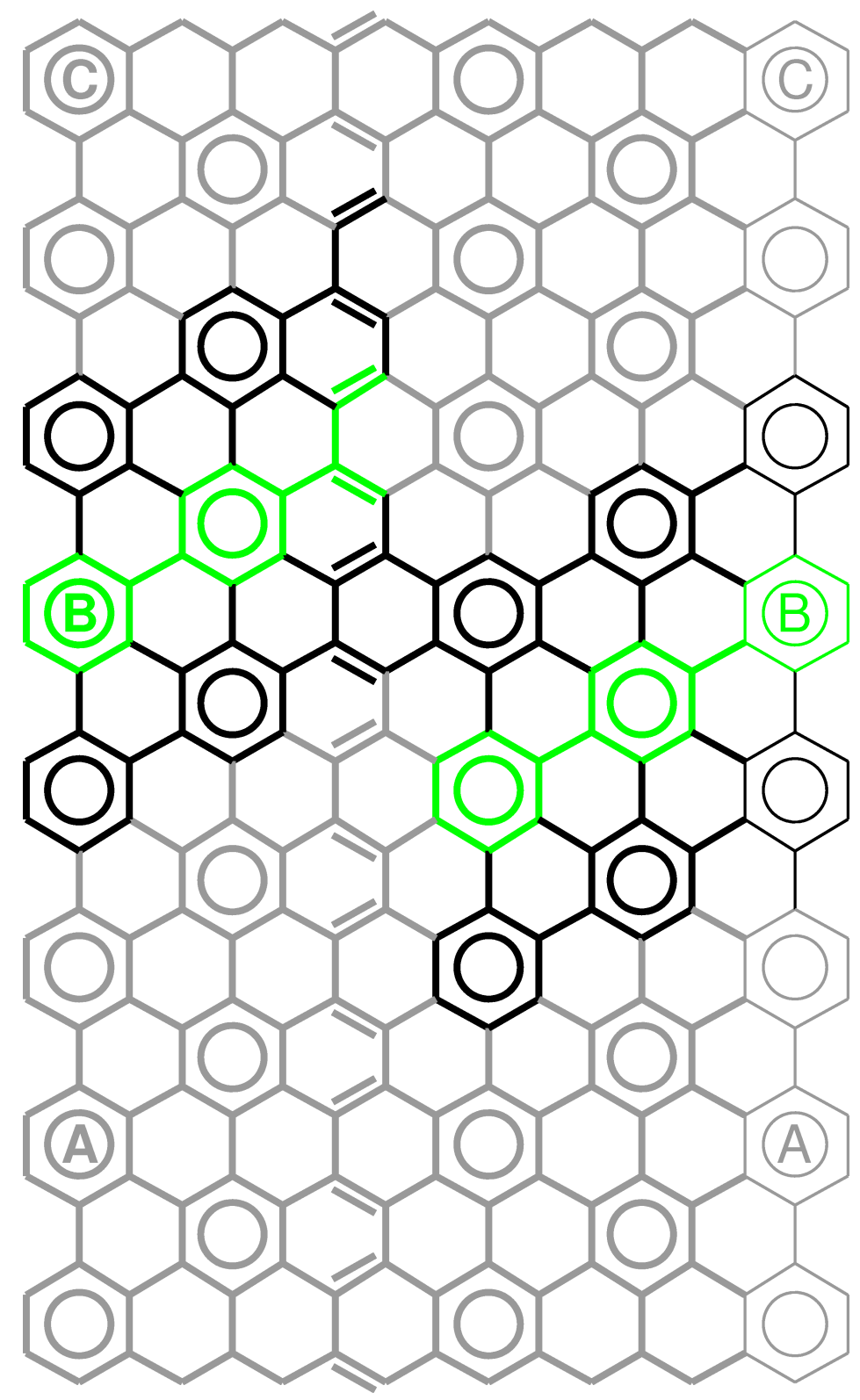


$(7,0), R=1$ (cell used in calculations)

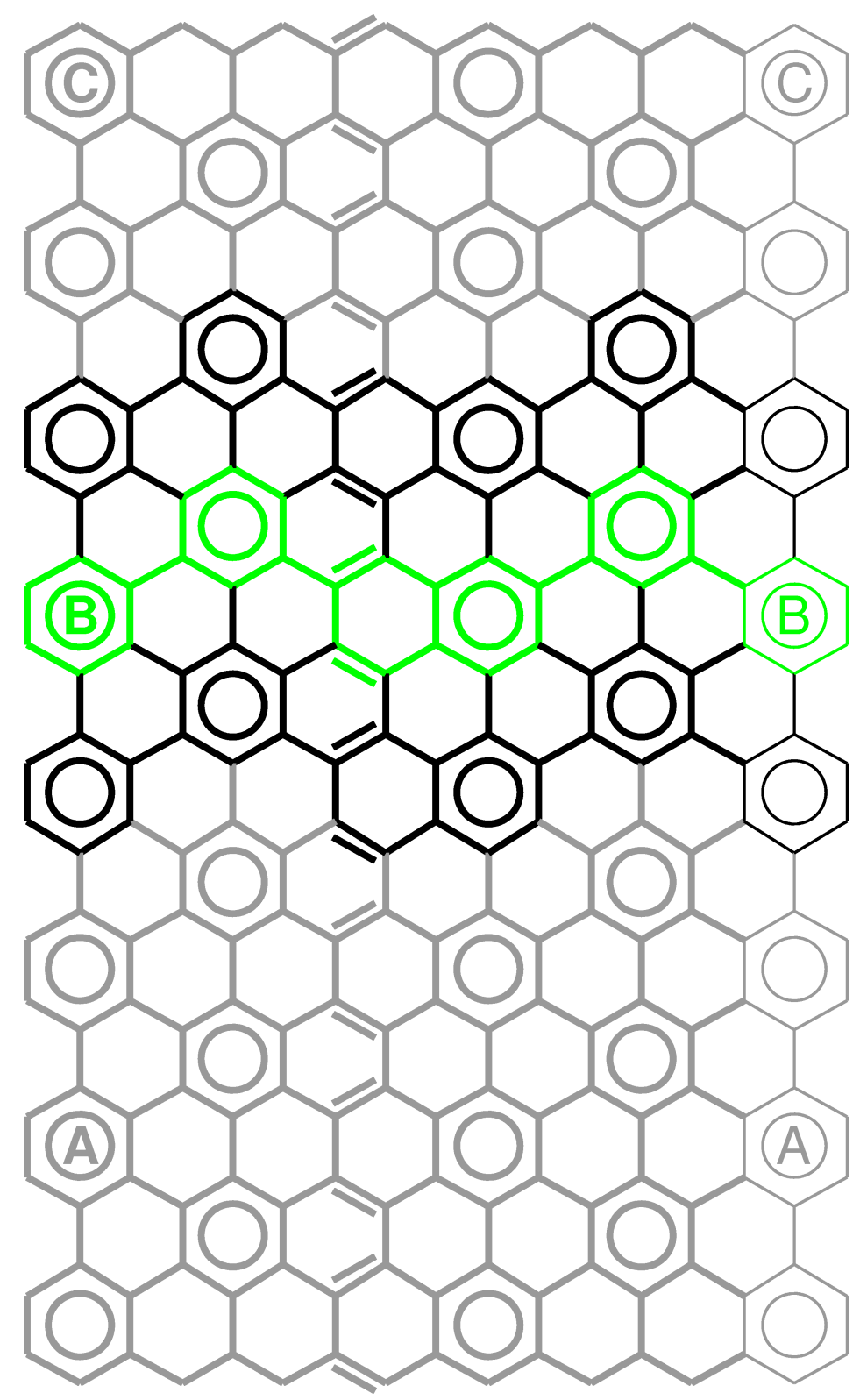


$(6,4), \mathrm{R}=2$ (canonical Clar cell)

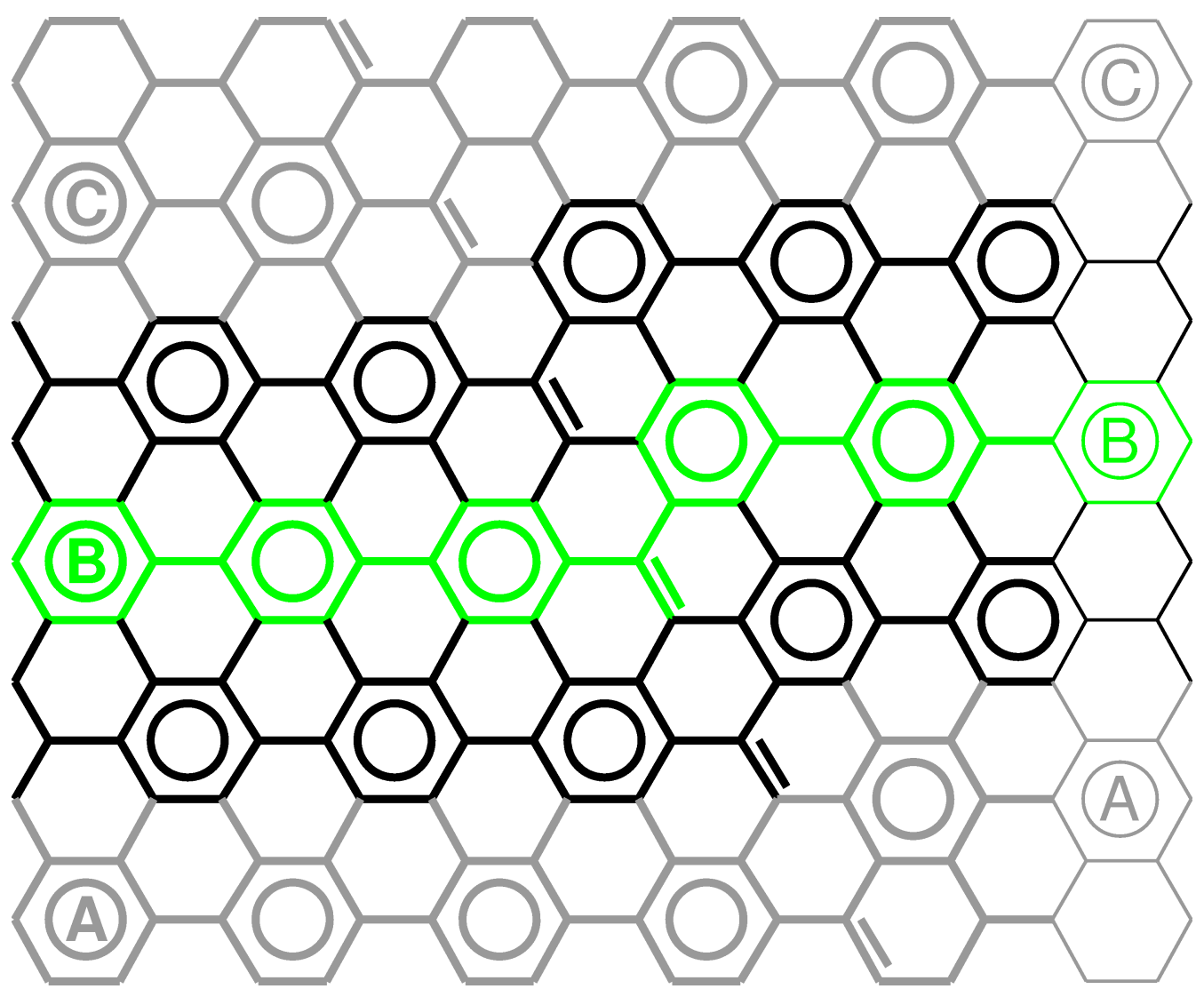


$(6,4), \mathrm{R}=2$ (cell used in calculations)

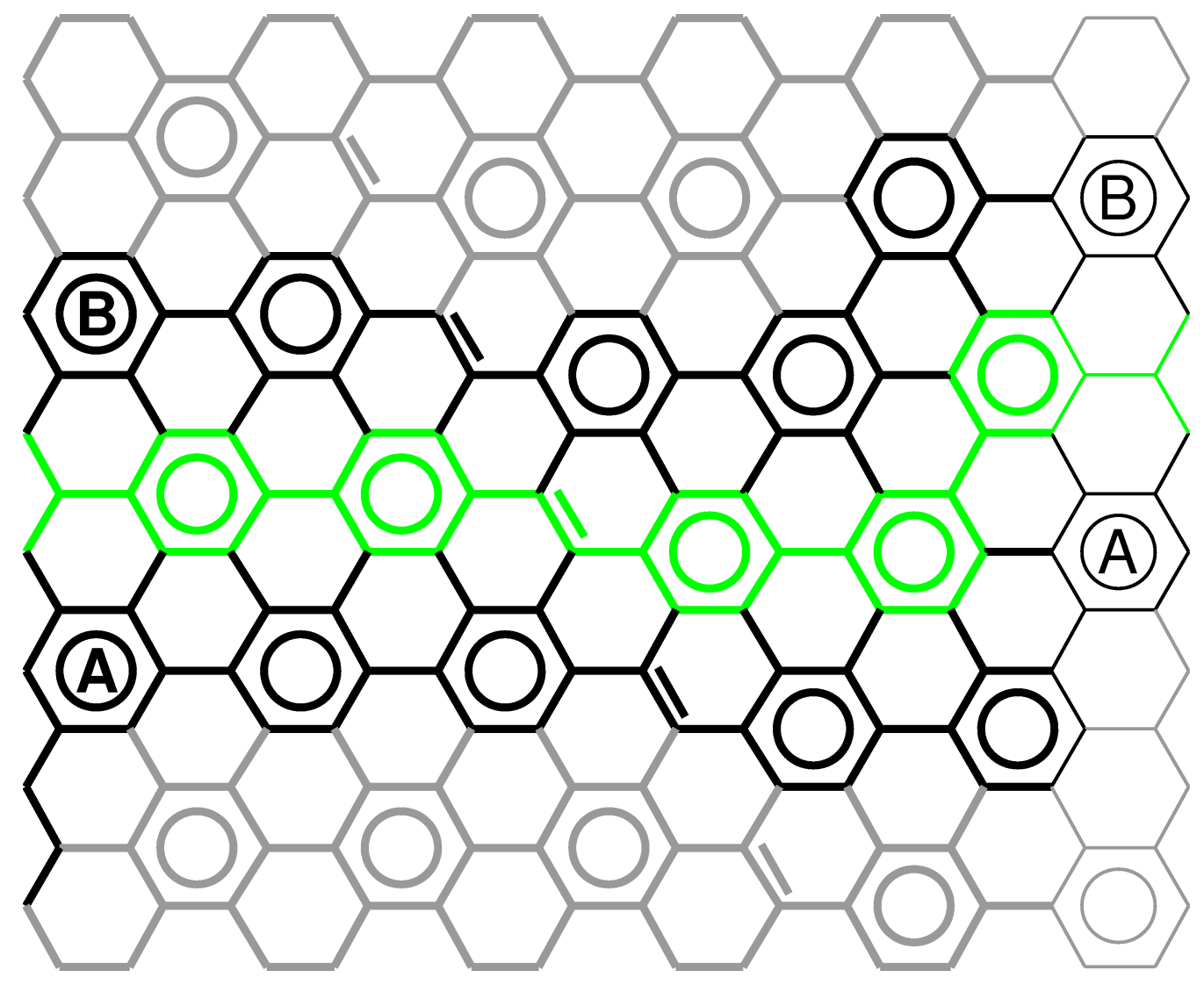


$(8,0), \mathrm{R}=2$ (canonical Clar cell)

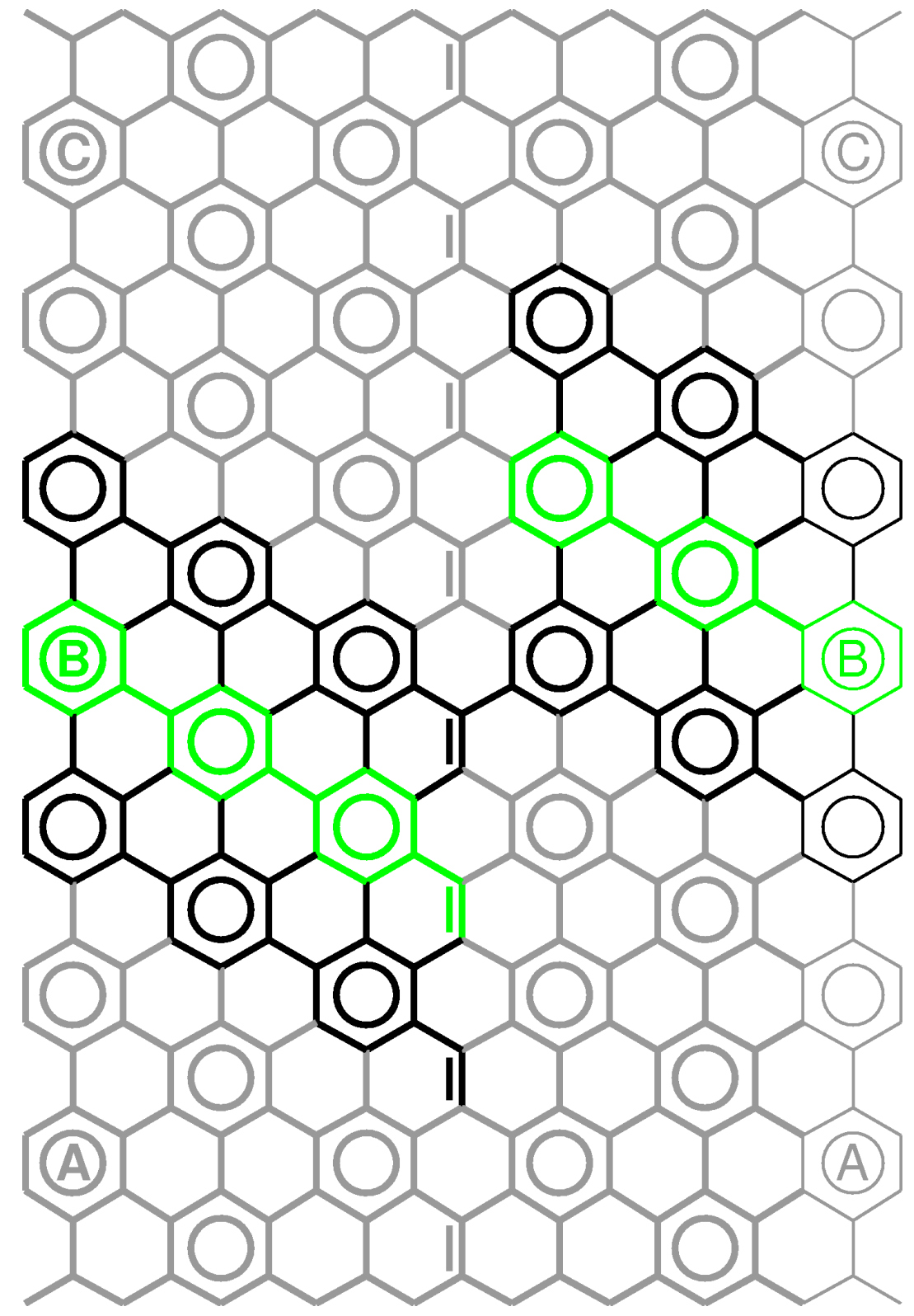


$(8,0), R=2$ (cell used in calculations)

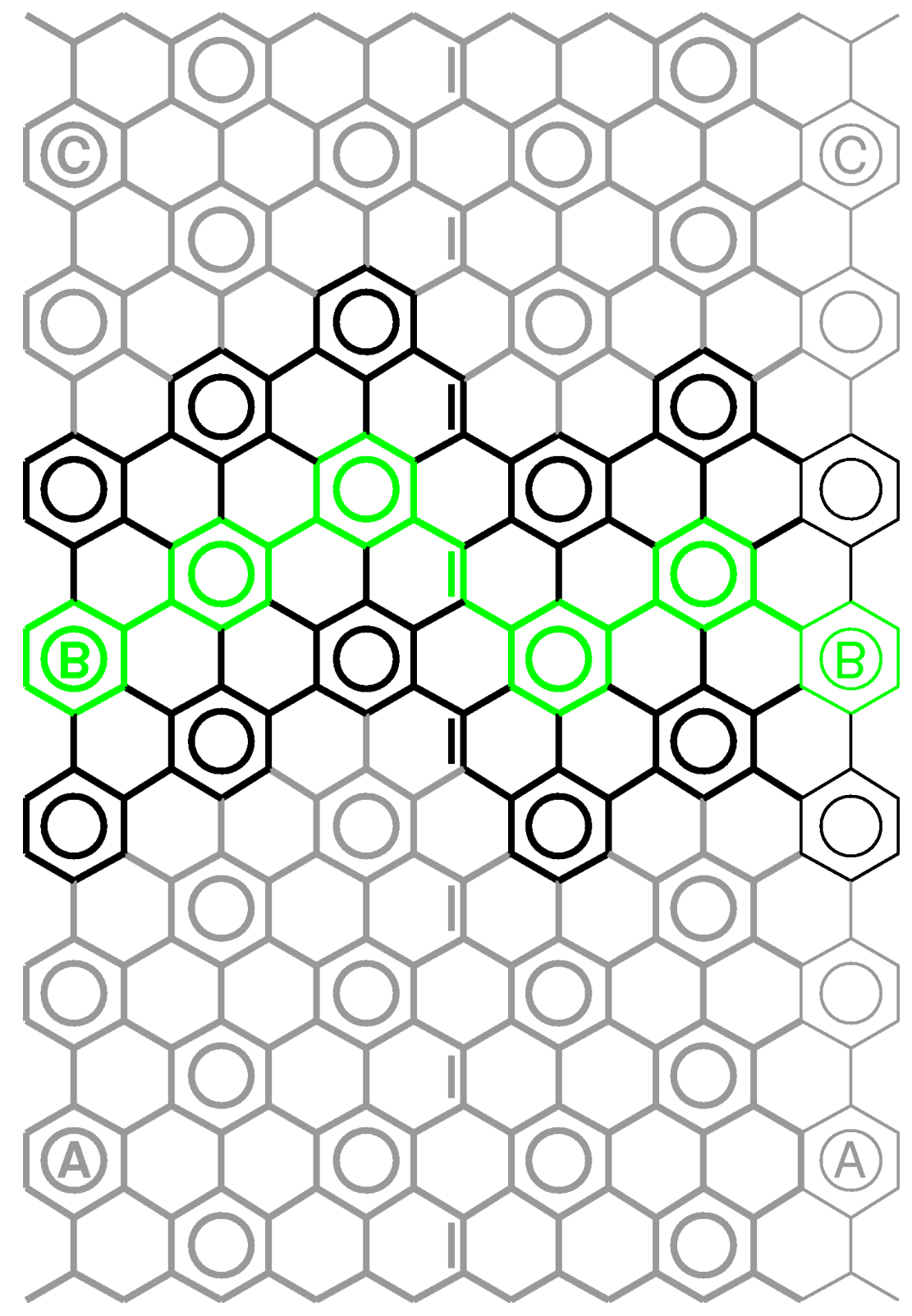




\section{Electronic properties of CNTs not discussed in the text}

HOMO/LUMO levels and HOMO-LUMO gap vs. clusters lenght computed at the B3LYP/3-21G//B3LYP/3-21G level of theory. 
CNT $(5,5) \quad R=0$

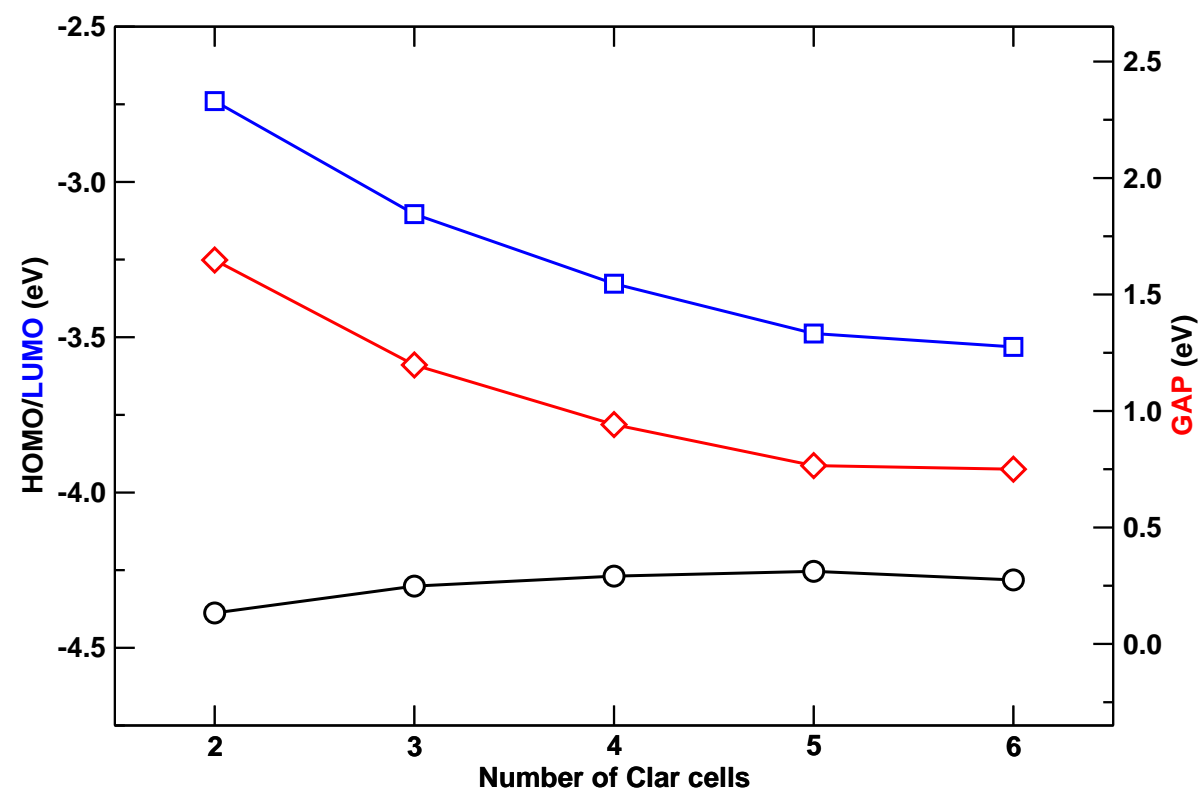

CNT $(7,7) \quad R=0$

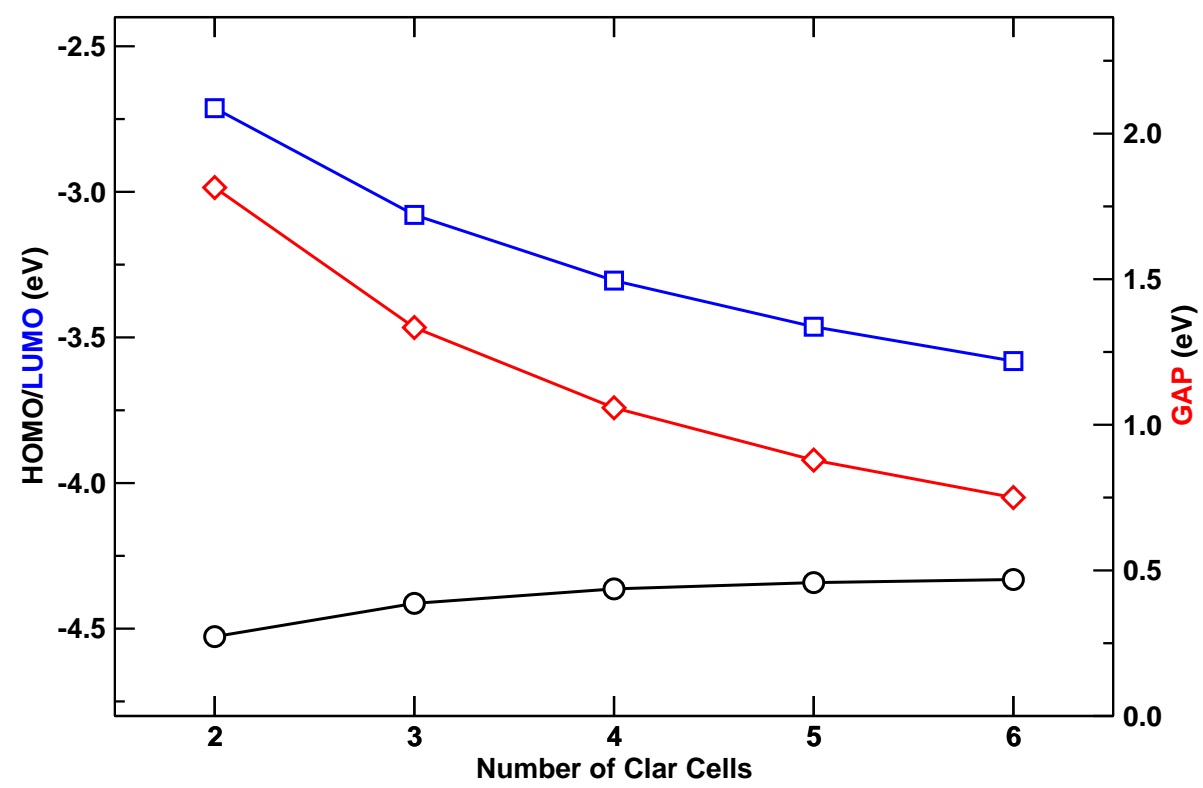




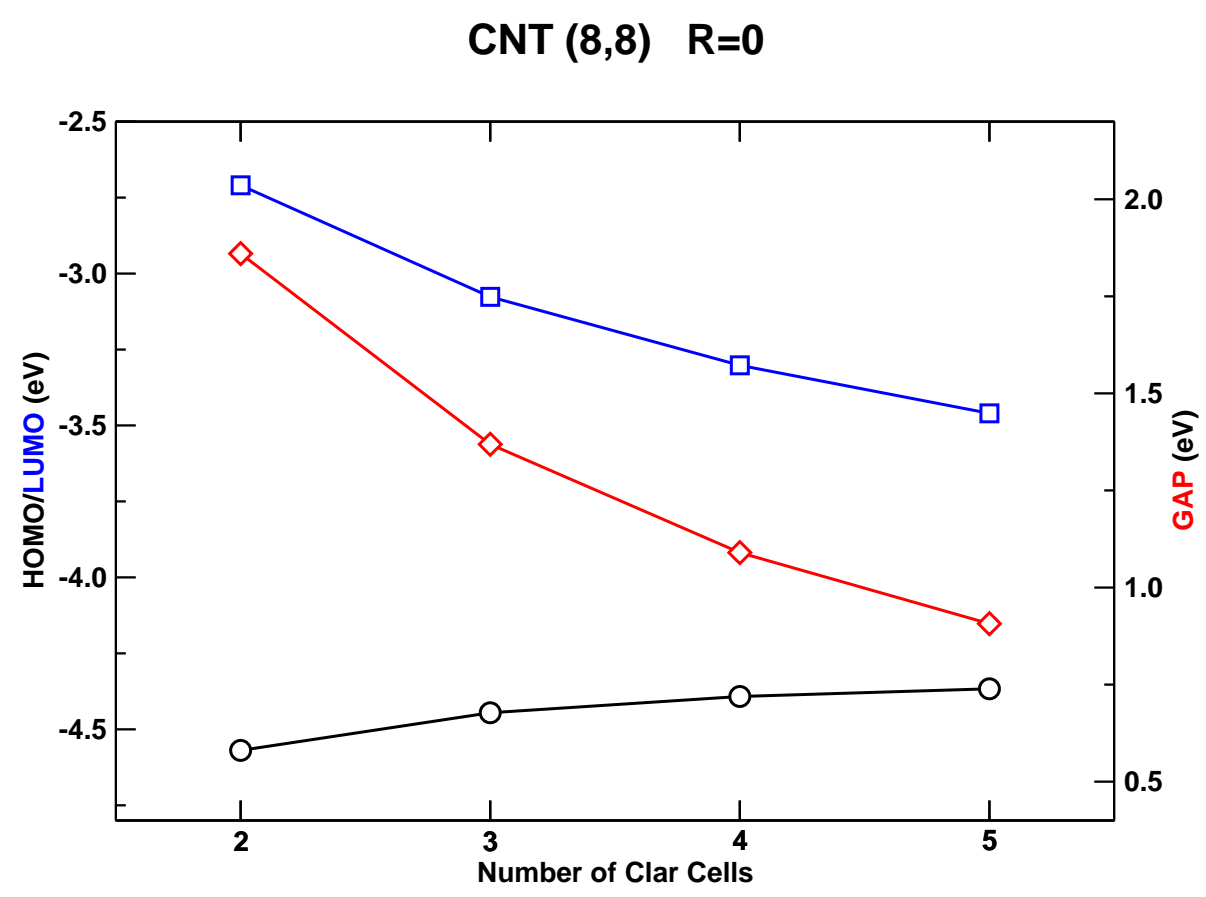

CNT $(9,9) \quad R=0$

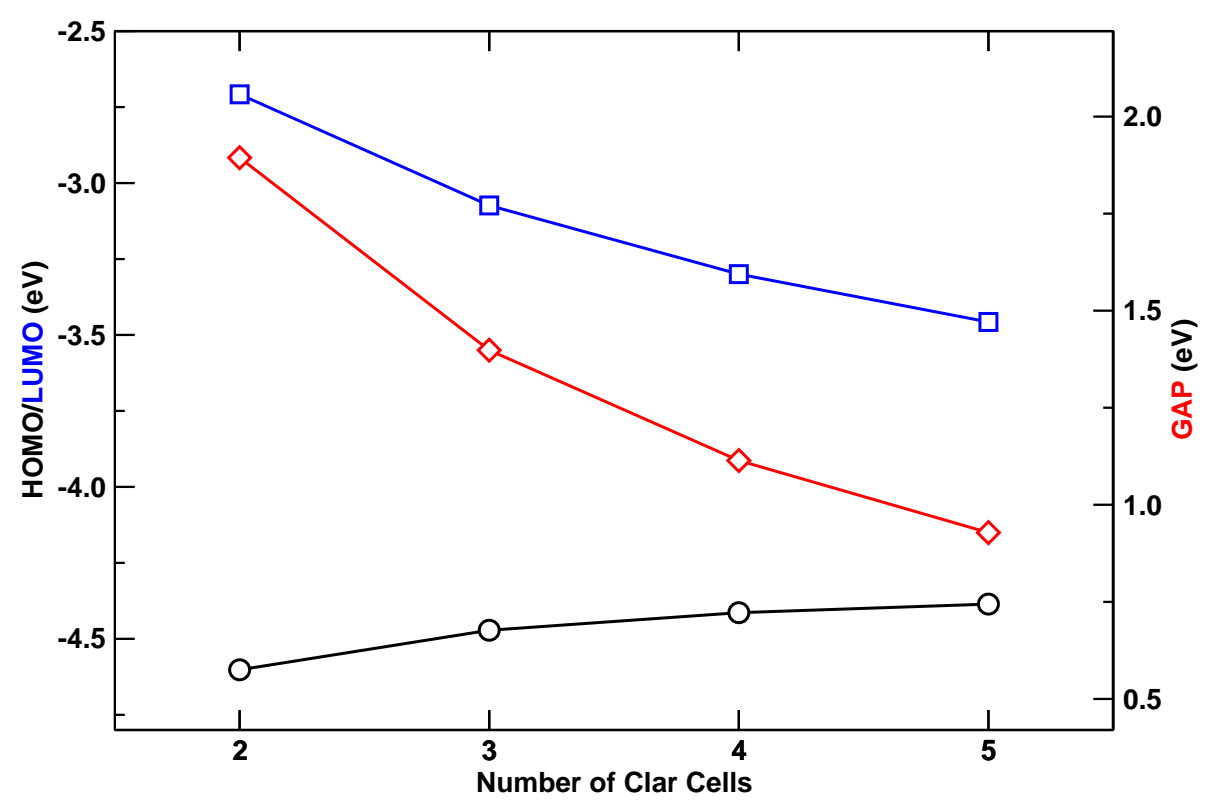


CNT $(5,4) \quad R=0$

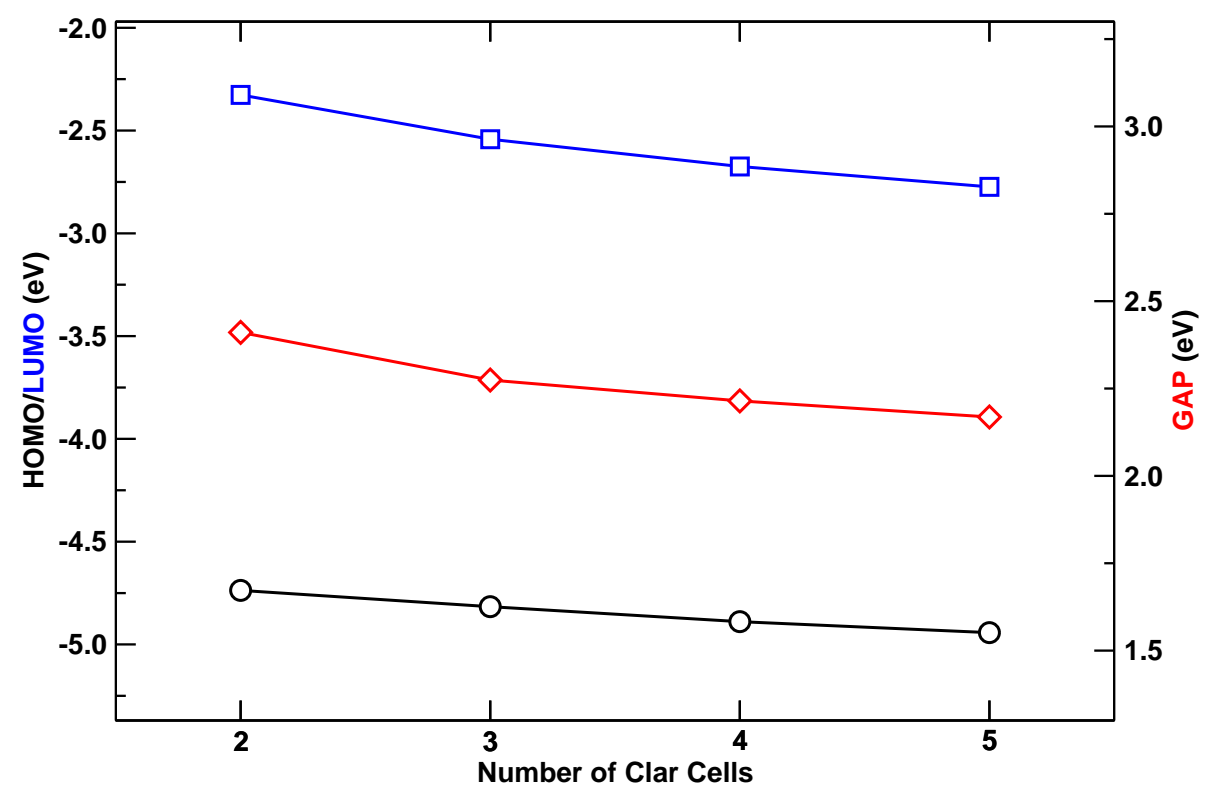

CNT $(7,6) \quad R=1$

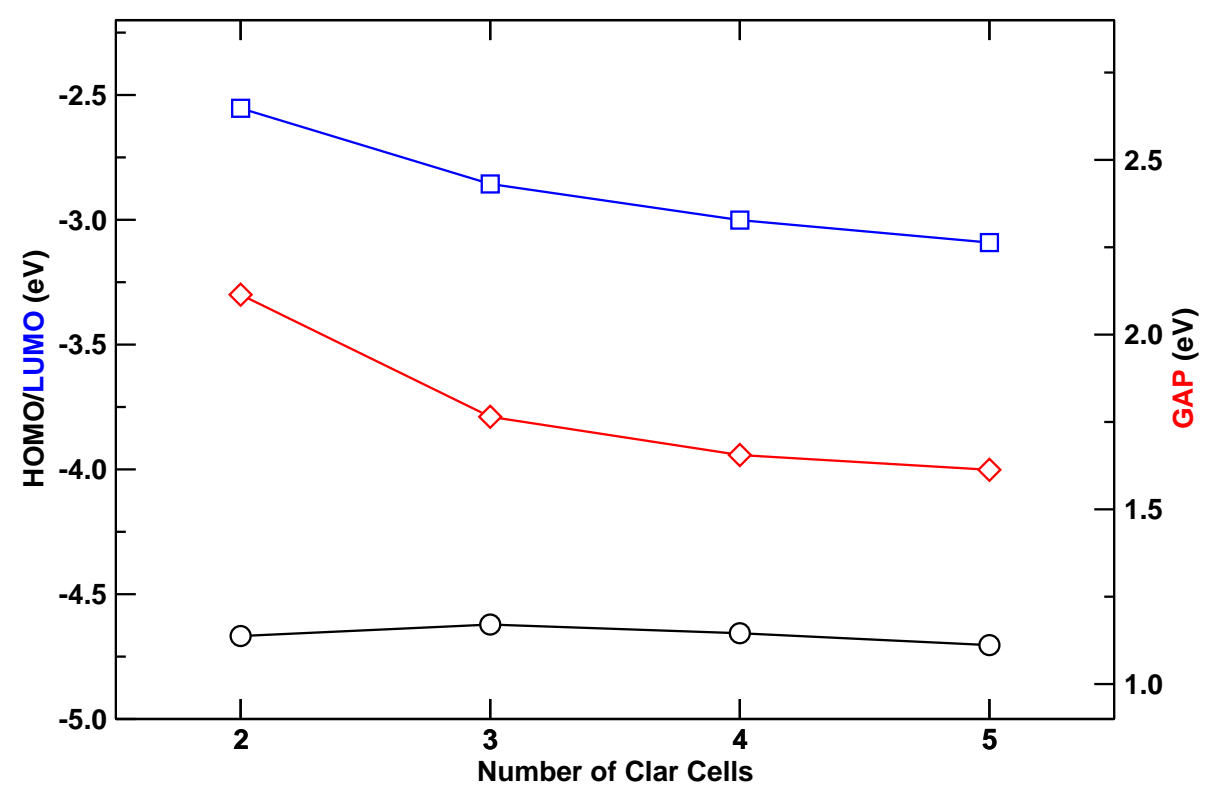

S16 
CNT $(8,7) \quad R=1$

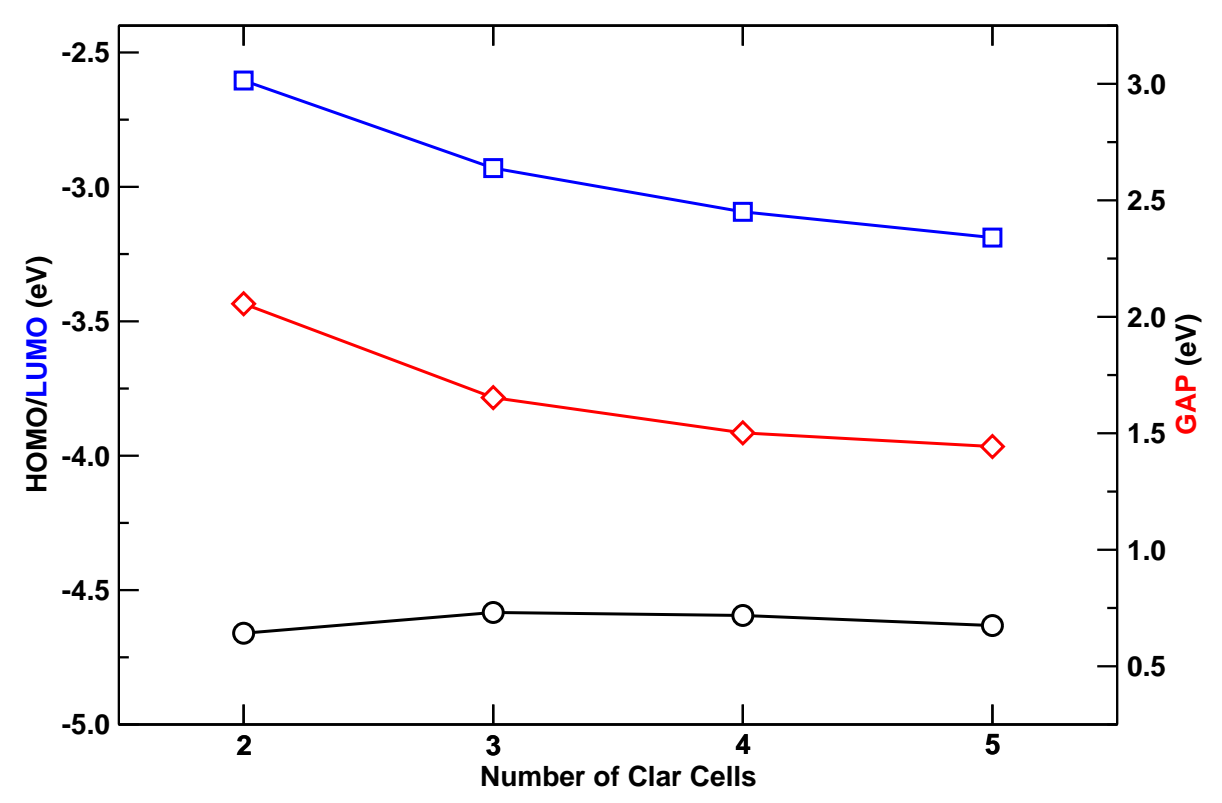

CNT $(9,8) \quad R=1$

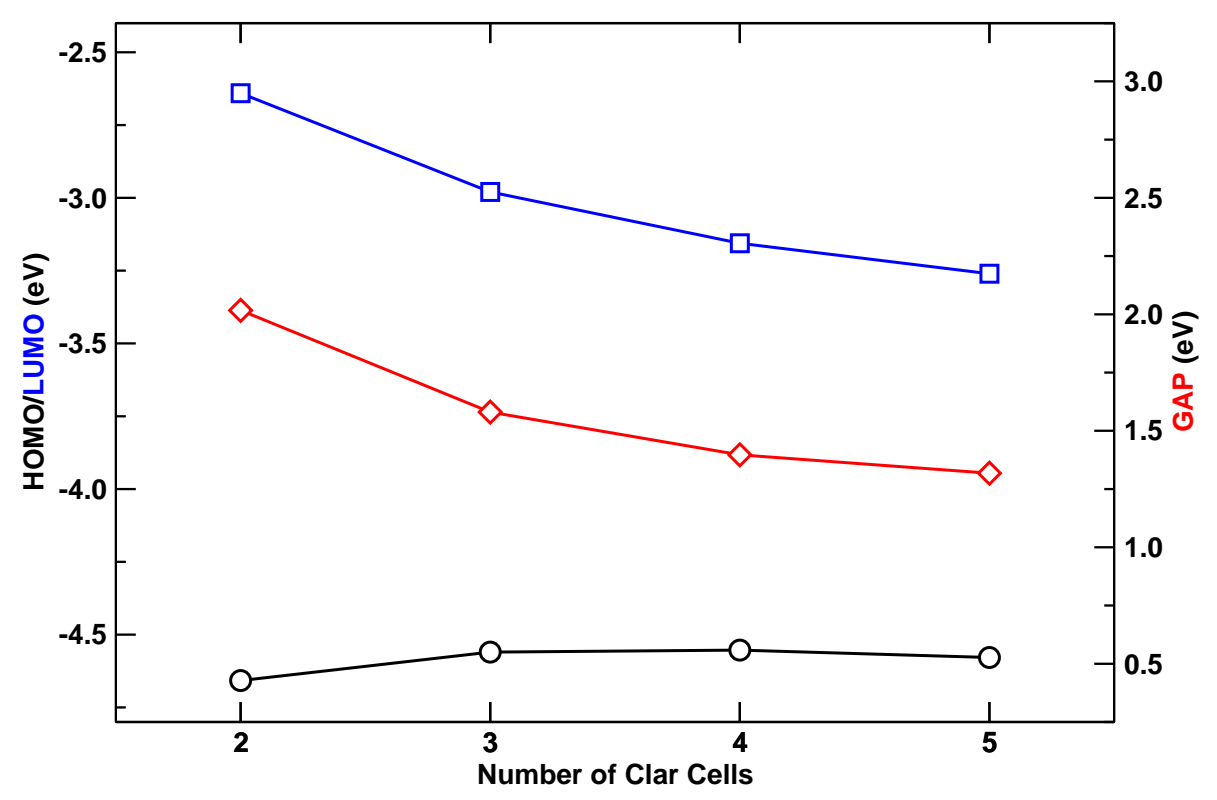

S17 
CNT $(5,3) \quad R=2$

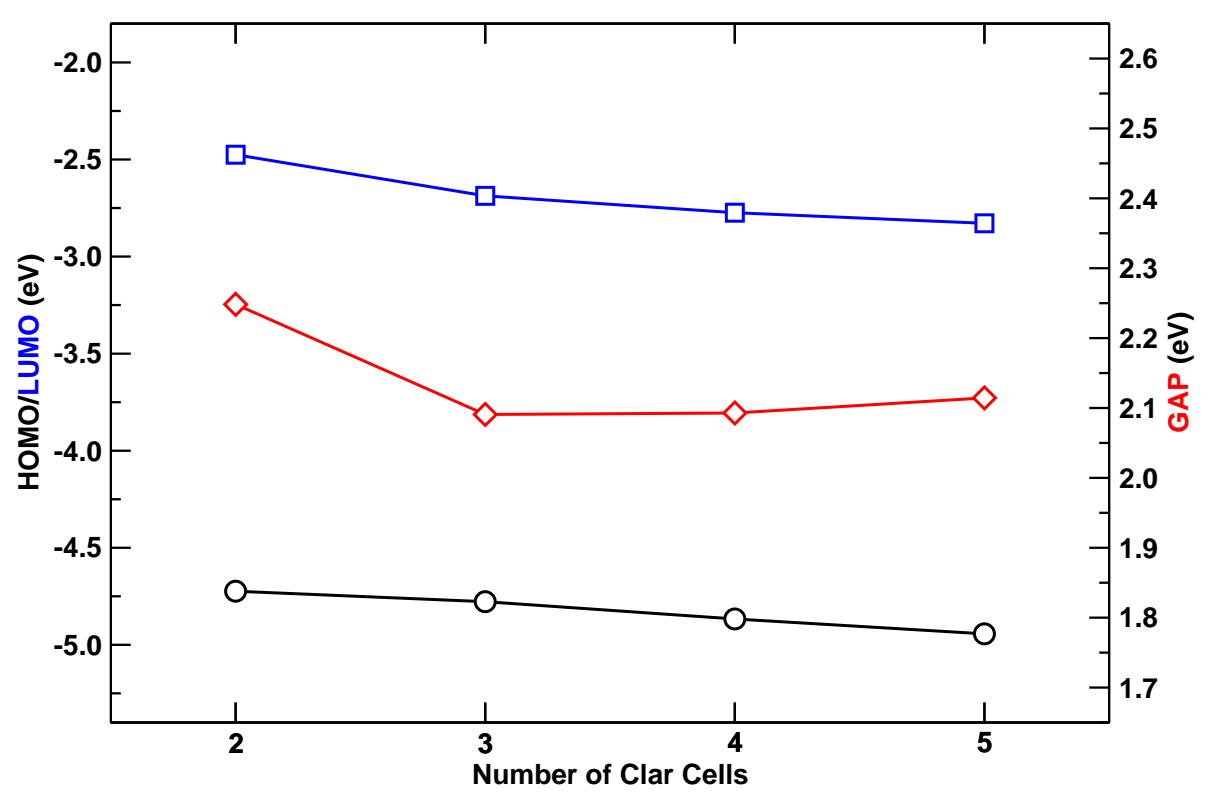

CNT $(7,5) \quad R=2$

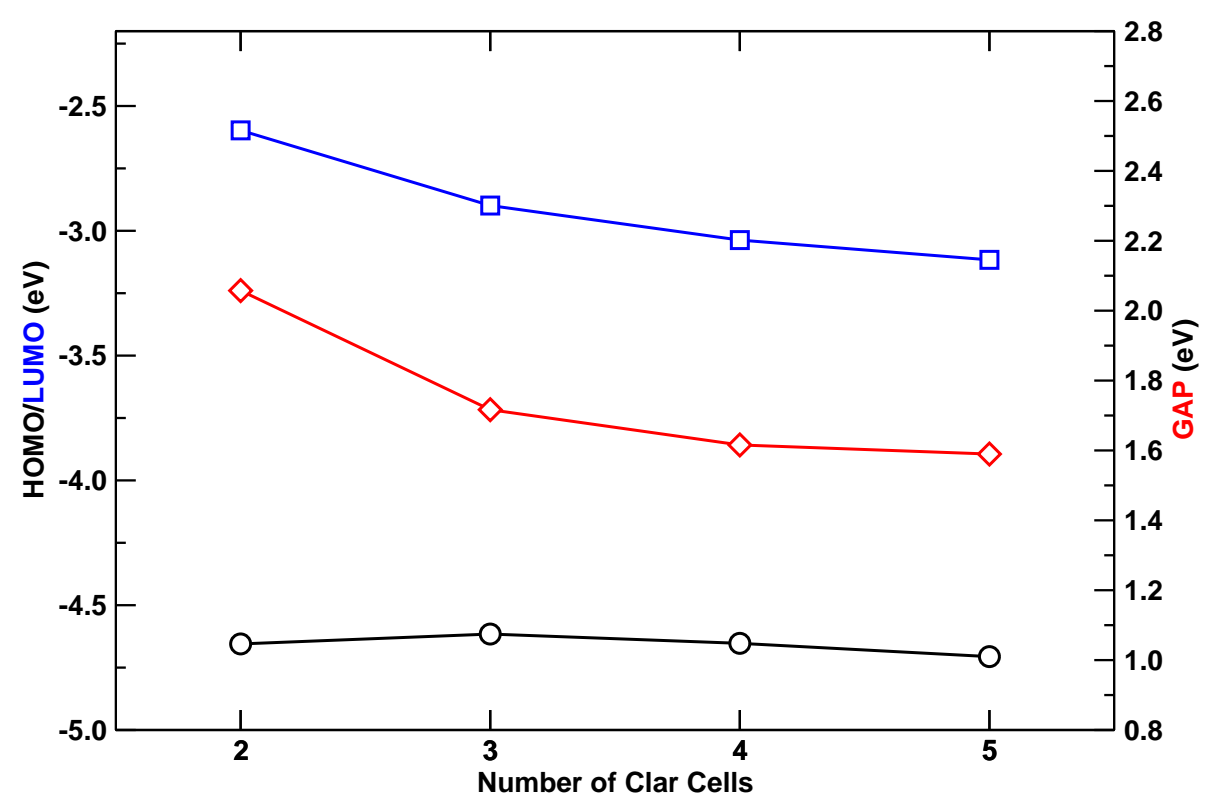

S18 
CNT $(8,6) \quad R=2$

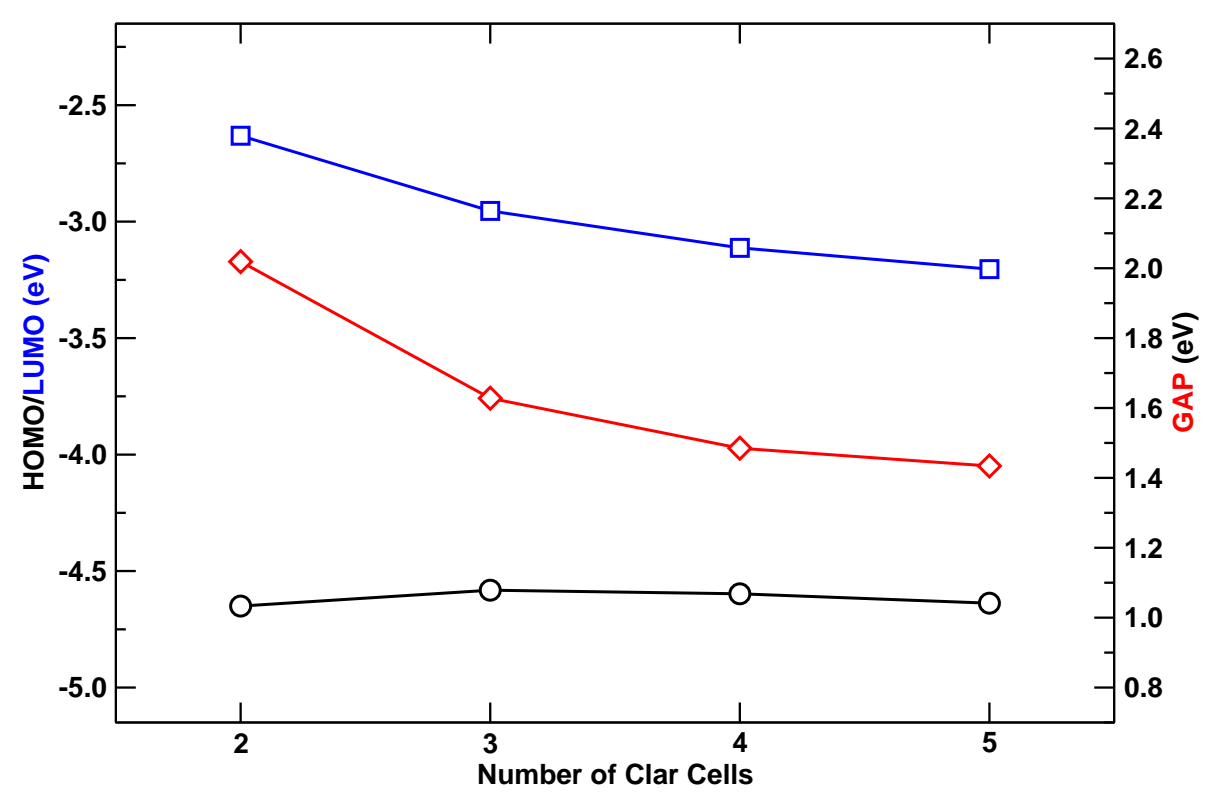

CNT $(9,7) \quad R=2$

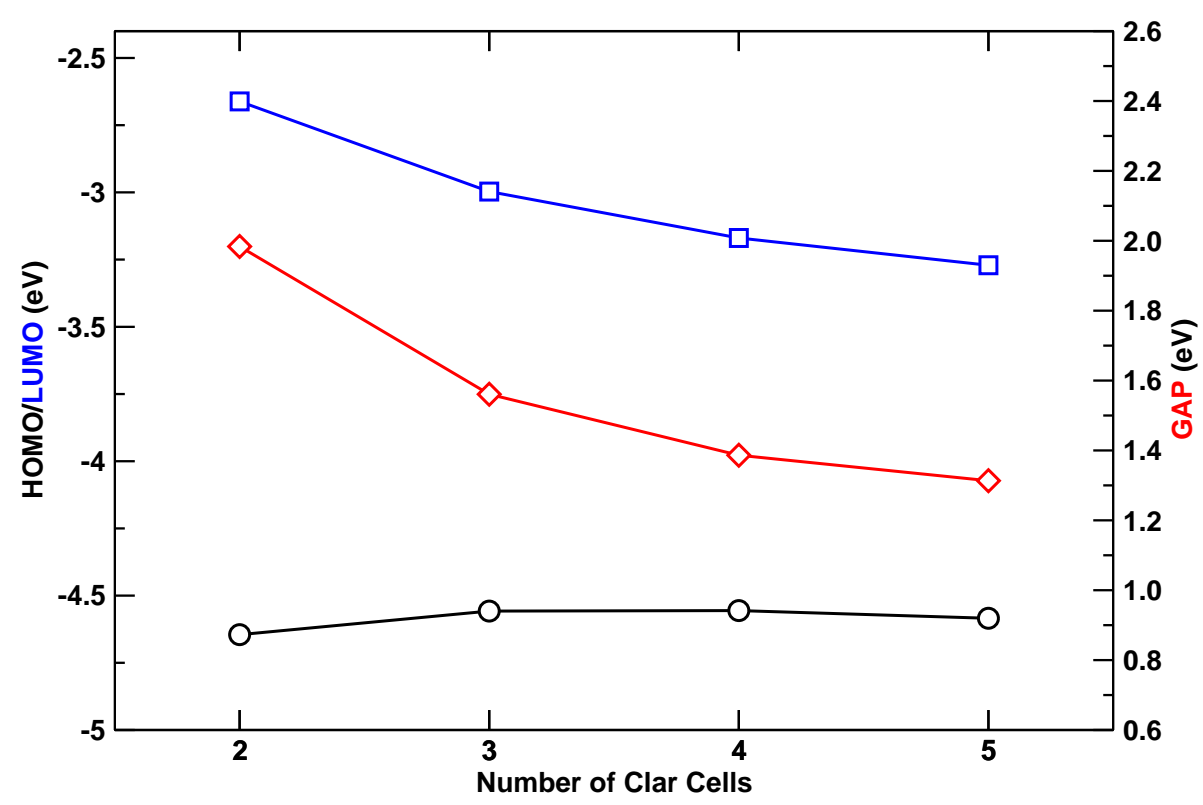




\section{Optimized Geometries}

Optimized geometries at the B3LYP/3-21G level of theory for all clusters discussed in the paper.

$\begin{array}{lrrr}\text { (6,6) } 2 \text { cells } & & \\ & & & \\ & 96 & & \\ \text { C } & -3.851773 & -1.746513 & -3.040830 \\ \text { C } & -3.426534 & -2.387051 & -1.850591 \\ \text { C } & -3.713173 & -1.732908 & -0.627148 \\ \text { C } & -4.081338 & -0.353346 & -0.627209 \\ \text { C } & -4.159582 & 0.356203 & -1.850803 \\ \text { C } & -4.208534 & -0.411289 & -3.040855 \\ \text { C } & -4.081099 & 0.355887 & 0.627251 \\ \text { C } & -3.712086 & 1.735220 & 0.627179 \\ \text { C } & -3.357250 & 2.349308 & -0.627457 \\ \text { C } & -3.779923 & 1.773664 & -1.851020 \\ \text { C } & -2.347233 & 3.358719 & -0.627458 \\ \text { C } & -1.771326 & 3.781036 & -1.851020 \\ \text { C } & -2.459792 & 3.438924 & -3.041232 \\ \text { C } & -3.437389 & 2.461919 & -3.041232 \\ \text { C } & -3.425028 & 2.389196 & 1.850621 \\ \text { C } & -2.387086 & 3.426543 & 1.850616 \\ \text { C } & -1.732932 & 3.713195 & 0.627176 \\ \text { C } & -0.353369 & 4.081359 & 0.627252 \\ \text { C } & 0.355872 & 4.081133 & -0.627204 \\ \text { C } & -0.353623 & 4.159806 & -1.850804 \\ \text { C } & -1.746552 & 3.851773 & 3.040858 \\ \text { C } & -0.411326 & 4.208528 & 3.040901 \\ \text { C } & 0.356172 & 4.159589 & 1.850852 \\ \text { C } & 1.773635 & 3.779929 & 1.851073 \\ \text { C } & 2.349285 & 3.357266 & 0.627509\end{array}$




\begin{tabular}{lrrr} 
C & 1.735205 & 3.712117 & -0.627126 \\
C & 2.389188 & 3.425072 & -1.850566 \\
C & 1.748908 & 3.850667 & -3.040812 \\
C & 0.413902 & 4.208241 & -3.040857 \\
C & -4.159760 & -0.353616 & 1.850846 \\
C & -4.208175 & 0.413897 & 3.040905 \\
C & -3.850603 & 1.748904 & 3.040867 \\
C & -3.358685 & -2.347224 & 0.627478 \\
C & -3.780994 & -1.771323 & 1.851049 \\
C & -3.438876 & -2.459798 & 3.041251 \\
C & -2.461872 & -3.437400 & 3.041238 \\
C & -1.773627 & -3.779922 & 1.851018 \\
C & -2.349281 & -3.357236 & 0.627462 \\
C & -1.735193 & -3.712063 & -0.627181 \\
C & -0.355870 & -4.081078 & -0.627269 \\
C & 0.353380 & -4.081331 & 0.627186 \\
C & -0.356158 & -4.159579 & 1.850786 \\
C & 1.732939 & -3.713162 & 0.627112 \\
C & 2.387096 & -3.426527 & 1.850555 \\
C & 1.746565 & -3.851768 & 3.040793 \\
C & 0.411340 & -4.208525 & 3.040836 \\
C & 0.353621 & -4.159734 & -1.850875 \\
C & 1.771335 & -3.780969 & -1.851086 \\
C & 2.347237 & -3.358664 & -0.627520 \\
C & 3.357251 & -2.349254 & -0.627505 \\
C & 3.712093 & -1.735185 & 0.627139 \\
C & 3.425041 & -2.389180 & 1.850570 \\
C & 4.081111 & -0.355854 & 0.627232 \\
C & 4.159777 & 0.353630 & 1.850839 \\
C & 4.208199 & -0.413904 & 3.040885 \\
C & 3.850625 & -1.748912 & 3.040825 \\
C & 4.081344 & 0.353399 & -0.627218 \\
C & 3.713179 & 1.732962 & -0.627131 \\
C & 3.358696 & 2.347251 & 0.627506 \\
C & 3.781008 & 1.771335 & 1.851066 \\
C & 2.461887 & 3.437390 & 3.041285 \\
C & 3.438893 & 2.459793 & 3.041281 \\
C & 4.159581 & -0.356130 & -1.850824 \\
& 3.779925 & -1.773595 & -1.851061 \\
\hline & 3.437401 & -2.461840 & -3.041280
\end{tabular}




$\begin{array}{lrrr}\text { C } & 2.459802 & -3.438848 & -3.041293 \\ \mathrm{C} & -2.389182 & -3.424999 & -1.850617 \\ \mathrm{C} & -1.748908 & -3.850554 & -3.040873 \\ \mathrm{C} & -0.413896 & -4.208132 & -3.040921 \\ \mathrm{C} & 3.426533 & 2.387128 & -1.850567 \\ \mathrm{C} & 3.851764 & 1.746604 & -3.040813 \\ \mathrm{C} & 4.208519 & 0.411378 & -3.040867 \\ \mathrm{H} & -2.263063 & 3.769379 & 3.988987 \\ \mathrm{H} & -3.767853 & 2.265348 & 3.989001 \\ \mathrm{H} & -4.394861 & -0.074569 & 3.989116 \\ \mathrm{H} & -3.843746 & -2.128928 & 3.989463 \\ \mathrm{H} & -2.131243 & -3.842493 & 3.989438 \\ \mathrm{H} & -0.077222 & -4.394967 & 3.989044 \\ \mathrm{H} & 2.263076 & -3.769378 & 3.988922 \\ \mathrm{H} & 3.767882 & -2.265374 & 3.988950 \\ \mathrm{H} & 4.394894 & 0.074543 & 3.989103 \\ \mathrm{H} & 3.843769 & 2.128909 & 3.989485 \\ \mathrm{H} & 2.131254 & 3.842464 & 3.989492 \\ \mathrm{H} & 0.077238 & 4.394959 & 3.989111 \\ \mathrm{H} & -3.842466 & 2.131286 & -3.989437 \\ \mathrm{H} & -4.394994 & 0.077284 & -3.989056 \\ \mathrm{H} & -2.128911 & 3.843800 & -3.989437 \\ \mathrm{H} & -0.074555 & 4.394945 & -3.989068 \\ \mathrm{H} & 2.265362 & 3.767933 & -3.988942 \\ \mathrm{H} & 3.769370 & 2.263122 & -3.988938 \\ \mathrm{H} & 4.394951 & -0.077179 & -3.989080 \\ \mathrm{H} & 3.842487 & -2.131204 & -3.989480 \\ \mathrm{H} & 2.128930 & -3.843722 & -3.989501 \\ \mathrm{H} & 0.074560 & -4.394805 & -3.989140 \\ \mathrm{H} & -2.265360 & -3.767791 & -3.988999 \\ \mathrm{H} & -3.769396 & -2.263024 & -3.988958\end{array}$

$(6,6) 3$ cells

132

$\begin{array}{lllr}\text { C } & -4.922417 & -3.691732 & 1.715690 \\ \text { C } & -4.922452 & -4.055846 & 0.349590 \\ \text { C } & -3.691848 & -4.054900 & -0.360040\end{array}$

S22 


$\begin{array}{lrrr}\text { C } & -2.461204 & -4.055851 & 0.349530 \\ \text { C } & -2.461173 & -3.691722 & 1.715630 \\ \text { C } & -3.691782 & -3.337737 & 2.330652 \\ \text { C } & -1.230603 & -4.054934 & -0.360100 \\ \text { C } & -1.230637 & -3.687224 & -1.725243 \\ \text { C } & -2.461267 & -3.331594 & -2.339271 \\ \text { C } & -3.691883 & -3.687190 & -1.725179 \\ \text { C } & -0.000071 & -3.331578 & -2.339343 \\ \text { C } & -0.000080 & -2.330533 & -3.337706 \\ \text { C } & -1.230702 & -1.715642 & -3.691739 \\ \text { C } & -2.461322 & -2.330600 & -3.337687 \\ \text { C } & 1.230512 & -1.715453 & -3.691650 \\ \text { C } & 2.461181 & -2.330607 & -3.337839 \\ \text { C } & 2.461217 & -3.331579 & -2.339404 \\ \text { C } & 1.230575 & -3.687153 & -1.725312 \\ \text { C } & -1.230680 & -0.349538 & -4.055856 \\ \text { C } & -0.000242 & 0.360157 & -4.054903 \\ \text { C } & 1.230427 & -0.349354 & -4.055782 \\ \text { C } & -0.000403 & 1.725272 & -3.687110 \\ \text { C } & -1.230598 & 2.339376 & -3.331631 \\ \text { C } & -2.461201 & 1.725247 & -3.687184 \\ \text { C } & -2.461277 & 0.360098 & -4.054851 \\ \text { C } & -3.691984 & 2.339311 & -3.331467 \\ \text { C } & -3.691961 & 3.337699 & -2.330446 \\ \text { C } & -2.461204 & 3.691695 & -1.715575 \\ \text { C } & -1.230604 & 3.337778 & -2.330652 \\ \text { C } & -2.461259 & 4.055823 & -0.349417 \\ \text { C } & -3.691861 & 4.054886 & 0.360216 \\ \text { C } & -4.922499 & 4.055814 & -0.349350 \\ \text { C } & -4.922567 & 3.691698 & -1.715430 \\ \text { C } & -1.230620 & 4.054896 & 0.360149 \\ \text { C } & -1.230583 & 3.687189 & 1.725288 \\ \text { C } & -2.461185 & 3.331573 & 2.339383 \\ \text { C } & -3.691823 & 3.687179 & 1.725355 \\ \text { C } & 0.000056 & 3.331581 & 2.339317 \\ \text { C } & 0.000086 & 2.330565 & 3.337711 \\ \text { C } & -1.230523 & 1.715565 & 3.691732 \\ \text { C } & -2.461154 & 2.330556 & 3.337778 \\ \text { C } & 0.000114 & -0.360129 & 4.054892\end{array}$




\begin{tabular}{|c|c|c|c|}
\hline C & 1.230731 & 0.349474 & 4.055791 \\
\hline C & 1.230717 & 1.715575 & 3.691667 \\
\hline $\mathrm{C}$ & 0.000108 & -1.725269 & 3.687187 \\
\hline C & 1.230721 & -2.339324 & 3.331539 \\
\hline $\mathrm{C}$ & 2.461348 & -1.725261 & 3.687123 \\
\hline $\mathrm{C}$ & 2.461354 & -0.360121 & 4.054828 \\
\hline $\mathrm{C}$ & 3.691962 & -2.339321 & 3.331484 \\
\hline $\mathrm{C}$ & 3.691941 & -3.337716 & 2.330469 \\
\hline $\mathrm{C}$ & 2.461308 & -3.691705 & 1.715502 \\
\hline $\mathrm{C}$ & 1.230698 & -3.337719 & 2.330522 \\
\hline $\mathrm{C}$ & 2.461278 & -4.055835 & 0.349403 \\
\hline $\mathrm{C}$ & 3.691876 & -4.054947 & -0.360234 \\
\hline $\mathrm{C}$ & 4.922500 & -4.055832 & 0.349342 \\
\hline $\mathrm{C}$ & 4.922540 & -3.691716 & 1.715445 \\
\hline $\mathrm{C}$ & 0.000062 & -3.691713 & 1.715567 \\
\hline $\mathrm{C}$ & 0.000021 & -4.055828 & 0.349465 \\
\hline $\mathrm{C}$ & 1.230625 & -4.054859 & -0.360165 \\
\hline $\mathrm{C}$ & 3.691843 & -3.687234 & -1.725380 \\
\hline $\mathrm{C}$ & -1.230540 & -3.337732 & 2.330595 \\
\hline C & -1.230517 & -2.339338 & 3.331612 \\
\hline C & 3.691969 & 0.349485 & 4.055729 \\
\hline $\mathrm{C}$ & 4.922593 & -0.360112 & 4.054762 \\
\hline $\mathrm{C}$ & 4.922587 & -1.725253 & 3.687057 \\
\hline $\mathrm{C}$ & 3.691955 & 1.715587 & 3.691605 \\
\hline $\mathrm{C}$ & 2.461324 & 2.330574 & 3.337649 \\
\hline C & -2.461126 & -0.360138 & 4.054957 \\
\hline $\mathrm{C}$ & -2.461130 & -1.725278 & 3.687253 \\
\hline $\mathrm{C}$ & 2.461294 & 3.331590 & 2.339252 \\
\hline $\mathrm{C}$ & 1.230657 & 3.687195 & 1.725223 \\
\hline $\mathrm{C}$ & -3.691763 & 1.715558 & 3.691799 \\
\hline $\mathrm{C}$ & -3.691749 & 0.349457 & 4.055921 \\
\hline C & -4.922394 & 2.330547 & 3.337844 \\
\hline $\mathrm{C}$ & -4.922425 & 3.331563 & 2.339450 \\
\hline $\mathrm{C}$ & -0.000019 & 4.055832 & -0.349484 \\
\hline $\mathrm{C}$ & 1.230619 & 4.054903 & 0.360083 \\
\hline C & -0.000206 & 3.691700 & -1.715455 \\
\hline $\mathrm{C}$ & 1.230406 & 3.337508 & -2.330349 \\
\hline $\mathrm{C}$ & 1.230310 & 2.339130 & -3.331471 \\
\hline $\mathrm{C}$ & -3.691969 & -0.349464 & -4.055727 \\
\hline $\mathrm{C}$ & -4.922598 & 0.360120 & -4.054775 \\
\hline
\end{tabular}




$\begin{array}{rrrr}\text { C } & -4.922613 & 1.725255 & -3.687056 \\ \mathrm{C} & -3.691945 & -1.715564 & -3.691604 \\ \mathrm{C} & 2.461349 & 0.360095 & -4.054986 \\ \mathrm{C} & 2.461632 & 1.725283 & -3.687462 \\ \mathrm{C} & 2.461404 & 3.691755 & -1.715897 \\ \mathrm{C} & 3.691982 & 3.338253 & -2.331252 \\ \mathrm{C} & 3.692079 & 2.339804 & -3.332043 \\ \mathrm{C} & 4.921731 & 1.725166 & -3.686574 \\ \mathrm{C} & 4.922130 & 0.360133 & -4.054670 \\ \mathrm{C} & 3.691896 & -0.349630 & -4.056113 \\ \mathrm{C} & 3.691811 & -1.715735 & -3.692005 \\ \mathrm{C} & 4.922391 & -3.331576 & -2.339453 \\ \mathrm{C} & 4.922346 & -2.330497 & -3.337785 \\ \mathrm{C} & 2.461221 & 4.055840 & -0.349548 \\ \mathrm{C} & 3.691859 & 4.054912 & 0.360019 \\ \mathrm{C} & 4.922461 & 4.055849 & -0.349613 \\ \mathrm{C} & 4.922037 & 3.691650 & -1.715294 \\ \mathrm{C} & 3.691896 & 3.687206 & 1.725159 \\ \mathrm{C} & -4.922522 & -3.331594 & -2.339211 \\ \mathrm{C} & -4.922551 & -2.330573 & -3.337597 \\ \mathrm{C} & -3.691756 & -2.339342 & 3.331670 \\ \mathrm{C} & -4.922370 & -1.725287 & 3.687316 \\ \mathrm{C} & -4.922365 & -0.360147 & 4.055023 \\ \mathrm{C} & 4.922564 & 2.330583 & 3.337585 \\ \mathrm{C} & 4.922534 & 3.331599 & 2.339188 \\ \mathrm{H} & -5.865463 & -0.137186 & -4.217270 \\ \mathrm{H} & -5.865386 & -1.980097 & -3.726291 \\ \mathrm{H} & -5.865397 & 3.583664 & -2.227486 \\ \mathrm{H} & -5.865442 & 2.237023 & -3.577592 \\ \mathrm{H} & -5.865327 & -3.721243 & -1.989698 \\ \mathrm{H} & -5.865323 & -4.217073 & -0.148090 \\ \mathrm{H} & -5.865335 & 4.217065 & 0.148392 \\ \mathrm{H} & -5.865255 & 3.721191 & 1.989980 \\ \mathrm{H} & -5.865206 & 1.980062 & 3.726587 \\ \mathrm{H} & -5.865235 & 0.137134 & 4.217568 \\ & -5.865223 & -3.583707 & 2.227797 \\ \mathrm{H} & -5.865199 & -2.237070 & 3.577918 \\ \mathrm{H} & 5.865341 & 3.721241 & 1.989672 \\ \mathrm{H} & 5.865397 & 1.980107 & 3.726283\end{array}$




$\begin{array}{rrrr}\text { H } & 5.865468 & 0.137175 & 4.217253 \\ \mathrm{H} & 5.865414 & -2.237029 & 3.577610 \\ \mathrm{H} & 5.865377 & -3.583668 & 2.227490 \\ \mathrm{H} & 5.865353 & -4.217059 & -0.148374 \\ \mathrm{H} & 5.865246 & -3.721071 & -1.989902 \\ \mathrm{H} & 5.865180 & -1.979971 & -3.726438 \\ \mathrm{H} & 5.865272 & -0.136862 & -4.216473 \\ \mathrm{H} & 5.864795 & 2.236432 & -3.576532 \\ \mathrm{H} & 5.864960 & 3.583751 & -2.227302\end{array}$

$(6,6) 4$ cells

168

$\begin{array}{llll}\text { C } & 6.768356 & -3.337730 & -2.330594\end{array}$

$\begin{array}{llll}\text { C } & 5.537794 & -3.691768 & -1.715613\end{array}$

$\begin{array}{llll}\text { C } & 4.307182 & -3.337724 & -2.330594\end{array}$

$\begin{array}{llll}\text { C } & 4.307169 & -2.339381 & -3.331658\end{array}$

$\begin{array}{llll}\text { C } & 5.537808 & -1.725447 & -3.687414\end{array}$

$\begin{array}{llll}\text { C } & 6.768334 & -2.339280 & -3.331554\end{array}$

$\begin{array}{llll}\text { C } & 5.537906 & -0.360304 & -4.055112\end{array}$

$\begin{array}{llll}\text { C } & 4.307361 & 0.349426 & -4.055877\end{array}$

$\begin{array}{llll}\text { C } & 3.076437 & -0.360019 & -4.054833\end{array}$

$\begin{array}{llll}\text { C } & 3.076509 & -1.725156 & -3.687111\end{array}$

$\begin{array}{llll}\text { C } & 4.307640 & 1.715576 & -3.691943\end{array}$

$\begin{array}{llll}\text { C } & 5.538082 & 2.331025 & -3.338116\end{array}$

$\begin{array}{llll}\text { C } & 6.767739 & 1.715453 & -3.691005\end{array}$

$\begin{array}{llll}\text { C } & 6.768141 & 0.349457 & -4.055510\end{array}$

$\begin{array}{llll}\text { C } & 1.845769 & 0.349496 & -4.055844\end{array}$

$\begin{array}{llll}\text { C } & 1.845605 & 1.715573 & -3.691641\end{array}$

$\begin{array}{llll}\text { C } & 3.076313 & 2.330361 & -3.337592\end{array}$

$\begin{array}{llll}\text { C } & 3.076393 & 3.331367 & -2.339099\end{array}$

$\begin{array}{llll}\text { C } & 4.307378 & 3.687225 & -1.725555\end{array}$

$\begin{array}{llll}\text { C } & 5.537969 & 3.332102 & -2.339953\end{array}$

$\begin{array}{llll}\text { C } & 0.615329 & -0.360195 & -4.054955\end{array}$

$\begin{array}{llll}\text { C } & 0.615294 & -1.725336 & -3.687248\end{array}$

$\begin{array}{llll}\text { C } & 1.845909 & -2.339298 & -3.331576\end{array}$

$\begin{array}{llll}\text { C } & 1.845894 & -3.337714 & -2.330584\end{array}$

$\begin{array}{llll}\text { C } & 3.076525 & -3.691678 & -1.715595\end{array}$ 


$\begin{array}{lrrr}\text { C } & 0.615405 & 2.330614 & -3.337803 \\ \text { C } & -0.615193 & 1.715557 & -3.691765 \\ \text { C } & -0.615266 & 0.349446 & -4.055842 \\ \text { C } & -1.845959 & -0.360111 & -4.054876 \\ \text { C } & -1.845948 & -1.725250 & -3.687163 \\ \text { C } & -0.615335 & -2.339357 & -3.331606 \\ \text { C } & -0.615303 & -3.337724 & -2.330562 \\ \text { C } & 0.615314 & -3.691743 & -1.715576 \\ \text { C } & -1.845981 & 2.330559 & -3.337689 \\ \text { C } & -3.076605 & 1.715574 & -3.691687 \\ \text { C } & -3.076586 & 0.349477 & -4.055816 \\ \text { C } & -4.307188 & -0.360135 & -4.054886 \\ \text { C } & -4.307183 & -1.725274 & -3.687174 \\ \text { C } & -3.076564 & -2.339321 & -3.331566 \\ \text { C } & -3.076558 & -3.337714 & -2.330551 \\ \text { C } & -1.845933 & -3.691699 & -1.715560 \\ \text { C } & -4.307182 & 2.330559 & -3.337704 \\ \text { C } & -5.537802 & 1.715563 & -3.691694 \\ \text { C } & -5.537809 & 0.349461 & -4.055809 \\ \text { C } & -6.768433 & -0.360135 & -4.054867 \\ \text { C } & -6.768432 & -1.725274 & -3.687155 \\ \text { C } & -5.537799 & -2.339338 & -3.331560 \\ \text { C } & -5.537796 & -3.337725 & -2.330536 \\ \text { C } & -4.307172 & -3.691723 & -1.715551 \\ \text { C } & -4.307175 & 3.331583 & -2.339316 \\ \text { C } & -5.537793 & 3.687182 & -1.725249 \\ \text { C } & -6.768424 & 3.331582 & -2.339299 \\ \text { C } & -6.768431 & 2.330559 & -3.337688 \\ \text { C } & -1.845974 & 3.331574 & -2.339296 \\ \text { C } & -3.076592 & 3.687193 & -1.725237 \\ \text { C } & -3.076551 & 4.054900 & -0.360120 \\ \text { C } & -4.307167 & 4.055832 & 0.349486 \\ \text { C } & -5.537791 & 4.054898 & -0.360105 \\ \text { C } & -0.615229 & 3.687181 & -1.725333 \\ \text { C } & -0.615311 & 4.054900 & -0.360137 \\ \text { C } & -1.845927 & 4.055833 & 0.349471 \\ \text { C } & -1.845917 & 3.691716 & 1.715572 \\ \text { C } & -3.076533 & 3.337719 & 2.330574 \\ \text { C } & -4.307157 & 3.691716 & 1.715587 \\ & -5.537773 & 3.337717 & 2.330591\end{array}$




$\begin{array}{lrrr}\text { C } & -6.768398 & 3.691712 & 1.715604 \\ \text { C } & -6.768408 & 4.055829 & 0.349503 \\ \text { C } & 0.615314 & 4.055834 & 0.349454 \\ \text { C } & 0.615323 & 3.691717 & 1.715555 \\ \text { C } & -0.615293 & 3.337721 & 2.330558 \\ \text { C } & -0.615286 & 2.339332 & 3.331581 \\ \text { C } & -1.845904 & 1.725271 & 3.687192 \\ \text { C } & -3.076526 & 2.339332 & 3.331597 \\ \text { C } & -4.307144 & 1.725270 & 3.687210 \\ \text { C } & -5.537766 & 2.339330 & 3.331613 \\ \text { C } & 0.615383 & 3.331645 & -2.339453 \\ \text { C } & 1.845769 & 3.687178 & -1.725164 \\ \text { C } & 1.845930 & 4.054900 & -0.360153 \\ \text { C } & 3.076554 & 4.055833 & 0.349438 \\ \text { C } & 3.076564 & 3.691716 & 1.715539 \\ \text { C } & 1.845948 & 3.337720 & 2.330542 \\ \text { C } & 1.845954 & 2.339333 & 3.331565 \\ \text { C } & 0.615336 & 1.725271 & 3.687176 \\ \text { C } & 4.307170 & 4.054900 & -0.360170 \\ \text { C } & 5.537794 & 4.055834 & 0.349422 \\ \text { C } & 5.537804 & 3.691718 & 1.715523 \\ \text { C } & 4.307188 & 3.337721 & 2.330526 \\ \text { C } & 4.307194 & 2.339333 & 3.331549 \\ \text { C } & 3.076576 & 1.725272 & 3.687160 \\ \text { C } & 5.537816 & 1.725273 & 3.687145 \\ \text { C } & 6.768434 & 2.339333 & 3.331534 \\ \text { C } & 6.768428 & 3.337721 & 2.330510 \\ \text { C } & 6.768011 & 3.687113 & -1.724903 \\ \text { C } & 6.768410 & 4.054899 & -0.360186 \\ \text { C } & 0.615339 & 0.360132 & 4.054891 \\ \text { C } & 1.845959 & -0.349466 & 4.055815 \\ \text { C } & 3.076579 & 0.360133 & 4.054875 \\ \text { C } & 4.307199 & -0.349466 & 4.055801 \\ \text { C } & 5.537819 & 0.360134 & 4.054860 \\ \text { C } & 1.845956 & -1.715568 & 3.691701 \\ \text { C } & 3.076574 & -2.330560 & 3.337693 \\ \text { C } & 4.307196 & -1.715567 & 3.691687 \\ & 5.537815 & -2.330564 & 3.337688 \\ \text { C.768435 } & -1.715567 & 3.691671 \\ \text { C. } & & -0.349465 & 4.055786\end{array}$




$\begin{array}{lrrr}\text { C } & 0.615335 & -2.330565 & 3.337717 \\ \text { C } & -0.615283 & -1.715568 & 3.691717 \\ \text { C } & -0.615281 & -0.349467 & 4.055832 \\ \text { C } & -1.845901 & 0.360132 & 4.054905 \\ \text { C } & -1.845904 & -2.330561 & 3.337726 \\ \text { C } & -3.076523 & -1.715569 & 3.691730 \\ \text { C } & -3.076520 & -0.349467 & 4.055847 \\ \text { C } & -4.307141 & 0.360131 & 4.054922 \\ \text { C } & -4.307147 & -2.330567 & 3.337744 \\ \text { C } & -5.537765 & -1.715573 & 3.691746 \\ \text { C } & -5.537761 & -0.349468 & 4.055865 \\ \text { C } & -6.768380 & 0.360130 & 4.054937 \\ \text { C } & -6.768385 & 1.725268 & 3.687225 \\ \text { C } & -4.307161 & -4.055840 & -0.349452 \\ \text { C } & -5.537776 & -4.054906 & 0.360158 \\ \text { C } & -6.768409 & -4.055838 & -0.349436 \\ \text { C } & -6.768418 & -3.691720 & -1.715536 \\ \text { C } & -1.845925 & -4.055817 & -0.349460 \\ \text { C } & -3.076543 & -4.054896 & 0.360143 \\ \text { C } & -3.076536 & -3.687190 & 1.725283 \\ \text { C } & -4.307153 & -3.331592 & 2.339353 \\ \text { C } & -5.537775 & -3.687194 & 1.725295 \\ \text { C } & -6.768387 & -2.330569 & 3.337754 \\ \text { C } & -6.768393 & -3.331591 & 2.339366 \\ \text { C } & -1.845912 & -3.331584 & 2.339337 \\ \text { C } & 0.615330 & -3.331588 & 2.339328 \\ \text { C } & -0.615292 & -3.687189 & 1.725272 \\ \text { C } & -0.615296 & -4.054908 & 0.360134 \\ \text { C } & 0.615320 & -4.055863 & -0.349472 \\ \text { C } & 3.076568 & -3.331583 & 2.339306 \\ \text { C } & 1.845943 & -3.687189 & 1.725257 \\ \text { C } & 1.845929 & -4.054896 & 0.360115 \\ \text { C } & 3.076548 & -4.055794 & -0.349488 \\ \text { C } & 5.537811 & -3.331587 & 2.339300 \\ \text { C } & 4.307189 & -3.687188 & 1.725242 \\ \text { C } & 4.307185 & -4.054908 & 0.360105 \\ \text { C } & 5.537798 & -4.055890 & -0.349507 \\ \text { C } & 6.768407 & -4.054914 & 0.360094 \\ & 6.768421 & -3.687208 & 1.725235 \\ & -7.711015 & 1.980517 & -3.727405\end{array}$




$\begin{array}{rrrr}\text { H } & -7.711000 & 0.137315 & -4.218514 \\ \mathrm{H} & -7.710964 & 2.237694 & 3.578740 \\ \mathrm{H} & -7.710979 & 3.584613 & 2.228322 \\ \mathrm{H} & -7.711020 & 4.218190 & -0.148305 \\ \mathrm{H} & -7.710993 & 3.722187 & -1.990233 \\ \mathrm{H} & -7.710946 & -0.137320 & 4.218593 \\ \mathrm{H} & -7.711008 & -2.237705 & -3.578663 \\ \mathrm{H} & -7.711003 & -3.584623 & -2.228246 \\ \mathrm{H} & -7.711012 & -4.218205 & 0.148385 \\ \mathrm{H} & -7.710968 & -3.722193 & 1.990313 \\ \mathrm{H} & -7.710969 & -1.980528 & 3.727479 \\ \mathrm{H} & 7.711006 & 3.727439 & 1.980465 \\ \mathrm{H} & 7.711062 & 4.218350 & 0.137160 \\ \mathrm{H} & 7.711009 & 1.990271 & 3.722128 \\ \mathrm{H} & 7.711048 & 0.148350 & 4.218138 \\ \mathrm{H} & 7.711018 & -2.228277 & 3.584564 \\ \mathrm{H} & 7.711005 & -3.578709 & 2.237647 \\ \mathrm{H} & 7.710977 & -4.218566 & -0.137357 \\ \mathrm{H} & 7.710963 & -3.727305 & -1.980477 \\ \mathrm{H} & 7.710932 & -1.990176 & -3.722076 \\ \mathrm{H} & 7.711040 & -0.148074 & -4.217107 \\ \mathrm{H} & 7.710527 & 2.227728 & -3.583372 \\ \mathrm{H} & 7.710754 & 3.578668 & -2.237148\end{array}$

$(6,6) 5$ cells

204

$\begin{array}{llll}\text { C } & 8.590562 & 3.675646 & -2.067969 \\ \text { C } & 8.590614 & 4.147274 & -0.773408 \\ \text { C } & 7.395180 & 4.172554 & -0.003226 \\ \text { C } & 6.170174 & 4.050210 & -0.707689 \\ \text { C } & 6.170180 & 3.558824 & -2.055382 \\ \text { C } & 7.395095 & 3.199648 & -2.673538 \\ \text { C } & 4.924005 & 4.105356 & 0.005054 \\ \text { C } & 4.923909 & 3.858056 & 1.404341 \\ \text { C } & 6.169942 & 3.562232 & 2.055358 \\ \text { C } & 7.394931 & 3.918681 & 1.435682 \\ \text { C } & 6.169966 & 2.637250 & 3.152021\end{array}$




$\begin{array}{lrrr}\text { C } & 7.394936 & 2.087776 & 3.609304 \\ \text { C } & 8.590122 & 2.743990 & 3.205084 \\ \text { C } & 8.590019 & 3.631903 & 2.151514 \\ \text { C } & 4.923770 & 2.046841 & 3.554310 \\ \text { C } & 3.694835 & 2.645105 & 3.162271 \\ \text { C } & 3.694895 & 3.574299 & 2.061049 \\ \text { C } & 2.468055 & 3.871577 & 1.411370 \\ \text { C } & 2.468090 & 4.120463 & 0.002962 \\ \text { C } & 3.694988 & 4.063447 & -0.709080 \\ \text { C } & 3.694941 & 3.570031 & -2.062654 \\ \text { C } & 4.923920 & 3.142688 & -2.636168 \\ \text { C } & 2.467978 & 2.056127 & 3.566081 \\ \text { C } & 1.228426 & 2.645367 & 3.154276 \\ \text { C } & 1.228446 & 3.566554 & 2.062625 \\ \text { C } & -0.000004 & 3.879990 & 1.418650 \\ \text { C } & -0.000003 & 4.130907 & -0.001040 \\ \text { C } & 1.228474 & 4.056778 & -0.713305 \\ \text { C } & 1.228459 & 3.567519 & -2.055110 \\ \text { C } & 2.468051 & 3.155505 & -2.644165 \\ \text { C } & -0.000005 & 2.064754 & 3.573073 \\ \text { C } & -1.228435 & 2.645367 & 3.154275 \\ \text { C } & -1.228454 & 3.566553 & 2.062623 \\ \text { C } & -2.468063 & 3.871576 & 1.411367 \\ \text { C } & -2.468096 & 4.120462 & 0.002959 \\ \text { C } & -1.228479 & 4.056777 & -0.713307 \\ \text { C } & -1.228462 & 3.567518 & -2.055111 \\ \text { C } & -0.000001 & 3.165988 & -2.647790 \\ \text { C } & -2.467988 & 2.056126 & 3.566078 \\ \text { C } & -3.694845 & 2.645104 & 3.162266 \\ \text { C } & -3.694904 & 3.574297 & 2.061044 \\ \text { C } & -4.923917 & 3.858053 & 1.404334 \\ \text { C } & -4.924011 & 4.105354 & 0.005047 \\ \text { C } & -3.694993 & 4.063445 & -0.709085 \\ \text { C } & -3.694943 & 3.570028 & -2.062658 \\ \text { C } & -2.468053 & 3.155507 & -2.644170 \\ \text { C } & -4.923780 & 2.046840 & 3.554304 \\ \text { C } & -6.169975 & 2.637248 & 3.152014 \\ \text { C } & -6.169950 & 3.562229 & 2.055350 \\ & -7.394938 & 3.918677 & 1.435673 \\ & & 4.172547 & -0.003235\end{array}$




$\begin{array}{lrrr}\text { C } & -6.170179 & 4.050207 & -0.707697 \\ \text { C } & -6.170183 & 3.558821 & -2.055392 \\ \text { C } & -4.923923 & 3.142682 & -2.636173 \\ \text { C } & -7.394946 & 2.087774 & 3.609296 \\ \text { C } & -8.590132 & 2.743990 & 3.205075 \\ \text { C } & -8.590027 & 3.631902 & 2.151505 \\ \text { C } & -7.395096 & 3.199646 & -2.673552 \\ \text { C } & -8.590565 & 3.675638 & -2.067981 \\ \text { C } & -8.590620 & 4.147264 & -0.773419 \\ \text { C } & -4.923697 & 2.056320 & -3.551694 \\ \text { C } & -6.169648 & 1.412330 & -3.862450 \\ \text { C } & -7.394574 & 2.082962 & -3.615291 \\ \text { C } & -6.169639 & -0.000787 & -4.111950 \\ \text { C } & -7.394576 & -0.715464 & -4.109336 \\ \text { C } & -8.589424 & 0.047774 & -4.222893 \\ \text { C } & -8.589432 & 1.404655 & -3.983272 \\ \text { C } & -4.923645 & -0.712079 & -4.040351 \\ \text { C } & -4.923774 & -2.046841 & -3.554285 \\ \text { C } & -6.169970 & -2.637250 & -3.151997 \\ \text { C } & -7.394941 & -2.087776 & -3.609280 \\ \text { C } & -6.169947 & -3.562231 & -2.055333 \\ \text { C } & -7.394935 & -3.918679 & -1.435657 \\ \text { C } & -8.590024 & -3.631905 & -2.151491 \\ \text { C } & -8.590127 & -2.743992 & -3.205061 \\ \text { C } & -4.923914 & -3.858055 & -1.404315 \\ \text { C } & -4.924010 & -4.105355 & -0.005029 \\ \text { C } & -6.170179 & -4.050208 & 0.707714 \\ \text { C } & -7.395185 & -4.172549 & 0.003251 \\ \text { C } & -6.170185 & -3.558823 & 2.055409 \\ \text { C } & -7.395099 & -3.199648 & 2.673567 \\ \text { C } & -8.590567 & -3.675641 & 2.067995 \\ \text { C } & -8.590620 & -4.147266 & 0.773433 \\ \text { C } & -4.923925 & -3.142683 & 2.636192 \\ \text { C } & -4.923702 & -2.056321 & 3.551713 \\ \text { C } & -6.169653 & -1.412331 & 3.862467 \\ \text { C } & -7.394579 & -2.082964 & 3.615306 \\ \text { C } & -6.169644 & 0.000786 & 4.111967 \\ \text { C } & -7.394582 & 0.715462 & 4.109351 \\ \text { C } & -8.589430 & -0.047776 & 4.222907 \\ \text { C } & -8.589437 & -1.404657 & 3.983286\end{array}$




$\begin{array}{lrrr}\text { C } & -4.923651 & 0.712078 & 4.040370 \\ \text { C } & -2.467944 & 0.712603 & 4.055272 \\ \text { C } & -3.694729 & 0.001612 & 4.124769 \\ \text { C } & -3.694755 & -1.417594 & 3.874136 \\ \text { C } & -2.467980 & -2.062059 & 3.565705 \\ \text { C } & -2.468055 & -3.155508 & 2.644192 \\ \text { C } & -3.694945 & -3.570030 & 2.062679 \\ \text { C } & -3.694993 & -4.063446 & 0.709106 \\ \text { C } & -2.468095 & -4.120463 & -0.002936 \\ \text { C } & -2.468060 & -3.871576 & -1.411345 \\ \text { C } & -3.694900 & -3.574298 & -2.061023 \\ \text { C } & -3.694840 & -2.645105 & -3.162246 \\ \text { C } & -2.467983 & -2.056127 & -3.566056 \\ \text { C } & -2.467938 & -0.712604 & -4.055250 \\ \text { C } & -3.694723 & -0.001613 & -4.124748 \\ \text { C } & -3.694750 & 1.417593 & -3.874115 \\ \text { C } & -2.467976 & 2.062059 & -3.565683 \\ \text { C } & -0.000005 & 0.710464 & 4.066083 \\ \text { C } & -1.228405 & -0.003698 & 4.118696 \\ \text { C } & -1.228414 & -1.410597 & 3.870347 \\ \text { C } & -0.000004 & -2.063819 & 3.576717 \\ \text { C } & -0.000004 & -3.165987 & 2.647815 \\ \text { C } & -1.228464 & -3.567518 & 2.055135 \\ \text { C } & -1.228479 & -4.056777 & 0.713331 \\ \text { C } & -0.000002 & -4.130907 & 0.001065 \\ \text { C } & -0.000001 & -3.879990 & -1.418624 \\ \text { C } & -1.228451 & -3.566553 & -2.062599 \\ \text { C } & -1.228430 & -2.645367 & -3.154250 \\ \text { C } & 0.000001 & -2.064754 & -3.573047 \\ \text { C } & 0.000001 & -0.710465 & -4.066058 \\ \text { C } & -1.228399 & 0.003698 & -4.118672 \\ \text { C } & -1.228409 & 1.410597 & -3.870323 \\ \text { C } & 0.000000 & 2.063819 & -3.576692 \\ \text { C } & 2.467934 & 0.712604 & 4.055274 \\ \text { C } & 1.228395 & -0.003698 & 4.118698 \\ \text { C } & 1.228404 & -1.410597 & 3.870349 \\ \text { C } & 2.467971 & -2.062059 & 3.565707 \\ \text { C } & 2.468048 & -3.155508 & 2.644196 \\ & 1.228457 & -3.567519 & 2.055137 \\ & 1.228474 & -4.056778 & 0.713332\end{array}$




$\begin{array}{lrrr}\text { C } & 2.468091 & -4.120462 & -0.002933 \\ \text { C } & 2.468058 & -3.871576 & -1.411341 \\ \text { C } & 1.228449 & -3.566554 & -2.062598 \\ \text { C } & 1.228430 & -2.645367 & -3.154249 \\ \text { C } & 2.467984 & -2.056125 & -3.566050 \\ \text { C } & 2.467939 & -0.712603 & -4.055244 \\ \text { C } & 1.228400 & 0.003698 & -4.118671 \\ \text { C } & 1.228409 & 1.410597 & -3.870321 \\ \text { C } & 2.467975 & 2.062059 & -3.565677 \\ \text { C } & 4.923641 & 0.712079 & 4.040376 \\ \text { C } & 3.694719 & 0.001613 & 4.124773 \\ \text { C } & 3.694746 & -1.417593 & 3.874140 \\ \text { C } & 4.923692 & -2.056320 & 3.551719 \\ \text { C } & 4.923918 & -3.142683 & 2.636198 \\ \text { C } & 3.694939 & -3.570030 & 2.062684 \\ \text { C } & 3.694989 & -4.063447 & 0.709111 \\ \text { C } & 4.924006 & -4.105356 & -0.005022 \\ \text { C } & 4.923912 & -3.858055 & -1.404308 \\ \text { C } & 3.694899 & -3.574298 & -2.061018 \\ \text { C } & 3.694841 & -2.645105 & -3.162241 \\ \text { C } & 4.923774 & -2.046841 & -3.554279 \\ \text { C } & 4.923646 & -0.712079 & -4.040345 \\ \text { C } & 3.694725 & -0.001611 & -4.124741 \\ \text { C } & 3.694751 & 1.417594 & -3.874109 \\ \text { C } & 4.923697 & 2.056323 & -3.551689 \\ \text { C } & 7.394572 & 0.715463 & 4.109360 \\ \text { C } & 6.169634 & 0.000787 & 4.111973 \\ \text { C } & 6.169643 & -1.412330 & 3.862474 \\ \text { C } & 7.394570 & -2.082962 & 3.615316 \\ \text { C } & 7.395092 & -3.199647 & 2.673577 \\ \text { C } & 6.170178 & -3.558822 & 2.055417 \\ \text { C } & 6.170174 & -4.050208 & 0.707722 \\ \text { C } & 7.395181 & -4.172550 & 0.003261 \\ \text { C } & 7.394933 & -3.918681 & -1.435649 \\ \text { C } & 6.169945 & -3.562230 & -2.055325 \\ \text { C } & 6.169970 & -2.637249 & -3.151987 \\ \text { C } & 7.394942 & -2.087777 & -3.609269 \\ \text { C } & 7.394578 & -0.715460 & -4.109324 \\ & 6.169640 & -0.000785 & -4.111939 \\ \text { C } & & 1.412330 & -3.862439\end{array}$




$\begin{array}{rrrr}\text { C } & 7.394576 & 2.082962 & -3.615279 \\ \mathrm{C} & 8.589426 & -1.404656 & 3.983298 \\ \mathrm{C} & 8.589419 & -0.047774 & 4.222918 \\ \mathrm{C} & 8.590615 & -4.147264 & 0.773443 \\ \mathrm{C} & 8.590560 & -3.675638 & 2.068006 \\ \mathrm{C} & 8.590126 & -2.743995 & -3.205052 \\ \mathrm{C} & 8.590021 & -3.631908 & -2.151482 \\ \mathrm{C} & 8.589433 & 1.404657 & -3.983256 \\ \mathrm{C} & 8.589425 & 0.047774 & -4.222875 \\ \mathrm{H} & 9.536737 & 4.012680 & 1.789778 \\ \mathrm{H} & 9.537538 & 4.379187 & -0.302397 \\ \mathrm{H} & -9.536745 & 4.012682 & 1.789770 \\ \mathrm{H} & -9.537545 & 4.379175 & -0.302409 \\ \mathrm{H} & -9.537437 & 3.550524 & -2.577785 \\ \mathrm{H} & -9.536067 & 1.929156 & -3.952141 \\ \mathrm{H} & -9.536112 & -0.455428 & -4.373492 \\ \mathrm{H} & -9.536997 & -2.452397 & -3.641613 \\ \mathrm{H} & -9.536741 & -4.012685 & -1.789757 \\ \mathrm{H} & -9.537544 & -4.379177 & 0.302421 \\ \mathrm{H} & -9.537440 & -3.550526 & 2.577797 \\ \mathrm{H} & -9.536072 & -1.929159 & 3.952153 \\ \mathrm{H} & -9.536118 & 0.455425 & 4.373505 \\ \mathrm{H} & -9.537003 & 2.452395 & 3.641626 \\ \mathrm{H} & 9.536994 & 2.452393 & 3.641633 \\ \mathrm{H} & 9.536107 & 0.455426 & 4.373518 \\ \mathrm{H} & 9.536062 & -1.929157 & 3.952166 \\ \mathrm{H} & 9.537433 & -3.550520 & 2.577808 \\ \mathrm{H} & 9.537540 & -4.379171 & 0.302432 \\ \mathrm{H} & 9.536739 & -4.012691 & -1.789749 \\ \mathrm{H} & 9.536998 & -2.452401 & -3.641603 \\ \mathrm{H} & 9.536113 & -0.455428 & -4.373467 \\ \mathrm{H} & 9.536067 & 1.929159 & -3.952119 \\ \mathrm{H} & 9.537435 & 3.550527 & -2.577768\end{array}$

$(6,6) 6$ cells

240

$\begin{array}{llll}\text { C } & -10.438590 & 3.982407 & -1.393704\end{array}$ 


$\begin{array}{lrrr}\text { C } & -10.438528 & 3.322818 & -2.602764 \\ \text { C } & -9.242733 & 2.759219 & -3.129350 \\ \text { C } & -8.017834 & 3.208944 & -2.573905 \\ \text { C } & -8.017877 & 3.896143 & -1.313811 \\ \text { C } & -9.242712 & 4.120346 & -0.635250 \\ \text { C } & -6.772226 & 2.708642 & -3.084739 \\ \text { C } & -6.772322 & 1.493976 & -3.821634 \\ \text { C } & -8.018117 & 0.810524 & -4.029996 \\ \text { C } & -9.243016 & 1.510798 & -3.886582 \\ \text { C } & -8.018150 & -0.624170 & -4.063772 \\ \text { C } & -9.243075 & -1.330369 & -3.952526 \\ \text { C } & -10.439113 & -0.592604 & -4.174758 \\ \text { C } & -10.439056 & 0.784235 & -4.142784 \\ \text { C } & -6.772352 & -1.316710 & -3.887182 \\ \text { C } & -5.542674 & -0.626521 & -4.075461 \\ \text { C } & -5.542668 & 0.813294 & -4.041552 \\ \text { C } & -4.315873 & 1.497274 & -3.836631 \\ \text { C } & -4.315874 & 2.720545 & -3.094588 \\ \text { C } & -5.542642 & 3.217891 & -2.581870 \\ \text { C } & -5.542636 & 3.907607 & -1.317287 \\ \text { C } & -6.772189 & 4.055465 & -0.617102 \\ \text { C } & -4.315883 & -1.319404 & -3.902256 \\ \text { C } & -3.076865 & -0.620484 & -4.070218 \\ \text { C } & -3.076865 & 0.806963 & -4.036607 \\ \text { C } & -1.847575 & 1.497305 & -3.845897 \\ \text { C } & -1.847600 & 2.728956 & -3.098840 \\ \text { C } & -3.076913 & 3.216645 & -2.574042 \\ \text { C } & -3.076934 & 3.900430 & -1.320330 \\ \text { C } & -4.315912 & 4.070212 & -0.621825 \\ \text { C } & -1.847576 & -1.319049 & -3.911460 \\ \text { C } & -0.619085 & -0.621386 & -4.070756 \\ \text { C } & -0.619083 & 0.807867 & -4.037104 \\ \text { C } & 0.619181 & 1.497692 & -3.836094 \\ \text { C } & 0.619157 & 2.720350 & -3.094711 \\ \text { C } & -0.619145 & 3.216973 & -2.575133 \\ \text { C } & -0.619175 & 3.901710 & -1.319889 \\ \text { C } & -1.847667 & 4.078536 & -0.626516 \\ \text { C } & 0.619186 & -1.319889 & -3.901733 \\ \text { C } & 1.847675 & -0.626510 & -4.078560 \\ & 1.847673 & 0.813358 & -4.044663\end{array}$




$\begin{array}{rrrr}\text { C } & 3.076940 & 1.498090 & -3.834774 \\ \text { C } & 3.076927 & 2.719257 & -3.094404 \\ \text { C } & 1.847610 & 3.221475 & -2.583527 \\ \text { C } & 1.847587 & 3.911438 & -1.319037 \\ \text { C } & 0.619093 & 4.070735 & -0.621380 \\ \text { C } & 3.076946 & -1.320318 & -3.900454 \\ \text { C } & 4.315920 & -0.621808 & -4.070237 \\ \text { C } & 4.315911 & 0.808322 & -4.036539 \\ \text { C } & 5.542626 & 1.495417 & -3.842071 \\ \text { C } & 5.542658 & 2.727162 & -3.095238 \\ \text { C } & 4.315886 & 3.216876 & -2.575270 \\ \text { C } & 4.315895 & 3.902237 & -1.319380 \\ \text { C } & 3.076873 & 4.070197 & -0.620466 \\ \text { C } & 5.542647 & -1.317263 & -3.907634 \\ \text { C } & 6.772197 & -0.617072 & -4.055492 \\ \text { C } & 6.772177 & 0.802978 & -4.021971 \\ \text { C } & 8.017824 & 1.491497 & -3.830729 \\ \text { C } & 8.017840 & 2.718860 & -3.086617 \\ \text { C } & 6.772242 & 3.206509 & -2.563726 \\ \text { C } & 6.772363 & 3.887165 & -1.316675 \\ \text { C } & 5.542682 & 4.075443 & -0.626492 \\ \text { C } & 8.017888 & -1.313775 & -3.896172 \\ \text { C } & 9.242720 & -0.635209 & -4.120375 \\ \text { C } & 9.242659 & 0.824222 & -4.086160 \\ \text { C } & 10.438447 & 1.575578 & -3.913664 \\ \text { C } & 10.438509 & 2.753133 & -3.199344 \\ \text { C } & 9.242744 & 3.253244 & -2.612053 \\ \text { C } & 9.243086 & 3.952509 & -1.330322 \\ \text { C } & 8.018158 & 4.063755 & -0.624128 \\ \text { C } & 8.017852 & -2.573869 & -3.208973 \\ \text { C } & 9.242754 & -3.129309 & -2.759248 \\ \text { C } & 10.438546 & -2.602716 & -3.322848 \\ \text { C } & 10.438602 & -1.393656 & -3.982436 \\ \text { C } & 5.542660 & -2.581847 & -3.217917 \\ \text { C } & 6.772247 & -3.084709 & -2.708669 \\ \text { C } & 6.772347 & -3.821604 & -1.494003 \\ \text { C } & 8.018144 & -4.029960 & -0.810553 \\ \text { C } & 9.243041 & -3.886540 & -1.510827 \\ & 8.018178 & -4.063736 & 0.624142 \\ \text { C.243102 } & -3.952484 & 1.330340\end{array}$




$\begin{array}{rrrr}\text { C } & 10.439141 & -4.174710 & 0.592574 \\ \text { C } & 10.439083 & -4.142737 & -0.784265 \\ \text { C } & 5.542694 & -4.041529 & -0.813320 \\ \text { C } & 5.542702 & -4.075437 & 0.626495 \\ \text { C } & 6.772379 & -3.887153 & 1.316683 \\ \text { C } & 6.772249 & -3.206497 & 2.563734 \\ \text { C } & 8.017843 & -2.718841 & 3.086630 \\ \text { C } & 9.242752 & -3.253218 & 2.612071 \\ \text { C } & 8.017816 & -1.491479 & 3.830742 \\ \text { C } & 9.242647 & -0.824196 & 4.086178 \\ \text { C } & 10.438440 & -1.575546 & 3.913687 \\ \text { C } & 10.438511 & -2.753100 & 3.199367 \\ \text { C } & 5.542660 & -2.727157 & 3.095241 \\ \text { C } & 5.542618 & -1.495412 & 3.842073 \\ \text { C } & 6.772165 & -0.802966 & 4.021979 \\ \text { C } & 6.772177 & 0.617084 & 4.055500 \\ \text { C } & 8.017865 & 1.313794 & 3.896185 \\ \text { C } & 9.242700 & 0.635234 & 4.120393 \\ \text { C } & 8.017824 & 2.573888 & 3.208986 \\ \text { C } & 9.242725 & 3.129334 & 2.759266 \\ \text { C } & 10.438518 & 2.602749 & 3.322871 \\ \text { C } & 10.438578 & 1.393689 & 3.982460 \\ \text { C } & 5.542624 & 1.317268 & 3.907637 \\ \text { C } & 5.542632 & 2.581852 & 3.217920 \\ \text { C } & 6.772219 & 3.084721 & 2.708677 \\ \text { C } & 6.772320 & 3.821616 & 1.494011 \\ \text { C } & 8.018118 & 4.029979 & 0.810566 \\ \text { C } & 9.243013 & 3.886566 & 1.510845 \\ \text { C } & 10.439120 & 4.174742 & -0.592551 \\ \text { C } & 10.439057 & 4.142769 & 0.784288 \\ \text { C } & 5.542669 & 4.041534 & 0.813323 \\ \text { C } & 3.076930 & -2.574030 & -3.216670 \\ \text { C } & 4.315894 & -3.094570 & -2.720571 \\ \text { C } & 4.315898 & -3.836613 & -1.497299 \\ \text { C } & 3.076892 & -4.036595 & -0.806987 \\ \text { C } & 3.076892 & -4.070206 & 0.620459 \\ \text { C } & 4.315911 & -3.902239 & 1.319378 \\ \text { C } & 4.315893 & -3.216878 & 2.575267 \\ & 3.076929 & -2.719265 & 3.094397 \\ \text { ( } & & -1.498099 & 3.834767\end{array}$




$\begin{array}{lrrr}\text { C } & 4.315899 & -0.808324 & 4.036536 \\ \text { C } & 4.315900 & 0.621806 & 4.070235 \\ \text { C } & 3.076922 & 1.320309 & 3.900447 \\ \text { C } & 3.076903 & 2.574022 & 3.216663 \\ \text { C } & 4.315866 & 3.094568 & 2.720569 \\ \text { C } & 4.315870 & 3.836611 & 1.497297 \\ \text { C } & 3.076866 & 4.036587 & 0.806980 \\ \text { C } & 0.619163 & -2.575133 & -3.216996 \\ \text { C } & 1.847620 & -3.098834 & -2.728979 \\ \text { C } & 1.847600 & -3.845891 & -1.497329 \\ \text { C } & 0.619110 & -4.037104 & -0.807890 \\ \text { C } & 0.619113 & -4.070757 & 0.621363 \\ \text { C } & 1.847603 & -3.911454 & 1.319025 \\ \text { C } & 1.847617 & -3.221490 & 2.583515 \\ \text { C } & 0.619160 & -2.720372 & 3.094693 \\ \text { C } & 0.619174 & -1.497714 & 3.836077 \\ \text { C } & 1.847661 & -0.813373 & 4.044650 \\ \text { C } & 1.847654 & 0.626495 & 4.078548 \\ \text { C } & 0.619163 & 1.319867 & 3.901716 \\ \text { C } & 0.619136 & 2.575111 & 3.216978 \\ \text { C } & 1.847592 & 3.098819 & 2.728967 \\ \text { C } & 1.847573 & 3.845875 & 1.497317 \\ \text { C } & 0.619084 & 4.037082 & 0.807873 \\ \text { C } & -1.847592 & -2.583539 & -3.221496 \\ \text { C } & -0.619137 & -3.094716 & -2.720372 \\ \text { C } & -0.619156 & -3.836100 & -1.497714 \\ \text { C } & -1.847647 & -4.044674 & -0.813379 \\ \text { C } & -1.847647 & -4.078571 & 0.626488 \\ \text { C } & -0.619159 & -3.901739 & 1.319867 \\ \text { C } & -0.619138 & -3.217001 & 2.575111 \\ \text { C } & -1.847597 & -2.728991 & 3.098813 \\ \text { C } & -1.847582 & -1.497341 & 3.845869 \\ \text { C } & -0.619095 & -0.807896 & 4.037081 \\ \text { C } & -0.619105 & 0.621357 & 4.070734 \\ \text { C } & -1.847599 & 1.319013 & 3.911432 \\ \text { C } & -1.847620 & 2.583503 & 3.221469 \\ \text { C } & -0.619165 & 3.094688 & 2.720350 \\ \text { C } & -0.619183 & 3.836071 & 1.497692 \\ \text { C } & -1.847673 & 4.044639 & 0.813352 \\ \text { C } & -4.315868 & -2.575293 & -3.216896\end{array}$




$\begin{array}{lrrr}\text { C } & -3.076906 & -3.094422 & -2.719277 \\ \text { C } & -3.076914 & -3.834792 & -1.498111 \\ \text { C } & -4.315885 & -4.036562 & -0.808342 \\ \text { C } & -4.315892 & -4.070261 & 0.621788 \\ \text { C } & -3.076918 & -3.900472 & 1.320297 \\ \text { C } & -3.076905 & -3.216688 & 2.574010 \\ \text { C } & -4.315871 & -2.720595 & 3.094550 \\ \text { C } & -4.315880 & -1.497323 & 3.836593 \\ \text { C } & -3.076877 & -0.807005 & 4.036575 \\ \text { C } & -3.076885 & 0.620441 & 4.070186 \\ \text { C } & -4.315907 & 1.319354 & 3.902219 \\ \text { C } & -4.315895 & 2.575244 & 3.216858 \\ \text { C } & -3.076934 & 3.094380 & 2.719245 \\ \text { C } & -3.076942 & 3.834749 & 1.498079 \\ \text { C } & -4.315910 & 4.036513 & 0.808304 \\ \text { C } & -6.772224 & -2.563762 & -3.206527 \\ \text { C } & -5.542637 & -3.095268 & -2.727181 \\ \text { C } & -5.542601 & -3.842100 & -1.495436 \\ \text { C } & -6.772150 & -4.022007 & -0.802996 \\ \text { C } & -6.772169 & -4.055528 & 0.617054 \\ \text { C } & -5.542620 & -3.907663 & 1.317244 \\ \text { C } & -5.542635 & -3.217947 & 2.581828 \\ \text { C } & -6.772224 & -2.708705 & 3.084692 \\ \text { C } & -6.772329 & -1.494039 & 3.821586 \\ \text { C } & -5.542680 & -0.813350 & 4.041510 \\ \text { C } & -5.542695 & 0.626465 & 4.075419 \\ \text { C } & -6.772375 & 1.316647 & 3.887135 \\ \text { C } & -6.772251 & 2.563699 & 3.206479 \\ \text { C } & -5.542665 & 3.095212 & 2.727138 \\ \text { C } & -5.542628 & 3.842044 & 1.495393 \\ \text { C } & -6.772176 & 4.021944 & 0.802948 \\ \text { C } & -9.242726 & -2.612101 & -3.253260 \\ \text { C } & -8.017820 & -3.086659 & -2.718876 \\ \text { C } & -8.017799 & -3.830770 & -1.491514 \\ \text { C } & -9.242632 & -4.086207 & -0.824238 \\ \text { C } & -9.242692 & -4.120423 & 0.635193 \\ \text { C } & -8.017861 & -3.896213 & 1.313758 \\ \text { C } & -8.017827 & -3.209014 & 2.573852 \\ \text { C } & -9.242731 & -2.759295 & 3.129293 \\ & -9.243023 & -1.510874 & 3.886524\end{array}$




$\begin{array}{lrrr}\text { C } & -8.018129 & -0.810594 & 4.029943 \\ \mathrm{C} & -8.018170 & 0.624100 & 4.063719 \\ \mathrm{C} & -9.243098 & 1.330293 & 3.952468 \\ \mathrm{C} & -9.242754 & 2.612024 & 3.253202 \\ \mathrm{C} & -8.017848 & 3.086589 & 2.718824 \\ \mathrm{C} & -8.017826 & 3.830700 & 1.491462 \\ \mathrm{C} & -9.242658 & 4.086131 & 0.824180 \\ \mathrm{C} & -10.438422 & -3.913718 & -1.575593 \\ \mathrm{C} & -10.438488 & -3.199398 & -2.753148 \\ \mathrm{C} & -10.438521 & -3.322901 & 2.602701 \\ \mathrm{C} & -10.438574 & -3.982490 & 1.393641 \\ \mathrm{C} & -10.439133 & 0.592521 & 4.174695 \\ \mathrm{C} & -10.439068 & -0.784318 & 4.142722 \\ \mathrm{C} & -10.438450 & 3.913634 & 1.575530 \\ \mathrm{C} & -10.438517 & 3.199314 & 2.753085 \\ \mathrm{H} & -11.385728 & 1.307611 & -4.187862 \\ \mathrm{H} & -11.385098 & 3.124835 & -3.089543 \\ \mathrm{H} & 11.384942 & 1.160207 & -4.235687 \\ \mathrm{H} & 11.385087 & 3.230465 & -2.979546 \\ \mathrm{H} & 11.385874 & 4.243902 & -1.113128 \\ \mathrm{H} & 11.385726 & 4.187848 & 1.307669 \\ \mathrm{H} & 11.385089 & 3.089529 & 3.124892 \\ \mathrm{H} & 11.385131 & 0.963701 & 4.284622 \\ \mathrm{H} & 11.384931 & -1.160169 & 4.235714 \\ \mathrm{H} & 11.385093 & -3.230428 & 2.979573 \\ \mathrm{H} & 11.385893 & -4.243865 & 1.113155 \\ \mathrm{H} & 11.385755 & -4.187810 & -1.307642 \\ \mathrm{H} & 11.385119 & -3.089491 & -3.124865 \\ \mathrm{H} & 11.385154 & -0.963664 & -4.284594 \\ \mathrm{H} & -11.385864 & -1.113186 & -4.243917 \\ \mathrm{H} & -11.385067 & -2.979604 & -3.230480 \\ \mathrm{H} & -11.384915 & -4.235745 & -1.160222 \\ \mathrm{H} & -11.385125 & -4.284652 & 0.963649 \\ \mathrm{H} & -11.385094 & -3.124923 & 3.089476 \\ \mathrm{H} & -11.385738 & -1.307699 & 4.187796 \\ & -11.385888 & 1.113097 & 4.243850 \\ -11.385097 & 2.979515 & 3.230413 \\ \mathrm{H} & -11.385144 & 4.284564 & -0.963716\end{array}$


$(9,0) 2$ cells

96

$\begin{array}{rrrr}\text { C } & -2.461890 & 2.439915 & -2.533909 \\ \text { C } & -2.499082 & 3.633421 & -0.364886 \\ \text { C } & -3.875516 & 3.882862 & -0.288653 \\ \text { C } & -4.538758 & 3.787989 & 0.937971 \\ \text { C } & -2.499041 & 3.040612 & 2.016332 \\ \text { C } & -3.875498 & 3.296888 & 2.065940 \\ \text { C } & -2.461902 & 0.971887 & 3.377676 \\ \text { C } & -2.499132 & -1.503544 & 3.330580 \\ \text { C } & -3.875807 & -1.693542 & 3.507804 \\ \text { C } & -4.539401 & -2.708171 & 2.812243 \\ \text { C } & -2.499170 & -3.270298 & 1.627504 \\ \text { C } & -3.875908 & -3.440086 & 1.823672 \\ \text { C } & -2.461695 & -3.411512 & -0.844409 \\ \text { C } & -2.498867 & -2.129358 & -2.963104 \\ \text { C } & -3.875317 & -2.188821 & -3.217382 \\ \text { C } & -4.538702 & -1.080258 & -3.750634 \\ \text { C } & -2.499070 & 0.227733 & -3.645396 \\ \text { C } & -3.875533 & 0.142000 & -3.891632 \\ \text { C } & -1.783402 & 1.476383 & -3.300525 \\ \text { C } & 1.782831 & 2.424959 & -2.518390 \\ \text { C } & 0.339253 & 2.430027 & -2.523671 \\ \text { C } & -0.366200 & 3.226440 & -1.585892 \\ \text { C } & -1.783405 & 3.241545 & -1.599535 \\ \text { C } & 1.783317 & 3.593995 & -0.373331 \\ \text { C } & 0.366223 & 3.573503 & -0.377128 \\ \text { C } & -0.339312 & 3.395793 & 0.840314 \\ \text { C } & -1.782764 & 3.389061 & 0.838712 \\ \text { C } & 1.783247 & 3.001603 & 2.005350 \\ \text { C } & 0.366103 & 2.981459 & 1.998695 \\ \text { C } & -0.366355 & 2.109200 & 2.904523 \\ \text { C } & -1.783486 & 2.116443 & 2.924213 \\ \text { C } & 1.782668 & 0.965710 & 3.355760 \\ \text { C } & 0.339166 & 0.967410 & 3.362341 \\ \text { C } & -0.366320 & -0.242381 & 3.586339 \\ \text { C } & -1.783419 & -0.237912 & 3.606676\end{array}$

S42 


$\begin{array}{rrrr}\text { C } & 1.783402 & -1.476383 & 3.300524 \\ \text { C } & 0.366185 & -1.463416 & 3.285137 \\ \text { C } & -0.339253 & -2.430027 & 2.523671 \\ \text { C } & -1.782830 & -2.424959 & 2.518390 \\ \text { C } & 1.783405 & -3.241545 & 1.599535 \\ \text { C } & 0.366200 & -3.226440 & 1.585892 \\ \text { C } & -0.366223 & -3.573503 & 0.377128 \\ \text { C } & -1.783317 & -3.593995 & 0.373331 \\ \text { C } & 1.782764 & -3.389061 & -0.838712 \\ \text { C } & 0.339312 & -3.395793 & -0.840314 \\ \text { C } & -0.366103 & -2.981459 & -1.998695 \\ \text { C } & -1.783247 & -3.001603 & -2.005351 \\ \text { C } & 1.783486 & -2.116443 & -2.924213 \\ \text { C } & 0.366355 & -2.109200 & -2.904523 \\ \text { C } & -0.339166 & -0.967410 & -3.362341 \\ \text { C } & -1.782668 & -0.965710 & -3.355761 \\ \text { C } & 1.783419 & 0.237912 & -3.606677 \\ \text { C } & 0.366320 & 0.242381 & -3.586339 \\ \text { C } & -0.366185 & 1.463416 & -3.285138 \\ \text { C } & 2.499132 & 1.503544 & -3.330580 \\ \text { C } & 4.539401 & 2.708171 & -2.812243 \\ \text { C } & 3.875908 & 3.440086 & -1.823673 \\ \text { C } & 2.499170 & 3.270298 & -1.627504 \\ \text { C } & 2.461695 & 3.411512 & 0.844409 \\ \text { C } & 3.875317 & 2.188821 & 3.217382 \\ \text { C } & 2.498867 & 2.129358 & 2.963103 \\ \text { C } & 4.538702 & 1.080257 & 3.750634 \\ \text { C } & 3.875534 & -0.142000 & 3.891632 \\ \text { C } & 2.499070 & -0.227733 & 3.645396 \\ \text { C } & 2.461890 & -2.439915 & 2.533909 \\ \text { C } & 3.875516 & -3.882862 & 0.288652 \\ \text { C } & 2.499082 & -3.633421 & 0.364886 \\ \text { C } & 4.538758 & -3.787989 & -0.937971 \\ \text { C } & 3.875499 & -3.296888 & -2.065941 \\ \text { C } & 2.499041 & -3.040612 & -2.016332 \\ \text { C } & 2.461903 & -0.971887 & -3.377676 \\ \text { H } & 3.875807 & 1.693542 & -3.507804 \\ & -3.536489 & 2.351861 & -2.442636 \\ \text { H } & -4.430184 & 4.124186 & -1.187962 \\ & & 4.018946 & 0.995428\end{array}$




$\begin{array}{rrrr}\text { H } & -4.430164 & 3.088316 & 2.973430 \\ \mathrm{H} & -3.536776 & 0.937300 & 3.258179 \\ \mathrm{H} & -4.430736 & -1.034380 & 4.165275 \\ \mathrm{H} & -5.596879 & -2.872508 & 2.982744 \\ \mathrm{H} & -4.430726 & -4.121345 & 1.189043 \\ \mathrm{H} & -3.536594 & -3.290942 & -0.814348 \\ \mathrm{H} & -4.429800 & -3.087945 & -2.974801 \\ \mathrm{H} & -5.595920 & -1.146524 & -3.979237 \\ \mathrm{H} & -4.430377 & 1.031540 & -4.166513 \\ \mathrm{H} & 5.596879 & 2.872508 & -2.982744 \\ \mathrm{H} & 4.430727 & 4.121345 & -1.189043 \\ \mathrm{H} & 3.536595 & 3.290942 & 0.814348 \\ \mathrm{H} & 4.429800 & 3.087945 & 2.974801 \\ \mathrm{H} & 5.595920 & 1.146524 & 3.979237 \\ \mathrm{H} & 4.430377 & -1.031540 & 4.166513 \\ \mathrm{H} & 3.536489 & -2.351861 & 2.442635 \\ \mathrm{H} & 4.430184 & -4.124186 & 1.187962 \\ \mathrm{H} & 5.595983 & -4.018946 & -0.995428 \\ \mathrm{H} & 4.430164 & -3.088317 & -2.973431 \\ \mathrm{H} & 3.536776 & -0.937300 & -3.258179 \\ \mathrm{H} & 4.430736 & 1.034380 & -4.165275\end{array}$

$(9,0) 3$ cells

132

$\begin{array}{lrrr}\text { C } & 4.596606 & -3.429559 & 0.842823 \\ \text { C } & 4.635258 & -2.133742 & 2.950344 \\ \text { C } & 6.012761 & -2.190911 & 3.199649 \\ \text { C } & 6.676041 & -1.081892 & 3.732364 \\ \text { C } & 4.635521 & 0.225885 & 3.637350 \\ \text { C } & 6.013031 & 0.140034 & 3.877911 \\ \text { C } & 4.596862 & 2.447506 & 2.550173 \\ \text { C } & 4.635263 & 3.624416 & 0.374799 \\ \text { C } & 6.012699 & 3.868653 & 0.298936 \\ \text { C } & 6.675710 & 3.773331 & -0.927901 \\ \text { C } & 4.635076 & 3.034843 & -2.011086 \\ \text { C } & 6.012553 & 3.286383 & -2.057860 \\ \text { C } & 4.596616 & 0.982523 & -3.392696\end{array}$




$\begin{array}{lrrr}\text { C } & 4.635418 & -1.490085 & -3.327966 \\ \text { C } & 6.013147 & -1.676883 & -3.500666 \\ \text { C } & 6.676636 & -2.691246 & -2.804377 \\ \text { C } & 4.635476 & -3.262189 & -1.625056 \\ \text { C } & 6.013280 & -3.426945 & -1.818401 \\ \text { C } & 3.917725 & -3.598648 & -0.376369 \\ \text { C } & 0.349617 & -3.451451 & 0.848085 \\ \text { C } & 1.787446 & -3.462044 & 0.850711 \\ \text { C } & 2.498588 & -2.999521 & 1.996250 \\ \text { C } & 3.917728 & -3.011559 & 2.000388 \\ \text { C } & 0.361234 & -2.110152 & 2.894140 \\ \text { C } & 1.774592 & -2.106939 & 2.880376 \\ \text { C } & 2.483213 & -0.971765 & 3.355867 \\ \text { C } & 3.919943 & -0.970188 & 3.349776 \\ \text { C } & 0.361350 & 0.236597 & 3.578538 \\ \text { C } & 1.774671 & 0.241231 & 3.565028 \\ \text { C } & 2.498788 & 1.468729 & 3.297227 \\ \text { C } & 3.917970 & 1.476190 & 3.306253 \\ \text { C } & 0.349628 & 2.464622 & 2.568411 \\ \text { C } & 1.787600 & 2.472129 & 2.576104 \\ \text { C } & 2.498634 & 3.232865 & 1.602575 \\ \text { C } & 3.917825 & 3.241973 & 1.610390 \\ \text { C } & 0.361172 & 3.564322 & 0.383131 \\ \text { C } & 1.774497 & 3.550853 & 0.387216 \\ \text { C } & 2.483051 & 3.392181 & -0.833443 \\ \text { C } & 3.919722 & 3.386080 & -0.832079 \\ \text { C } & 0.361170 & 2.977693 & -1.989970 \\ \text { C } & 1.774525 & 2.963643 & -1.987223 \\ \text { C } & 2.498550 & 2.117132 & -2.915471 \\ \text { C } & 3.917664 & 2.121715 & -2.927278 \\ \text { C } & 0.349533 & 0.988758 & -3.414633 \\ \text { C } & 1.787400 & 0.991769 & -3.425117 \\ \text { C } & 2.498657 & -0.231112 & -3.600674 \\ \text { C } & 3.917740 & -0.228490 & -3.612804 \\ \text { C } & 0.361157 & -1.453882 & -3.280787 \\ \text { C } & 1.774612 & -1.443577 & -3.271220 \\ \text { C } & 2.483201 & -2.422115 & -2.524262 \\ \text { C } & 3.919991 & -2.417341 & -2.519259 \\ & 0.361211 & -3.216408 & -1.586998 \\ & 1.774655 & -3.207116 & -1.576261\end{array}$




$\begin{array}{lrrr}\text { C } & 2.498642 & -3.586310 & -0.378511 \\ \text { C } & -0.361172 & -3.564322 & -0.383132 \\ \text { C } & -3.919722 & -3.386080 & 0.832079 \\ \text { C } & -2.483051 & -3.392181 & 0.833443 \\ \text { C } & -1.774525 & -2.963643 & 1.987222 \\ \text { C } & -0.361170 & -2.977693 & 1.989970 \\ \text { C } & -3.917664 & -2.121716 & 2.927278 \\ \text { C } & -2.498550 & -2.117132 & 2.915470 \\ \text { C } & -1.787401 & -0.991769 & 3.425117 \\ \text { C } & -0.349533 & -0.988758 & 3.414632 \\ \text { C } & -3.917740 & 0.228490 & 3.612804 \\ \text { C } & -2.498657 & 0.231112 & 3.600673 \\ \text { C } & -1.774612 & 1.443577 & 3.271220 \\ \text { C } & -0.361157 & 1.453882 & 3.280786 \\ \text { C } & -3.919991 & 2.417341 & 2.519259 \\ \text { C } & -2.483201 & 2.422115 & 2.524261 \\ \text { C } & -1.774655 & 3.207116 & 1.576261 \\ \text { C } & -0.361211 & 3.216408 & 1.586998 \\ \text { C } & -3.917725 & 3.598648 & 0.376368 \\ \text { C } & -2.498642 & 3.586310 & 0.378511 \\ \text { C } & -1.787446 & 3.462044 & -0.850711 \\ \text { C } & -0.349617 & 3.451450 & -0.848085 \\ \text { C } & -3.917728 & 3.011559 & -2.000388 \\ \text { C } & -2.498588 & 2.999521 & -1.996251 \\ \text { C } & -1.774592 & 2.106939 & -2.880376 \\ \text { C } & -0.361234 & 2.110152 & -2.894140 \\ \text { C } & -3.919943 & 0.970188 & -3.349776 \\ \text { C } & -2.483214 & 0.971765 & -3.355867 \\ \text { C } & -1.774672 & -0.241231 & -3.565028 \\ \text { C } & -0.361350 & -0.236597 & -3.578538 \\ \text { C } & -3.917970 & -1.476190 & -3.306253 \\ \text { C } & -2.498788 & -1.468729 & -3.297227 \\ \text { C } & -1.787600 & -2.472129 & -2.576105 \\ \text { C } & -0.349628 & -2.464622 & -2.568411 \\ \text { C } & -3.917825 & -3.241973 & -1.610390 \\ \text { C } & -2.498635 & -3.232865 & -1.602575 \\ \text { C } & -1.774497 & -3.550853 & -0.387216 \\ \text { C } & -4.635263 & -3.624416 & -0.374799 \\ \text { C } & -6.675710 & -3.773331 & 0.927901 \\ & -6.012553 & -3.286384 & 2.057860\end{array}$

S46 


\begin{tabular}{lrrr} 
C & -4.635076 & -3.034843 & 2.011085 \\
$\mathrm{C}$ & -4.596616 & -0.982523 & 3.392696 \\
$\mathrm{C}$ & -6.013147 & 1.676883 & 3.500665 \\
$\mathrm{C}$ & -4.635418 & 1.490084 & 3.327966 \\
$\mathrm{C}$ & -6.676636 & 2.691246 & 2.804377 \\
$\mathrm{C}$ & -6.013280 & 3.426945 & 1.818401 \\
$\mathrm{C}$ & -4.635476 & 3.262189 & 1.625056 \\
$\mathrm{C}$ & -4.596606 & 3.429558 & -0.842823 \\
$\mathrm{C}$ & -6.012761 & 2.190911 & -3.199649 \\
$\mathrm{C}$ & -4.635258 & 2.133742 & -2.950345 \\
$\mathrm{C}$ & -6.676041 & 1.081893 & -3.732364 \\
$\mathrm{C}$ & -6.013031 & -0.140034 & -3.877911 \\
$\mathrm{C}$ & -4.635521 & -0.225885 & -3.637350 \\
$\mathrm{C}$ & -4.596862 & -2.447506 & -2.550173 \\
$\mathrm{C}$ & -6.012699 & -3.868653 & -0.298936 \\
$\mathrm{H}$ & 5.671963 & -3.314358 & 0.814314 \\
$\mathrm{H}$ & 6.568359 & -3.088903 & 2.955752 \\
$\mathrm{H}$ & 7.733807 & -1.147791 & 3.958328 \\
$\mathrm{H}$ & 6.569019 & 1.028406 & 4.153962 \\
$\mathrm{H}$ & 5.671925 & 2.363487 & 2.462670 \\
$\mathrm{H}$ & 6.568549 & 4.108342 & 1.197863 \\
$\mathrm{H}$ & 7.733448 & 4.001971 & -0.984426 \\
$\mathrm{H}$ & 6.568300 & 3.079508 & -2.964991 \\
$\mathrm{H}$ & 5.671941 & 0.949357 & -3.278563 \\
$\mathrm{H}$ & 6.569198 & -1.017135 & -4.156477 \\
$\mathrm{H}$ & 7.734677 & -2.853430 & -2.973178 \\
$\mathrm{H}$ & 6.569213 & -4.108586 & -1.185285 \\
$\mathrm{H}$ & -7.733448 & -4.001971 & 0.984426 \\
$\mathrm{H}$ & -6.568300 & -3.079509 & 2.964991 \\
$\mathrm{H}$ & -5.671941 & -0.949357 & 3.278563 \\
$\mathrm{H}$ & -6.569198 & 1.017135 & 4.156477 \\
$\mathrm{H}$ & -7.734677 & 2.853430 & 2.973178 \\
$\mathrm{H}$ & -6.569213 & 4.108586 & 1.185285 \\
$\mathrm{H}$ & -5.671963 & 3.314358 & -0.814315 \\
$\mathrm{H}$ & -6.568359 & 3.088903 & -2.955752 \\
& -7.733807 & 1.147791 & -3.958328 \\
$\mathrm{H}$ & -6.569020 & -1.028406 & -4.153962 \\
\hline & -6.568549 & -4.108342 & -1.197863
\end{tabular}


$(9,0) 4$ cells

168

$\begin{array}{lrrr}\text { C } & 6.732298 & -3.390964 & 0.994033 \\ \text { C } & 6.769652 & -2.001160 & 3.040989 \\ \text { C } & 8.146860 & -2.047298 & 3.293986 \\ \text { C } & 8.809750 & -0.915896 & 3.777901 \\ \text { C } & 6.769831 & 0.386906 & 3.622706 \\ \text { C } & 8.146995 & 0.311432 & 3.868457 \\ \text { C } & 6.732438 & 2.559365 & 2.440070 \\ \text { C } & 6.770001 & 3.637832 & 0.214017 \\ \text { C } & 8.147258 & 3.879285 & 0.126901 \\ \text { C } & 8.809975 & 3.730562 & -1.094785 \\ \text { C } & 6.769668 & 2.943278 & -2.143653 \\ \text { C } & 8.146903 & 3.193670 & -2.201909 \\ \text { C } & 6.732042 & 0.832257 & -3.434021 \\ \text { C } & 6.770002 & -1.635076 & -3.256590 \\ \text { C } & 8.147554 & -1.829863 & -3.421548 \\ \text { C } & 8.810713 & -2.813993 & -2.683247 \\ \text { C } & 6.770063 & -3.332524 & -1.478899 \\ \text { C } & 8.147527 & -3.506624 & -1.666177 \\ \text { C } & 6.053397 & -3.614224 & -0.216532 \\ \text { C } & 2.486839 & -3.424162 & 1.003618 \\ \text { C } & 3.922988 & -3.429690 & 1.005220 \\ \text { C } & 4.634056 & -2.910294 & 2.126922 \\ \text { C } & 6.053256 & -2.921014 & 2.131480 \\ \text { C } & 2.495628 & -1.980055 & 2.976887 \\ \text { C } & 3.909381 & -1.977064 & 2.965225 \\ \text { C } & 4.617608 & -0.821637 & 3.392010 \\ \text { C } & 6.053724 & -0.820792 & 3.387985 \\ \text { C } & 2.495615 & 0.398019 & 3.556407 \\ \text { C } & 3.909333 & 0.400698 & 3.544930 \\ \text { C } & 4.634088 & 1.614596 & 3.228465 \\ \text { C } & 6.053372 & 1.621523 & 3.237001 \\ \text { C } & 2.486877 & 2.586108 & 2.465226 \\ \text { C } & 3.923101 & 2.590090 & 2.469133 \\ \text { C } & 4.634208 & 3.303241 & 1.459144 \\ \text { C } & 6.053470 & 3.311674 & 1.465662\end{array}$

S48 


$\begin{array}{rrrr}\text { C } & 2.495707 & 3.573099 & 0.228243 \\ \text { C } & 3.909428 & 3.561535 & 0.231446 \\ \text { C } & 4.617639 & 3.350152 & -0.982116 \\ \text { C } & 6.053819 & 3.346112 & -0.981138 \\ \text { C } & 2.495511 & 2.880278 & -2.119306 \\ \text { C } & 3.909257 & 2.868956 & -2.115901 \\ \text { C } & 4.633864 & 1.986883 & -3.007993 \\ \text { C } & 6.053096 & 1.991022 & -3.019026 \\ \text { C } & 2.486679 & 0.839954 & -3.466926 \\ \text { C } & 3.922788 & 0.841421 & -3.472642 \\ \text { C } & 4.633974 & -0.389471 & -3.586596 \\ \text { C } & 6.053149 & -0.387774 & -3.598054 \\ \text { C } & 2.495608 & -1.591339 & -3.207249 \\ \text { C } & 3.909448 & -1.582674 & -3.198960 \\ \text { C } & 4.617788 & -2.530032 & -2.411831 \\ \text { C } & 6.054017 & -2.526434 & -2.408542 \\ \text { C } & 2.495707 & -3.281823 & -1.437236 \\ \text { C } & 3.909541 & -3.273112 & -1.429100 \\ \text { C } & 4.634219 & -3.603142 & -0.218656 \\ \text { C } & 1.774267 & -3.582442 & -0.222369 \\ \text { C } & -1.785295 & -3.409757 & 0.999511 \\ \text { C } & -0.355020 & -3.417655 & 1.001773 \\ \text { C } & 0.358497 & -2.887073 & 2.119020 \\ \text { C } & 1.774310 & -2.891075 & 2.118982 \\ \text { C } & -1.774150 & -1.979564 & 2.988045 \\ \text { C } & -0.358329 & -1.979660 & 2.983896 \\ \text { C } & 0.355115 & -0.838248 & 3.460235 \\ \text { C } & 1.785346 & -0.836297 & 3.452213 \\ \text { C } & -1.774206 & 0.392401 & 3.565753 \\ \text { C } & -0.358405 & 0.394461 & 3.562201 \\ \text { C } & 0.358413 & 1.597644 & 3.210342 \\ \text { C } & 1.774317 & 1.601233 & 3.212249 \\ \text { C } & -1.785390 & 2.575324 & 2.454918 \\ \text { C } & -0.355054 & 2.581316 & 2.460608 \\ \text { C } & 0.358452 & 3.285129 & 1.443217 \\ \text { C } & 1.774337 & 3.287077 & 1.446651 \\ \text { C } & -1.774267 & 3.582441 & 0.222369 \\ & -0.358482 & 3.578962 & 0.224516 \\ \text { C.355020 } & 3.417655 & -1.001774 \\ \text { C } & 1.785295 & 3.409757 & -0.999511\end{array}$




$\begin{array}{lrrr}\text { C } & -1.774310 & 2.891075 & -2.118982 \\ \text { C } & -0.358497 & 2.887073 & -2.119020 \\ \text { C } & 0.358329 & 1.979660 & -2.983896 \\ \text { C } & 1.774150 & 1.979564 & -2.988045 \\ \text { C } & -1.785346 & 0.836297 & -3.452213 \\ \text { C } & -0.355115 & 0.838248 & -3.460235 \\ \text { C } & 0.358405 & -0.394461 & -3.562201 \\ \text { C } & 1.774206 & -0.392401 & -3.565753 \\ \text { C } & -1.774317 & -1.601233 & -3.212250 \\ \text { C } & -0.358413 & -1.597644 & -3.210342 \\ \text { C } & 0.355054 & -2.581316 & -2.460608 \\ \text { C } & 1.785390 & -2.575325 & -2.454918 \\ \text { C } & -1.774337 & -3.287077 & -1.446651 \\ \text { C } & -0.358452 & -3.285130 & -1.443217 \\ \text { C } & 0.358483 & -3.578962 & -0.224516 \\ \text { C } & -2.495707 & -3.573099 & -0.228243 \\ \text { C } & -6.053819 & -3.346112 & 0.981138 \\ \text { C } & -4.617639 & -3.350152 & 0.982116 \\ \text { C } & -3.909257 & -2.868956 & 2.115901 \\ \text { C } & -2.495511 & -2.880278 & 2.119306 \\ \text { C } & -6.053096 & -1.991022 & 3.019026 \\ \text { C } & -4.633864 & -1.986883 & 3.007993 \\ \text { C } & -3.922788 & -0.841421 & 3.472642 \\ \text { C } & -2.486679 & -0.839954 & 3.466926 \\ \text { C } & -6.053149 & 0.387774 & 3.598054 \\ \text { C } & -4.633974 & 0.389471 & 3.586596 \\ \text { C } & -3.909448 & 1.582674 & 3.198960 \\ \text { C } & -2.495608 & 1.591339 & 3.207249 \\ \text { C } & -6.054017 & 2.526434 & 2.408542 \\ \text { C } & -4.617788 & 2.530031 & 2.411831 \\ \text { C } & -3.909541 & 3.273112 & 1.429100 \\ \text { C } & -2.495707 & 3.281822 & 1.437236 \\ \text { C } & -6.053397 & 3.614224 & 0.216532 \\ \text { C } & -4.634219 & 3.603141 & 0.218656 \\ \text { C } & -3.922988 & 3.429690 & -1.005220 \\ \text { C } & -2.486839 & 3.424161 & -1.003618 \\ \text { C } & -6.053256 & 2.921013 & -2.131480 \\ \text { C } & -4.634056 & 2.910294 & -2.126922 \\ \text { C } & -3.909381 & 1.977064 & -2.965225 \\ & -2.495628 & 1.980055 & -2.976887\end{array}$




\begin{tabular}{|c|c|c|c|}
\hline C & -6.053724 & 0.820792 & -3.387985 \\
\hline C & -4.617608 & 0.821637 & -3.392010 \\
\hline C & -3.909333 & -0.400698 & -3.544930 \\
\hline $\mathrm{C}$ & -2.495615 & -0.398019 & -3.556407 \\
\hline C & -6.053372 & -1.621523 & -3.237001 \\
\hline $\mathrm{C}$ & -4.634088 & -1.614597 & -3.228466 \\
\hline $\mathrm{C}$ & -3.923101 & -2.590090 & -2.469133 \\
\hline $\mathrm{C}$ & -2.486877 & -2.586109 & -2.465226 \\
\hline C & -6.053470 & -3.311674 & -1.465662 \\
\hline C & -4.634208 & -3.303241 & -1.459144 \\
\hline C & -3.909428 & -3.561535 & -0.231446 \\
\hline $\mathrm{C}$ & -6.770001 & -3.637832 & -0.214017 \\
\hline C & -8.809975 & -3.730562 & 1.094785 \\
\hline $\mathrm{C}$ & -8.146903 & -3.193671 & 2.201909 \\
\hline C & -6.769668 & -2.943278 & 2.143653 \\
\hline C & -6.732042 & -0.832257 & 3.434021 \\
\hline C & -8.147554 & 1.829863 & 3.421548 \\
\hline $\mathrm{C}$ & -6.770002 & 1.635075 & 3.256590 \\
\hline $\mathrm{C}$ & -8.810713 & 2.813992 & 2.683247 \\
\hline $\mathrm{C}$ & -8.147527 & 3.506624 & 1.666177 \\
\hline C & -6.770063 & 3.332524 & 1.478899 \\
\hline $\mathrm{C}$ & -6.732298 & 3.390963 & -0.994033 \\
\hline $\mathrm{C}$ & -8.146860 & 2.047298 & -3.293986 \\
\hline $\mathrm{C}$ & -6.769652 & 2.001160 & -3.040989 \\
\hline C & -8.809750 & 0.915896 & -3.777901 \\
\hline $\mathrm{C}$ & -8.146995 & -0.311432 & -3.868457 \\
\hline $\mathrm{C}$ & -6.769831 & -0.386907 & -3.622707 \\
\hline C & -6.732438 & -2.559365 & -2.440070 \\
\hline C & -8.147258 & -3.879285 & -0.126901 \\
\hline $\mathrm{H}$ & 7.807699 & -3.277605 & 0.960734 \\
\hline $\mathrm{H}$ & 8.702572 & -2.955314 & 3.091043 \\
\hline $\mathrm{H}$ & 9.867136 & -0.972002 & 4.008127 \\
\hline $\mathrm{H}$ & 8.702796 & 1.210908 & 4.106092 \\
\hline $\mathrm{H}$ & 7.807587 & 2.472171 & 2.356865 \\
\hline $\mathrm{H}$ & 8.703242 & 4.158970 & 1.014120 \\
\hline $\mathrm{H}$ & 9.867401 & 3.957635 & -1.161823 \\
\hline $\mathrm{H}$ & 8.702433 & 2.947825 & -3.099388 \\
\hline $\mathrm{H}$ & 7.807486 & 0.804353 & -3.319505 \\
\hline $\mathrm{H}$ & 8.703376 & -1.199578 & -4.105866 \\
\hline $\mathrm{H}$ & 9.868416 & -2.984269 & -2.84589 \\
\hline
\end{tabular}




$\begin{array}{lrrr}\mathrm{H} & 8.703600 & -4.160983 & -1.005039 \\ \mathrm{H} & -9.867401 & -3.957636 & 1.161823 \\ \mathrm{H} & -8.702433 & -2.947825 & 3.099387 \\ \mathrm{H} & -7.807486 & -0.804353 & 3.319505 \\ \mathrm{H} & -8.703376 & 1.199578 & 4.105866 \\ \mathrm{H} & -9.868416 & 2.984269 & 2.845896 \\ \mathrm{H} & -8.703600 & 4.160983 & 1.005039 \\ \mathrm{H} & -7.807699 & 3.277605 & -0.960734 \\ \mathrm{H} & -8.702572 & 2.955314 & -3.091043 \\ \mathrm{H} & -9.867136 & 0.972001 & -4.008127 \\ \mathrm{H} & -8.702796 & -1.210908 & -4.106093 \\ \mathrm{H} & -7.807587 & -2.472172 & -2.356865 \\ \mathrm{H} & -8.703242 & -4.158970 & -1.014120\end{array}$

$(9,0) 5$ cells

204

$\begin{array}{lrrr}\text { C } & 8.866779 & -3.438964 & -0.812910 \\ \text { C } & 8.904676 & -3.246963 & 1.653457 \\ \text { C } & 10.282264 & -3.410568 & 1.848939 \\ \text { C } & 10.945264 & -2.666957 & 2.829088 \\ \text { C } & 8.904707 & -1.459846 & 3.341135 \\ \text { C } & 10.282185 & -1.645996 & 3.516070 \\ \text { C } & 8.866916 & 1.013502 & 3.385894 \\ \text { C } & 8.904153 & 3.052535 & 1.984337 \\ \text { C } & 10.281380 & 3.305538 & 2.028975 \\ \text { C } & 10.944169 & 3.783111 & 0.894860 \\ \text { C } & 8.904406 & 3.620625 & -0.407114 \\ \text { C } & 10.281579 & 3.866579 & -0.333025 \\ \text { C } & 8.867175 & 2.425830 & -2.573062 \\ \text { C } & 8.904787 & 0.193511 & -3.638849 \\ \text { C } & 10.282096 & 0.105125 & -3.879389 \\ \text { C } & 10.944685 & -1.115756 & -3.723969 \\ \text { C } & 8.904427 & -2.160363 & -2.931190 \\ \text { C } & 10.281703 & -2.219886 & -3.180909 \\ \text { C } & 8.187938 & -3.030225 & -1.974020 \\ \text { C } & 4.622285 & -3.473502 & -0.820796 \\ \text { C } & 6.057757 & -3.478189 & -0.821995\end{array}$




$\begin{array}{lrrr}\text { C } & 6.768781 & -3.584055 & 0.409853 \\ \text { C } & 8.187943 & -3.595470 & 0.408199 \\ \text { C } & 4.630125 & -3.197283 & 1.608705 \\ \text { C } & 6.044145 & -3.189323 & 1.600438 \\ \text { C } & 6.752498 & -2.397312 & 2.543805 \\ \text { C } & 8.188611 & -2.394170 & 2.540329 \\ \text { C } & 4.630207 & -1.417825 & 3.289646 \\ \text { C } & 6.044201 & -1.410149 & 3.281196 \\ \text { C } & 6.768965 & -0.198186 & 3.604672 \\ \text { C } & 8.188132 & -0.195958 & 3.615640 \\ \text { C } & 4.622313 & 1.023670 & 3.420674 \\ \text { C } & 6.057829 & 1.025021 & 3.425182 \\ \text { C } & 6.768711 & 2.143597 & 2.898484 \\ \text { C } & 8.187901 & 2.148200 & 2.909171 \\ \text { C } & 4.629987 & 2.987165 & 1.963264 \\ \text { C } & 6.043921 & 2.976091 & 1.960443 \\ \text { C } & 6.752194 & 3.396851 & 0.802722 \\ \text { C } & 8.188187 & 3.393081 & 0.801999 \\ \text { C } & 4.630041 & 3.553141 & -0.418337 \\ \text { C } & 6.043926 & 3.542207 & -0.420666 \\ \text { C } & 6.768849 & 3.219200 & -1.632510 \\ \text { C } & 8.188126 & 3.227718 & -1.639421 \\ \text { C } & 4.622489 & 2.451844 & -2.601381 \\ \text { C } & 6.058070 & 2.455013 & -2.604510 \\ \text { C } & 6.769088 & 1.440357 & -3.311372 \\ \text { C } & 8.188339 & 1.446856 & -3.319684 \\ \text { C } & 4.630324 & 0.208356 & -3.573577 \\ \text { C } & 6.044219 & 0.211406 & -3.562444 \\ \text { C } & 6.752454 & -1.001121 & -3.344731 \\ \text { C } & 8.188522 & -1.000153 & -3.340833 \\ \text { C } & 4.630098 & -2.135499 & -2.867454 \\ \text { C } & 6.044014 & -2.132092 & -2.856697 \\ \text { C } & 6.768703 & -3.019201 & -1.969985 \\ \text { C } & 3.909647 & -2.999733 & -1.962780 \\ \text { C } & 0.352042 & -3.470062 & -0.819895 \\ \text { C } & 1.780283 & -3.473204 & -0.820644 \\ \text { C } & 2.493743 & -3.561308 & 0.414044 \\ & 3.909669 & -3.563723 & 0.412457 \\ \text { C.360016 } & -3.199114 & 1.613220 \\ \text { C } & & -3.198016 & 1.611742\end{array}$




$\begin{array}{lrrr}\text { C } & 2.489599 & -2.444072 & 2.593502 \\ \text { C } & 3.919206 & -2.439786 & 2.588933 \\ \text { C } & 0.360013 & -1.422080 & 3.291684 \\ \text { C } & 1.776372 & -1.420693 & 3.290563 \\ \text { C } & 2.493760 & -0.203479 & 3.582196 \\ \text { C } & 3.909654 & -0.201815 & 3.584501 \\ \text { C } & 0.351970 & 1.022737 & 3.417430 \\ \text { C } & 1.780257 & 1.023642 & 3.420510 \\ \text { C } & 2.493682 & 2.135682 & 2.876938 \\ \text { C } & 3.909617 & 2.135519 & 2.879758 \\ \text { C } & 0.360010 & 2.991807 & 1.962506 \\ \text { C } & 1.776343 & 2.989997 & 1.962322 \\ \text { C } & 2.489513 & 3.462364 & 0.818117 \\ \text { C } & 3.919023 & 3.456401 & 0.816761 \\ \text { C } & 0.360040 & 3.556727 & -0.415854 \\ \text { C } & 1.776344 & 3.555084 & -0.416454 \\ \text { C } & 2.493722 & 3.202072 & -1.617174 \\ \text { C } & 3.909746 & 3.203259 & -1.619665 \\ \text { C } & 0.352061 & 2.449619 & -2.599352 \\ \text { C } & 1.780377 & 2.451808 & -2.601602 \\ \text { C } & 2.493873 & 1.425897 & -3.294582 \\ \text { C } & 3.909861 & 1.428358 & -3.295681 \\ \text { C } & 0.360160 & 0.205522 & -3.577601 \\ \text { C } & 1.776445 & 0.206249 & -3.575859 \\ \text { C } & 2.489638 & -1.020456 & -3.409697 \\ \text { C } & 3.919198 & -1.018709 & -3.403737 \\ \text { C } & 0.360087 & -2.134970 & -2.872045 \\ \text { C } & 1.776400 & -2.134700 & -2.870285 \\ \text { C } & 2.493703 & -2.996831 & -1.963018 \\ \text { C } & -0.360010 & -2.991807 & -1.962506 \\ \text { C } & -3.919023 & -3.456401 & -0.816762 \\ \text { C } & -2.489514 & -3.462364 & -0.818117 \\ \text { C } & -1.776344 & -3.555084 & 0.416453 \\ \text { C } & -0.360040 & -3.556727 & 0.415853 \\ \text { C } & -3.909747 & -3.203259 & 1.619664 \\ \text { C } & -2.493722 & -3.202072 & 1.617174 \\ \text { C } & -1.780377 & -2.451808 & 2.601601 \\ \text { C } & -0.352061 & -2.449619 & 2.599352 \\ & -2.909861 & -1.428358 & 3.295680 \\ & & -1.425897 & 3.294582\end{array}$




$\begin{array}{lrrr}\text { C } & -1.776445 & -0.206249 & 3.575859 \\ \text { C } & -0.360160 & -0.205522 & 3.577601 \\ \text { C } & -3.919198 & 1.018709 & 3.403737 \\ \text { C } & -2.489638 & 1.020456 & 3.409696 \\ \text { C } & -1.776400 & 2.134700 & 2.870285 \\ \text { C } & -0.360087 & 2.134969 & 2.872045 \\ \text { C } & -3.909647 & 2.999733 & 1.962780 \\ \text { C } & -2.493703 & 2.996831 & 1.963018 \\ \text { C } & -1.780283 & 3.473204 & 0.820644 \\ \text { C } & -0.352042 & 3.470062 & 0.819895 \\ \text { C } & -3.909669 & 3.563723 & -0.412457 \\ \text { C } & -2.493743 & 3.561308 & -0.414044 \\ \text { C } & -1.776435 & 3.198016 & -1.611742 \\ \text { C } & -0.360016 & 3.199114 & -1.613221 \\ \text { C } & -3.919206 & 2.439786 & -2.588933 \\ \text { C } & -2.489600 & 2.444072 & -2.593502 \\ \text { C } & -1.776372 & 1.420692 & -3.290563 \\ \text { C } & -0.360013 & 1.422080 & -3.291684 \\ \text { C } & -3.909654 & 0.201815 & -3.584502 \\ \text { C } & -2.493760 & 0.203479 & -3.582197 \\ \text { C } & -1.780257 & -1.023642 & -3.420510 \\ \text { C } & -0.351970 & -1.022737 & -3.417430 \\ \text { C } & -3.909617 & -2.135519 & -2.879759 \\ \text { C } & -2.493682 & -2.135682 & -2.876938 \\ \text { C } & -1.776343 & -2.989997 & -1.962323 \\ \text { C } & -4.629987 & -2.987165 & -1.963265 \\ \text { C } & -8.188187 & -3.393081 & -0.801999 \\ \text { C } & -6.752194 & -3.396851 & -0.802722 \\ \text { C } & -6.043926 & -3.542207 & 0.420666 \\ \text { C } & -4.630041 & -3.553141 & 0.418336 \\ \text { C } & -8.188126 & -3.227718 & 1.639420 \\ \text { C } & -6.768849 & -3.219200 & 1.632510 \\ \text { C } & -6.058070 & -2.455013 & 2.604509 \\ \text { C } & -4.622489 & -2.451844 & 2.601381 \\ \text { C } & -8.188339 & -1.446856 & 3.319684 \\ \text { C } & -6.769088 & -1.440357 & 3.311372 \\ \text { C } & -6.044219 & -0.211406 & 3.562444 \\ \text { C } & -4.630324 & -0.208356 & 3.573577 \\ \text { C } & -8.188522 & 1.000153 & 3.340833 \\ & -6.752454 & 1.001121 & 3.344731\end{array}$




$\begin{array}{rrrr}\text { C } & -6.044015 & 2.132092 & 2.856697 \\ \text { C } & -4.630098 & 2.135499 & 2.867454 \\ \text { C } & -8.187938 & 3.030225 & 1.974020 \\ \text { C } & -6.768704 & 3.019201 & 1.969984 \\ \text { C } & -6.057757 & 3.478189 & 0.821995 \\ \text { C } & -4.622285 & 3.473502 & 0.820795 \\ \text { C } & -8.187943 & 3.595470 & -0.408200 \\ \text { C } & -6.768781 & 3.584055 & -0.409854 \\ \text { C } & -6.044145 & 3.189323 & -1.600438 \\ \text { C } & -4.630126 & 3.197283 & -1.608705 \\ \text { C } & -8.188611 & 2.394170 & -2.540329 \\ \text { C } & -6.752498 & 2.397312 & -2.543805 \\ \text { C } & -6.044201 & 1.410149 & -3.281197 \\ \text { C } & -4.630207 & 1.417825 & -3.289647 \\ \text { C } & -8.188133 & 0.195958 & -3.615640 \\ \text { C } & -6.768965 & 0.198186 & -3.604672 \\ \text { C } & -6.057829 & -1.025021 & -3.425182 \\ \text { C } & -4.622313 & -1.023670 & -3.420675 \\ \text { C } & -8.187901 & -2.148200 & -2.909171 \\ \text { C } & -6.768711 & -2.143597 & -2.898484 \\ \text { C } & -6.043921 & -2.976091 & -1.960443 \\ \text { C } & -8.904153 & -3.052535 & -1.984338 \\ \text { C } & -10.944169 & -3.783111 & -0.894860 \\ \text { C } & -10.281579 & -3.866579 & 0.333024 \\ \text { C } & -8.904406 & -3.620625 & 0.407114 \\ \text { C } & -8.867175 & -2.425830 & 2.573062 \\ \text { C } & -10.282096 & -0.105125 & 3.879389 \\ \text { C } & -8.904787 & -0.193511 & 3.638849 \\ \text { C } & -10.944686 & 1.115756 & 3.723968 \\ \text { C } & -10.281703 & 2.219885 & 3.180909 \\ \text { C } & -8.904427 & 2.160363 & 2.931189 \\ \text { C } & -8.866779 & 3.438964 & 0.812910 \\ \text { C } & -10.282264 & 3.410568 & -1.848940 \\ \text { C } & -8.904676 & 3.246963 & -1.653457 \\ \text { C } & -10.945265 & 2.666957 & -2.829088 \\ \text { C } & -10.282185 & 1.645996 & -3.516071 \\ \text { C } & -8.904707 & 1.459846 & -3.341135 \\ \text { C } & -8.866916 & -1.013502 & -3.385894 \\ \text { H } & 9.942314 & -3.325124 & -0.785841\end{array}$

S56 


$\begin{array}{rrrr}\text { H } & 10.838058 & -4.098571 & 1.222674 \\ \mathrm{H} & 12.002850 & -2.828927 & 3.000554 \\ \mathrm{H} & 10.838263 & -0.981478 & 4.166971 \\ \mathrm{H} & 9.942402 & 0.979857 & 3.273498 \\ \mathrm{H} & 10.837067 & 3.108051 & 2.938195 \\ \mathrm{H} & 12.001429 & 4.014065 & 0.949778 \\ \mathrm{H} & 10.837396 & 4.099383 & -1.233736 \\ \mathrm{H} & 9.942422 & 2.343782 & -2.486037 \\ \mathrm{H} & 10.838098 & 0.990703 & -4.164162 \\ \mathrm{H} & 12.002012 & -1.184148 & -3.950959 \\ \mathrm{H} & 10.837214 & -3.116058 & -2.930352 \\ \mathrm{H} & -12.001429 & -4.014065 & -0.949779 \\ \mathrm{H} & -10.837396 & -4.099384 & 1.233736 \\ \mathrm{H} & -9.942422 & -2.343782 & 2.486037 \\ \mathrm{H} & -10.838098 & -0.990703 & 4.164162 \\ \mathrm{H} & -12.002012 & 1.184148 & 3.950959 \\ \mathrm{H} & -10.837214 & 3.116058 & 2.930352 \\ \mathrm{H} & -9.942315 & 3.325124 & 0.785841 \\ \mathrm{H} & -10.838058 & 4.098571 & -1.222674 \\ \mathrm{H} & -12.002850 & 2.828926 & -3.000555 \\ \mathrm{H} & -10.838263 & 0.981477 & -4.166971 \\ \mathrm{H} & -9.942402 & -0.979857 & -3.273498 \\ \mathrm{H} & -10.837067 & -3.108052 & -2.938195\end{array}$

$(9,0) 6$ cells

240

$\begin{array}{lrrr}\text { C } & 11.001421 & -3.514498 & 0.364845 \\ \text { C } & 11.039354 & -2.523107 & 2.630894 \\ \text { C } & 12.416954 & -2.613051 & 2.869417 \\ \text { C } & 13.079947 & -1.587119 & 3.548827 \\ \text { C } & 11.039424 & -0.278838 & 3.634022 \\ \text { C } & 12.417149 & -0.396489 & 3.859757 \\ \text { C } & 11.001191 & 2.071847 & 2.863094 \\ \text { C } & 11.039180 & 3.535995 & 0.868746 \\ \text { C } & 12.416708 & 3.788469 & 0.827397 \\ \text { C } & 13.079433 & 3.865297 & -0.400771 \\ \text { C } & 11.038986 & 3.285455 & -1.576644\end{array}$




$\begin{array}{lrrr}\text { C } & 12.416423 & 3.540526 & -1.587618 \\ \text { C } & 11.001206 & 1.444742 & -3.228811 \\ \text { C } & 11.038981 & -1.014212 & -3.499284 \\ \text { C } & 12.416311 & -1.176753 & -3.697406 \\ \text { C } & 13.079041 & -2.278341 & -3.148739 \\ \text { C } & 11.039093 & -3.004040 & -2.056061 \\ \text { C } & 12.416332 & -3.142228 & -2.272342 \\ \text { C } & 10.322621 & -3.510562 & -0.866106 \\ \text { C } & 6.757236 & -3.551532 & 0.368948 \\ \text { C } & 8.192456 & -3.556103 & 0.369331 \\ \text { C } & 8.903469 & -3.250452 & 1.567485 \\ \text { C } & 10.322642 & -3.261408 & 1.569615 \\ \text { C } & 6.764848 & -2.491558 & 2.572372 \\ \text { C } & 8.178865 & -2.486726 & 2.562076 \\ \text { C } & 8.887209 & -1.427436 & 3.191739 \\ \text { C } & 10.323295 & -1.425370 & 3.187378 \\ \text { C } & 6.764760 & -0.256575 & 3.571060 \\ \text { C } & 8.178750 & -0.252025 & 3.560773 \\ \text { C } & 8.903285 & 0.998628 & 3.466806 \\ \text { C } & 10.322514 & 1.004607 & 3.476832 \\ \text { C } & 6.757037 & 2.092556 & 2.892033 \\ \text { C } & 8.192245 & 2.095424 & 2.895907 \\ \text { C } & 8.903242 & 2.978755 & 2.030653 \\ \text { C } & 10.322495 & 2.986784 & 2.039446 \\ \text { C } & 6.764523 & 3.467630 & 0.870133 \\ \text { C } & 8.178574 & 3.456369 & 0.871176 \\ \text { C } & 8.887010 & 3.473272 & -0.360547 \\ \text { C } & 10.323004 & 3.469069 & -0.359892 \\ \text { C } & 6.764655 & 3.219122 & -1.565155 \\ \text { C } & 8.178654 & 3.207909 & -1.563698 \\ \text { C } & 8.903267 & 2.504283 & -2.601796 \\ \text { C } & 10.322411 & 2.509733 & -2.611230 \\ \text { C } & 6.757110 & 1.460383 & -3.263826 \\ \text { C } & 8.192411 & 1.462181 & -3.267857 \\ \text { C } & 8.903358 & 0.270918 & -3.599692 \\ \text { C } & 10.322547 & 0.274263 & -3.610393 \\ \text { C } & 6.764646 & -0.978265 & -3.440901 \\ \text { C } & 8.178635 & -0.971835 & -3.431691 \\ & 8.887026 & -2.045764 & -2.827983 \\ \text { (0.322938 } & -2.043465 & -2.824774\end{array}$




$\begin{array}{lrrr}\text { C } & 6.764676 & -2.959973 & -2.003795 \\ \text { C } & 8.178632 & -2.953164 & -1.994853 \\ \text { C } & 8.903331 & -3.499114 & -0.865904 \\ \text { C } & 6.044534 & -3.478612 & -0.865512 \\ \text { C } & 2.487861 & -3.550627 & 0.368971 \\ \text { C } & 3.915195 & -3.552803 & 0.369176 \\ \text { C } & 4.628555 & -3.228162 & 1.564100 \\ \text { C } & 6.044600 & -3.230681 & 1.563312 \\ \text { C } & 2.494574 & -2.491775 & 2.576261 \\ \text { C } & 3.911191 & -2.491306 & 2.575006 \\ \text { C } & 4.624459 & -1.455493 & 3.253885 \\ \text { C } & 6.053672 & -1.452978 & 3.248435 \\ \text { C } & 2.494500 & -0.259642 & 3.573350 \\ \text { C } & 3.911052 & -0.258906 & 3.572306 \\ \text { C } & 4.628350 & 0.985875 & 3.447144 \\ \text { C } & 6.044407 & 0.988251 & 3.448709 \\ \text { C } & 2.487649 & 2.091583 & 2.890816 \\ \text { C } & 3.914947 & 2.093003 & 2.892738 \\ \text { C } & 4.628286 & 2.963916 & 2.012605 \\ \text { C } & 6.044291 & 2.964702 & 2.015348 \\ \text { C } & 2.494327 & 3.470642 & 0.867966 \\ \text { C } & 3.910955 & 3.469447 & 0.868312 \\ \text { C } & 4.624296 & 3.540759 & -0.367776 \\ \text { C } & 6.053423 & 3.534852 & -0.367069 \\ \text { C } & 2.494401 & 3.222603 & -1.564172 \\ \text { C } & 3.911016 & 3.221345 & -1.564134 \\ \text { C } & 4.628414 & 2.493823 & -2.581788 \\ \text { C } & 6.044469 & 2.493931 & -2.584392 \\ \text { C } & 2.487708 & 1.459957 & -3.263062 \\ \text { C } & 3.915108 & 1.460897 & -3.265063 \\ \text { C } & 4.628445 & 0.262882 & -3.578359 \\ \text { C } & 6.044420 & 0.264819 & -3.580238 \\ \text { C } & 2.494485 & -0.981529 & -3.442511 \\ \text { C } & 3.911075 & -0.980640 & -3.441609 \\ \text { C } & 4.624401 & -2.085440 & -2.882607 \\ \text { C } & 6.053464 & -2.081952 & -2.877881 \\ \text { C } & 2.494546 & -2.960674 & -2.007234 \\ \text { C } & 3.911095 & -2.960036 & -2.006162 \\ & 1.628475 & -3.476233 & -0.866688 \\ \text { C } & & -3.471984 & -0.867599\end{array}$




\begin{tabular}{|c|c|c|c|}
\hline C & -1.781478 & -3.548188 & 0.368661 \\
\hline C & -0.354258 & -3.549284 & 0.368816 \\
\hline C & 0.358977 & -3.223387 & 1.564208 \\
\hline $\mathrm{C}$ & 1.775531 & -3.223947 & 1.564248 \\
\hline $\mathrm{C}$ & -1.775369 & -2.492456 & 2.577671 \\
\hline C & -0.358816 & -2.492175 & 2.577114 \\
\hline C & 0.354378 & -1.459269 & 3.261791 \\
\hline $\mathrm{C}$ & 1.781659 & -1.458734 & 3.260762 \\
\hline C & -1.775394 & -0.260558 & 3.574580 \\
\hline C & -0.358918 & -0.260226 & 3.574035 \\
\hline $\mathrm{C}$ & 0.358820 & 0.982229 & 3.443171 \\
\hline $\mathrm{C}$ & 1.775359 & 0.982684 & 3.443713 \\
\hline C & -1.781619 & 2.089877 & 2.888609 \\
\hline $\mathrm{C}$ & -0.354453 & 2.090591 & 2.889535 \\
\hline C & 0.358786 & 2.961176 & 2.008007 \\
\hline $\mathrm{C}$ & 1.775280 & 2.961589 & 2.008579 \\
\hline C & -1.775533 & 3.471984 & 0.867599 \\
\hline $\mathrm{C}$ & -0.358974 & 3.471396 & 0.867691 \\
\hline $\mathrm{C}$ & 0.354258 & 3.549284 & -0.368816 \\
\hline C & 1.781478 & 3.548188 & -0.368661 \\
\hline C & -1.775531 & 3.223947 & -1.564248 \\
\hline $\mathrm{C}$ & -0.358977 & 3.223387 & -1.564208 \\
\hline $\mathrm{C}$ & 0.358816 & 2.492175 & -2.577114 \\
\hline C & 1.775369 & 2.492456 & -2.577671 \\
\hline C & -1.781659 & 1.458734 & -3.260762 \\
\hline $\mathrm{C}$ & -0.354378 & 1.459269 & -3.261791 \\
\hline $\mathrm{C}$ & 0.358918 & 0.260226 & -3.574035 \\
\hline $\mathrm{C}$ & 1.775394 & 0.260558 & -3.574580 \\
\hline C & -1.775358 & -0.982684 & -3.443713 \\
\hline $\mathrm{C}$ & -0.358820 & -0.982229 & -3.443171 \\
\hline $\mathrm{C}$ & 0.354453 & -2.090591 & -2.889535 \\
\hline $\mathrm{C}$ & 1.781620 & -2.089877 & -2.888609 \\
\hline C & -1.775280 & -2.961588 & -2.008579 \\
\hline C & -0.358786 & -2.961175 & -2.008007 \\
\hline $\mathrm{C}$ & 0.358974 & -3.471396 & -0.867691 \\
\hline $\mathrm{C}$ & -2.494327 & -3.470642 & -0.867966 \\
\hline C & -6.053423 & -3.534852 & 0.367069 \\
\hline C & -4.624296 & -3.540759 & 0.367776 \\
\hline C & -3.911016 & -3.221345 & 1.564134 \\
\hline $\mathrm{C}$ & -2.494401 & -3.222603 & 1.564173 \\
\hline
\end{tabular}




$\begin{array}{lrrr}\text { C } & -6.044469 & -2.493931 & 2.584393 \\ \text { C } & -4.628414 & -2.493823 & 2.581788 \\ \text { C } & -3.915108 & -1.460897 & 3.265063 \\ \text { C } & -2.487708 & -1.459956 & 3.263062 \\ \text { C } & -6.044420 & -0.264819 & 3.580238 \\ \text { C } & -4.628445 & -0.262882 & 3.578359 \\ \text { C } & -3.911075 & 0.980640 & 3.441609 \\ \text { C } & -2.494485 & 0.981529 & 3.442511 \\ \text { C } & -6.053464 & 2.081952 & 2.877881 \\ \text { C } & -4.624401 & 2.085440 & 2.882607 \\ \text { C } & -3.911095 & 2.960036 & 2.006163 \\ \text { C } & -2.494546 & 2.960674 & 2.007234 \\ \text { C } & -6.044534 & 3.478612 & 0.865512 \\ \text { C } & -4.628475 & 3.476233 & 0.866688 \\ \text { C } & -3.915195 & 3.552803 & -0.369176 \\ \text { C } & -2.487861 & 3.550627 & -0.368971 \\ \text { C } & -6.044600 & 3.230681 & -1.563312 \\ \text { C } & -4.628555 & 3.228162 & -1.564100 \\ \text { C } & -3.911190 & 2.491306 & -2.575006 \\ \text { C } & -2.494574 & 2.491775 & -2.576261 \\ \text { C } & -6.053671 & 1.452978 & -3.248435 \\ \text { C } & -4.624459 & 1.455493 & -3.253885 \\ \text { C } & -3.911052 & 0.258906 & -3.572306 \\ \text { C } & -2.494500 & 0.259642 & -3.573350 \\ \text { C } & -6.044407 & -0.988251 & -3.448709 \\ \text { C } & -4.628350 & -0.985875 & -3.447144 \\ \text { C } & -3.914947 & -2.093003 & -2.892738 \\ \text { C } & -2.487648 & -2.091583 & -2.890816 \\ \text { C } & -6.044290 & -2.964702 & -2.015348 \\ \text { C } & -4.628286 & -2.963916 & -2.012605 \\ \text { C } & -3.910955 & -3.469447 & -0.868312 \\ \text { C } & -6.764523 & -3.467630 & -0.870133 \\ \text { C } & -10.323003 & -3.469069 & 0.359892 \\ \text { C } & -8.887010 & -3.473272 & 0.360547 \\ \text { C } & -8.178654 & -3.207909 & 1.563698 \\ \text { C } & -6.764655 & -3.219122 & 1.565155 \\ \text { C } & -10.322411 & -2.509733 & 2.611230 \\ \text { C } & -8.903267 & -2.504282 & 2.601796 \\ \text { C } & -8.192411 & -1.462180 & 3.267857 \\ & -6.757110 & -1.460383 & 3.263826\end{array}$




\begin{tabular}{lrrr} 
& & & \\
C & -10.322547 & -0.274263 & 3.610393 \\
C & -8.903358 & -0.270918 & 3.599692 \\
C & -8.178635 & 0.971835 & 3.431691 \\
C & -6.764646 & 0.978265 & 3.440901 \\
C & -10.322938 & 2.043465 & 2.824774 \\
C & -8.887026 & 2.045764 & 2.827983 \\
C & -8.178632 & 2.953164 & 1.994853 \\
C & -6.764675 & 2.959973 & 2.003795 \\
C & -10.322621 & 3.510562 & 0.866106 \\
C & -8.903331 & 3.499114 & 0.865904 \\
C & -8.192456 & 3.556103 & -0.369331 \\
C & -6.757236 & 3.551532 & -0.368948 \\
C & -10.322642 & 3.261408 & -1.569615 \\
C & -8.903469 & 3.250452 & -1.567485 \\
C & -8.178865 & 2.486726 & -2.562076 \\
C & -6.764848 & 2.491558 & -2.572372 \\
C & -10.323295 & 1.425370 & -3.187378 \\
C & -8.887208 & 1.427436 & -3.191739 \\
C & -8.178750 & 0.252025 & -3.560773 \\
C & -6.764760 & 0.256575 & -3.571060 \\
C & -10.322514 & -1.004607 & -3.476832 \\
C & -8.903285 & -0.998628 & -3.466806 \\
C & -8.192245 & -2.095424 & -2.895907 \\
C & -6.757037 & -2.092556 & -2.892033 \\
C & -10.322495 & -2.986784 & -2.039446 \\
C & -8.903242 & -2.978755 & -2.030653 \\
C & -8.178574 & -3.456369 & -0.871176 \\
C & -11.039180 & -3.535995 & -0.868746 \\
C & -13.079433 & -3.865297 & 0.400771 \\
C & -12.416423 & -3.540526 & 1.587618 \\
C & -11.038986 & -3.285455 & 1.576644 \\
C & -11.001206 & -1.444742 & 3.228811 \\
C & -12.416311 & 1.176753 & 3.697406 \\
C & -11.038981 & 1.014212 & 3.499284 \\
C & -13.079041 & 2.278341 & 3.148739 \\
C & -12.416332 & 3.142228 & 2.272343 \\
& -11.039093 & 3.004040 & 2.056061 \\
C & -11.001421 & 3.514498 & -0.364845 \\
\hline
\end{tabular}

S62 


$\begin{array}{rrrr}\text { C } & -13.079947 & 1.587119 & -3.548827 \\ \mathrm{C} & -12.417149 & 0.396489 & -3.859757 \\ \mathrm{C} & -11.039424 & 0.278838 & -3.634022 \\ \mathrm{C} & -11.001191 & -2.071847 & -2.863094 \\ \mathrm{C} & -12.416708 & -3.788469 & -0.827397 \\ \mathrm{H} & 12.076905 & -3.397665 & 0.353131 \\ \mathrm{H} & 12.972994 & -3.469129 & 2.505500 \\ \mathrm{H} & 14.137557 & -1.683362 & 3.764034 \\ \mathrm{H} & 12.973245 & 0.445947 & 4.254232 \\ \mathrm{H} & 12.076806 & 2.003450 & 2.769118 \\ \mathrm{H} & 12.972493 & 3.901175 & 1.750897 \\ \mathrm{H} & 14.136879 & 4.100542 & -0.424991 \\ \mathrm{H} & 12.972279 & 3.463365 & -2.514737 \\ \mathrm{H} & 12.076600 & 1.396639 & -3.120747 \\ \mathrm{H} & 12.972256 & -0.434404 & -4.258048 \\ \mathrm{H} & 14.136327 & -2.417600 & -3.340761 \\ \mathrm{H} & 12.971885 & -3.906161 & -1.741090 \\ \mathrm{H} & -14.136879 & -4.100542 & 0.424991 \\ \mathrm{H} & -12.972279 & -3.463365 & 2.514737 \\ \mathrm{H} & -12.076600 & -1.396639 & 3.120747 \\ \mathrm{H} & -12.972255 & 0.434404 & 4.258048 \\ \mathrm{H} & -14.136327 & 2.417600 & 3.340762 \\ \mathrm{H} & -12.971885 & 3.906161 & 1.741090 \\ \mathrm{H} & -12.076905 & 3.397665 & -0.353131 \\ \mathrm{H} & -12.972994 & 3.469129 & -2.505500 \\ \mathrm{H} & -14.137557 & 1.683362 & -3.764034 \\ \mathrm{H} & -12.973245 & -0.445947 & -4.254232 \\ \mathrm{H} & -12.076806 & -2.003450 & -2.769118 \\ \mathrm{H} & -12.972493 & -3.901175 & -1.750897\end{array}$

$(6,5) 2$ cells

86

$\begin{array}{llll}\text { C } & -3.120973 & 2.805360 & 1.648981 \\ \text { C } & -3.218078 & 2.259241 & 0.337700 \\ \text { C } & -3.747417 & 0.950950 & 0.153680 \\ \text { C } & -4.152423 & 0.193329 & 1.287324 \\ \text { C } & -4.375657 & 0.907127 & 2.506536\end{array}$




$\begin{array}{lrrr}\text { C } & -3.885409 & 2.177371 & 2.682380 \\ \text { C } & -3.912080 & -1.236500 & 1.265195 \\ \text { C } & -3.322303 & -1.805016 & 0.102428 \\ \text { C } & -3.364983 & -1.101279 & -1.152212 \\ \text { C } & -3.556241 & 0.313145 & -1.120441 \\ \text { C } & -2.394227 & -2.880897 & 0.234438 \\ \text { C } & -2.049165 & -3.355394 & 1.528927 \\ \text { C } & -2.942445 & -3.034368 & 2.591560 \\ \text { C } & -3.851751 & -2.010398 & 2.461531 \\ \text { C } & -2.893149 & -1.723701 & -2.338909 \\ \text { C } & -1.990379 & -2.855688 & -2.210543 \\ \text { C } & -1.587116 & -3.235204 & -0.902324 \\ \text { C } & -0.244170 & -3.663041 & -0.676773 \\ \text { C } & 0.244169 & -3.663041 & 0.676773 \\ \text { C } & -0.666438 & -3.733238 & 1.764706 \\ \text { C } & 1.587115 & -3.235206 & 0.902324 \\ \text { C } & 1.990378 & -2.855689 & 2.210543 \\ \text { C } & 1.182830 & -3.313181 & 3.291516 \\ \text { C } & -0.105211 & -3.746345 & 3.074854 \\ \text { C } & 2.394226 & -2.880898 & -0.234438 \\ \text { C } & 2.049164 & -3.355395 & -1.528927 \\ \text { C } & 0.666436 & -3.733238 & -1.764707 \\ \text { C } & 0.105210 & -3.746345 & -3.074854 \\ \text { C } & -1.182832 & -3.313181 & -3.291516 \\ \text { C } & 3.322302 & -1.805017 & -0.102428 \\ \text { C } & 3.364982 & -1.101281 & 1.152212 \\ \text { C } & 2.893148 & -1.723702 & 2.338909 \\ \text { C } & 2.942443 & -3.034369 & -2.591560 \\ \text { C } & 3.851750 & -2.010400 & -2.461531 \\ \text { C } & 3.912080 & -1.236502 & -1.265195 \\ \text { C } & 4.152424 & 0.193327 & -1.287324 \\ \text { C } & 3.747417 & 0.950949 & -0.153680 \\ \text { C } & 3.556241 & 0.313143 & 1.120441 \\ \text { C } & 3.241880 & 1.092067 & 2.267360 \\ \text { C } & 3.143671 & 0.399009 & 3.507901 \\ \text { C } & 2.982018 & -0.967317 & 3.543371 \\ \text { C } & 3.218079 & 2.259240 & -0.337700 \\ \text { C } & 3.120975 & 2.805358 & -1.648981 \\ & 3.885411 & 2.177370 & -2.682379 \\ \text { (.375658 } & 0.907125 & -2.506535\end{array}$




\begin{tabular}{|c|c|c|c|}
\hline C & 2.654732 & 2.406900 & 2.062555 \\
\hline C & 2.470412 & 2.860203 & 0.723108 \\
\hline C & 1.333516 & 3.661531 & 0.384235 \\
\hline $\mathrm{C}$ & 0.377321 & 3.958272 & 1.392508 \\
\hline C & 0.797681 & 3.821819 & 2.740490 \\
\hline $\mathrm{C}$ & 1.911179 & 3.074317 & 3.069734 \\
\hline C & -3.241879 & 1.092069 & -2.267360 \\
\hline C & -3.143672 & 0.399011 & -3.507901 \\
\hline C & -2.982019 & -0.967315 & -3.543371 \\
\hline C & -2.470411 & 2.860204 & -0.723107 \\
\hline C & -2.654731 & 2.406902 & -2.062554 \\
\hline C & -1.333515 & 3.661531 & -0.384235 \\
\hline C & -0.377319 & 3.958272 & -1.392508 \\
\hline C & -0.797680 & 3.821819 & -2.740490 \\
\hline $\mathrm{C}$ & -1.911178 & 3.074318 & -3.069734 \\
\hline C & 2.040921 & 3.671596 & -1.948180 \\
\hline C & 1.038245 & 3.913315 & -1.010154 \\
\hline C & -1.038243 & 3.913316 & 1.010154 \\
\hline $\mathrm{C}$ & -2.040919 & 3.671597 & 1.948180 \\
\hline $\mathrm{H}$ & 2.820332 & -3.509120 & -3.557424 \\
\hline $\mathrm{H}$ & 4.424004 & -1.704301 & -3.328344 \\
\hline $\mathrm{H}$ & 4.831193 & 0.397144 & -3.346350 \\
\hline $\mathrm{H}$ & 0.737994 & -3.956782 & -3.928070 \\
\hline $\mathrm{H}$ & -0.160939 & 4.183130 & -3.539082 \\
\hline $\mathrm{H}$ & 1.875768 & 3.912988 & -2.991450 \\
\hline $\mathrm{H}$ & -1.532708 & -3.196253 & -4.309863 \\
\hline $\mathrm{H}$ & -2.777167 & -1.445424 & -4.493129 \\
\hline $\mathrm{H}$ & -2.116722 & 2.877227 & -4.114575 \\
\hline $\mathrm{H}$ & -3.063714 & 0.960256 & -4.430762 \\
\hline $\mathrm{H}$ & 3.953473 & 2.657273 & -3.652700 \\
\hline $\mathrm{H}$ & 3.063714 & 0.960254 & 4.430762 \\
\hline $\mathrm{H}$ & 2.777167 & -1.445426 & 4.493129 \\
\hline $\mathrm{H}$ & 1.532707 & -3.196254 & 4.309862 \\
\hline $\mathrm{H}$ & 2.116723 & 2.877226 & 4.114575 \\
\hline $\mathrm{H}$ & 0.160941 & 4.183129 & 3.539082 \\
\hline $\mathrm{H}$ & -1.875765 & 3.912988 & 2.991451 \\
\hline $\mathrm{H}$ & -3.953471 & 2.657274 & 3.652701 \\
\hline $\mathrm{H}$ & -4.831192 & 0.397146 & 3.346351 \\
\hline $\mathrm{H}$ & -4.424005 & -1.704300 & 3.328344 \\
\hline $\mathrm{H}$ & -2.820334 & -3.509120 & 3.55742 \\
\hline
\end{tabular}




$\mathrm{H} \quad-0.737996 \quad-3.956782 \quad 3.928069$

$(6,5) 3$ cells

118

$\begin{array}{llll}\text { C } & 5.339092 & -1.956668 & -2.730988\end{array}$

$\begin{array}{llll}\text { C } & 4.268100 & -2.597189 & -2.025598\end{array}$

$\begin{array}{llll}\text { C } & 2.948332 & -2.359527 & -2.509128\end{array}$

$\begin{array}{llll}\text { C } & 2.700282 & -1.233716 & -3.362310\end{array}$

$\begin{array}{llll}\text { C } & 3.771389 & -0.355435 & -3.687568\end{array}$

$\begin{array}{llll}\text { C } & 5.099157 & -0.868017 & -3.527257\end{array}$

$\begin{array}{llll}\text { C } & 3.494993 & 1.061433 & -3.747045\end{array}$

$\begin{array}{llll}\text { C } & 2.158917 & 1.502742 & -3.535393\end{array}$

$\begin{array}{llll}\text { C } & 1.071683 & 0.579122 & -3.682502\end{array}$

$\begin{array}{llll}\text { C } & 1.345797 & -0.810786 & -3.569997\end{array}$

$\begin{array}{llll}\text { C } & 4.530486 & 2.037479 & -3.591063\end{array}$

$\begin{array}{llll}\text { C } & 4.303777 & 3.192186 & -2.886752\end{array}$

$\begin{array}{llll}\text { C } & 3.023348 & 3.458335 & -2.306384\end{array}$

$\begin{array}{llll}\text { C } & 1.919615 & 2.723840 & -2.821529\end{array}$

$\begin{array}{llll}\text { C } & 0.596657 & 2.991102 & -2.336640\end{array}$

$\begin{array}{llll}\text { C } & 0.444181 & 3.660493 & -1.093046\end{array}$

$\begin{array}{llll}\text { C } & 1.621201 & 4.003723 & -0.350580\end{array}$

$\begin{array}{llll}\text { C } & 2.876414 & 4.096052 & -1.015577\end{array}$

$\begin{array}{llll}\text { C } & -0.514089 & 2.278798 & -2.878161\end{array}$

$\begin{array}{llll}\text { C } & -1.828805 & 2.564165 & -2.404843\end{array}$

$\begin{array}{llll}\text { C } & -1.986863 & 3.271709 & -1.182234\end{array}$

C $\quad-0.824432 \quad 3.636086 \quad-0.440422$

$\begin{array}{llll}\text { C } & -2.948034 & 1.830158 & -2.917281\end{array}$

$\begin{array}{llll}\text { C } & -4.267942 & 2.156232 & -2.488871\end{array}$

$\begin{array}{llll}\text { C } & -4.433744 & 2.909867 & -1.272877\end{array}$

$\begin{array}{llll}\text { C } & -3.265810 & 3.260089 & -0.537108\end{array}$

$\begin{array}{llll}\text { C } & -3.308370 & 3.244550 & 0.892723\end{array}$

$\begin{array}{llll}\text { C } & -4.526579 & 2.905511 & 1.557829\end{array}$

$\begin{array}{llll}\text { C } & -5.740817 & 2.978265 & 0.788441\end{array}$

$\begin{array}{llll}\text { C } & -5.692104 & 2.969474 & -0.577026\end{array}$

$\begin{array}{llll}\text { C } & -2.699713 & 0.561015 & -3.537306\end{array}$

$\begin{array}{llll}\text { C } & -3.770769 & -0.363436 & -3.687791\end{array}$

$\begin{array}{llll}\text { C } & -5.098525 & 0.170570 & -3.630275\end{array}$ 


$\begin{array}{lrrr}\text { C } & -5.338687 & 1.392150 & -3.058564 \\ \text { C } & -0.867948 & 3.569838 & 0.984922 \\ \text { C } & -2.088329 & 3.185348 & 1.624249 \\ \text { C } & 1.581214 & 3.891562 & 1.079446 \\ \text { C } & 0.355132 & 3.489428 & 1.706079 \\ \text { C } & 0.411467 & 2.668977 & 2.866425 \\ \text { C } & -0.764365 & 1.991085 & 3.302306 \\ \text { C } & -2.041132 & 2.409101 & 2.820626 \\ \text { C } & 4.006483 & 4.450885 & -0.215822 \\ \text { C } & 3.970724 & 4.319477 & 1.150703 \\ \text { C } & 2.798664 & 3.840041 & 1.811802 \\ \text { C } & 2.863824 & 2.962306 & 2.965107 \\ \text { C } & 1.695097 & 2.236286 & 3.332410 \\ \text { C } & -0.271316 & 1.036982 & -3.541312 \\ \text { C } & -1.345198 & 0.106091 & -3.659342 \\ \text { C } & -1.071100 & -1.279438 & -3.502013 \\ \text { C } & 0.271866 & -1.701620 & -3.275307 \\ \text { C } & 0.514360 & -2.792211 & -2.385023 \\ \text { C } & 1.828875 & -2.980816 & -1.865051 \\ \text { C } & -0.640938 & 0.678043 & 3.848712 \\ \text { C } & 0.641653 & 0.078420 & 3.906214 \\ \text { C } & 1.818779 & 0.899218 & 3.839083 \\ \text { C } & 3.106384 & 0.308241 & 3.938856 \\ \text { C } & 4.220722 & 1.195565 & 3.948571 \\ \text { C } & 4.103530 & 2.485305 & 3.482892 \\ \text { C } & 0.764612 & -1.315337 & 3.622963 \\ \text { C } & -0.411509 & -2.064298 & 3.326546 \\ \text { C } & -1.694814 & -1.549744 & 3.701220 \\ \text { C } & -1.818049 & -0.140241 & 3.941729 \\ \text { C } & -2.863865 & -2.332404 & 3.480779 \\ \text { C } & -4.103027 & -1.764916 & 3.898965 \\ \text { C } & -4.219786 & -0.409783 & 4.108690 \\ \text { C } & -3.105600 & 0.459055 & 3.927228 \\ \text { C } & -3.494433 & -1.765232 & -3.473084 \\ \text { C } & -2.158382 & -2.157618 & -3.180413 \\ \text { C } & -1.919326 & -3.218220 & -2.244524 \\ \text { C } & -3.023278 & -3.839180 & -1.597381 \\ \text { C } & -4.303364 & -3.690577 & -2.219034 \\ & -0.596608 & -3.386501 & -1.716482\end{array}$




$\begin{array}{lrrr}\mathrm{C} & -0.355840 & -3.093404 & 2.346458 \\ \mathrm{C} & -1.582216 & -3.608106 & 1.809044 \\ \mathrm{C} & -2.799743 & -3.415078 & 2.517244 \\ \mathrm{C} & 0.867280 & -3.312780 & 1.654831 \\ \mathrm{C} & 2.087898 & -2.812668 & 2.207949 \\ \mathrm{C} & 2.041148 & -1.818933 & 3.230905 \\ \mathrm{C} & -1.622079 & -3.994890 & 0.427742 \\ \mathrm{C} & -2.877166 & -4.213937 & -0.207162 \\ \mathrm{C} & -4.007806 & -4.405735 & 0.645736 \\ \mathrm{C} & -3.972319 & -4.011788 & 1.960821 \\ \mathrm{C} & 0.823800 & -3.652980 & 0.269085 \\ \mathrm{C} & -0.444735 & -3.802538 & -0.366789 \\ \mathrm{C} & 1.986475 & -3.439433 & -0.528956 \\ \mathrm{C} & 3.265411 & -3.304410 & 0.101987 \\ \mathrm{C} & 3.307972 & -3.013402 & 1.502005 \\ \mathrm{C} & 4.433510 & -3.103337 & -0.687471 \\ \mathrm{C} & 5.691841 & -3.028590 & 0.006981 \\ \mathrm{C} & 5.740516 & -2.773815 & 1.348486 \\ \mathrm{C} & 4.526324 & -2.552514 & 2.089003 \\ \mathrm{C} & -4.468356 & 2.216179 & 2.780939 \\ \mathrm{C} & -3.239520 & 1.776931 & 3.304006 \\ \mathrm{C} & 3.239780 & -1.105360 & 3.582300 \\ \mathrm{C} & 4.468450 & -1.638186 & 3.154482 \\ \mathrm{H} & -5.537482 & -2.526837 & -3.492499 \\ \mathrm{H} & -5.936250 & -0.445789 & -3.932423 \\ \mathrm{H} & -6.361725 & 1.718305 & -2.919733 \\ \mathrm{H} & -6.613613 & 2.897931 & -1.141338 \\ \mathrm{H} & -5.203275 & 0.009182 & 4.283103 \\ \mathrm{H} & -5.395415 & 1.817901 & 3.175293 \\ \mathrm{H} & -4.996708 & -2.376157 & 3.913184 \\ \mathrm{H} & -4.884460 & -4.043329 & 2.543858 \\ \mathrm{H} & -4.947299 & -4.737842 & 0.222224 \\ \mathrm{H} & -5.136583 & -4.292512 & -1.877999 \\ \mathrm{H} & -6.692780 & 2.909515 & 1.303425 \\ & 4.882614 & 4.464175 & 1.716778 \\ \mathrm{H} & 4.945893 & 4.695323 & -0.695461 \\ \mathrm{H} & 5.137034 & 3.848343 & -2.667593 \\ \mathrm{H} & 5.204534 & 0.817644 & 4.198539 \\ \mathrm{H} & & -1.170778 & 3.463425\end{array}$




$\begin{array}{rrrr}\mathrm{H} & 6.692511 & -2.607541 & 1.840646 \\ \mathrm{H} & 6.613397 & -3.067612 & -0.560424 \\ \mathrm{H} & 6.362098 & -2.249579 & -2.531188 \\ \mathrm{H} & 5.937037 & -0.321143 & -3.941827 \\ \mathrm{H} & 5.538287 & 1.804553 & -3.911109\end{array}$

$(6,5) 4$ cells

150

$\begin{array}{llll}\text { C } & 6.551705 & 2.834027 & -2.693057\end{array}$

$\begin{array}{llll}\text { C } & 6.462057 & 3.641487 & -1.589132\end{array}$

$\begin{array}{llll}\text { C } & 5.219368 & 3.803439 & -0.897138\end{array}$

$\begin{array}{llll}\text { C } & 4.037855 & 3.456271 & -1.607784\end{array}$

$\begin{array}{llll}\text { C } & 4.131739 & 2.589005 & -2.747566\end{array}$

$\begin{array}{llll}\text { C } & 5.406384 & 2.117909 & -3.169886\end{array}$

$\begin{array}{llll}\text { C } & 2.755296 & 3.661001 & -1.000853\end{array}$

$\begin{array}{llll}\text { C } & 2.678914 & 3.809000 & 0.408755\end{array}$

$\begin{array}{llll}\text { C } & 3.885432 & 3.697800 & 1.174645\end{array}$

$\begin{array}{llll}\text { C } & 5.144872 & 3.898494 & 0.544240\end{array}$

$\begin{array}{llll}\text { C } & 6.307064 & 3.778189 & 1.369082\end{array}$

$\begin{array}{llll}\text { C } & 6.249198 & 3.119366 & 2.571792\end{array}$

$\begin{array}{llll}\text { C } & 5.023330 & 2.551845 & 3.039565\end{array}$

$\begin{array}{llll}\text { C } & 3.825154 & 3.031330 & 2.444661\end{array}$

$\begin{array}{llll}\text { C } & 2.556256 & 2.554872 & 2.913907\end{array}$

$\begin{array}{llll}\text { C } & 2.507879 & 1.337748 & 3.644206\end{array}$

$\begin{array}{llll}\text { C } & 3.727074 & 0.611152 & 3.844266\end{array}$

$\begin{array}{llll}\text { C } & 4.976010 & 1.285006 & 3.743995\end{array}$

$\begin{array}{llll}\text { C } & 1.352369 & 3.066916 & 2.345448\end{array}$

$\begin{array}{llll}\text { C } & 1.412551 & 3.683639 & 1.057373\end{array}$

$\begin{array}{llll}\text { C } & 1.253947 & 0.682722 & 3.827954\end{array}$

$\begin{array}{llll}\text { C } & 0.046358 & 1.408009 & 3.613327\end{array}$

$\begin{array}{llll}\text { C } & 0.094065 & 2.609374 & 2.839441\end{array}$

$\begin{array}{llll}\text { C } & -1.112043 & 3.090349 & 2.246197\end{array}$

$\begin{array}{llll}\text { C } & -1.050546 & 3.659638 & 0.936392\end{array}$

$\begin{array}{llll}\text { C } & 0.217767 & 3.776621 & 0.285885\end{array}$

$\begin{array}{llll}\text { C } & 0.294760 & 3.579793 & -1.127939\end{array}$

$\begin{array}{llll}\text { C } & 1.567566 & 3.344416 & -1.727785\end{array}$

$\begin{array}{llll}\text { C } & -1.211808 & 0.757241 & 3.806233\end{array}$ 


$\begin{array}{lrrr}\text { C } & -2.416213 & 1.472637 & 3.560313 \\ \text { C } & -2.370013 & 2.644749 & 2.754298 \\ \text { C } & -3.582226 & 3.099195 & 2.144507 \\ \text { C } & -3.514826 & 3.609840 & 0.814915 \\ \text { C } & -2.243223 & 3.713648 & 0.161073 \\ \text { C } & -2.167105 & 3.472746 & -1.242170 \\ \text { C } & -0.893348 & 3.225031 & -1.837845 \\ \text { C } & -3.353775 & 3.088276 & -1.940445 \\ \text { C } & -4.634814 & 3.361450 & -1.363365 \\ \text { C } & -4.704358 & 3.654590 & 0.036509 \\ \text { C } & -5.822457 & 2.991346 & -2.056411 \\ \text { C } & -7.079243 & 3.342974 & -1.444197 \\ \text { C } & -7.151172 & 3.647374 & -0.115896 \\ \text { C } & -5.966793 & 3.598658 & 0.704427 \\ \text { C } & -3.259364 & 2.119138 & -2.973621 \\ \text { C } & -4.446692 & 1.421645 & -3.365262 \\ \text { C } & -5.726060 & 1.978051 & -3.071918 \\ \text { C } & -0.799433 & 2.285071 & -2.909054 \\ \text { C } & -1.976297 & 1.592104 & -3.319837 \\ \text { C } & -1.253956 & -0.673292 & 3.829590 \\ \text { C } & -2.507887 & -1.328763 & 3.647431 \\ \text { C } & -3.727084 & -0.601684 & 3.845701 \\ \text { C } & -3.684606 & 0.831651 & 3.774552 \\ \text { C } & -4.976020 & -1.275781 & 3.747074 \\ \text { C } & -6.147300 & -0.494248 & 3.977240 \\ \text { C } & -6.104433 & 0.877503 & 3.890682 \\ \text { C } & -4.889476 & 1.556060 & 3.580658 \\ \text { C } & 1.661477 & 2.440076 & -2.829243 \\ \text { C } & 0.484384 & 1.763668 & -3.264536 \\ \text { C } & 1.211799 & -0.747864 & 3.808081 \\ \text { C } & -0.046365 & -1.399100 & 3.616746 \\ \text { C } & 2.943345 & 1.923931 & -3.193128 \\ \text { C } & 3.684596 & -0.822354 & 3.776611 \\ \text { C } & 2.416206 & -1.463859 & 3.563914 \\ \text { C } & 4.889468 & -1.547234 & 3.584487 \\ \text { C } & 6.104419 & -0.867923 & 3.892883 \\ \text { C } & 6.147286 & 0.504037 & 3.976089 \\ \text { C } & -2.556258 & -2.547678 & 2.920125 \\ & -5.023332 & -2.544352 & 3.045769\end{array}$




$\begin{array}{lrrr}\text { C } & -0.094067 & -2.602357 & 2.845807 \\ \text { C } & -1.352367 & -3.061119 & 2.352940 \\ \text { C } & 2.370013 & -2.637932 & 2.760761 \\ \text { C } & 1.112046 & -3.084783 & 2.253752 \\ \text { C } & -3.885424 & -3.694923 & 1.183701 \\ \text { C } & -5.144860 & -3.897197 & 0.553789 \\ \text { C } & -6.307054 & -3.774852 & 1.378329 \\ \text { C } & -6.249196 & -3.113037 & 2.579397 \\ \text { C } & -1.412543 & -3.681031 & 1.066398 \\ \text { C } & -2.678904 & -3.808014 & 0.418089 \\ \text { C } & 1.050553 & -3.657302 & 0.945357 \\ \text { C } & -0.217758 & -3.775910 & 0.295142 \\ \text { C } & 2.243231 & -3.713216 & 0.170176 \\ \text { C } & 3.514833 & -3.607776 & 0.823757 \\ \text { C } & 3.582231 & -3.093863 & 2.152089 \\ \text { C } & -2.755286 & -3.663496 & -0.991882 \\ \text { C } & -4.037844 & -3.460268 & -1.599318 \\ \text { C } & -5.219355 & -3.805700 & -0.887821 \\ \text { C } & -0.294753 & -3.582579 & -1.119166 \\ \text { C } & -1.567559 & -3.348691 & -1.719594 \\ \text { C } & 2.167109 & -3.475787 & -1.233657 \\ \text { C } & 0.893351 & -3.229560 & -1.829947 \\ \text { C } & 3.353775 & -3.093036 & -1.932881 \\ \text { C } & 4.634815 & -3.364774 & -1.355128 \\ \text { C } & 4.704365 & -3.654441 & 0.045466 \\ \text { C } & 5.822455 & -2.996387 & -2.049093 \\ \text { C } & 7.079245 & -3.346484 & -1.436011 \\ \text { C } & 7.151179 & -3.647588 & -0.106962 \\ \text { C } & 5.966800 & -3.596852 & 0.713240 \\ \text { C } & -4.131734 & -2.595788 & -2.741214 \\ \text { C } & -5.406381 & -2.125732 & -3.164679 \\ \text { C } & -6.551695 & -2.840700 & -2.686113 \\ \text { C } & -6.462043 & -3.645455 & -1.580214 \\ \text { C } & -1.661475 & -2.447049 & -2.823263 \\ \text { C } & -2.943345 & -1.931793 & -3.188396 \\ \text { C } & 0.799431 & -2.292230 & -2.903459 \\ \text { C } & -0.484387 & -1.771699 & -3.260209 \\ \text { C } & 3.259357 & -2.126459 & -2.968453 \\ \text { C } & 1.976290 & -1.600271 & -3.315951 \\ & 5.726051 & -1.985615 & -3.067109\end{array}$




$\begin{array}{rrrr}\text { C } & 4.446683 & -1.429930 & -3.361815 \\ \mathrm{C} & -3.047854 & -0.592436 & -3.645945 \\ \mathrm{C} & -4.339780 & 0.026655 & -3.686502 \\ \mathrm{C} & -5.510015 & -0.781734 & -3.679563 \\ \mathrm{C} & -0.589256 & -0.409293 & -3.677017 \\ \mathrm{C} & -1.870797 & 0.216511 & -3.686226 \\ \mathrm{C} & 1.870788 & -0.225579 & -3.685706 \\ \mathrm{C} & 0.589248 & 0.400248 & -3.678015 \\ \mathrm{C} & 4.339770 & -0.035732 & -3.686477 \\ \mathrm{C} & 3.047846 & 0.583462 & -3.647415 \\ \mathrm{C} & 5.510008 & 0.772667 & -3.681513 \\ \mathrm{C} & 6.767336 & 0.092763 & -3.796641 \\ \mathrm{C} & 6.871088 & -1.241082 & -3.508017 \\ \mathrm{C} & -6.871099 & 1.232431 & -3.510984 \\ \mathrm{C} & -6.767345 & -0.102117 & -3.796339 \\ \mathrm{C} & -4.853126 & 2.720721 & 2.695581 \\ \mathrm{C} & -6.013926 & 3.176141 & 2.041250 \\ \mathrm{C} & 4.853129 & -2.714040 & 2.702239 \\ \mathrm{C} & 6.013932 & -3.171050 & 2.049021 \\ \mathrm{H} & 7.168734 & 2.923781 & 3.109505 \\ \mathrm{H} & 7.271010 & 4.087039 & 0.984804 \\ \mathrm{H} & -7.032957 & 1.433517 & 3.932468 \\ \mathrm{H} & -6.988236 & 2.976341 & 2.470302 \\ \mathrm{H} & 7.366536 & 4.064566 & -1.169861 \\ \mathrm{H} & 7.107487 & 0.993499 & 4.080243 \\ \mathrm{H} & 7.032943 & -1.423832 & 3.936034 \\ \mathrm{H} & -7.168734 & -2.916127 & 3.116623 \\ \mathrm{H} & -7.107502 & -0.983456 & 4.082581 \\ \mathrm{H} & 6.988241 & -2.970205 & 2.477587 \\ \mathrm{H} & 8.112905 & -3.801259 & 0.370045 \\ \mathrm{H} & -7.366521 & -4.067511 & -1.159910 \\ \mathrm{H} & -7.849662 & 1.695424 & -3.493422 \\ \mathrm{H} & -7.270997 & -4.084665 & 0.994820 \\ \mathrm{H} & 7.991284 & -3.266278 & -2.014346 \\ \mathrm{H} & 7.849652 & -1.704029 & -3.489308 \\ & -7.665691 & -0.671360 & -4.000832 \\ \mathrm{H} & -7.525160 & -2.641437 & -3.116228 \\ & 7.665684 & 0.661506 & -4.002515 \\ \mathrm{H} & -7.991284 & 2.633705 & -3.122684 \\ \mathrm{H} & & & -2.022329 \\ \mathrm{H} & & \end{array}$




$\begin{array}{llll}\mathrm{H} & -8.112896 & 3.802227 & 0.360732\end{array}$

$(6,5) 5$ cells

182

$\begin{array}{llll}\text { C } & 8.635147 & -0.215712 & -3.773097\end{array}$

$\begin{array}{llll}\text { C } & 8.559466 & 1.143860 & -3.639331\end{array}$

$\begin{array}{llll}\text { C } & 7.316314 & 1.781131 & -3.314006\end{array}$

$\begin{array}{llll}\text { C } & 6.129373 & 1.037106 & -3.558244\end{array}$

$\begin{array}{llll}\text { C } & 6.206640 & -0.391833 & -3.676870\end{array}$

$\begin{array}{llll}\text { C } & 7.474216 & -1.036502 & -3.574139\end{array}$

$\begin{array}{llll}\text { C } & 4.851014 & 1.640208 & -3.321515\end{array}$

$\begin{array}{llll}\text { C } & 3.656180 & 0.905078 & -3.596362\end{array}$

$\begin{array}{llll}\text { C } & 3.732328 & -0.517886 & -3.666543\end{array}$

$\begin{array}{llll}\text { C } & 5.005455 & -1.151249 & -3.506984\end{array}$

$\begin{array}{llll}\text { C } & 2.388275 & 1.524206 & -3.389433\end{array}$

$\begin{array}{llll}\text { C } & 1.193955 & 0.776770 & -3.625691\end{array}$

$\begin{array}{llll}\text { C } & 1.269778 & -0.648139 & -3.648945\end{array}$

$\begin{array}{llll}\text { C } & 2.541638 & -1.279166 & -3.480771\end{array}$

$\begin{array}{llll}\text { C } & -0.076715 & 1.402657 & -3.435907\end{array}$

$\begin{array}{llll}\text { C } & -1.269777 & 0.647291 & -3.649107\end{array}$

$\begin{array}{llll}\text { C } & -1.193953 & -0.777612 & -3.625508\end{array}$

$\begin{array}{llll}\text { C } & 0.076715 & -1.403453 & -3.435569\end{array}$

$\begin{array}{llll}\text { C } & -2.541638 & 1.278359 & -3.481086\end{array}$

$\begin{array}{llll}\text { C } & -3.732327 & 0.517032 & -3.666682\end{array}$

$\begin{array}{llll}\text { C } & -3.656178 & -0.905915 & -3.596160\end{array}$

$\begin{array}{llll}\text { C } & -2.388274 & -1.524992 & -3.389075\end{array}$

$\begin{array}{llll}\text { C } & -5.005454 & 1.150433 & -3.507276\end{array}$

$\begin{array}{llll}\text { C } & -6.206638 & 0.390974 & -3.676989\end{array}$

$\begin{array}{llll}\text { C } & -6.129370 & -1.037938 & -3.558022\end{array}$

$\begin{array}{llll}\text { C } & -4.851012 & -1.640980 & -3.321139\end{array}$

$\begin{array}{llll}\text { C } & -7.474214 & 1.035665 & -3.574412\end{array}$

$\begin{array}{llll}\text { C } & -8.635143 & 0.214827 & -3.773187\end{array}$

$\begin{array}{llll}\text { C } & -8.559462 & -1.144713 & -3.639097\end{array}$

C $\quad-7.316312 \quad-1.781904 \quad-3.313606$

$\begin{array}{llll}\text { C } & -7.241867 & -2.908088 & -2.414869\end{array}$

$\begin{array}{llll}\text { C } & -8.402883 & -3.420862 & -1.749913\end{array}$

$\begin{array}{llll}\text { C } & -7.549444 & 2.311280 & -2.916541\end{array}$ 


$\begin{array}{lrrr}\text { C } & -8.799573 & 2.857384 & -2.448353 \\ \text { C } & -4.775549 & -2.779783 & -2.478821 \\ \text { C } & -5.978120 & -3.254088 & -1.860723 \\ \text { C } & -5.079683 & 2.389625 & -2.820032 \\ \text { C } & -6.354580 & 2.852186 & -2.362837 \\ \text { C } & -2.313235 & -2.700232 & -2.578011 \\ \text { C } & -3.504558 & -3.187463 & -1.966776 \\ \text { C } & -2.615901 & 2.503722 & -2.748138 \\ \text { C } & -3.884459 & 2.945338 & -2.264230 \\ \text { C } & 0.151670 & -2.603303 & -2.665212 \\ \text { C } & -1.041922 & -3.114524 & -2.071114 \\ \text { C } & -0.151672 & 2.602691 & -2.665834 \\ \text { C } & -1.422207 & 3.034122 & -2.172594 \\ \text { C } & 2.615899 & -2.504358 & -2.747537 \\ \text { C } & 1.422204 & -3.034623 & -2.171871 \\ \text { C } & 2.313234 & 2.699642 & -2.578652 \\ \text { C } & 1.041920 & 3.114052 & -2.071854 \\ \text { C } & 5.079681 & -2.390285 & -2.819456 \\ \text { C } & 3.884455 & -2.945868 & -2.263529 \\ \text { C } & 4.775548 & 2.779218 & -2.479476 \\ \text { C } & 3.504555 & 3.187020 & -1.967531 \\ \text { C } & 7.549442 & -2.311969 & -2.915981 \\ \text { C } & 6.354575 & -2.852747 & -2.362157 \\ \text { C } & 7.241866 & 2.907540 & -2.415552 \\ \text { C } & 5.978118 & 3.253675 & -1.861492 \\ \text { C } & 8.799569 & -2.857976 & -2.447672 \\ \text { C } & 8.402881 & 3.420478 & -1.750720 \\ \text { C } & -6.417748 & 3.559151 & -1.118538 \\ \text { C } & -7.681315 & 3.732563 & -0.472914 \\ \text { C } & -8.865077 & 3.552623 & -1.276500 \\ \text { C } & -3.955457 & 3.603443 & -1.002495 \\ \text { C } & -5.230084 & 3.729731 & -0.356252 \\ \text { C } & -1.495050 & 3.654373 & -0.888057 \\ \text { C } & -2.764110 & 3.767057 & -0.241176 \\ \text { C } & 0.968683 & 3.688452 & -0.767237 \\ \text { C } & -0.300112 & 3.779216 & -0.116248 \\ \text { C } & 3.430779 & 3.715184 & -0.642437 \\ \text { C } & 2.164659 & 3.785652 & 0.008622 \\ & 5.903448 & 3.732726 & -0.510237 \\ \text { (.625961 } & 3.768252 & 0.138756\end{array}$




$\begin{array}{lrrr}\text { C } & 8.331067 & 3.852560 & -0.452204 \\ \text { C } & 7.092010 & 3.820300 & 0.264612 \\ \text { C } & -7.737193 & 3.737490 & 0.927966 \\ \text { C } & -5.307871 & 3.649565 & 1.064770 \\ \text { C } & -6.585262 & 3.481803 & 1.697266 \\ \text { C } & -2.837107 & 3.623858 & 1.180798 \\ \text { C } & -4.104420 & 3.376588 & 1.791335 \\ \text { C } & -0.372877 & 3.583986 & 1.296654 \\ \text { C } & -1.642970 & 3.320965 & 1.898737 \\ \text { C } & 2.091585 & 3.539855 & 1.415984 \\ \text { C } & 0.820798 & 3.255548 & 2.006967 \\ \text { C } & 4.552458 & 3.477578 & 1.525346 \\ \text { C } & 3.282922 & 3.186717 & 2.112341 \\ \text { C } & 7.019327 & 3.469599 & 1.666212 \\ \text { C } & 5.756141 & 3.111263 & 2.212550 \\ \text { C } & 8.178838 & 3.076638 & 2.406439 \\ \text { C } & -6.645828 & 2.642573 & 2.894416 \\ \text { C } & -7.875249 & 2.115529 & 3.389312 \\ \text { C } & -4.175379 & 2.505935 & 2.912704 \\ \text { C } & -5.457020 & 1.987061 & 3.306235 \\ \text { C } & -1.715948 & 2.411622 & 2.998546 \\ \text { C } & -2.985056 & 1.875443 & 3.372515 \\ \text { C } & 0.747390 & 2.309298 & 3.073566 \\ \text { C } & -0.521415 & 1.758350 & 3.429529 \\ \text { C } & 3.209001 & 2.203234 & 3.147698 \\ \text { C } & 1.942542 & 1.642723 & 3.483872 \\ \text { C } & 5.681103 & 2.087315 & 3.216177 \\ \text { C } & 4.402053 & 1.515257 & 3.522540 \\ \text { C } & 8.106417 & 2.081610 & 3.348728 \\ \text { C } & 6.868040 & 1.423566 & 3.627747 \\ \text { C } & -7.947197 & 0.836501 & 3.888156 \\ \text { C } & -5.530093 & 0.643967 & 3.808184 \\ \text { C } & -6.792572 & -0.002427 & 3.911964 \\ \text { C } & -3.058172 & 0.519347 & 3.827113 \\ \text { C } & -4.326556 & -0.134427 & 3.844798 \\ \text { C } & -0.595742 & 0.392385 & 3.840373 \\ \text { C } & -1.867868 & -0.261193 & 3.850907 \\ \text { C } & 1.867874 & 0.262094 & 3.850832 \\ & 4.395748 & -0.391485 & 3.840465 \\ & & 0.135327 & 3.844741\end{array}$




$\begin{array}{lrrr}\text { C } & 3.058178 & -0.518450 & 3.827220 \\ \text { C } & 6.792579 & 0.003342 & 3.911929 \\ \text { C } & 5.530099 & -0.643076 & 3.808309 \\ \text { C } & 7.947204 & -0.835592 & 3.888317 \\ \text { C } & -6.868035 & -1.422717 & 3.628115 \\ \text { C } & -8.106414 & -2.080822 & 3.349245 \\ \text { C } & -4.402048 & -1.514433 & 3.522921 \\ \text { C } & -5.681100 & -2.086562 & 3.216693 \\ \text { C } & -1.942538 & -1.641909 & 3.484272 \\ \text { C } & -3.208998 & -2.202499 & 3.148235 \\ \text { C } & 0.521419 & -1.757549 & 3.429948 \\ \text { C } & -0.747388 & -2.308582 & 3.074120 \\ \text { C } & 2.985059 & -1.874657 & 3.372953 \\ \text { C } & 1.715950 & -2.410926 & 2.999118 \\ \text { C } & 5.457022 & -1.986293 & 3.306692 \\ \text { C } & 4.175381 & -2.505262 & 2.913291 \\ \text { C } & 7.875252 & -2.114743 & 3.389789 \\ \text { C } & 6.645829 & -2.641908 & 2.895029 \\ \text { C } & -8.178839 & -3.076058 & 2.407177 \\ \text { C } & -5.756141 & -3.110732 & 2.213293 \\ \text { C } & -7.019329 & -3.469186 & 1.667036 \\ \text { C } & -3.282923 & -3.186216 & 2.113100 \\ \text { C } & -4.552460 & -3.477205 & 1.526171 \\ \text { C } & -0.820800 & -3.255081 & 2.007742 \\ \text { C } & -2.091588 & -3.539517 & 1.416823 \\ \text { C } & 1.642969 & -3.320531 & 1.899525 \\ \text { C } & 0.372874 & -3.583687 & 1.297503 \\ \text { C } & 4.104417 & -3.376186 & 1.792133 \\ \text { C } & 2.837103 & -3.623596 & 1.181656 \\ \text { C } & 6.585257 & -3.481430 & 1.698085 \\ \text { C } & 5.307866 & -3.649339 & 1.065631 \\ \text { C } & 7.737186 & -3.737309 & 0.928844 \\ \text { C } & -7.092014 & -3.820205 & 0.265517 \\ \text { C } & -8.331070 & -3.852632 & -0.451293 \\ \text { C } & -4.625965 & -3.768193 & 0.139647 \\ \text { C } & -5.903451 & -3.732813 & -0.509352 \\ \text { C } & -2.164663 & -3.785637 & 0.009518 \\ \text { C } & -3.430782 & -3.715313 & -0.641557 \\ & 0.300107 & -3.779241 & -0.115354 \\ \text { - } 0.968687 & -3.688620 & -0.766363\end{array}$

S76 


$\begin{array}{rrrr}\text { C } & 2.764104 & -3.767123 & -0.240287 \\ \text { C } & 1.495045 & -3.654581 & -0.887193 \\ \text { C } & 5.230077 & -3.729836 & -0.355374 \\ \text { C } & 3.955451 & -3.603687 & -1.001644 \\ \text { C } & 7.681308 & -3.732706 & -0.472037 \\ \text { C } & 6.417741 & -3.559435 & -1.117700 \\ \text { C } & 8.865069 & -3.552955 & -1.275665 \\ \text { H } & 9.603496 & -0.681748 & -3.904487 \\ \text { H } & 9.469247 & 1.730659 & -3.667658 \\ \text { H } & -9.371425 & -3.343247 & -2.227579 \\ \text { H } & -9.469242 & -1.731521 & -3.667293 \\ \text { H } & -9.712776 & 2.622540 & -2.980878 \\ \text { H } & -9.603491 & 0.680831 & -3.904699 \\ \text { H } & 9.712772 & -2.623257 & -2.980251 \\ \text { H } & 9.371423 & 3.342751 & -2.228368 \\ \text { H } & 9.244161 & 4.110250 & 0.069981 \\ \text { H } & -8.715212 & 3.696266 & 1.391643 \\ \text { H } & -9.823037 & 3.865317 & -0.875775 \\ \text { H } & 9.149219 & 3.468590 & 2.128913 \\ \text { H } & -8.791376 & 2.677722 & 3.256321 \\ \text { H } & 9.021172 & 1.711652 & 3.795052 \\ \text { H } & -8.917213 & 0.422672 & 4.133619 \\ \text { H } & 8.917221 & -0.421701 & 4.133671 \\ \text { H } & -9.021168 & -1.710763 & 3.795488 \\ \text { H } & 8.791378 & -2.676969 & 3.256932 \\ \text { H } & -9.149220 & -3.468070 & 2.129740 \\ \text { H } & 8.715206 & -3.695982 & 1.392510 \\ \text { H } & -9.244165 & -4.110199 & 0.070951 \\ \text { H } & 9.823028 & -3.865566 & -0.874871\end{array}$

$(6,5) 6$ cells

214

$\begin{array}{llll}\text { C } & 8.414824 & 1.936080 & 3.435556 \\ \text { C } & 7.229769 & 2.528802 & 2.928845 \\ \text { C } & 7.310441 & 3.416511 & 1.803431 \\ \text { C } & 8.576831 & 3.711481 & 1.228368 \\ \text { C } & 9.726172 & 3.432692 & 2.027983\end{array}$




$\begin{array}{lrrr}\text { C } & 9.646908 & 2.567612 & 3.093256 \\ \text { C } & 6.111832 & 3.688315 & 1.064434 \\ \text { C } & 6.196937 & 3.802539 & -0.347031 \\ \text { C } & 7.480783 & 3.685794 & -0.976512 \\ \text { C } & 8.662249 & 3.874075 & -0.210328 \\ \text { C } & 5.008736 & 3.655904 & -1.124856 \\ \text { C } & 5.091660 & 2.970276 & -2.377350 \\ \text { C } & 6.364956 & 2.500646 & -2.824914 \\ \text { C } & 7.564819 & 3.043105 & -2.257757 \\ \text { C } & 3.904676 & 2.415745 & -2.935096 \\ \text { C } & 3.982517 & 1.151476 & -3.600292 \\ \text { C } & 5.249137 & 0.510099 & -3.722939 \\ \text { C } & 6.443264 & 1.269482 & -3.524866 \\ \text { C } & 2.787596 & 0.382941 & -3.754322 \\ \text { C } & 2.859907 & -1.034084 & -3.606203 \\ \text { C } & 4.128889 & -1.643817 & -3.356882 \\ \text { C } & 5.321935 & -0.913322 & -3.624326 \\ \text { C } & 1.663319 & -1.756380 & -3.311247 \\ \text { C } & 1.730999 & -2.853751 & -2.399965 \\ \text { C } & 2.997696 & -3.225338 & -1.851516 \\ \text { C } & 4.196829 & -2.774238 & -2.483293 \\ \text { C } & 0.533463 & -3.285099 & -1.754599 \\ \text { C } & 0.599228 & -3.695360 & -0.387603 \\ \text { C } & 1.864481 & -3.705626 & 0.275141 \\ \text { C } & 3.063628 & -3.680213 & -0.501022 \\ \text { C } & 4.330202 & -3.715201 & 0.160472 \\ \text { C } & 4.395193 & -3.391070 & 1.552069 \\ \text { C } & 3.197708 & -3.003240 & 2.224163 \\ \text { C } & 1.930199 & -3.339564 & 1.653254 \\ \text { C } & 5.526127 & -3.660892 & -0.612498 \\ \text { C } & 6.794611 & -3.703716 & 0.048571 \\ \text { C } & 6.859600 & -3.426886 & 1.438450 \\ \text { C } & 5.659659 & -3.066062 & 2.129099 \\ \text { C } & 5.724405 & -2.065998 & 3.141707 \\ \text { C } & 6.997404 & -1.490108 & 3.468067 \\ \text { C } & 8.187028 & -2.164824 & 3.080853 \\ \text { C } & 8.130390 & -3.134394 & 2.027782 \\ & 9.329591 & -3.498107 & 1.352224 \\ \text { C.575335 } & -3.219919 & 2.024193 \\ \text { C.634477 } & -2.316116 & 3.044079\end{array}$




$\begin{array}{lrrr}\text { C } & 9.448408 & -1.604114 & 3.452110 \\ \text { C } & 8.001246 & -3.635549 & -0.718020 \\ \text { C } & 9.263836 & -3.736151 & -0.063635 \\ \text { C } & 3.264427 & -1.971353 & 3.208583 \\ \text { C } & 4.531061 & -1.391036 & 3.523141 \\ \text { C } & 4.602733 & 0.007184 & 3.822432 \\ \text { C } & 5.870596 & 0.663250 & 3.780540 \\ \text { C } & 7.073779 & -0.112788 & 3.826741 \\ \text { C } & 0.732846 & -2.931724 & 2.313960 \\ \text { C } & 0.799957 & -1.865605 & 3.263064 \\ \text { C } & 2.066766 & -1.273697 & 3.555481 \\ \text { C } & 2.138339 & 0.130344 & 3.802333 \\ \text { C } & 3.409994 & 0.783695 & 3.744417 \\ \text { C } & -0.599228 & -3.695361 & 0.387595 \\ \text { C } & -0.533462 & -3.285102 & 1.754593 \\ \text { C } & -1.730999 & -2.853756 & 2.399959 \\ \text { C } & -1.663319 & -1.756387 & 3.311244 \\ \text { C } & -0.396401 & -1.156269 & 3.584127 \\ \text { C } & -0.324514 & 0.257617 & 3.781995 \\ \text { C } & 0.945513 & 0.907071 & 3.700788 \\ \text { C } & -1.864481 & -3.705625 & -0.275149 \\ \text { C } & -3.063627 & -3.680215 & 0.501014 \\ \text { C } & -2.997696 & -3.225342 & 1.851510 \\ \text { C } & -4.196829 & -2.774243 & 2.483288 \\ \text { C } & -4.128889 & -1.643824 & 3.356879 \\ \text { C } & -2.859907 & -1.034092 & 3.606200 \\ \text { C } & -2.787596 & 0.382933 & 3.754323 \\ \text { C } & -1.517300 & 1.030091 & 3.652101 \\ \text { C } & -4.330202 & -3.715201 & -0.160480 \\ \text { C } & -5.526127 & -3.660894 & 0.612491 \\ \text { C } & -5.459953 & -3.160649 & 1.947105 \\ \text { C } & -6.659814 & -2.674932 & 2.554150 \\ \text { C } & -6.591064 & -1.525803 & 3.382522 \\ \text { C } & -5.321935 & -0.913330 & 3.624325 \\ \text { C } & -5.249138 & 0.510091 & 3.722940 \\ \text { C } & -3.982517 & 1.151468 & 3.600293 \\ \text { C } & -6.794611 & -3.703716 & -0.048578 \\ \text { C } & -8.001246 & -3.635551 & 0.718013 \\ & -7.933979 & -3.086063 & 2.042972 \\ & & -2.626816 & 2.667603\end{array}$




$\begin{array}{rrrr}\text { C } & -9.057874 & -1.426814 & 3.466005 \\ \text { C } & -7.795711 & -0.792989 & 3.636338 \\ \text { C } & -7.721935 & 0.640099 & 3.680540 \\ \text { C } & -6.443264 & 1.269474 & 3.524868 \\ \text { C } & -9.263836 & -3.736153 & 0.063627 \\ \text { C } & -10.430988 & -3.676456 & 0.897738 \\ \text { C } & -10.364934 & -3.132585 & 2.151382 \\ \text { C } & -8.909293 & 1.403811 & 3.518068 \\ \text { C } & -10.150430 & 0.730803 & 3.756932 \\ \text { C } & -10.221631 & -0.637489 & 3.741000 \\ \text { C } & -6.364957 & 2.500639 & 2.824918 \\ \text { C } & -7.564820 & 3.043099 & 2.257762 \\ \text { C } & -8.831424 & 2.631495 & 2.756445 \\ \text { C } & -6.859600 & -3.426884 & -1.438457 \\ \text { C } & -8.130390 & -3.134391 & -2.027788 \\ \text { C } & -9.329591 & -3.498105 & -1.352231 \\ \text { C } & -3.904676 & 2.415739 & 2.935100 \\ \text { C } & -5.091661 & 2.970270 & 2.377356 \\ \text { C } & -4.395193 & -3.391067 & -1.552076 \\ \text { C } & -5.659658 & -3.066059 & -2.129105 \\ \text { C } & -1.439745 & 2.314934 & 3.031794 \\ \text { C } & -2.630139 & 2.889373 & 2.491057 \\ \text { C } & -1.930199 & -3.339561 & -1.653260 \\ \text { C } & -3.197708 & -3.003236 & -2.224169 \\ \text { C } & 1.022621 & 2.212740 & 3.124600 \\ \text { C } & -0.167695 & 2.804968 & 2.605712 \\ \text { C } & -0.732846 & -2.931720 & -2.313966 \\ \text { C } & 3.486776 & 2.108131 & 3.214896 \\ \text { C } & 2.294669 & 2.717097 & 2.714267 \\ \text { C } & 5.459953 & -3.160644 & -1.947111 \\ \text { C } & 7.933979 & -3.086058 & -2.042978 \\ \text { C } & 6.659814 & -2.674926 & -2.554156 \\ \text { C } & 9.125757 & -2.626810 & -2.667608 \\ \text { C } & 10.364934 & -3.132579 & -2.151388 \\ \text { C } & 10.430988 & -3.676453 & -0.897746 \\ \text { C } & -8.187028 & -2.164819 & -3.080858 \\ \text { C } & -9.448409 & -1.604108 & -3.452113 \\ \text { C } & -10.634477 & -2.316112 & -3.044084 \\ & -5.724405 & -2.065992 & -3.141712\end{array}$

S80 


$\begin{array}{lrrr}\text { C } & -6.997404 & -1.490103 & -3.468070 \\ \text { C } & -3.264427 & -1.971347 & -3.208587 \\ \text { C } & -4.531061 & -1.391030 & -3.523144 \\ \text { C } & -0.799957 & -1.865598 & -3.263068 \\ \text { C } & -2.066766 & -1.273690 & -3.555484 \\ \text { C } & 0.396400 & -1.156262 & -3.584130 \\ \text { C } & 6.591064 & -1.525795 & -3.382525 \\ \text { C } & 9.057874 & -1.426806 & -3.466007 \\ \text { C } & 7.795711 & -0.792981 & -3.636340 \\ \text { C } & -4.602734 & 0.007191 & -3.822432 \\ \text { C } & -5.870597 & 0.663257 & -3.780539 \\ \text { C } & -7.073779 & -0.112782 & -3.826741 \\ \text { C } & -2.138339 & 0.130351 & -3.802333 \\ \text { C } & -3.409995 & 0.783702 & -3.744416 \\ \text { C } & 0.324514 & 0.257624 & -3.781995 \\ \text { C } & -0.945514 & 0.907078 & -3.700788 \\ \text { C } & 1.517300 & 1.030098 & -3.652099 \\ \text { C } & 7.721935 & 0.640108 & -3.680539 \\ \text { C } & 8.909293 & 1.403819 & -3.518066 \\ \text { C } & 10.150429 & 0.730812 & -3.756930 \\ \text { C } & 10.221631 & -0.637480 & -3.741001 \\ \text { C } & -1.022622 & 2.212746 & -3.124595 \\ \text { C } & -2.294670 & 2.717102 & -2.714262 \\ \text { C } & -3.486777 & 2.108137 & -3.214892 \\ \text { C } & 1.439744 & 2.314941 & -3.031790 \\ \text { C } & 0.167694 & 2.804974 & -2.605707 \\ \text { C } & 2.630138 & 2.889378 & -2.491052 \\ \text { C } & 8.831423 & 2.631503 & -2.756440 \\ \text { C } & 2.547564 & 3.614884 & -1.265371 \\ \text { C } & 1.273356 & 3.785263 & -0.641441 \\ \text { C } & 0.085334 & 3.572897 & -1.402475 \\ \text { C } & 3.738082 & 3.804093 & -0.497318 \\ \text { C } & 9.906138 & 3.807292 & -0.912374 \\ \text { C } & 9.987172 & 3.214247 & -2.146958 \\ \text { C } & 4.838775 & 3.473293 & 1.673164 \\ \text { C } & 3.653872 & 3.732817 & 0.928766 \\ \text { C } & -9.987173 & 3.214240 & 2.146964 \\ \text { C } & -9.906139 & 3.807288 & 0.912381 \\ & -8.662249 & 3.874073 & 0.210335 \\ & -7.480783 & 3.685791 & 0.976519\end{array}$




$\begin{array}{rrrr}\text { C } & -6.196938 & 3.802537 & 0.347038 \\ \mathrm{C} & -6.111833 & 3.688316 & -1.064428 \\ \mathrm{C} & -7.310442 & 3.416514 & -1.803424 \\ \mathrm{C} & -8.576832 & 3.711482 & -1.228361 \\ \mathrm{C} & -9.726173 & 3.432695 & -2.027976 \\ \mathrm{C} & -9.646908 & 2.567617 & -3.093252 \\ \mathrm{C} & -8.414825 & 1.936085 & -3.435553 \\ \mathrm{C} & -7.229770 & 2.528806 & -2.928841 \\ \mathrm{C} & -5.008737 & 3.655900 & 1.124863 \\ \mathrm{C} & -3.738083 & 3.804091 & 0.497325 \\ \mathrm{C} & -3.653873 & 3.732818 & -0.928759 \\ \mathrm{C} & -4.838776 & 3.473296 & -1.673158 \\ \mathrm{C} & -2.547565 & 3.614881 & 1.265378 \\ \mathrm{C} & -0.085335 & 3.572894 & 1.402482 \\ \mathrm{C} & -1.273357 & 3.785262 & 0.641449 \\ \mathrm{C} & 9.502371 & -0.271885 & 3.885106 \\ \mathrm{C} & 8.350818 & 0.539860 & 3.868776 \\ \mathrm{C} & 5.945258 & 1.996492 & 3.294518 \\ \mathrm{C} & 4.757933 & 2.627124 & 2.826256 \\ \mathrm{C} & -9.502372 & -0.271879 & -3.885106 \\ \mathrm{C} & -8.350819 & 0.539866 & -3.868776 \\ \mathrm{C} & -5.945259 & 1.996498 & -3.294514 \\ \mathrm{C} & -4.757934 & 2.627129 & -2.826251 \\ \mathrm{C} & -2.376829 & 3.522706 & -1.539354 \\ \mathrm{C} & -1.189230 & 3.761912 & -0.785212 \\ \mathrm{C} & 1.189229 & 3.761911 & 0.785219 \\ \mathrm{C} & 2.376828 & 3.522704 & 1.539361 \\ \mathrm{H} & -11.278871 & -2.981126 & 2.712289 \\ \mathrm{H} & -11.190495 & -1.116601 & 3.804197 \\ \mathrm{H} & -11.064416 & 1.306474 & 3.834441 \\ \mathrm{H} & -11.396021 & -3.945867 & 0.487476 \\ \mathrm{H} & 11.396022 & -3.945865 & -0.487484 \\ \mathrm{H} & 11.490682 & -3.657190 & 1.645256 \\ \mathrm{H} & -11.490682 & -3.657189 & -1.645264 \\ \mathrm{H} & -11.589582 & -2.031332 & -3.471495 \\ & 11.190495 & -1.116592 & -3.804200 \\ \mathrm{H} & 11.278871 & -2.981119 & -2.712296 \\ \mathrm{H} & -10.589076 & 0.180933 & -3.995894 \\ \mathrm{H} & 2.269344 & -3.594723 \\ \mathrm{H} & 3.068314 & -2.597443\end{array}$

S82 


$\begin{array}{rrrr}\text { H } & 11.064415 & 1.306484 & -3.834439 \\ \mathrm{H} & -10.698223 & 3.792789 & -1.715227 \\ \mathrm{H} & -10.817468 & 4.116871 & 0.415935 \\ \mathrm{H} & 10.698222 & 3.792787 & 1.715234 \\ \mathrm{H} & 10.817467 & 4.116873 & -0.415928 \\ \mathrm{H} & -10.960814 & 3.068306 & 2.597448 \\ \mathrm{H} & 10.480075 & 0.180927 & 3.995894 \\ \mathrm{H} & 10.559341 & 2.269339 & 3.594726 \\ \mathrm{H} & 11.589582 & -2.031337 & 3.471491\end{array}$

(7_0) 2 cells

74

$\begin{array}{rrrr}\text { C } & 2.863454 & -2.270123 & 1.340324 \\ \text { C } & 4.235193 & -2.526600 & 1.205062 \\ \text { C } & 2.952186 & -0.000427 & 2.269742 \\ \text { C } & 2.863443 & 2.269594 & 1.341115 \\ \text { C } & 4.235181 & 2.526130 & 1.205948 \\ \text { C } & 4.733445 & 3.037608 & 0.003437 \\ \text { C } & 2.541682 & 2.859121 & -1.011677 \\ \text { C } & 3.911177 & 3.114575 & -1.129366 \\ \text { C } & 2.259926 & 1.212184 & -2.793615 \\ \text { C } & 2.259934 & -1.211217 & -2.794029 \\ \text { C } & 2.541695 & -2.858798 & -1.012683 \\ \text { C } & 3.911193 & -3.114191 & -1.130468 \\ \text { C } & 4.733460 & -3.037634 & 0.002363 \\ \text { C } & 1.995257 & -2.658054 & 0.284868 \\ \text { C } & -1.381776 & -2.246910 & 1.913264 \\ \text { C } & 0.023585 & -2.227000 & 1.712915 \\ \text { C } & 0.855615 & -1.224932 & 2.383926 \\ \text { C } & 2.261559 & -1.227816 & 2.215380 \\ \text { C } & -1.256225 & -0.000529 & 2.806937 \\ \text { C } & 0.177879 & -0.000496 & 2.632328 \\ \text { C } & 0.855610 & 1.224029 & 2.384353 \\ \text { C } & 2.261554 & 1.226978 & 2.215807 \\ \text { C } & -1.381784 & 2.246166 & 1.914052 \\ \text { C } & 0.023577 & 2.226329 & 1.713695 \\ \text { C } & 0.564796 & 2.677551 & 0.483961\end{array}$

S83 


\begin{tabular}{|c|c|c|c|}
\hline C & 1.995245 & 2.657897 & 0.285799 \\
\hline C & -1.705067 & 2.830531 & -0.446809 \\
\hline C & -0.301690 & 2.805557 & -0.642619 \\
\hline C & 0.263828 & 2.243017 & -1.863152 \\
\hline C & 1.677442 & 2.249524 & -2.065828 \\
\hline $\mathrm{C}$ & -1.956765 & 1.214463 & -2.216413 \\
\hline $\mathrm{C}$ & -0.534913 & 1.215150 & -2.435037 \\
\hline C & 0.123332 & 0.000480 & -2.814202 \\
\hline $\mathrm{C}$ & 1.537692 & 0.000517 & -3.004969 \\
\hline $\mathrm{C}$ & -1.956757 & -1.213716 & -2.216827 \\
\hline $\mathrm{C}$ & -0.534905 & -1.214324 & -2.435455 \\
\hline $\mathrm{C}$ & 0.263840 & -2.242391 & -1.863936 \\
\hline C & 1.677453 & -2.248819 & -2.066613 \\
\hline $\mathrm{C}$ & -1.705055 & -2.830427 & -0.447808 \\
\hline $\mathrm{C}$ & -0.301678 & -2.805376 & -0.643608 \\
\hline $\mathrm{C}$ & 0.564807 & -2.677780 & 0.483020 \\
\hline $\mathrm{C}$ & -2.207402 & -2.697369 & 0.870644 \\
\hline C & -3.303656 & -1.215692 & 3.270353 \\
\hline $\mathrm{C}$ & -1.978694 & -1.225325 & 2.818324 \\
\hline $\mathrm{C}$ & -3.925969 & -0.000669 & 3.580236 \\
\hline $\mathrm{C}$ & -3.303659 & 1.214465 & 3.270779 \\
\hline C & -1.978697 & 1.224261 & 2.818757 \\
\hline $\mathrm{C}$ & -2.207413 & 2.696992 & 0.871596 \\
\hline $\mathrm{C}$ & -3.993446 & 2.330299 & -1.476061 \\
\hline $\mathrm{C}$ & -2.572756 & 2.269266 & -1.501663 \\
\hline C & -4.751037 & 1.247366 & -1.868198 \\
\hline $\mathrm{C}$ & -4.110346 & 0.000352 & -2.136313 \\
\hline $\mathrm{C}$ & -2.707682 & 0.000397 & -2.368425 \\
\hline $\mathrm{C}$ & -4.751031 & -1.246759 & -1.868636 \\
\hline C & -3.993435 & -2.329827 & -1.476882 \\
\hline $\mathrm{C}$ & -2.572746 & -2.268777 & -1.502459 \\
\hline $\mathrm{H}$ & 5.788077 & -3.271667 & -0.084921 \\
\hline $\mathrm{H}$ & 4.912256 & -2.285628 & 2.016599 \\
\hline $\mathrm{H}$ & 3.996195 & -0.000376 & 1.984451 \\
\hline $\mathrm{H}$ & 4.912244 & 2.284869 & 2.017400 \\
\hline $\mathrm{H}$ & 5.788059 & 3.271683 & -0.083759 \\
\hline $\mathrm{H}$ & 4.344192 & 3.312635 & -2.103396 \\
\hline $\mathrm{H}$ & 3.341076 & 1.162915 & -2.847601 \\
\hline $\mathrm{H}$ & 3.341084 & -1.161921 & -2.847988 \\
\hline $\mathrm{H}$ & 4.344209 & -3.311884 & -2.104572 \\
\hline
\end{tabular}




$\begin{array}{rrrr}\text { H } & -3.860140 & -2.143852 & 3.333179 \\ \mathrm{H} & -4.939247 & -0.000738 & 3.964805 \\ \mathrm{H} & -3.860146 & 2.142600 & 3.333934 \\ \mathrm{H} & -3.274928 & 2.560808 & 0.983579 \\ \mathrm{H} & -4.475701 & 3.210552 & -1.065475 \\ \mathrm{H} & -5.832922 & 1.283255 & -1.801692 \\ \mathrm{H} & -5.832915 & -1.282676 & -1.802144 \\ \mathrm{H} & -4.475685 & -3.210229 & -1.066611 \\ \mathrm{H} & -3.274918 & -2.561234 & 0.982676\end{array}$

$(7,0) 3$ cells

102

$\begin{array}{llll}\text { C } & 4.861414 & -2.245711 & 1.526813\end{array}$

$\begin{array}{llll}\text { C } & 6.239792 & -2.500378 & 1.515902\end{array}$

$\begin{array}{llll}\text { C } & 4.862806 & -0.000676 & 2.501524\end{array}$

$\begin{array}{llll}\text { C } & 4.861407 & 2.244866 & 1.527979\end{array}$

$\begin{array}{llll}\text { C } & 6.239784 & 2.499551 & 1.517207\end{array}$

$\begin{array}{llll}\text { C } & 6.847253 & 2.995712 & 0.359132\end{array}$

$\begin{array}{llll}\text { C } & 4.760326 & 2.810604 & -0.857095\end{array}$

$\begin{array}{llll}\text { C } & 6.135385 & 3.062731 & -0.846921\end{array}$

$\begin{array}{llll}\text { C } & 4.638011 & 1.206933 & -2.699746\end{array}$

$\begin{array}{llll}\text { C } & 4.638012 & -1.205527 & -2.700362\end{array}$

$\begin{array}{llll}\text { C } & 4.760329 & -2.810179 & -0.858564\end{array}$

$\begin{array}{llll}\text { C } & 6.135392 & -3.062301 & -0.848527\end{array}$

$\begin{array}{llll}\text { C } & 6.847262 & -2.995918 & 0.357561\end{array}$

$\begin{array}{llll}\text { C } & 4.096987 & -2.622879 & 0.388038\end{array}$

$\begin{array}{llll}\text { C } & 0.591339 & -2.206211 & 1.687422\end{array}$

$\begin{array}{llll}\text { C } & 2.004844 & -2.188874 & 1.626133\end{array}$

$\begin{array}{llll}\text { C } & 2.760726 & -1.220615 & 2.408466\end{array}$

$\begin{array}{llll}\text { C } & 4.178267 & -1.224664 & 2.364636\end{array}$

$\begin{array}{llll}\text { C } & 0.621284 & -0.000739 & 2.705851\end{array}$

$\begin{array}{llll}\text { C } & 2.056811 & -0.000725 & 2.664751\end{array}$

$\begin{array}{llll}\text { C } & 2.760721 & 1.219297 & 2.409087\end{array}$

$\begin{array}{llll}\text { C } & 4.178263 & 1.223377 & 2.365263\end{array}$

$\begin{array}{llll}\text { C } & 0.591332 & 2.205261 & 1.688561\end{array}$

$\begin{array}{llll}\text { C } & 2.004837 & 2.187962 & 1.627265\end{array}$

$\begin{array}{llll}\text { C } & 2.664134 & 2.642498 & 0.454960\end{array}$ 


$\begin{array}{lrrr}\text { C } & 4.096981 & 2.622633 & 0.389404 \\ \text { C } & 0.489894 & 2.761706 & -0.680662 \\ \text { C } & 1.901420 & 2.737965 & -0.748565 \\ \text { C } & 2.566379 & 2.210461 & -1.920880 \\ \text { C } & 3.993633 & 2.221820 & -1.993165 \\ \text { C } & 0.387966 & 1.218646 & -2.547826 \\ \text { C } & 1.815940 & 1.217917 & -2.627740 \\ \text { C } & 2.509233 & 0.000766 & -2.948077 \\ \text { C } & 3.935393 & 0.000778 & -2.995352 \\ \text { C } & 0.387968 & -1.217312 & -2.548437 \\ \text { C } & 1.815942 & -1.216547 & -2.628356 \\ \text { C } & 2.566380 & -2.209465 & -1.922024 \\ \text { C } & 3.993634 & -2.220790 & -1.994319 \\ \text { C } & 0.489897 & -2.761375 & -0.682099 \\ \text { C } & 1.901423 & -2.737601 & -0.749991 \\ \text { C } & 2.664140 & -2.642780 & 0.453585 \\ \text { C } & -0.165378 & -2.732707 & 0.592308 \\ \text { C } & -3.683018 & -2.257417 & 1.881404 \\ \text { C } & -2.262574 & -2.239264 & 1.812943 \\ \text { C } & -1.512751 & -1.222151 & 2.529272 \\ \text { C } & -0.098969 & -1.219768 & 2.490482 \\ \text { C } & -3.648590 & -0.000761 & 2.774318 \\ \text { C } & -2.214415 & -0.000751 & 2.736564 \\ \text { C } & -1.512756 & 1.220752 & 2.529881 \\ \text { C } & -0.098974 & 1.218393 & 2.491092 \\ \text { C } & -3.683025 & 2.256351 & 1.882552 \\ \text { C } & -2.262581 & 2.238236 & 1.814086 \\ \text { C } & -1.597952 & 2.755412 & 0.658262 \\ \text { C } & -0.165383 & 2.732352 & 0.593729 \\ \text { C } & -3.782828 & 2.844870 & -0.491191 \\ \text { C } & -2.364052 & 2.820108 & -0.553313 \\ \text { C } & -1.698947 & 2.232775 & -1.702776 \\ \text { C } & -0.284429 & 2.219799 & -1.775236 \\ \text { C } & -3.877026 & 1.215470 & -2.271101 \\ \text { C } & -2.449765 & 1.214686 & -2.361219 \\ \text { C } & -1.756337 & 0.000695 & -2.671701 \\ \text { C } & -0.338025 & 0.000722 & -2.771282 \\ \text { C } & -3.877024 & -1.214284 & -2.271711 \\ & -1.449762 & -1.213453 & -2.361832 \\ & & -2.231887 & -1.703923\end{array}$

S86 


$\begin{array}{lrrr}\text { C } & -0.284426 & -2.218872 & -1.776381 \\ \mathrm{C} & -3.782824 & -2.844631 & -0.492665 \\ \mathrm{C} & -2.364048 & -2.819832 & -0.554776 \\ \mathrm{C} & -1.597947 & -2.755801 & 0.656832 \\ \mathrm{C} & -4.406844 & -2.726684 & 0.774586 \\ \mathrm{C} & -5.730899 & -1.216911 & 3.028448 \\ \mathrm{C} & -4.367246 & -1.228565 & 2.711747 \\ \mathrm{C} & -6.379857 & -0.000895 & 3.273896 \\ \mathrm{C} & -5.730908 & 1.215245 & 3.029049 \\ \mathrm{C} & -4.367253 & 1.227069 & 2.712360 \\ \mathrm{C} & -4.406851 & 2.726225 & 0.775994 \\ \mathrm{C} & -5.969817 & 2.333771 & -1.712202 \\ \mathrm{C} & -4.552378 & 2.273934 & -1.610689 \\ \mathrm{C} & -6.689710 & 1.248716 & -2.166144 \\ \mathrm{C} & -6.028969 & 0.000615 & -2.374390 \\ \mathrm{C} & -4.612727 & 0.000645 & -2.483399 \\ \mathrm{C} & -6.689707 & -1.247594 & -2.166785 \\ \mathrm{C} & -5.969813 & -2.332880 & -1.713400 \\ \mathrm{C} & -4.552375 & -2.273092 & -1.611851 \\ \mathrm{H} & 7.905540 & -3.229474 & 0.366391 \\ \mathrm{H} & 6.839135 & -2.272517 & 2.389869 \\ \mathrm{H} & 5.930205 & -0.000628 & 2.324025 \\ \mathrm{H} & 6.839126 & 2.271234 & 2.391057 \\ \mathrm{H} & 7.905528 & 3.229274 & 0.368090 \\ \mathrm{H} & 6.658801 & 3.256282 & -1.776290 \\ \mathrm{H} & 5.719814 & 1.156936 & -2.664095 \\ \mathrm{H} & 5.719814 & -1.155542 & -2.664670 \\ \mathrm{H} & 6.658808 & -3.255352 & -1.778000 \\ \mathrm{H} & -6.292439 & -2.144079 & 3.038411 \\ \mathrm{H} & -7.426169 & -0.000968 & 3.556408 \\ \mathrm{H} & -6.292456 & 2.142404 & 3.039479 \\ \mathrm{H} & -5.481469 & 2.603527 & 0.790415 \\ \mathrm{H} & -6.487515 & 3.215304 & -1.350580 \\ \mathrm{H} & -7.773138 & 1.285905 & -2.196682 \\ & -7.773135 & -1.284769 & -2.197343 \\ \mathrm{H} & -5.481463 & -2.604004 & 0.789076\end{array}$

$(7,0) 4$ cells 


$\begin{array}{lrrr}\text { C } & -6.959547 & 2.242135 & 1.592255 \\ \text { C } & -8.336654 & 2.501857 & 1.610608 \\ \text { C } & -6.944302 & -0.000305 & 2.572065 \\ \text { C } & -6.959549 & -2.242518 & 1.591737 \\ \text { C } & -8.336656 & -2.502240 & 1.610026 \\ \text { C } & -8.967105 & -2.997900 & 0.464013 \\ \text { C } & -6.907899 & -2.801854 & -0.796994 \\ \text { C } & -8.281364 & -3.059708 & -0.757176 \\ \text { C } & -6.831202 & -1.205364 & -2.648940 \\ \text { C } & -6.831202 & 1.205984 & -2.648667 \\ \text { C } & -6.907898 & 2.802036 & -0.796343 \\ \text { C } & -8.281362 & 3.059883 & -0.756463 \\ \text { C } & -8.967102 & 2.997790 & 0.464712 \\ \text { C } & -6.217878 & 2.613297 & 0.435891 \\ \text { C } & -2.687487 & 2.187916 & 1.664443 \\ \text { C } & -4.102300 & 2.175759 & 1.631947 \\ \text { C } & -4.844128 & 1.218709 & 2.438210 \\ \text { C } & -6.262016 & 1.223458 & 2.420194 \\ \text { C } & -2.702562 & -0.000327 & 2.712191 \\ \text { C } & -4.135664 & -0.000323 & 2.692807 \\ \text { C } & -4.844130 & -1.219295 & 2.437934 \\ \text { C } & -6.262018 & -1.224036 & 2.419914 \\ \text { C } & -2.687489 & -2.188328 & 1.663941 \\ \text { C } & -4.102302 & -2.176160 & 1.631446 \\ \text { C } & -4.784520 & -2.626996 & 0.469741 \\ \text { C } & -6.217879 & -2.613411 & 0.435285 \\ \text { C } & -2.634526 & -2.730370 & -0.714586 \\ \text { C } & -4.047931 & -2.713990 & -0.751249 \\ \text { C } & -4.740052 & -2.199172 & -1.910999 \\ \text { C } & -6.168778 & -2.214652 & -1.951059 \\ \text { C } & -2.579968 & -1.214732 & -2.608653 \\ \text { C } & -4.007885 & -1.215358 & -2.650430 \\ \text { C } & -4.710503 & 0.000346 & -2.957845 \\ \text { C } & -6.136692 & 0.000346 & -2.966403 \\ \text { C } & -2.579968 & 1.215349 & -2.608383 \\ \text { C } & -4.007885 & 1.215982 & -2.650158 \\ \text { C } & -4.740052 & 2.199620 & -1.910493\end{array}$




$\begin{array}{rrrr}\text { C } & -6.168778 & 2.215107 & -1.950548 \\ \text { C } & -2.634526 & 2.730533 & -0.713953 \\ \text { C } & -4.047931 & 2.714159 & -0.750620 \\ \text { C } & -4.784518 & 2.626873 & 0.470349 \\ \text { C } & -1.953488 & 2.713880 & 0.549655 \\ \text { C } & 1.579660 & 2.210819 & 1.753030 \\ \text { C } & 0.161845 & 2.201057 & 1.723537 \\ \text { C } & -0.565248 & 1.216034 & 2.485865 \\ \text { C } & -1.983404 & 1.214652 & 2.465012 \\ \text { C } & 1.570837 & -0.000335 & 2.770262 \\ \text { C } & 0.146305 & -0.000333 & 2.756208 \\ \text { C } & -0.565250 & -1.216642 & 2.485595 \\ \text { C } & -1.983405 & -1.215253 & 2.464742 \\ \text { C } & 1.579658 & -2.211256 & 1.752526 \\ \text { C } & 0.161844 & -2.201486 & 1.723034 \\ \text { C } & -0.530626 & -2.729631 & 0.583199 \\ \text { C } & -1.953490 & -2.714022 & 0.549027 \\ \text { C } & 1.629602 & -2.768376 & -0.610789 \\ \text { C } & 0.212421 & -2.752589 & -0.644851 \\ \text { C } & -0.469916 & -2.201110 & -1.788485 \\ \text { C } & -1.887133 & -2.196559 & -1.827861 \\ \text { C } & 1.689798 & -1.218247 & -2.480343 \\ \text { C } & 0.268333 & -1.216440 & -2.527255 \\ \text { C } & -0.436867 & 0.000332 & -2.820843 \\ \text { C } & -1.858495 & 0.000337 & -2.864811 \\ \text { C } & 1.689799 & 1.218836 & -2.480073 \\ \text { C } & 0.268334 & 1.217040 & -2.526985 \\ \text { C } & -0.469916 & 2.201537 & -1.787982 \\ \text { C } & -1.887132 & 2.196994 & -1.827358 \\ \text { C } & 1.629603 & 2.768518 & -0.610149 \\ \text { C } & 0.212422 & 2.752738 & -0.644215 \\ \text { C } & -0.530625 & 2.729480 & 0.583830 \\ \text { C } & 2.314942 & 2.754556 & 0.649416 \\ \text { C } & 5.856946 & 2.259445 & 1.857649 \\ \text { C } & 4.435426 & 2.242898 & 1.819398 \\ \text { C } & 3.700795 & 1.222088 & 2.541623 \\ \text { C } & 2.285809 & 1.220310 & 2.529354 \\ \text { C } & 5.839858 & -0.000332 & 2.745861 \\ & 4.406043 & -0.000332 & 2.735571 \\ & 3.700794 & -1.222709 & 2.541356\end{array}$

S89 


\begin{tabular}{|c|c|c|c|}
\hline C & 2.285808 & -1.220929 & 2.529086 \\
\hline $\mathrm{C}$ & 5.856944 & -2.259909 & 1.857140 \\
\hline $\mathrm{C}$ & 4.435424 & -2.243352 & 1.818891 \\
\hline C & 3.745729 & -2.772729 & 0.681330 \\
\hline C & 2.314942 & -2.754722 & 0.648780 \\
\hline $\mathrm{C}$ & 5.905407 & -2.850422 & -0.517416 \\
\hline $\mathrm{C}$ & 4.485487 & -2.827798 & -0.548150 \\
\hline $\mathrm{C}$ & 3.793939 & -2.234694 & -1.677311 \\
\hline $\mathrm{C}$ & 2.377729 & -2.220337 & -1.715326 \\
\hline $\mathrm{C}$ & 5.958503 & -1.215146 & -2.293842 \\
\hline $\mathrm{C}$ & 4.530336 & -1.214463 & -2.350946 \\
\hline $\mathrm{C}$ & 3.830878 & 0.000311 & -2.643933 \\
\hline $\mathrm{C}$ & 2.412195 & 0.000320 & -2.715339 \\
\hline $\mathrm{C}$ & 5.958504 & 1.215689 & -2.293571 \\
\hline $\mathrm{C}$ & 4.530337 & 1.215020 & -2.350675 \\
\hline $\mathrm{C}$ & 3.793940 & 2.235094 & -1.676802 \\
\hline $\mathrm{C}$ & 2.377729 & 2.220747 & -1.714819 \\
\hline $\mathrm{C}$ & 5.905408 & 2.850546 & -0.516760 \\
\hline $\mathrm{C}$ & 4.485488 & 2.827930 & -0.547498 \\
\hline C & 3.745730 & 2.772557 & 0.681969 \\
\hline C & 6.556899 & 2.732070 & 0.736863 \\
\hline $\mathrm{C}$ & 7.927202 & 1.215754 & 2.959116 \\
\hline $\mathrm{C}$ & 6.557566 & 1.227815 & 2.669869 \\
\hline $\mathrm{C}$ & 8.580854 & -0.000384 & 3.190910 \\
\hline $\mathrm{C}$ & 7.927199 & -1.216470 & 2.958851 \\
\hline $\mathrm{C}$ & 6.557564 & -1.228465 & 2.669600 \\
\hline $\mathrm{C}$ & 6.556897 & -2.732256 & 0.736236 \\
\hline $\mathrm{C}$ & 8.064089 & -2.334229 & -1.785422 \\
\hline $\mathrm{C}$ & 6.649455 & -2.275042 & -1.651084 \\
\hline $\mathrm{C}$ & 8.772776 & -1.247898 & -2.253851 \\
\hline $\mathrm{C}$ & 8.107109 & 0.000287 & -2.445045 \\
\hline $\mathrm{C}$ & 6.688870 & 0.000296 & -2.521137 \\
\hline C & 8.772777 & 1.248428 & -2.253568 \\
\hline $\mathrm{C}$ & 8.064090 & 2.334653 & -1.784891 \\
\hline $\mathrm{C}$ & 6.649456 & 2.275437 & -1.650569 \\
\hline $\mathrm{H}$ & -10.023874 & 3.235985 & 0.496176 \\
\hline $\mathrm{H}$ & -8.917727 & 2.278523 & 2.497947 \\
\hline $\mathrm{H}$ & -8.015116 & -0.000286 & 2.416384 \\
\hline $\mathrm{H}$ & -8.917730 & -2.279111 & 2.497417 \\
\hline $\mathrm{H}$ & -10.023878 & -3.236099 & $0.49542 C$ \\
\hline
\end{tabular}




$\begin{array}{rrrr}\mathrm{H} & -8.823777 & -3.255176 & -1.675142 \\ \mathrm{H} & -7.912011 & -1.156985 & -2.589236 \\ \mathrm{H} & -7.912011 & 1.157594 & -2.588980 \\ \mathrm{H} & -8.823775 & 3.255569 & -1.674383 \\ \mathrm{H} & 8.488712 & 2.142964 & 2.959307 \\ \mathrm{H} & 9.632430 & -0.000414 & 3.452977 \\ \mathrm{H} & 8.488707 & -2.143681 & 2.958840 \\ \mathrm{H} & 7.631736 & -2.610927 & 0.727614 \\ \mathrm{H} & 8.590344 & -3.216380 & -1.438006 \\ \mathrm{H} & 9.855165 & -1.284833 & -2.309998 \\ \mathrm{H} & 9.855166 & 1.285375 & -2.309706 \\ \mathrm{H} & 8.590345 & 3.216723 & -1.437272 \\ \mathrm{H} & 7.631737 & 2.610741 & 0.728211\end{array}$

$(7,0) 5$ cells

158

$\begin{array}{lrrr}\text { C } & 9.078227 & -2.242908 & 1.627277 \\ \text { C } & 10.454607 & -2.504748 & 1.657766 \\ \text { C } & 9.055788 & -0.000333 & 2.607160 \\ \text { C } & 9.078227 & 2.242480 & 1.627820 \\ \text { C } & 10.454606 & 2.504316 & 1.658376 \\ \text { C } & 11.094363 & 3.001394 & 0.518108 \\ \text { C } & 9.046874 & 2.802087 & -0.761097 \\ \text { C } & 10.419404 & 3.062459 & -0.709060 \\ \text { C } & 8.989019 & 1.206102 & -2.613855 \\ \text { C } & 8.989018 & -1.205474 & -2.614143 \\ \text { C } & 9.046872 & -2.801920 & -0.761780 \\ \text { C } & 10.419403 & -3.062305 & -0.709809 \\ \text { C } & 11.094363 & -3.001542 & 0.517374 \\ \text { C } & 8.346019 & -2.612183 & 0.464153 \\ \text { C } & 4.805632 & -2.183955 & 1.663032 \\ \text { C } & 6.220767 & -2.173755 & 1.642438 \\ \text { C } & 6.956934 & -1.219445 & 2.457100 \\ \text { C } & 8.374734 & -1.224234 & 2.449823 \\ \text { C } & 4.815145 & -0.000351 & 2.719548 \\ \text { C } & 6.247244 & -0.000348 & 2.708815 \\ \text { C } & 6.956933 & 1.218809 & 2.457389\end{array}$

S91 


$\begin{array}{lrrr}\text { C } & 8.374733 & 1.223604 & 2.450116 \\ \text { C } & 4.805631 & 2.183508 & 1.663557 \\ \text { C } & 6.220766 & 2.173316 & 1.642961 \\ \text { C } & 6.912370 & 2.623377 & 0.486446 \\ \text { C } & 8.346019 & 2.612041 & 0.464788 \\ \text { C } & 4.771968 & 2.721277 & -0.716925 \\ \text { C } & 6.186156 & 2.708624 & -0.740968 \\ \text { C } & 6.890018 & 2.197634 & -1.895110 \\ \text { C } & 8.319145 & 2.214530 & -1.921848 \\ \text { C } & 4.738706 & 1.214826 & -2.619386 \\ \text { C } & 6.166382 & 1.215794 & -2.645402 \\ \text { C } & 6.872441 & 0.000355 & -2.947021 \\ \text { C } & 8.298250 & 0.000353 & -2.939736 \\ \text { C } & 4.738705 & -1.214185 & -2.619668 \\ \text { C } & 6.166381 & -1.215151 & -2.645687 \\ \text { C } & 6.890015 & -2.197179 & -1.895640 \\ \text { C } & 8.319142 & -2.214073 & -1.922385 \\ \text { C } & 4.771965 & -2.721116 & -0.717586 \\ \text { C } & 6.186154 & -2.708460 & -0.741626 \\ \text { C } & 6.912370 & -2.623524 & 0.485809 \\ \text { C } & 4.079077 & -2.704923 & 0.540181 \\ \text { C } & 0.537748 & -2.193568 & 1.718374 \\ \text { C } & 1.956295 & -2.188877 & 1.699402 \\ \text { C } & 2.679369 & -1.215447 & 2.476544 \\ \text { C } & 4.097414 & -1.214686 & 2.463530 \\ \text { C } & 0.544818 & -0.000358 & 2.767073 \\ \text { C } & 1.966292 & -0.000357 & 2.756353 \\ \text { C } & 2.679368 & 1.214798 & 2.476825 \\ \text { C } & 4.097413 & 1.214041 & 2.463813 \\ \text { C } & 0.537749 & 2.193105 & 1.718900 \\ \text { C } & 1.956295 & 2.188419 & 1.699927 \\ \text { C } & 2.656498 & 2.714445 & 0.562420 \\ \text { C } & 4.079078 & 2.704763 & 0.540838 \\ \text { C } & 0.506009 & 2.737556 & -0.651729 \\ \text { C } & 1.924302 & 2.729381 & -0.672849 \\ \text { C } & 2.618680 & 2.190971 & -1.813061 \\ \text { C } & 4.036613 & 2.190292 & -1.838685 \\ & 0.469390 & 1.216119 & -2.547907 \\ \text { C.889729 } & 1.215690 & -2.575096 \\ \text { C. } & & 0.000351 & -2.865659\end{array}$

S92 


$\begin{array}{lrrr}\text { C } & 4.020671 & 0.000352 & -2.888932 \\ \text { C } & 0.469389 & -1.215487 & -2.548188 \\ \text { C } & 1.889728 & -1.215054 & -2.575377 \\ \text { C } & 2.618678 & -2.190523 & -1.813586 \\ \text { C } & 4.036611 & -2.189841 & -1.839211 \\ \text { C } & 0.506007 & -2.737405 & -0.652395 \\ \text { C } & 1.924300 & -2.729226 & -0.673511 \\ \text { C } & 2.656496 & -2.714610 & 0.561760 \\ \text { C } & -0.189015 & -2.736899 & 0.604685 \\ \text { C } & -3.729829 & -2.214024 & 1.772744 \\ \text { C } & -2.311807 & -2.206129 & 1.755320 \\ \text { C } & -1.590849 & -1.217463 & 2.514141 \\ \text { C } & -0.171675 & -1.216685 & 2.501847 \\ \text { C } & -3.727510 & -0.000358 & 2.786758 \\ \text { C } & -2.303895 & -0.000358 & 2.781630 \\ \text { C } & -1.590848 & 1.216806 & 2.514422 \\ \text { C } & -0.171675 & 1.216030 & 2.502128 \\ \text { C } & -3.729827 & 2.213553 & 1.773274 \\ \text { C } & -2.311805 & 2.205661 & 1.755848 \\ \text { C } & -1.609229 & 2.747392 & 0.626153 \\ \text { C } & -0.189013 & 2.736726 & 0.605350 \\ \text { C } & -3.759055 & 2.773929 & -0.588856 \\ \text { C } & -2.341468 & 2.760565 & -0.609796 \\ \text { C } & -1.647438 & 2.203666 & -1.741994 \\ \text { C } & -0.229302 & 2.197927 & -1.765160 \\ \text { C } & -3.800229 & 1.219377 & -2.455481 \\ \text { C } & -2.379068 & 1.217694 & -2.487815 \\ \text { C } & -1.671785 & 0.000342 & -2.773471 \\ \text { C } & -0.251245 & 0.000346 & -2.806951 \\ \text { C } & -3.800230 & -1.218765 & -2.455763 \\ \text { C } & -2.379068 & -1.217075 & -2.488097 \\ \text { C } & -1.647439 & -2.203231 & -1.742522 \\ \text { C } & -0.229304 & -2.197488 & -1.765687 \\ \text { C } & -3.759057 & -2.773790 & -0.589530 \\ \text { C } & -2.341470 & -2.760422 & -0.610467 \\ \text { C } & -1.609231 & -2.747568 & 0.625485 \\ \text { C } & -4.455881 & -2.760901 & 0.664093 \\ \text { C } & -8.007069 & -2.260332 & 1.840263 \\ \text { C } & -6.585307 & -2.244375 & 1.814441 \\ & -5.856509 & -1.222870 & 2.541146\end{array}$




$\begin{array}{lrrr}\text { C } & -4.441305 & -1.221193 & 2.539835 \\ \text { C } & -7.997140 & -0.000347 & 2.727837 \\ \text { C } & -6.563386 & -0.000349 & 2.729162 \\ \text { C } & -5.856509 & 1.222212 & 2.541426 \\ \text { C } & -4.441303 & 1.220534 & 2.540115 \\ \text { C } & -8.007067 & 2.259849 & 1.840798 \\ \text { C } & -6.585305 & 2.243895 & 1.814973 \\ \text { C } & -5.886163 & 2.776530 & 0.684415 \\ \text { C } & -4.455878 & 2.760719 & 0.664763 \\ \text { C } & -8.034778 & 2.851821 & -0.533948 \\ \text { C } & -6.614797 & 2.830336 & -0.551984 \\ \text { C } & -5.912618 & 2.236309 & -1.673905 \\ \text { C } & -4.496139 & 2.222378 & -1.698328 \\ \text { C } & -8.070838 & 1.215691 & -2.310045 \\ \text { C } & -6.642259 & 1.215071 & -2.353413 \\ \text { C } & -5.939632 & 0.000326 & -2.639335 \\ \text { C } & -4.520351 & 0.000333 & -2.696798 \\ \text { C } & -8.070838 & -1.215118 & -2.310331 \\ \text { C } & -6.642260 & -1.214486 & -2.353698 \\ \text { C } & -5.912619 & -2.235891 & -1.674441 \\ \text { C } & -4.496140 & -2.221953 & -1.698861 \\ \text { C } & -8.034779 & -2.851687 & -0.534637 \\ \text { C } & -6.614799 & -2.830199 & -0.552670 \\ \text { C } & -5.886165 & -2.776713 & 0.683743 \\ \text { C } & -8.697255 & -2.732738 & 0.713292 \\ \text { C } & -10.086103 & -1.216517 & 2.924672 \\ \text { C } & -8.714305 & -1.228509 & 2.646233 \\ \text { C } & -10.741534 & -0.000397 & 3.151497 \\ \text { C } & -10.086105 & 1.215774 & 2.924949 \\ \text { C } & -8.714306 & 1.227833 & 2.646515 \\ \text { C } & -8.697254 & 2.732551 & 0.713951 \\ \text { C } & -10.181352 & 2.334879 & -1.821957 \\ \text { C } & -8.768102 & 2.275670 & -1.674020 \\ \text { C } & -10.885367 & 1.248424 & -2.297062 \\ \text { C } & -10.217807 & 0.000306 & -2.481776 \\ \text { C } & -8.799001 & 0.000314 & -2.544344 \\ \text { C } & -10.885368 & -1.247855 & -2.297360 \\ \text { C } & -10.181353 & -2.334424 & -1.822515 \\ & -8.768103 & -2.275250 & -1.674562 \\ & 12.150330 & -3.241769 & 0.558231\end{array}$




$\begin{array}{lrrr}\text { H } & 11.028144 & -2.282653 & 2.550288 \\ \mathrm{H} & 10.127875 & -0.000315 & 2.460319 \\ \mathrm{H} & 11.028143 & 2.282004 & 2.550844 \\ \mathrm{H} & 12.150330 & 3.241613 & 0.559025 \\ \mathrm{H} & 10.969492 & 3.259493 & -1.622097 \\ \mathrm{H} & 10.069247 & 1.158539 & -2.543837 \\ \mathrm{H} & 10.069245 & -1.157928 & -2.544106 \\ \mathrm{H} & 10.969491 & -3.259112 & -1.622894 \\ \mathrm{H} & -10.647533 & -2.143750 & 2.920611 \\ \mathrm{H} & -11.795044 & -0.000426 & 3.405582 \\ \mathrm{H} & -10.647537 & 2.143007 & 2.921102 \\ \mathrm{H} & -9.772021 & 2.611460 & 0.695932 \\ \mathrm{H} & -10.710894 & 3.217156 & -1.479939 \\ \mathrm{H} & -11.967132 & 1.285343 & -2.363868 \\ \mathrm{H} & -11.967132 & -1.284758 & -2.364174 \\ \mathrm{H} & -10.710894 & -3.216784 & -1.480710 \\ \mathrm{H} & -9.772022 & -2.611642 & 0.695303\end{array}$

$(7,0) 6$ cells

186

$\begin{array}{lrrr}\text { C } & -11.204099 & 2.242704 & 1.651364 \\ \text { C } & -12.580237 & 2.504849 & 1.688279 \\ \text { C } & -11.177350 & -0.000377 & 2.630117 \\ \text { C } & -11.204101 & -2.243182 & 1.650735 \\ \text { C } & -12.580240 & -2.505332 & 1.687574 \\ \text { C } & -13.225064 & -3.002730 & 0.550266 \\ \text { C } & -11.183595 & -2.802370 & -0.738296 \\ \text { C } & -12.555768 & -3.063190 & -0.680049 \\ \text { C } & -11.134736 & -1.205450 & -2.590296 \\ \text { C } & -11.134737 & 1.206191 & -2.589965 \\ \text { C } & -11.183595 & 2.802578 & -0.737507 \\ \text { C } & -12.555766 & 3.063384 & -0.679184 \\ \text { C } & -13.225061 & 3.002575 & 0.551114 \\ \text { C } & -10.477091 & 2.612230 & 0.485050 \\ \text { C } & -6.931356 & 2.182906 & 1.667577 \\ \text { C } & -8.346580 & 2.173118 & 1.653447 \\ \text { C } & -9.079280 & 1.218883 & 2.471253\end{array}$




$\begin{array}{lrrr}\text { C } & -10.497021 & 1.223645 & 2.470143 \\ \text { C } & -6.937007 & -0.000397 & 2.724875 \\ \text { C } & -8.368764 & -0.000394 & 2.719877 \\ \text { C } & -9.079282 & -1.219600 & 2.470918 \\ \text { C } & -10.497022 & -1.224357 & 2.469804 \\ \text { C } & -6.931359 & -2.183405 & 1.666970 \\ \text { C } & -8.346583 & -2.173608 & 1.652842 \\ \text { C } & -9.043383 & -2.623365 & 0.499330 \\ \text { C } & -10.477093 & -2.612378 & 0.484317 \\ \text { C } & -6.908170 & -2.719661 & -0.713827 \\ \text { C } & -8.322618 & -2.707881 & -0.731363 \\ \text { C } & -9.032173 & -2.197000 & -1.881985 \\ \text { C } & -10.461415 & -2.214188 & -1.901997 \\ \text { C } & -6.884951 & -1.214121 & -2.617146 \\ \text { C } & -8.312525 & -1.215133 & -2.635950 \\ \text { C } & -9.020059 & 0.000419 & -2.933861 \\ \text { C } & -10.445649 & 0.000416 & -2.919356 \\ \text { C } & -6.884952 & 1.214881 & -2.616819 \\ \text { C } & -8.312526 & 1.215893 & -2.635621 \\ \text { C } & -9.032175 & 2.197542 & -1.881372 \\ \text { C } & -10.461416 & 2.214732 & -1.901377 \\ \text { C } & -6.908170 & 2.719865 & -0.713063 \\ \text { C } & -8.322618 & 2.708086 & -0.730602 \\ \text { C } & -9.043381 & 2.623211 & 0.500066 \\ \text { C } & -6.209148 & 2.703175 & 0.541395 \\ \text { C } & -2.662982 & 2.188483 & 1.704878 \\ \text { C } & -4.081780 & 2.185731 & 1.691659 \\ \text { C } & -4.802560 & 1.214730 & 2.473654 \\ \text { C } & -6.220376 & 1.214051 & 2.465694 \\ \text { C } & -2.668927 & -0.000406 & 2.761826 \\ \text { C } & -4.089230 & -0.000404 & 2.753632 \\ \text { C } & -4.802562 & -1.215463 & 2.473329 \\ \text { C } & -6.220377 & -1.214779 & 2.465368 \\ \text { C } & -2.662982 & -2.189000 & 1.704272 \\ \text { C } & -4.081781 & -2.186242 & 1.691054 \\ \text { C } & -4.786359 & -2.711028 & 0.555611 \\ \text { C } & -6.209149 & -2.703342 & 0.540636 \\ \text { C } & -2.640387 & -2.727978 & -0.668244 \\ \text { C } & -4.059354 & -2.723471 & -0.682851 \\ & -4.760338 & -2.188151 & -1.820242\end{array}$

S96 


$\begin{array}{lrrr}\text { C } & -6.178540 & -2.188584 & -1.838988 \\ \text { C } & -2.616676 & -1.214966 & -2.571880 \\ \text { C } & -4.036511 & -1.214839 & -2.589584 \\ \text { C } & -4.748231 & 0.000416 & -2.877100 \\ \text { C } & -6.168725 & 0.000417 & -2.891340 \\ \text { C } & -2.616677 & 1.215721 & -2.571555 \\ \text { C } & -4.036512 & 1.215597 & -2.589259 \\ \text { C } & -4.760339 & 2.188689 & -1.819636 \\ \text { C } & -6.178541 & 2.189124 & -1.838381 \\ \text { C } & -2.640388 & 2.728173 & -0.667477 \\ \text { C } & -4.059354 & 2.723669 & -0.682086 \\ \text { C } & -4.786358 & 2.710856 & 0.556372 \\ \text { C } & -1.938844 & 2.727454 & 0.586598 \\ \text { C } & 1.604958 & 2.195810 & 1.744593 \\ \text { C } & 0.186302 & 2.192955 & 1.731503 \\ \text { C } & -0.533912 & 1.215475 & 2.501581 \\ \text { C } & -1.952898 & 1.215335 & 2.491084 \\ \text { C } & 1.600058 & -0.000410 & 2.789127 \\ \text { C } & 0.179525 & -0.000409 & 2.781181 \\ \text { C } & -0.533913 & -1.216220 & 2.501256 \\ \text { C } & -1.952899 & -1.216077 & 2.490759 \\ \text { C } & 1.604958 & -2.196338 & 1.743984 \\ \text { C } & 0.186302 & -2.193480 & 1.730895 \\ \text { C } & -0.519044 & -2.732508 & 0.600245 \\ \text { C } & -1.938844 & -2.727635 & 0.585831 \\ \text { C } & 1.626173 & -2.742719 & -0.625422 \\ \text { C } & 0.207654 & -2.737013 & -0.639587 \\ \text { C } & -0.493473 & -2.192539 & -1.771022 \\ \text { C } & -1.912152 & -2.190675 & -1.786627 \\ \text { C } & 1.651750 & -1.215958 & -2.517678 \\ \text { C } & 0.231964 & -1.215630 & -2.536432 \\ \text { C } & -0.478785 & 0.000411 & -2.821563 \\ \text { C } & -1.898412 & 0.000413 & -2.840516 \\ \text { C } & 1.651750 & 1.216700 & -2.517353 \\ \text { C } & 0.231965 & 1.216377 & -2.536107 \\ \text { C } & -0.493474 & 2.193067 & -1.770414 \\ \text { C } & -1.912152 & 2.191207 & -1.786020 \\ \text { C } & 1.626172 & 2.742903 & -0.624650 \\ & 0.207654 & 2.737201 & -0.638817 \\ & -0.519045 & 2.732323 & 0.601013\end{array}$




\begin{tabular}{|c|c|c|c|}
\hline $\mathrm{C}$ & 2.327244 & 2.743003 & 0.629428 \\
\hline C & 5.871941 & 2.213956 & 1.780372 \\
\hline $\mathrm{C}$ & 4.453893 & 2.206567 & 1.769235 \\
\hline C & 3.735818 & 1.216837 & 2.528876 \\
\hline $\mathrm{C}$ & 2.316373 & 1.216174 & 2.521430 \\
\hline $\mathrm{C}$ & 5.873514 & -0.000408 & 2.793023 \\
\hline $\mathrm{C}$ & 4.449978 & -0.000409 & 2.793213 \\
\hline $\mathrm{C}$ & 3.735818 & -1.217587 & 2.528551 \\
\hline $\mathrm{C}$ & 2.316373 & -1.216924 & 2.521105 \\
\hline $\mathrm{C}$ & 5.871941 & -2.214489 & 1.779759 \\
\hline $\mathrm{C}$ & 4.453894 & -2.207099 & 1.768623 \\
\hline C & 3.746766 & -2.751711 & 0.642821 \\
\hline $\mathrm{C}$ & 2.327244 & -2.743195 & 0.628656 \\
\hline $\mathrm{C}$ & 5.890626 & -2.774983 & -0.582471 \\
\hline $\mathrm{C}$ & 4.473172 & -2.762614 & -0.596839 \\
\hline C & 3.773439 & -2.204187 & -1.724497 \\
\hline $\mathrm{C}$ & 2.355190 & -2.198942 & -1.740221 \\
\hline $\mathrm{C}$ & 5.922215 & -1.218702 & -2.447918 \\
\hline $\mathrm{C}$ & 4.500931 & -1.217046 & -2.472856 \\
\hline $\mathrm{C}$ & 3.791763 & 0.000401 & -2.753866 \\
\hline $\mathrm{C}$ & 2.371075 & 0.000405 & -2.779375 \\
\hline $\mathrm{C}$ & 5.922215 & 1.219421 & -2.447591 \\
\hline $\mathrm{C}$ & 4.500932 & 1.217773 & -2.472529 \\
\hline $\mathrm{C}$ & 3.773439 & 2.204701 & -1.723886 \\
\hline C & 2.355190 & 2.199460 & -1.739611 \\
\hline $\mathrm{C}$ & 5.890625 & 2.775155 & -0.581691 \\
\hline $\mathrm{C}$ & 4.473171 & 2.762791 & -0.596061 \\
\hline $\mathrm{C}$ & 3.746765 & 2.751516 & 0.643595 \\
\hline C & 6.593123 & 2.761727 & 0.668851 \\
\hline $\mathrm{C}$ & 10.149164 & 2.259673 & 1.828481 \\
\hline $\mathrm{C}$ & 8.727336 & 2.243849 & 1.809141 \\
\hline $\mathrm{C}$ & 8.001726 & 1.222166 & 2.538606 \\
\hline $\mathrm{C}$ & 6.586496 & 1.220458 & 2.543367 \\
\hline $\mathrm{C}$ & 10.143188 & -0.000394 & 2.715388 \\
\hline $\mathrm{C}$ & 8.709508 & -0.000397 & 2.723129 \\
\hline $\mathrm{C}$ & 8.001726 & -1.222913 & 2.538282 \\
\hline C & 6.586496 & -1.221209 & 2.543041 \\
\hline C & 10.149164 & -2.260218 & 1.827862 \\
\hline $\mathrm{C}$ & 8.727336 & -2.244389 & 1.808525 \\
\hline $\mathrm{C}$ & 8.023235 & -2.777204 & 0.68110 \\
\hline
\end{tabular}




$\begin{array}{rrrr}\text { C } & 6.593123 & -2.761927 & 0.668076 \\ \mathrm{C} & 10.166019 & -2.851507 & -0.547268 \\ \mathrm{C} & 8.746056 & -2.830266 & -0.558768 \\ \mathrm{C} & 8.038635 & -2.235884 & -1.677117 \\ \mathrm{C} & 6.622085 & -2.222045 & -1.694795 \\ \mathrm{C} & 10.193685 & -1.215005 & -2.323168 \\ \mathrm{C} & 8.764956 & -1.214364 & -2.359694 \\ \mathrm{C} & 8.060791 & 0.000383 & -2.641970 \\ \mathrm{C} & 6.641230 & 0.000391 & -2.692368 \\ \mathrm{C} & 10.193685 & 1.215682 & -2.322838 \\ \mathrm{C} & 8.764957 & 1.215053 & -2.359365 \\ \mathrm{C} & 8.038635 & 2.236381 & -1.676499 \\ \mathrm{C} & 6.622086 & 2.222548 & -1.694179 \\ \mathrm{C} & 10.166018 & 2.851675 & -0.546472 \\ \mathrm{C} & 8.746056 & 2.830438 & -0.557976 \\ \mathrm{C} & 8.023235 & 2.777003 & 0.681881 \\ \mathrm{C} & 10.834201 & 2.732345 & 0.698430 \\ \mathrm{C} & 12.233005 & 1.215722 & 2.903347 \\ \mathrm{C} & 10.860017 & 1.227765 & 2.630965 \\ \mathrm{C} & 12.889390 & -0.000451 & 3.127245 \\ \mathrm{C} & 12.233002 & -1.216564 & 2.903025 \\ \mathrm{C} & 10.860016 & -1.228532 & 2.630638 \\ \mathrm{C} & 10.834201 & -2.732549 & 0.697669 \\ \mathrm{C} & 12.306548 & -2.334183 & -1.844941 \\ \mathrm{C} & 10.894002 & -2.274984 & -1.690422 \\ \mathrm{C} & 13.008281 & -1.247698 & -2.323432 \\ \mathrm{C} & 12.339750 & 0.000362 & -2.504845 \\ \mathrm{C} & 10.920742 & 0.000370 & -2.560720 \\ \mathrm{C} & 13.008281 & 1.248371 & -2.323089 \\ \mathrm{C} & 12.306548 & 2.334725 & -1.844298 \\ \mathrm{C} & 10.894002 & 2.275484 & -1.689797 \\ \mathrm{H} & -14.280688 & 3.243307 & 0.596987 \\ \mathrm{H} & -13.149762 & 2.282665 & 2.583331 \\ \mathrm{H} & -12.250119 & -0.000356 & 2.488451 \\ \mathrm{H} & -13.149766 & -2.283398 & 2.582688 \\ & -14.280692 & -3.243471 & 0.596069 \\ \mathrm{H} & -13.109979 & -3.260410 & -1.590535 \\ \mathrm{H} & -12.214633 & -1.158203 & -2.515377 \\ \mathrm{H} & 1.158926 & -2.515067 \\ & & 3.260864 & -1.589613\end{array}$




$\begin{array}{rrrr}\mathrm{H} & 12.794414 & 2.142943 & 2.897261 \\ \mathrm{H} & 13.943922 & -0.000484 & 3.376970 \\ \mathrm{H} & 12.794412 & -2.143783 & 2.896694 \\ \mathrm{H} & 11.908909 & -2.611876 & 0.674915 \\ \mathrm{H} & 12.837665 & -3.216544 & -1.505629 \\ \mathrm{H} & 14.089692 & -1.284633 & -2.395483 \\ \mathrm{H} & 14.089692 & 1.285325 & -2.395132 \\ \mathrm{H} & 12.837665 & 3.216991 & -1.504740 \\ \mathrm{H} & 11.908909 & 2.611677 & 0.675641\end{array}$

$(6,4) 2$ cells

86

$\begin{array}{rrrr}\text { C } & 3.255890 & -3.279949 & 2.781244 \\ \text { C } & 2.433957 & -3.006558 & 1.688509 \\ \text { C } & 3.013016 & -2.476495 & 0.498765 \\ \text { C } & 4.337533 & -1.955365 & 0.526940 \\ \text { C } & 5.152482 & -2.296789 & 1.626898 \\ \text { C } & 4.627227 & -2.994253 & 2.709920 \\ \text { C } & 2.208389 & -2.341777 & -0.685997 \\ \text { C } & 0.932201 & -2.961667 & -0.737673 \\ \text { C } & 0.248428 & -3.147003 & 0.520427 \\ \text { C } & 0.957028 & -2.962589 & 1.737109 \\ \text { C } & 2.550751 & -1.370929 & -1.656325 \\ \text { C } & 1.625964 & -1.059521 & -2.697820 \\ \text { C } & 0.553410 & -1.957489 & -2.913262 \\ \text { C } & 0.180771 & -2.893703 & -1.941301 \\ \text { C } & 3.638390 & -0.476806 & -1.336151 \\ \text { C } & 3.482702 & 0.892440 & -1.697625 \\ \text { C } & 2.297138 & 1.301158 & -2.389180 \\ \text { C } & 1.526051 & 0.346075 & -3.117076 \\ \text { C } & 4.295282 & 1.878348 & -1.075450 \\ \text { C } & 5.482741 & 1.436728 & -0.421173 \\ \text { C } & 5.639357 & 0.109385 & -0.089483 \\ \text { C } & 4.626247 & -0.846236 & -0.390098 \\ \text { C } & 0.438638 & 0.851897 & -3.864801 \\ \text { C } & -0.084867 & 2.106945 & -3.595324 \\ \text { C } & 0.443067 & 2.913970 & -2.559279\end{array}$




$\begin{array}{lrrr}\text { C } & 1.735393 & 2.578904 & -2.081080 \\ \text { C } & -1.160861 & -2.973122 & 0.510314 \\ \text { C } & -1.896506 & -3.241495 & -0.695764 \\ \text { C } & -1.197809 & -3.428635 & -1.923248 \\ \text { C } & -1.905637 & -3.845132 & -3.050235 \\ \text { C } & -3.293426 & -4.033640 & -2.970241 \\ \text { C } & -3.997946 & -3.655611 & -1.831224 \\ \text { C } & -3.317750 & -3.177877 & -0.692042 \\ \text { C } & -1.781481 & -2.262223 & 1.563823 \\ \text { C } & -3.090221 & -1.710831 & 1.295976 \\ \text { C } & -3.925063 & -2.294712 & 0.313061 \\ \text { C } & -0.991854 & -1.784772 & 2.650102 \\ \text { C } & 0.314763 & -2.307988 & 2.795255 \\ \text { C } & -3.336457 & -0.374876 & 1.738314 \\ \text { C } & -4.382322 & 0.371163 & 1.135335 \\ \text { C } & -5.398410 & -0.365985 & 0.467815 \\ \text { C } & -5.178480 & -1.669051 & 0.074294 \\ \text { C } & -2.321227 & 0.289467 & 2.515449 \\ \text { C } & -1.327581 & -0.463086 & 3.197315 \\ \text { C } & -2.130525 & 1.692796 & 2.326795 \\ \text { C } & -2.893372 & 2.332677 & 1.282454 \\ \text { C } & -4.117862 & 1.776550 & 0.836648 \\ \text { C } & -0.981209 & 2.329235 & 2.862516 \\ \text { C } & -0.274053 & 1.625049 & 3.876434 \\ \text { C } & -0.437296 & 0.263850 & 4.032391 \\ \text { C } & -2.209458 & 3.279577 & 0.466122 \\ \text { C } & -0.851939 & 3.611643 & 0.765425 \\ \text { C } & -0.337192 & 3.379723 & 2.074571 \\ \text { C } & -2.732307 & 3.609945 & -0.814786 \\ \text { C } & -4.107695 & 3.317329 & -1.055103 \\ \text { C } & -4.781391 & 2.431972 & -0.244579 \\ \text { C } & 0.973531 & 3.843577 & 2.332667 \\ \text { C } & 1.834773 & 4.138714 & 1.289089 \\ \text { C } & 1.438939 & 3.962707 & -0.059654 \\ \text { C } & 0.049607 & 3.860308 & -0.315508 \\ \text { C } & 3.705720 & 3.142394 & -0.768730 \\ \text { C } & 2.368776 & 3.377093 & -1.046227 \\ \text { C } & -0.444313 & 3.690066 & -1.670607 \\ \text { C } & -1.809606 & 3.814339 & -1.884135 \\ \text { H } & -0.097514 & 0.204046 & -4.547655\end{array}$

S101 


$\begin{array}{rrrr}\text { H } & -0.150686 & -1.761189 & -3.711369 \\ \mathrm{H} & -1.383280 & -4.014034 & -3.984606 \\ \mathrm{H} & -3.833110 & -4.406099 & -3.833135 \\ \mathrm{H} & -5.080524 & -3.683927 & -1.842859 \\ \mathrm{H} & -1.017107 & 2.387307 & -4.070114 \\ \mathrm{H} & -2.208723 & 3.787496 & -2.892158 \\ \mathrm{H} & -5.910079 & -2.154890 & -0.559443 \\ \mathrm{H} & -6.298390 & 0.137534 & 0.136616 \\ \mathrm{H} & -5.777160 & 2.116018 & -0.529156 \\ \mathrm{H} & -4.575924 & 3.683882 & -1.962243 \\ \mathrm{H} & 2.831481 & -3.705184 & 3.683193 \\ \mathrm{H} & 0.930220 & -1.974075 & 3.620232 \\ \mathrm{H} & 6.475087 & -0.179307 & 0.535557 \\ \mathrm{H} & 6.186434 & -1.975840 & 1.654474 \\ \mathrm{H} & 4.237245 & 3.776328 & -0.067596 \\ \mathrm{H} & 6.189126 & 2.173558 & -0.054356 \\ \mathrm{H} & 2.875098 & 4.331386 & 1.520137 \\ \mathrm{H} & 1.367351 & 3.821574 & 3.341651 \\ \mathrm{H} & 0.517013 & 2.121625 & 4.424821 \\ \mathrm{H} & 0.226991 & -0.268287 & 4.702784 \\ \mathrm{H} & 5.271866 & -3.254554 & 3.541350\end{array}$

$(6,4) 3$ cells

118

$\begin{array}{llll}\text { C } & 6.397856 & -3.596308 & 0.819691 \\ \text { C } & 5.303180 & -3.204687 & 0.017970 \\ \text { C } & 4.001453 & -3.275269 & 0.595977 \\ \text { C } & 3.860632 & -3.378410 & 2.012881 \\ \text { C } & 4.972408 & -3.711143 & 2.783000 \\ \text { C } & 6.220075 & -3.895437 & 2.164984 \\ \text { C } & 2.841075 & -3.085446 & -0.221905 \\ \text { C } & 1.538347 & -3.222493 & 0.351820 \\ \text { C } & 1.413446 & -3.003527 & 1.765085 \\ \text { C } & 2.590906 & -2.853382 & 2.556571 \\ \text { C } & 2.608046 & -1.869535 & 3.545844 \\ \text { C } & 1.502389 & -0.998685 & 3.735210 \\ \text { C } & 0.239631 & -1.409356 & 3.212875\end{array}$




$\begin{array}{rrrr}\text { C } & 0.187718 & -2.462616 & 2.246555 \\ \text { C } & -0.900507 & -0.537288 & 3.304843 \\ \text { C } & -0.661771 & 0.866049 & 3.416082 \\ \text { C } & 0.690043 & 1.328997 & 3.527258 \\ \text { C } & 1.715753 & 0.435364 & 3.955115 \\ \text { C } & 1.055082 & 2.562516 & 2.887101 \\ \text { C } & 2.422618 & 2.917776 & 2.759244 \\ \text { C } & 3.345462 & 2.207934 & 3.574591 \\ \text { C } & 3.005848 & 0.997848 & 4.146806 \\ \text { C } & -1.010303 & -2.665650 & 1.488457 \\ \text { C } & -2.234570 & -2.099087 & 1.949919 \\ \text { C } & -2.165389 & -0.983246 & 2.845183 \\ \text { C } & -3.283025 & -0.085191 & 2.878016 \\ \text { C } & -3.033581 & 1.314647 & 2.926640 \\ \text { C } & -1.685780 & 1.769173 & 3.011429 \\ \text { C } & 0.396607 & -3.095192 & -0.477808 \\ \text { C } & -0.912569 & -3.065257 & 0.121073 \\ \text { C } & -2.057260 & -2.994664 & -0.711720 \\ \text { C } & -3.345899 & -2.793800 & -0.120288 \\ \text { C } & -3.429300 & -2.315201 & 1.204497 \\ \text { C } & -4.663070 & -1.699650 & 1.624581 \\ \text { C } & -4.564692 & -0.537895 & 2.455414 \\ \text { C } & 2.976685 & -2.469357 & -1.484768 \\ \text { C } & 1.813404 & -2.059231 & -2.193346 \\ \text { C } & 0.539899 & -2.560534 & -1.794280 \\ \text { C } & -0.630890 & -2.168026 & -2.520607 \\ \text { C } & -1.903424 & -2.642544 & -2.094200 \\ \text { C } & 5.435635 & -2.418833 & -1.209843 \\ \text { C } & 4.265823 & -1.922742 & -1.830254 \\ \text { C } & 4.283329 & -0.643370 & -2.480245 \\ \text { C } & 3.036403 & -0.036666 & -2.844149 \\ \text { C } & 1.853128 & -0.835450 & -2.941019 \\ \text { C } & 0.628590 & -0.228203 & -3.333938 \\ \text { C } & -0.581172 & -1.008623 & -3.356867 \\ \text { C } & -3.059384 & -2.299445 & -2.859416 \\ \text { C } & -2.980911 & -1.216760 & -3.732175 \\ \text { C } & -1.800241 & -0.429217 & -3.819189 \\ \text { C } & -1.896379 & 1.030017 & -3.844602 \\ \text { C } & 0.808844 & 1.770183 & -3.299735 \\ & & 1.188532 & -3.251751\end{array}$

S103 


$\begin{array}{lrrr}\text { C } & 1.590608 & 1.941211 & -2.720013 \\ \text { C } & 2.894892 & 1.368593 & -2.697592 \\ \text { C } & -1.086671 & 2.922765 & -2.488277 \\ \text { C } & -2.423989 & 3.358953 & -2.306249 \\ \text { C } & -3.394541 & 2.850478 & -3.219180 \\ \text { C } & -3.141506 & 1.714139 & -3.955419 \\ \text { C } & -0.062455 & 3.362636 & -1.579413 \\ \text { C } & 1.288069 & 3.014730 & -1.818928 \\ \text { C } & 3.984616 & 2.094048 & -2.098012 \\ \text { C } & 3.652207 & 3.090661 & -1.123401 \\ \text { C } & 2.287495 & 3.390469 & -0.864654 \\ \text { C } & 1.883593 & 3.674691 & 0.472399 \\ \text { C } & 0.497054 & 3.694550 & 0.784769 \\ \text { C } & -0.458794 & 3.760598 & -0.269093 \\ \text { C } & -1.852327 & 3.833530 & 0.043272 \\ \text { C } & -2.809135 & 3.906411 & -1.010201 \\ \text { C } & -2.290315 & 3.486694 & 1.366379 \\ \text { C } & -3.671666 & 3.314903 & 1.627472 \\ \text { C } & -4.578113 & 3.831126 & 0.659781 \\ \text { C } & -4.162978 & 4.101983 & -0.627978 \\ \text { C } & 5.299854 & 1.565934 & -2.132994 \\ \text { C } & 6.327211 & 2.307075 & -1.451888 \\ \text { C } & 6.006635 & 3.222822 & -0.486264 \\ \text { C } & 4.631431 & 3.475473 & -0.158418 \\ \text { C } & 5.462805 & 0.148782 & -2.394045 \\ \text { C } & -4.515889 & -2.777871 & -0.946297 \\ \text { C } & -4.377803 & -2.752418 & -2.367609 \\ \text { C } & 6.669894 & -1.793256 & -1.556359 \\ \text { C } & 6.683288 & -0.539668 & -2.120268 \\ \text { C } & -5.873066 & -1.981283 & 0.947910 \\ \text { C } & -5.809020 & -2.627478 & -0.360713 \\ \text { C } & -6.932988 & -2.817937 & -1.197243 \\ \text { C } & -6.777115 & -2.999413 & -2.564717 \\ \text { C } & -5.510786 & -2.888793 & -3.164299 \\ \text { C } & -5.667653 & 0.364009 & 2.520219 \\ \text { C } & -6.951935 & -0.138392 & 2.129422 \\ \text { C } & -7.046880 & -1.278016 & 1.371641 \\ \text { C } & 2.863351 & 3.593301 & 1.527041 \\ & 4.210029 & 3.724449 & 1.168355 \\ & 0.061596 & 3.201988 & 2.059348\end{array}$




$\begin{array}{lrrr}\mathrm{C} & -1.304860 & 2.933110 & 2.265030 \\ \mathrm{C} & -4.082259 & 2.220552 & 2.525616 \\ \mathrm{C} & -5.398478 & 1.752967 & 2.577141 \\ \mathrm{H} & 7.627762 & -0.021244 & -2.231156 \\ \mathrm{H} & 7.364527 & 2.032537 & -1.596274 \\ \mathrm{H} & 3.783083 & 0.412725 & 4.623018 \\ \mathrm{H} & 3.566168 & -1.613385 & 3.978760 \\ \mathrm{H} & 4.873567 & -3.817573 & 3.856926 \\ \mathrm{H} & 7.394771 & -3.621580 & 0.397614 \\ \mathrm{H} & 7.605091 & -2.236096 & -1.237231 \\ \mathrm{H} & 4.379723 & 2.526460 & 3.614976 \\ \mathrm{H} & 7.070934 & -4.203448 & 2.761332 \\ \mathrm{H} & 4.974700 & 3.780714 & 1.934995 \\ \mathrm{H} & 6.784448 & 3.664026 & 0.127406 \\ \mathrm{H} & -5.414714 & -2.896968 & -4.243692 \\ \mathrm{H} & -3.908313 & -0.826107 & -4.129604 \\ \mathrm{H} & -8.012005 & -1.566929 & 0.974872 \\ \mathrm{H} & -7.930111 & -2.782946 & -0.776650 \\ \mathrm{H} & -6.224276 & 2.429182 & 2.387696 \\ \mathrm{H} & -7.833158 & 0.464871 & 2.318451 \\ \mathrm{H} & -5.639097 & 3.848492 & 0.875357 \\ \mathrm{H} & -4.908233 & 4.329796 & -1.380412 \\ \mathrm{H} & -4.395457 & 3.263726 & -3.224565 \\ \mathrm{H} & -3.950573 & 1.267934 & -4.520805 \\ \mathrm{H} & -7.650509 & -3.155599 & -3.187029\end{array}$

$(6,4) 4$ cells

150

$\begin{array}{lrrr}\text { C } & 5.693967 & 2.568068 & 2.964542 \\ \text { C } & 5.461956 & 1.445128 & 3.730011 \\ \text { C } & 4.169610 & 0.852984 & 3.787689 \\ \text { C } & 3.076104 & 1.672506 & 3.383513 \\ \text { C } & 3.324792 & 2.807420 & 2.536051 \\ \text { C } & 4.654412 & 3.153196 & 2.186766 \\ \text { C } & 3.962757 & -0.596152 & 3.802566 \\ \text { C } & 2.650268 & -1.082776 & 3.533547 \\ \text { C } & 1.514717 & -0.209742 & 3.656982\end{array}$




$\begin{array}{lrrr}\text { C } & 1.733405 & 1.191532 & 3.523674 \\ \text { C } & 0.204050 & -0.728209 & 3.461724 \\ \text { C } & -0.918042 & 0.157459 & 3.532548 \\ \text { C } & -0.693398 & 1.552916 & 3.314787 \\ \text { C } & 0.638383 & 2.020548 & 3.133619 \\ \text { C } & 2.488438 & -2.261200 & 2.735619 \\ \text { C } & 1.203025 & -2.569095 & 2.189434 \\ \text { C } & 0.039984 & -1.964047 & 2.755105 \\ \text { C } & -1.243418 & -2.310348 & 2.247111 \\ \text { C } & -2.405639 & -1.651603 & 2.767941 \\ \text { C } & -2.234012 & -0.365186 & 3.377489 \\ \text { C } & 1.115336 & -3.117539 & 0.876095 \\ \text { C } & -0.144094 & -3.143270 & 0.213813 \\ \text { C } & -1.343173 & -2.958649 & 0.977726 \\ \text { C } & -2.610689 & -3.021666 & 0.326020 \\ \text { C } & -3.800097 & -2.760792 & 1.075907 \\ \text { C } & -3.688163 & -2.022699 & 2.293601 \\ \text { C } & -4.845579 & -1.305268 & 2.755661 \\ \text { C } & -4.670771 & 0.007275 & 3.275644 \\ \text { C } & -3.347198 & 0.529270 & 3.392480 \\ \text { C } & -0.196716 & -2.908809 & -1.197291 \\ \text { C } & -1.452103 & -2.628424 & -1.808691 \\ \text { C } & -2.669048 & -2.925462 & -1.101559 \\ \text { C } & -3.914787 & -2.688905 & -1.734606 \\ \text { C } & -5.129083 & -2.825685 & -0.981920 \\ \text { C } & -5.068970 & -2.831288 & 0.425919 \\ \text { C } & -6.273020 & -2.520476 & 1.155629 \\ \text { C } & -6.138690 & -1.704445 & 2.325522 \\ \text { C } & 2.324992 & -3.211701 & 0.104575 \\ \text { C } & 2.272961 & -2.840158 & -1.277237 \\ \text { C } & 1.011574 & -2.525911 & -1.866376 \\ \text { C } & 0.942507 & -1.493450 & -2.851024 \\ \text { C } & -0.326438 & -0.958145 & -3.209109 \\ \text { C } & -1.512837 & -1.680703 & -2.871725 \\ \text { C } & -2.784447 & -1.171243 & -3.282381 \\ \text { C } & -3.963045 & -1.877366 & -2.914479 \\ \text { C } & 3.474959 & -2.392452 & -1.907372 \\ \text { C } & 3.400178 & -1.283905 & -2.809330 \\ & 2.129377 & -0.732293 & -3.122396 \\ & 1.997973 & 0.687138 & -3.255335\end{array}$




$\begin{array}{lrrr}\text { C } & 0.696642 & 1.270843 & -3.222166 \\ \text { C } & -0.449405 & 0.447300 & -3.456697 \\ \text { C } & -1.744930 & 1.039304 & -3.463371 \\ \text { C } & -2.905232 & 0.210141 & -3.643021 \\ \text { C } & -5.226950 & -1.399337 & -3.383187 \\ \text { C } & -5.320868 & -0.078044 & -3.806574 \\ \text { C } & -4.200689 & 0.798615 & -3.727505 \\ \text { C } & -4.368277 & 2.156752 & -3.218056 \\ \text { C } & -3.256156 & 2.758836 & -2.563504 \\ \text { C } & -1.926758 & 2.315507 & -2.859979 \\ \text { C } & -0.812784 & 2.928881 & -2.208055 \\ \text { C } & 0.506543 & 2.512651 & -2.539197 \\ \text { C } & -3.480231 & 3.535808 & -1.374851 \\ \text { C } & -4.802899 & 3.768456 & -0.919596 \\ \text { C } & -5.857734 & 3.519475 & -1.849905 \\ \text { C } & -5.649135 & 2.727007 & -2.954894 \\ \text { C } & -2.372326 & 3.720425 & -0.475348 \\ \text { C } & -1.042162 & 3.592527 & -0.957745 \\ \text { C } & 1.621157 & 3.068931 & -1.828883 \\ \text { C } & 1.386195 & 3.620460 & -0.527118 \\ \text { C } & 0.050344 & 3.708007 & -0.041355 \\ \text { C } & -0.203274 & 3.488844 & 1.349914 \\ \text { C } & -1.538704 & 3.283632 & 1.789265 \\ \text { C } & -2.622790 & 3.619051 & 0.921822 \\ \text { C } & -3.971036 & 3.463996 & 1.377089 \\ \text { C } & -5.050449 & 3.807101 & 0.514893 \\ \text { C } & -4.230369 & 2.643926 & 2.528735 \\ \text { C } & -5.558688 & 2.266225 & 2.839000 \\ \text { C } & -6.601962 & 3.008163 & 2.211858 \\ \text { C } & -6.358762 & 3.742214 & 1.072311 \\ \text { C } & 2.937399 & 2.681746 & -2.185580 \\ \text { C } & 4.048164 & 3.174610 & -1.420069 \\ \text { C } & 3.813566 & 3.616492 & -0.086150 \\ \text { C } & 2.472869 & 3.659079 & 0.399786 \\ \text { C } & 3.137538 & 1.498890 & -2.962138 \\ \text { C } & -6.393416 & -2.647689 & -1.628364 \\ \text { C } & -6.442413 & -2.124769 & -2.957246 \\ \text { C } & 5.370074 & 2.839604 & -1.811313 \\ & 5.588808 & 1.718906 & -2.679760 \\ & 4.441993 & 0.923744 & -3.026179\end{array}$




$\begin{array}{lrrr}\text { C } & 4.579822 & -0.487550 & -2.991579 \\ \text { C } & -7.540493 & -2.674520 & 0.548019 \\ \text { C } & -7.607377 & -2.831952 & -0.900301 \\ \text { C } & -8.817186 & -2.839147 & -1.634880 \\ \text { C } & -8.827706 & -2.529095 & -2.986923 \\ \text { C } & -7.656822 & -2.093192 & -3.633340 \\ \text { C } & -7.275356 & -0.983358 & 2.802740 \\ \text { C } & -8.569435 & -1.449931 & 2.391854 \\ \text { C } & -8.692366 & -2.273984 & 1.304611 \\ \text { C } & 3.644759 & -2.847222 & 2.151846 \\ \text { C } & 3.573498 & -3.237141 & 0.773267 \\ \text { C } & 4.783724 & -3.172872 & 0.009557 \\ \text { C } & 4.733517 & -2.718476 & -1.324103 \\ \text { C } & 5.955576 & -2.230483 & -1.914959 \\ \text { C } & 5.869039 & -1.046424 & -2.723381 \\ \text { C } & 7.039691 & -0.253610 & -2.898154 \\ \text { C } & 6.894323 & 1.182406 & -2.809207 \\ \text { C } & 7.994310 & 2.006398 & -2.374192 \\ \text { C } & 7.789052 & 3.040134 & -1.504351 \\ \text { C } & 6.461069 & 3.334959 & -1.032460 \\ \text { C } & 5.054025 & -1.481076 & 3.575316 \\ \text { C } & 4.919919 & -2.588956 & 2.741819 \\ \text { C } & 6.109181 & -3.185423 & 2.098952 \\ \text { C } & 6.048564 & -3.265592 & 0.674229 \\ \text { C } & 7.256166 & -3.272167 & -0.083877 \\ \text { C } & 7.205816 & -2.649442 & -1.405583 \\ \text { C } & 8.374624 & -2.079806 & -1.997207 \\ \text { C } & 8.296329 & -0.908042 & -2.708507 \\ \text { C } & 8.458132 & -3.562685 & 0.600649 \\ \text { C } & 8.473549 & -3.687199 & 1.983619 \\ \text { C } & 7.320778 & -3.420257 & 2.741982 \\ \text { C } & 0.889326 & 3.062770 & 2.177712 \\ \text { C } & 2.218581 & 3.314172 & 1.760751 \\ \text { C } & -1.793652 & 2.347606 & 2.849617 \\ \text { C } & -3.118452 & 1.899922 & 3.071321 \\ \text { C } & -5.803021 & 0.895154 & 3.315184 \\ \text { C } & -7.080192 & 0.318875 & 3.312914 \\ \text { C } & 4.917834 & 3.664969 & 0.834108 \\ \text { H } & 6.210322 & 3.747641 & 0.290964 \\ & 6.306222 & 0.937931 & 4.180872\end{array}$




$\begin{array}{rrrr}\text { H } & 6.056774 & -1.163587 & 3.829817 \\ \text { H } & 7.374259 & -3.386327 & 3.823788 \\ \text { H } & 9.386630 & -3.645438 & 0.049674 \\ \text { H } & 9.349164 & -2.488159 & -1.760703 \\ \text { H } & 9.209627 & -0.413991 & -3.016384 \\ \text { H } & 9.006915 & 1.714896 & -2.622998 \\ \text { H } & 9.403225 & -3.919563 & 2.489663 \\ \text { H } & 6.714933 & 2.903967 & 2.833029 \\ \text { H } & 7.063683 & 3.906028 & 0.940451 \\ \text { H } & 8.632072 & 3.561270 & -1.064083 \\ \text { H } & -7.700275 & -1.721031 & -4.650131 \\ \text { H } & -6.311157 & 0.337307 & -3.938718 \\ \text { H } & -9.680889 & -2.512587 & 0.932981 \\ \text { H } & -9.752048 & -3.050408 & -1.131284 \\ \text { H } & -7.957516 & 0.939503 & 3.454862 \\ \text { H } & -9.452626 & -1.036931 & 2.866732 \\ \text { H } & -7.627371 & 2.862572 & 2.527647 \\ \text { H } & -7.197173 & 4.158793 & 0.527386 \\ \text { H } & -6.867790 & 3.827181 & -1.609996 \\ \text { H } & -6.500205 & 2.434884 & -3.557917 \\ \text { H } & -9.762637 & -2.551260 & -3.534471\end{array}$

$(6,4) 5$ cells

182

$\begin{array}{llll}\text { C } & -8.347043 & 2.898204 & 2.453119 \\ \text { C } & -7.063869 & 3.211508 & 1.919461 \\ \text { C } & -5.942110 & 2.620132 & 2.564077 \\ \text { C } & -6.134313 & 1.427076 & 3.343045 \\ \text { C } & -7.438068 & 0.911293 & 3.532649 \\ \text { C } & -8.525307 & 1.791206 & 3.251516 \\ \text { C } & -4.617750 & 2.979566 & 2.153878 \\ \text { C } & -4.428391 & 3.582846 & 0.880950 \\ \text { C } & -5.569655 & 3.697777 & 0.012169 \\ \text { C } & -6.876046 & 3.705439 & 0.563110 \\ \text { C } & -5.381579 & 3.407122 & -1.383526 \\ \text { C } & -6.508788 & 3.043443 & -2.173649 \\ \text { C } & -7.788716 & 3.439329 & -1.681330\end{array}$




$\begin{array}{lrrr}\text { C } & -7.965097 & 3.774273 & -0.359457 \\ \text { C } & -3.115049 & 3.681678 & 0.342014 \\ \text { C } & -2.926744 & 3.515869 & -1.069589 \\ \text { C } & -4.057627 & 3.142502 & -1.862356 \\ \text { C } & -3.879377 & 2.178813 & -2.892652 \\ \text { C } & -5.029459 & 1.432815 & -3.324665 \\ \text { C } & -6.338313 & 1.965637 & -3.143180 \\ \text { C } & -1.615824 & 3.291062 & -1.571573 \\ \text { C } & -1.434976 & 2.389094 & -2.668042 \\ \text { C } & -2.572897 & 1.670267 & -3.148424 \\ \text { C } & -2.411690 & 0.278118 & -3.442777 \\ \text { C } & -3.566504 & -0.559921 & -3.350423 \\ \text { C } & -4.864872 & 0.019600 & -3.498545 \\ \text { C } & -6.009617 & -0.813074 & -3.369847 \\ \text { C } & -7.304394 & -0.242920 & -3.584216 \\ \text { C } & -7.444398 & 1.137118 & -3.494377 \\ \text { C } & -3.435384 & -1.825443 & -2.709796 \\ \text { C } & -4.609629 & -2.403026 & -2.116051 \\ \text { C } & -5.887968 & -1.997405 & -2.573355 \\ \text { C } & -7.062849 & -2.444747 & -1.879822 \\ \text { C } & -8.359239 & -2.091338 & -2.371420 \\ \text { C } & -8.482130 & -1.119981 & -3.412607 \\ \text { C } & -2.144988 & -2.262834 & -2.289067 \\ \text { C } & -0.980245 & -1.627401 & -2.827192 \\ \text { C } & -1.119156 & -0.306470 & -3.359781 \\ \text { C } & 0.035255 & 0.541952 & -3.370186 \\ \text { C } & -0.127902 & 1.902114 & -2.959061 \\ \text { C } & 1.009934 & 2.587759 & -2.429118 \\ \text { C } & 0.829652 & 3.400153 & -1.265496 \\ \text { C } & -0.481059 & 3.586603 & -0.744817 \\ \text { C } & -0.669965 & 3.634669 & 0.672316 \\ \text { C } & -1.987672 & 3.502341 & 1.202442 \\ \text { C } & -2.179315 & 2.793392 & 2.432099 \\ \text { C } & -3.489274 & 2.394678 & 2.807855 \\ \text { C } & -4.480032 & -3.004953 & -0.821756 \\ \text { C } & -5.639221 & -3.074417 & 0.013232 \\ \text { C } & -6.936069 & -2.957296 & -0.574069 \\ \text { C } & -8.111869 & -2.980151 & 0.259549 \\ \text { C } & -9.401763 & -2.954743 & -0.318233 \\ & & -2.575740 & -1.719745\end{array}$




$\begin{array}{lrrr}\text { C } & -10.775710 & -2.360847 & -2.363179 \\ \text { C } & -10.856300 & -1.577828 & -3.504987 \\ \text { C } & -9.727037 & -0.890053 & -3.986477 \\ \text { C } & -3.185221 & -3.127021 & -0.236106 \\ \text { C } & -2.016776 & -2.980894 & -1.058986 \\ \text { C } & -7.943329 & -2.633412 & 1.639960 \\ \text { C } & -9.074767 & -2.175453 & 2.382241 \\ \text { C } & -10.374870 & -2.519946 & 1.877451 \\ \text { C } & -10.527370 & -2.903423 & 0.572013 \\ \text { C } & -6.642749 & -2.362025 & 2.139154 \\ \text { C } & -5.488610 & -2.817754 & 1.409049 \\ \text { C } & -4.194632 & -2.591912 & 1.940284 \\ \text { C } & -3.041583 & -2.968247 & 1.175424 \\ \text { C } & -4.029643 & -1.606665 & 2.970671 \\ \text { C } & -5.163619 & -0.820915 & 3.343569 \\ \text { C } & -6.478399 & -1.316818 & 3.089511 \\ \text { C } & -2.725047 & -1.125392 & 3.263974 \\ \text { C } & -1.582804 & -1.875306 & 2.829650 \\ \text { C } & -1.742080 & -2.772179 & 1.727192 \\ \text { C } & -0.587944 & -3.092593 & 0.942772 \\ \text { C } & -0.725915 & -3.142165 & -0.480121 \\ \text { C } & 0.443801 & -2.911105 & -1.280972 \\ \text { C } & 0.312715 & -2.088134 & -2.442986 \\ \text { C } & 1.475364 & -1.403554 & -2.925193 \\ \text { C } & 1.330976 & -0.042797 & -3.341986 \\ \text { C } & -0.281459 & -1.417980 & 3.171635 \\ \text { C } & 0.862781 & -2.128198 & 2.683567 \\ \text { C } & 0.709108 & -2.934373 & 1.511369 \\ \text { C } & 1.867037 & -3.186682 & 0.708383 \\ \text { C } & 1.734687 & -3.112209 & -0.714398 \\ \text { C } & 2.903241 & -2.799480 & -1.487234 \\ \text { C } & 2.769827 & -1.888545 & -2.577903 \\ \text { C } & 3.933374 & -1.163597 & -3.005923 \\ \text { C } & 3.782577 & 0.229110 & -3.307622 \\ \text { C } & 2.482366 & 0.808196 & -3.282716 \\ \text { C } & 2.315930 & 2.128803 & -2.762000 \\ \text { C } & 2.161909 & -1.701748 & 3.069990 \\ \text { C } & 3.305407 & -2.361102 & 2.523620 \\ \text { C } & 3.159971 & -3.067171 & 1.294697 \\ & 4.328282 & -3.241773 & 0.476912\end{array}$

S111 


$\begin{array}{rrrr}\text { C } & 4.197946 & -3.037190 & -0.935326 \\ \text { C } & 5.359889 & -2.659660 & -1.676309 \\ \text { C } & 5.224931 & -1.667396 & -2.698128 \\ \text { C } & 6.386529 & -0.894150 & -3.039172 \\ \text { C } & 6.233344 & 0.501398 & -3.237390 \\ \text { C } & 4.927813 & 1.074968 & -3.177582 \\ \text { C } & 4.755764 & 2.345593 & -2.549196 \\ \text { C } & 3.455369 & 2.774200 & -2.183679 \\ \text { C } & 3.274846 & 3.483806 & -0.950292 \\ \text { C } & 1.963963 & 3.625476 & -0.417033 \\ \text { C } & 1.775057 & 3.554741 & 0.998951 \\ \text { C } & 0.458692 & 3.382124 & 1.517164 \\ \text { C } & 4.610870 & -1.971987 & 2.958121 \\ \text { C } & 5.744858 & -2.613079 & 2.390990 \\ \text { C } & 5.609045 & -3.172722 & 1.077343 \\ \text { C } & 6.777846 & -3.191725 & 0.248877 \\ \text { C } & 6.652263 & -2.905545 & -1.125430 \\ \text { C } & 7.836140 & -2.487903 & -1.835804 \\ \text { C } & 7.693722 & -1.411422 & -2.776392 \\ \text { C } & 8.845031 & -0.639217 & -3.106505 \\ \text { C } & 8.689805 & 0.795581 & -3.182506 \\ \text { C } & 7.387457 & 1.338513 & -3.052065 \\ \text { C } & 7.201230 & 2.556598 & -2.316109 \\ \text { C } & 5.897946 & 2.934051 & -1.905726 \\ \text { C } & 5.721818 & 3.535038 & -0.626324 \\ \text { C } & 4.403519 & 3.630257 & -0.085304 \\ \text { C } & 7.044697 & -2.269511 & 2.876042 \\ \text { C } & 8.208333 & -2.932171 & 2.251031 \\ \text { C } & 8.075962 & -3.190352 & 0.852473 \\ \text { C } & 9.242745 & -3.284634 & 0.038839 \\ \text { C } & 9.115877 & -2.833537 & -1.345475 \\ \text { C } & 10.246332 & -2.335680 & -2.064408 \\ \text { C } & 10.117725 & -1.260257 & -2.907174 \\ \text { C } & 8.324031 & 3.144115 & -1.654639 \\ \text { C } & 9.630856 & 2.798792 & -2.153100 \\ \text { C } & 9.802724 & 1.671095 & -2.904051 \\ \text { C } & 9.453943 & -3.077101 & 2.853782 \\ & 10.569880 & -3.429965 & 2.075051 \\ \text { C. } & 2.339738 & -0.380693 & 3.596770\end{array}$




$\begin{array}{rrrr}\text { C } & 3.650930 & 0.171732 & 3.655904 \\ \mathrm{C} & 4.792645 & -0.699836 & 3.591873 \\ \mathrm{C} & 6.107982 & -0.170701 & 3.731132 \\ \mathrm{C} & 7.201901 & -1.066341 & 3.558737 \\ \mathrm{C} & 3.839944 & 1.545568 & 3.339202 \\ \mathrm{C} & 5.168122 & 2.020754 & 3.082667 \\ \mathrm{C} & 6.290640 & 1.267247 & 3.531188 \\ \mathrm{C} & 5.362123 & 3.047366 & 2.093851 \\ \mathrm{C} & 6.669510 & 3.359287 & 1.643960 \\ \mathrm{C} & 7.751701 & 2.885645 & 2.441191 \\ \mathrm{C} & 7.570778 & 1.861553 & 3.345076 \\ \mathrm{C} & -0.103213 & -0.060011 & 3.586285 \\ \mathrm{C} & 1.209378 & 0.494104 & 3.605004 \\ \mathrm{C} & 1.400040 & 1.852651 & 3.196254 \\ \mathrm{C} & 2.713651 & 2.308786 & 2.900205 \\ \mathrm{C} & -2.545609 & 0.260137 & 3.567835 \\ \mathrm{C} & -1.233723 & 0.814447 & 3.536387 \\ \mathrm{C} & -8.890236 & -1.134090 & 3.316336 \\ \mathrm{C} & -7.628143 & -0.547012 & 3.484110 \\ \mathrm{C} & 6.865754 & 3.698191 & 0.227633 \\ \mathrm{C} & 8.132267 & 3.714737 & -0.382013 \\ \mathrm{C} & 4.215113 & 3.444567 & 1.313915 \\ \mathrm{C} & 2.906414 & 3.232894 & 1.817624 \\ \mathrm{C} & 0.267001 & 2.565719 & 2.677455 \\ \mathrm{C} & -1.044660 & 2.133570 & 3.014589 \\ \mathrm{C} & -4.983275 & 0.578105 & 3.537879 \\ \mathrm{C} & -3.679305 & 1.126891 & 3.458003 \\ \mathrm{H} & 11.007451 & -0.803957 & -3.323377 \\ \mathrm{H} & 10.804233 & 1.357074 & -3.169586 \\ \mathrm{H} & 11.382048 & -3.626542 & 0.106221 \\ \mathrm{H} & 11.236053 & -2.709066 & -1.833369 \\ \mathrm{H} & 10.489173 & 3.372879 & -1.821743 \\ \mathrm{H} & 11.526944 & -3.591833 & 2.556890 \\ \mathrm{H} & 9.562758 & -2.908426 & 3.918674 \\ \mathrm{H} & 8.210511 & -0.709962 & 3.722053 \\ \mathrm{H} & 8.440869 & 1.423159 & 3.818431 \\ & 8.759967 & 3.217599 & 2.227320 \\ \mathrm{H} & -9.013594 & 3.955260 & 0.201303 \\ \mathrm{H} & -8.447772 & 1.537391 & -3.433193\end{array}$

S113 


$\begin{array}{rrrr}\mathrm{H} & -11.525394 & -3.036478 & 0.174016 \\ \mathrm{H} & -11.680859 & -2.778283 & -1.940441 \\ \mathrm{H} & -9.775432 & -0.642670 & 3.703325 \\ \mathrm{H} & -11.244679 & -2.344172 & 2.500824 \\ \mathrm{H} & -9.532638 & 1.502279 & 3.523922 \\ \mathrm{H} & -9.216665 & 3.453732 & 2.123716 \\ \mathrm{H} & -8.969178 & 3.943872 & 0.008504 \\ \mathrm{H} & -8.658132 & 3.357816 & -2.322196 \\ \mathrm{H} & -11.814920 & -1.434027 & -3.989481\end{array}$

$(6,4) 6$ cells

\section{4}

C $\quad-8.538348$

C $\quad-8.375803$

C $\quad-7.065783$

C $\quad-5.914516$

C $\quad-6.082495$

C $\quad-7.400161$

C $\quad-9.480955$

C $\quad-9.330426$

C $\quad-8.026157$

C $\quad-6.892092$

C -10.496023

C -10.343443

C $\quad-9.034392$

C $\quad-7.877757$

C -11.499292

C $\quad-12.756815$

C $\quad-12.867444$

C -11.754326

C $\quad-8.876527$

C $\quad-10.034936$

C $\quad-11.336204$

C $\quad-7.566903$

C $\quad-6.425863$

C $\quad-6.587454$

C $\quad-5.431269$
3.352467

3.616950

3. 520761

3.565449

3.190699

2.893867

3.458781

2.815532

2.363092

2.932656

2.185539

0.793707

0.218462

1.069132

$-0.040591$

0.593139

1.973499

2.767552

$-1.159806$

$-1.909497$

$-1.431356$

$-1.693841$

$-0.919919$

0.495504

1.328793
1.428566

0.002618

$-0.548792$

0.311172

1.671717

2.150086

$-0.884883$

$-2.107691$

$-2.484696$

$-1.844662$

$-2.763419$

$-3.050420$

$-3.098166$

$-3.080580$

$-3.121811$

$-3.269722$

$-3.196161$

$-2.863435$

$-2.856227$

$-2.440166$

$-2.716589$

$-2.653984$

$-3.032605$

$-3.192457$

$-3.010668$ 


$\begin{array}{lrrr}\text { C } & -5.586033 & 2.531230 & -2.263870 \\ \text { C } & -5.118691 & -1.454480 & -2.835391 \\ \text { C } & -3.968669 & -0.650335 & -3.144617 \\ \text { C } & -4.129001 & 0.770445 & -3.170843 \\ \text { C } & -2.982167 & 1.585975 & -2.911959 \\ \text { C } & -3.142423 & 2.723904 & -2.058259 \\ \text { C } & -4.440411 & 3.072280 & -1.599723 \\ \text { C } & -4.607654 & 3.544590 & -0.257905 \\ \text { C } & -2.665307 & -1.199400 & -2.985550 \\ \text { C } & -1.516517 & -0.369739 & -3.211935 \\ \text { C } & -1.679222 & 1.046602 & -3.112417 \\ \text { C } & -0.532339 & 1.839215 & -2.782189 \\ \text { C } & -0.694897 & 2.894876 & -1.830684 \\ \text { C } & -1.996012 & 3.195847 & -1.340565 \\ \text { C } & -2.161186 & 3.551078 & 0.033647 \\ \text { C } & -3.467563 & 3.535218 & 0.603442 \\ \text { C } & -0.210742 & -0.929040 & -3.093731 \\ \text { C } & 0.936057 & -0.081920 & -3.246526 \\ \text { C } & 0.770406 & 1.321569 & -3.028862 \\ \text { C } & 1.916344 & 2.084833 & -2.632313 \\ \text { C } & 1.751190 & 3.054953 & -1.592165 \\ \text { C } & 0.449537 & 3.307812 & -1.077227 \\ \text { C } & 0.285301 & 3.548246 & 0.323509 \\ \text { C } & -1.017508 & 3.482470 & 0.892196 \\ \text { C } & 2.242687 & -0.646583 & -3.172535 \\ \text { C } & 3.386905 & 0.211580 & -3.252653 \\ \text { C } & 3.218672 & 1.592641 & -2.922099 \\ \text { C } & 4.364280 & 2.321421 & -2.458682 \\ \text { C } & 4.197363 & 3.198041 & -1.343238 \\ \text { C } & 2.894383 & 3.404770 & -0.807136 \\ \text { C } & 2.731970 & 3.526901 & 0.607963 \\ \text { C } & 1.431544 & 3.410919 & 1.171282 \\ \text { C } & 4.695305 & -0.355750 & -3.217558 \\ \text { C } & 5.841589 & 0.509227 & -3.236603 \\ \text { C } & 5.669483 & 1.861307 & -2.792213 \\ \text { C } & 6.808987 & 2.548038 & -2.267530 \\ \text { C } & 6.638295 & 3.325894 & -1.083015 \\ & 5.342248 & 3.490028 & -0.535123 \\ \text { C } & 3.181040 & 3.483533 & 0.890644 \\ \text { C } & & 3.315938 & 1.440359\end{array}$




$\begin{array}{rrrr}\text { C } & 2.410383 & -1.943588 & -2.590154 \\ \text { C } & 3.714211 & -2.373959 & -2.215824 \\ \text { C } & 4.862782 & -1.689518 & -2.738628 \\ \text { C } & 6.170864 & -2.146345 & -2.396470 \\ \text { C } & 7.312589 & -1.423323 & -2.859663 \\ \text { C } & 7.144866 & -0.054676 & -3.240701 \\ \text { C } & 8.291392 & 0.807976 & -3.161332 \\ \text { C } & 8.119393 & 2.109717 & -2.626562 \\ \text { C } & 6.325300 & 3.193772 & 1.697229 \\ \text { C } & 7.633331 & 3.405851 & 1.164243 \\ \text { C } & 7.788358 & 3.533415 & -0.245613 \\ \text { C } & 9.085928 & 3.439134 & -0.807401 \\ \text { C } & 9.268585 & 2.762366 & -2.060151 \\ \text { C } & 10.573453 & 2.384424 & -2.462795 \\ \text { C } & 10.745194 & 1.110135 & -3.122268 \\ \text { C } & 9.609258 & 0.254426 & -3.210336 \\ \text { C } & 9.783097 & -1.145835 & -2.940291 \\ \text { C } & 8.618860 & -1.886806 & -2.521927 \\ \text { C } & 11.076230 & -1.665613 & -2.704701 \\ \text { C } & 12.186211 & -0.852411 & -3.091253 \\ \text { C } & 12.028482 & 0.497768 & -3.278528 \\ \text { C } & 10.216643 & 3.634232 & 0.045518 \\ \text { C } & 11.516224 & 3.613333 & -0.576465 \\ \text { C } & 11.683340 & 3.021779 & -1.795893 \\ \text { C } & 8.775426 & -2.821424 & -1.478833 \\ \text { C } & 10.084985 & -3.097514 & -0.970687 \\ \text { C } & 11.236202 & -2.747446 & -1.734959 \\ \text { C } & 6.332462 & -3.029455 & -1.279249 \\ \text { C } & 7.623343 & -3.243641 & -0.739332 \\ \text { C } & 3.876777 & -3.149323 & -1.024002 \\ \text { C } & 5.179337 & -3.311905 & -0.470585 \\ \text { C } & 10.242138 & -3.573193 & 0.366966 \\ \text { C } & 11.501192 & -3.974068 & 0.802087 \\ \text { C } & 12.605567 & -3.866059 & -0.060881 \\ \text { C } & 12.490846 & -3.217294 & -1.283016 \\ \text { C } & 7.778191 & -3.417131 & 0.676029 \\ \text { C } & 9.083356 & -3.338222 & 1.253599 \\ \text { C } & 5.339759 & -3.313708 & 0.944409 \\ & 6.648396 & -3.169983 & 1.501380 \\ \text { - } & & -2.172135 & -2.407255\end{array}$

S116 


$\begin{array}{rrrr}\text { C } & 1.262682 & -2.572915 & -2.002362 \\ \text { C } & 1.428811 & -3.241714 & -0.750124 \\ \text { C } & 2.733531 & -3.359901 & -0.191040 \\ \text { C } & 2.898981 & -3.241744 & 1.226097 \\ \text { C } & 4.198800 & -3.038931 & 1.760076 \\ \text { C } & 6.827361 & -2.387252 & 2.687816 \\ \text { C } & 8.139089 & -1.977197 & 3.061374 \\ \text { C } & 9.239773 & -2.641754 & 2.448506 \\ \text { C } & 4.370633 & -2.157265 & 2.876895 \\ \text { C } & 5.677500 & -1.687128 & 3.194415 \\ \text { C } & 5.846490 & -0.338452 & 3.612400 \\ \text { C } & 7.165378 & 0.224884 & 3.616338 \\ \text { C } & 8.303179 & -0.631803 & 3.612696 \\ \text { C } & 0.285848 & -3.383274 & 0.100815 \\ \text { C } & 0.453188 & -3.143621 & 1.501209 \\ \text { C } & 1.755430 & -2.888734 & 2.012751 \\ \text { C } & 1.923678 & -1.918150 & 3.048540 \\ \text { C } & 3.231230 & -1.426327 & 3.334888 \\ \text { C } & 3.400498 & -0.044391 & 3.667732 \\ \text { C } & 4.704003 & 0.521693 & 3.631596 \\ \text { C } & 7.331412 & 1.612413 & 3.275799 \\ \text { C } & 8.626740 & 2.130412 & 3.026178 \\ \text { C } & 9.728859 & 1.339834 & 3.463366 \\ \text { C } & 9.574452 & -0.001884 & 3.734684 \\ \text { C } & -0.689186 & -2.730572 & 2.257909 \\ \text { C } & -0.522915 & -1.674935 & 3.210054 \\ \text { C } & 0.780624 & -1.157753 & 3.453387 \\ \text { C } & 1.267973 & 2.738646 & 2.425056 \\ \text { C } & 2.414421 & 2.107660 & 3.007443 \\ \text { C } & 3.720381 & 2.540601 & 2.630766 \\ \text { C } & -1.183478 & 2.915649 & 2.196058 \\ \text { C } & -0.037130 & 2.336764 & 2.831590 \\ \text { C } & -3.636306 & 3.072123 & 1.947828 \\ \text { C } & -2.488855 & 2.544223 & 2.629668 \\ \text { C } & -2.495806 & -2.382775 & -2.197654 \\ \text { C } & -1.188641 & -2.750329 & -1.766597 \\ \text { C } & -4.939895 & 2.735465 & 2.404195 \\ \text { C } & -4.946798 & -2.570743 & -1.962851 \\ & -7.390104 & -2.746631 & -1.706677\end{array}$




$\begin{array}{lrrr}\text { C } & -6.087690 & -3.052060 & -1.239387 \\ \text { C } & -9.841851 & -2.902107 & -1.424008 \\ \text { C } & -8.534251 & -3.156165 & -0.934062 \\ \text { C } & -10.962785 & -3.319883 & -0.643367 \\ \text { C } & -12.269544 & -3.098426 & -1.197940 \\ \text { C } & -12.444436 & -2.189195 & -2.206228 \\ \text { C } & -1.018681 & -3.316204 & -0.463903 \\ \text { C } & -3.464229 & -3.370964 & -0.168210 \\ \text { C } & -2.160683 & -3.390239 & 0.397475 \\ \text { C } & -5.911682 & -3.409270 & 0.139633 \\ \text { C } & -4.606969 & -3.376632 & 0.700401 \\ \text { C } & -8.361391 & -3.414555 & 0.453265 \\ \text { C } & -7.046601 & -3.341889 & 1.006598 \\ \text { C } & -1.991588 & -3.032865 & 1.774143 \\ \text { C } & -4.437822 & -2.906969 & 2.040031 \\ \text { C } & -3.133191 & -2.558642 & 2.494270 \\ \text { C } & -2.653200 & 1.361116 & 3.413428 \\ \text { C } & -1.505957 & 0.534183 & 3.644267 \\ \text { C } & -0.201736 & 1.092705 & 3.520045 \\ \text { C } & -5.104364 & 1.614481 & 3.283034 \\ \text { C } & -3.960213 & 0.812124 & 3.579715 \\ \text { C } & -6.406913 & 1.073929 & 3.478757 \\ \text { C } & -6.566009 & -0.329900 & 3.626679 \\ \text { C } & -5.418700 & -1.167898 & 3.468185 \\ \text { C } & -4.121982 & -0.610776 & 3.614394 \\ \text { C } & -7.565396 & 1.850687 & 3.126419 \\ \text { C } & -8.860958 & 1.355020 & 3.419870 \\ \text { C } & -9.018177 & -0.063816 & 3.704167 \\ \text { C } & -7.878021 & -0.897099 & 3.535500 \\ \text { C } & -10.287580 & -0.710693 & 3.715668 \\ \text { C } & -10.437922 & -1.973775 & 3.189652 \\ \text { C } & -9.335622 & -2.648898 & 2.585577 \\ \text { C } & -8.041739 & -2.188785 & 2.924828 \\ \text { C } & -9.812945 & 3.112581 & 2.025620 \\ \text { C } & -9.967897 & 2.156191 & 3.001038 \\ \text { C } & 10.046187 & 3.482018 & 1.434322 \\ \text { C } & 8.792219 & 3.138435 & 1.969784 \\ \text { C } & 4.868638 & 1.869382 & 3.161482 \\ \text { C } & 6.165895 & 2.327863 & 2.815457 \\ & 2.250661 & 0.813242 & 3.592210\end{array}$

S118 


$\begin{array}{rrrr}\text { C } & 0.946708 & 0.247421 & 3.672293 \\ \mathrm{C} & -10.769927 & -3.567708 & 0.731913 \\ \mathrm{C} & -9.510597 & -3.375419 & 1.317982 \\ \mathrm{C} & -6.878031 & -2.771176 & 2.299779 \\ \mathrm{C} & -5.581768 & -2.386991 & 2.724044 \\ \mathrm{C} & -2.969775 & -1.425881 & 3.349971 \\ \mathrm{C} & -1.669385 & -0.885849 & 3.548244 \\ \mathrm{H} & 12.904125 & 1.118999 & -3.421267 \\ \mathrm{H} & 12.681956 & 2.903980 & -2.197171 \\ \mathrm{H} & 12.375460 & 3.958875 & -0.012237 \\ \mathrm{H} & 13.184457 & -1.271759 & -3.092190 \\ \mathrm{H} & 13.380523 & -3.032695 & -1.871898 \\ \mathrm{H} & 13.574090 & -4.227299 & 0.264344 \\ \mathrm{H} & 11.628950 & -4.358595 & 1.807121 \\ \mathrm{H} & 10.246984 & -2.397474 & 2.759635 \\ \mathrm{H} & 10.457070 & -0.603827 & 3.913670 \\ \mathrm{H} & 10.729678 & 1.751905 & 3.431336 \\ \mathrm{H} & 10.936882 & 3.413222 & 2.048219 \\ \mathrm{H} & -11.877623 & 3.827037 & -2.672061 \\ \mathrm{H} & -10.486341 & 3.595462 & -0.509122 \\ \mathrm{H} & -13.448725 & -1.941551 & -2.525958 \\ \mathrm{H} & -13.649330 & -0.005298 & -3.402513 \\ \mathrm{H} & -11.651976 & -3.660945 & 1.354882 \\ \mathrm{H} & -13.128228 & -3.558082 & -0.721094 \\ \mathrm{H} & -11.436397 & -2.379970 & 3.087518 \\ \mathrm{H} & -11.169682 & -0.159573 & 4.017931 \\ \mathrm{H} & -10.966292 & 1.911501 & 3.341259 \\ \mathrm{H} & -10.693249 & 3.599552 & 1.624138 \\ \mathrm{H} & -13.836852 & 2.440835 & -3.323340\end{array}$

$(8,0) 2$ cells

86

$\begin{array}{lrrr}\text { C } & -4.927418 & 3.456286 & -1.624673 \\ \text { C } & -5.595384 & -2.858423 & -0.346673 \\ \text { C } & 0.324784 & 0.565002 & -3.147830 \\ \text { C } & -0.144219 & 2.801198 & -2.156489 \\ \text { C } & -1.357554 & 3.071442 & -2.734135\end{array}$




$\begin{array}{rrrr}\text { C } & -2.518369 & 3.353989 & -1.914944 \\ \text { C } & -3.806851 & 3.582506 & -2.440452 \\ \text { C } & -1.098558 & 3.039407 & 0.077146 \\ \text { C } & -2.399939 & 3.074533 & -0.519942 \\ \text { C } & -3.551250 & 2.719717 & 0.236572 \\ \text { C } & -4.811603 & 2.970728 & -0.312599 \\ \text { C } & -1.994117 & 1.767837 & 1.944399 \\ \text { C } & -3.287084 & 1.785861 & 1.358561 \\ \text { C } & -4.084746 & 0.633571 & 1.447463 \\ \text { C } & -2.261462 & -0.613418 & 2.460519 \\ \text { C } & -3.553459 & -0.594628 & 1.884725 \\ \text { C } & -4.039920 & -1.812082 & 1.189805 \\ \text { C } & -5.349517 & -2.006731 & 0.736988 \\ \text { C } & -1.690548 & -2.616625 & 1.225953 \\ \text { C } & -2.995898 & -2.585926 & 0.612383 \\ \text { C } & -3.214044 & -3.206566 & -0.648965 \\ \text { C } & -4.534649 & -3.384000 & -1.087945 \\ \text { C } & -0.745775 & -3.201347 & -0.920866 \\ \text { C } & -2.021291 & -3.227696 & -1.518223 \\ \text { C } & -2.134672 & -2.792981 & -2.863214 \\ \text { C } & 0.119404 & -1.881651 & -2.790774 \\ \text { C } & -1.106121 & -2.079434 & -3.461692 \\ \text { C } & 0.970543 & -0.679270 & -2.931439 \\ \text { C } & 4.191522 & 0.555911 & -1.420334 \\ \text { C } & 2.885418 & 0.549371 & -2.009245 \\ \text { C } & 2.106883 & 1.728130 & -1.992406 \\ \text { C } & 0.825365 & 1.752567 & -2.599999 \\ \text { C } & 3.820757 & 2.861416 & -0.686027 \\ \text { C } & 2.499348 & 2.750799 & -1.031400 \\ \text { C } & 1.341846 & 3.142884 & -0.173679 \\ \text { C } & 0.044855 & 3.118154 & -0.746332 \\ \text { C } & 1.459354 & 2.991381 & 1.212174 \\ \text { C } & 0.347450 & 2.627766 & 2.012262 \\ \text { C } & -0.939228 & 2.634529 & 1.436873 \\ \text { C } & 1.753081 & 1.769816 & 3.965041 \\ \text { C } & 0.598614 & 1.741127 & 3.170341 \\ \text { C } & -0.222691 & 0.581160 & 3.203290 \\ \text { C } & -1.541612 & 0.602026 & 2.617111 \\ & 1.475183 & -0.582688 & 4.490675 \\ \text { - } & -323229 & -0.636094 & 3.698017\end{array}$




\begin{tabular}{|c|c|c|c|}
\hline C & -0.143342 & -1.837354 & 2.961320 \\
\hline C & -1.425186 & -1.806825 & 2.363310 \\
\hline C & 0.853266 & -2.655707 & 2.395479 \\
\hline $\mathrm{C}$ & 0.684102 & -3.234630 & 1.123809 \\
\hline $\mathrm{C}$ & -0.601522 & -3.200761 & 0.529484 \\
\hline $\mathrm{C}$ & 3.197508 & -3.425754 & 0.690214 \\
\hline C & 1.873651 & -3.263977 & 0.238463 \\
\hline $\mathrm{C}$ & 1.671565 & -2.640957 & -1.015675 \\
\hline $\mathrm{C}$ & 0.363287 & -2.637704 & -1.621299 \\
\hline $\mathrm{C}$ & 3.998132 & -1.842642 & -0.981500 \\
\hline C & 2.709465 & -1.829577 & -1.562229 \\
\hline $\mathrm{C}$ & 2.248403 & -0.685486 & -2.332169 \\
\hline $\mathrm{C}$ & 4.871897 & -0.665718 & -1.150370 \\
\hline $\mathrm{C}$ & 6.836707 & 0.630980 & -0.544378 \\
\hline C & 6.105335 & 1.815131 & -0.592946 \\
\hline $\mathrm{C}$ & 4.753534 & 1.796832 & -0.989973 \\
\hline $\mathrm{C}$ & 2.135318 & 0.635577 & 4.685766 \\
\hline $\mathrm{C}$ & 4.246562 & -2.770230 & 0.057548 \\
\hline C & 6.215659 & -0.606623 & -0.761665 \\
\hline $\mathrm{H}$ & -3.919014 & 3.824382 & -3.491463 \\
\hline $\mathrm{H}$ & -5.911678 & 3.659534 & -2.030366 \\
\hline $\mathrm{H}$ & -5.704980 & 2.751109 & 0.260640 \\
\hline $\mathrm{H}$ & -6.166919 & -1.464121 & 1.197898 \\
\hline $\mathrm{H}$ & -6.614689 & -3.032361 & -0.671020 \\
\hline $\mathrm{H}$ & -4.729335 & -3.900850 & -2.020470 \\
\hline $\mathrm{H}$ & -0.703567 & 0.550573 & -3.484499 \\
\hline $\mathrm{H}$ & -1.521207 & 2.879497 & -3.789912 \\
\hline $\mathrm{H}$ & -5.002929 & 0.608202 & 0.875691 \\
\hline $\mathrm{H}$ & -3.096845 & -2.845585 & -3.357928 \\
\hline $\mathrm{H}$ & -1.279913 & -1.590538 & -4.413658 \\
\hline $\mathrm{H}$ & 2.448938 & 2.860987 & 1.629920 \\
\hline $\mathrm{H}$ & 1.862257 & -2.551904 & 2.771676 \\
\hline $\mathrm{H}$ & 7.882022 & 0.657890 & -0.259229 \\
\hline $\mathrm{H}$ & 6.559447 & 2.751969 & -0.289924 \\
\hline $\mathrm{H}$ & 4.147054 & 3.634426 & 0.002674 \\
\hline $\mathrm{H}$ & 2.365242 & 2.663742 & 3.994736 \\
\hline $\mathrm{H}$ & 3.007090 & 0.676290 & 5.328150 \\
\hline $\mathrm{H}$ & 1.878802 & -1.493556 & 4.917812 \\
\hline $\mathrm{H}$ & 3.388219 & -3.981853 & 1.601288 \\
\hline $\mathrm{H}$ & 5.238871 & -2.831367 & 0.487340 \\
\hline
\end{tabular}

S121 


$\mathrm{H} \quad 6.771540 \quad-1.521552 \quad-0.593254$

$(8,0) 3$ cells

118

$\begin{array}{lrrr}\text { C } & -7.306997 & 3.382363 & -0.683776 \\ \text { C } & -7.594057 & -2.811290 & 0.653762 \\ \text { C } & -2.537775 & 0.601933 & -3.566550 \\ \text { C } & -2.796528 & 2.760245 & -2.390172 \\ \text { C } & -4.121828 & 3.024490 & -2.646853 \\ \text { C } & -5.046375 & 3.278686 & -1.567202 \\ \text { C } & -6.429385 & 3.495802 & -1.755827 \\ \text { C } & -3.185996 & 3.005792 & 0.018341 \\ \text { C } & -4.585747 & 3.026324 & -0.237651 \\ \text { C } & -5.509130 & 2.685480 & 0.793284 \\ \text { C } & -6.865971 & 2.924134 & 0.570479 \\ \text { C } & -3.563224 & 1.769712 & 2.082341 \\ \text { C } & -4.963310 & 1.776665 & 1.832917 \\ \text { C } & -5.704787 & 0.623264 & 2.127020 \\ \text { C } & -3.668625 & -0.613684 & 2.616322 \\ \text { C } & -5.065861 & -0.604895 & 2.386373 \\ \text { C } & -5.705527 & -1.801933 & 1.788461 \\ \text { C } & -7.085909 & -1.998787 & 1.674428 \\ \text { C } & -3.429817 & -2.572193 & 1.198676 \\ \text { C } & -4.839645 & -2.542134 & 0.935499 \\ \text { C } & -5.365990 & -3.121091 & -0.255600 \\ \text { C } & -6.754865 & -3.296062 & -0.352282 \\ \text { C } & -3.044162 & -3.118251 & -1.136381 \\ \text { C } & -4.430259 & -3.131273 & -1.394456 \\ \text { C } & -4.869995 & -2.706700 & -2.674580 \\ \text { C } & -2.653937 & -1.835816 & -3.184848 \\ \text { C } & -4.014707 & -2.013067 & -3.518767 \\ \text { C } & -1.857721 & -0.640498 & -3.532048 \\ \text { C } & 1.637948 & 0.592469 & -2.816483 \\ \text { C } & 0.231072 & 0.598284 & -3.104529 \\ \text { C } & -0.532563 & 1.776376 & -2.854244 \\ \text { C } & -1.931180 & 1.784402 & -3.121305 \\ \text { C } & 1.400370 & 2.723088 & -1.633686\end{array}$

S122 


$\begin{array}{rrrr}\text { C } & 0.032055 & 2.700267 & -1.880559 \\ \text { C } & -0.889309 & 3.086046 & -0.828260 \\ \text { C } & -2.281820 & 3.041597 & -1.063521 \\ \text { C } & 1.010363 & 3.096572 & 0.745645 \\ \text { C } & -0.401957 & 3.060144 & 0.502466 \\ \text { C } & -1.301997 & 2.624160 & 1.535187 \\ \text { C } & -2.685545 & 2.618806 & 1.304398 \\ \text { C } & 0.660892 & 1.732022 & 2.741165 \\ \text { C } & -0.736726 & 1.742154 & 2.533946 \\ \text { C } & -1.524771 & 0.604768 & 2.885319 \\ \text { C } & -2.945183 & 0.619068 & 2.663308 \\ \text { C } & 0.556364 & -0.655905 & 3.262890 \\ \text { C } & -0.839047 & -0.640609 & 3.057297 \\ \text { C } & -1.489484 & -1.802574 & 2.484299 \\ \text { C } & -2.879224 & -1.776358 & 2.244233 \\ \text { C } & 0.767647 & -2.703127 & 1.964282 \\ \text { C } & -0.646398 & -2.668892 & 1.717955 \\ \text { C } & -1.160534 & -3.154235 & 0.479981 \\ \text { C } & -2.547341 & -3.112567 & 0.228047 \\ \text { C } & 1.157583 & -3.205621 & -0.384216 \\ \text { C } & -0.228702 & -3.164207 & -0.631440 \\ \text { C } & -0.721643 & -2.622758 & -1.856345 \\ \text { C } & -2.132035 & -2.605824 & -2.113616 \\ \text { C } & 1.534319 & -1.803877 & -2.350935 \\ \text { C } & 0.147348 & -1.795334 & -2.622459 \\ \text { C } & -0.467351 & -0.644043 & -3.261591 \\ \text { C } & 2.342983 & -0.651212 & -2.693199 \\ \text { C } & 5.812708 & 0.593686 & -1.975136 \\ \text { C } & 4.413575 & 0.580857 & -2.244445 \\ \text { C } & 3.644905 & 1.741548 & -2.007264 \\ \text { C } & 2.260323 & 1.754717 & -2.289826 \\ \text { C } & 5.610627 & 2.907036 & -1.182481 \\ \text { C } & 4.241179 & 2.789032 & -1.200123 \\ \text { C } & 3.313625 & 3.229889 & -0.116217 \\ \text { C } & 1.912821 & 3.195921 & -0.354920 \\ \text { C } & 3.776258 & 3.068524 & 1.197997 \\ \text { C } & 2.915631 & 2.652805 & 2.238113 \\ \text { C } & 1.521695 & 2.644384 & 2.003654 \\ & 4.796253 & 1.762994 & 3.719941 \\ & 3.474048 & 1.733488 & 3.254708\end{array}$




$\begin{array}{rrrr}\text { C } & 2.705794 & 0.554859 & 3.473579 \\ \mathrm{C} & 1.286723 & 0.567715 & 3.259358 \\ \mathrm{C} & 4.692796 & -0.608081 & 4.239319 \\ \mathrm{C} & 3.372411 & -0.666342 & 3.779782 \\ \mathrm{C} & 2.729028 & -1.869854 & 3.198026 \\ \mathrm{C} & 1.331186 & -1.847727 & 2.958115 \\ \mathrm{C} & 3.538872 & -2.708337 & 2.412446 \\ \mathrm{C} & 3.045650 & -3.293509 & 1.228012 \\ \mathrm{C} & 1.649892 & -3.252963 & 0.980629 \\ \mathrm{C} & 5.369515 & -3.475653 & 0.195626 \\ \mathrm{C} & 3.975427 & -3.319685 & 0.076355 \\ \mathrm{C} & 3.474260 & -2.679267 & -1.087591 \\ \mathrm{C} & 2.063047 & -2.665118 & -1.349332 \\ \mathrm{C} & 5.741841 & -1.821701 & -1.554210 \\ \mathrm{C} & 4.350058 & -1.813868 & -1.816141 \\ \mathrm{C} & 3.719315 & -0.656886 & -2.415376 \\ \mathrm{C} & 6.544157 & -0.628355 & -1.885629 \\ \mathrm{C} & 8.585008 & 0.683859 & -1.728298 \\ \mathrm{C} & 7.857834 & 1.862670 & -1.598282 \\ \mathrm{C} & 6.448882 & 1.838802 & -1.672885 \\ \mathrm{C} & 5.366738 & 0.617791 & 4.281521 \\ \mathrm{C} & 6.235210 & -2.784712 & -0.643617 \\ \mathrm{C} & 7.939362 & -0.559358 & -1.812419 \\ \mathrm{H} & -6.802938 & 3.722568 & -2.748085 \\ \mathrm{H} & -8.362690 & 3.576675 & -0.833774 \\ \mathrm{H} & -7.589418 & 2.716509 & 1.350438 \\ \mathrm{H} & -7.762979 & -1.487424 & 2.348951 \\ \mathrm{H} & -8.661569 & -2.987100 & 0.591400 \\ \mathrm{H} & -7.179594 & -3.782968 & -1.222259 \\ \mathrm{H} & -3.617808 & 0.581962 & -3.627050 \\ \mathrm{H} & -4.530597 & 2.879872 & -3.641703 \\ \mathrm{H} & -6.739255 & 0.593106 & 1.812390 \\ \mathrm{H} & -5.925095 & -2.751806 & -2.915216 \\ \mathrm{H} & -4.416558 & -1.523611 & -4.398705 \\ \mathrm{H} & 4.840642 & 2.941414 & 1.343406 \\ & 4.611318 & -2.613923 & 2.516457 \\ \mathrm{H} & 9.667720 & 0.716163 & -1.689909 \\ \mathrm{H} & 8.365345 & 2.800858 & -1.403807 \\ \mathrm{H} & 5.086426 & 3.710175 & -0.628831 \\ \mathrm{H} & & 2.667075 & 3.617009\end{array}$




$\begin{array}{rrrr}\mathrm{H} & 6.376366 & 0.659652 & 4.672835 \\ \mathrm{H} & 5.205553 & -1.518353 & 4.528086 \\ \mathrm{H} & 5.774187 & -4.051394 & 1.020523 \\ \mathrm{H} & 7.301317 & -2.849061 & -0.463740 \\ \mathrm{H} & 8.527519 & -1.469095 & -1.786776\end{array}$

$(8,0) 4$ cells

150

$\begin{array}{lrrr}\text { C } & -9.463901 & 3.381485 & -0.254533 \\ \text { C } & -9.628491 & -2.823010 & 1.036576 \\ \text { C } & -4.942063 & 0.632799 & -3.568377 \\ \text { C } & -5.106516 & 2.759365 & -2.321870 \\ \text { C } & -6.448121 & 3.032163 & -2.468211 \\ \text { C } & -7.281301 & 3.274637 & -1.316705 \\ \text { C } & -8.675087 & 3.497996 & -1.392254 \\ \text { C } & -5.302107 & 2.988707 & 0.114030 \\ \text { C } & -6.716364 & 3.015293 & -0.028805 \\ \text { C } & -7.556674 & 2.673351 & 1.072167 \\ \text { C } & -8.925426 & 2.915732 & 0.959146 \\ \text { C } & -5.516520 & 1.755856 & 2.203559 \\ \text { C } & -6.931806 & 1.760194 & 2.061987 \\ \text { C } & -7.645025 & 0.602551 & 2.403816 \\ \text { C } & -5.573155 & -0.631453 & 2.720833 \\ \text { C } & -6.983559 & -0.626492 & 2.598743 \\ \text { C } & -7.661626 & -1.816811 & 2.032293 \\ \text { C } & -9.045216 & -2.022292 & 2.026142 \\ \text { C } & -5.436194 & -2.559398 & 1.248239 \\ \text { C } & -6.861531 & -2.537053 & 1.100150 \\ \text { C } & -7.479065 & -3.101846 & -0.054217 \\ \text { C } & -8.870267 & -3.285767 & -0.041061 \\ \text { C } & -5.236579 & -3.076542 & -1.119395 \\ \text { C } & -6.639566 & -3.098614 & -1.264322 \\ \text { C } & -7.183639 & -2.680818 & -2.505841 \\ \text { C } & -5.020788 & -1.804583 & -3.200354 \\ \text { C } & -6.403403 & -1.987164 & -3.420346 \\ \text { C } & -4.259322 & -0.607452 & -3.608654 \\ \text { C } & -0.715386 & 0.626241 & -3.196700\end{array}$




$\begin{array}{lrrr}\text { C } & -2.140930 & 0.632259 & -3.350277 \\ \text { C } & -2.887244 & 1.798946 & -2.997245 \\ \text { C } & -4.303360 & 1.807732 & -3.146942 \\ \text { C } & -0.857499 & 2.683634 & -1.894467 \\ \text { C } & -2.248651 & 2.678706 & -2.034992 \\ \text { C } & -3.078571 & 3.052952 & -0.913302 \\ \text { C } & -4.487018 & 3.018292 & -1.037457 \\ \text { C } & -1.073785 & 3.070665 & 0.514317 \\ \text { C } & -2.489964 & 3.039923 & 0.380747 \\ \text { C } & -3.306204 & 2.606221 & 1.483308 \\ \text { C } & -4.703043 & 2.602225 & 1.359877 \\ \text { C } & -1.253988 & 1.731307 & 2.554039 \\ \text { C } & -2.664827 & 1.734364 & 2.442662 \\ \text { C } & -3.423041 & 0.596028 & 2.854384 \\ \text { C } & -4.852828 & 0.605491 & 2.735931 \\ \text { C } & -1.308617 & -0.657505 & 3.052473 \\ \text { C } & -2.717488 & -0.649077 & 2.945612 \\ \text { C } & -3.403914 & -1.797002 & 2.392262 \\ \text { C } & -4.808807 & -1.778324 & 2.263079 \\ \text { C } & -1.200370 & -2.670702 & 1.675431 \\ \text { C } & -2.619880 & -2.646281 & 1.544518 \\ \text { C } & -3.227698 & -3.105154 & 0.335399 \\ \text { C } & -4.630944 & -3.073302 & 0.198254 \\ \text { C } & -0.987489 & -3.134713 & -0.713433 \\ \text { C } & -2.391759 & -3.102998 & -0.844909 \\ \text { C } & -2.984708 & -2.583817 & -2.034624 \\ \text { C } & -4.409201 & -2.570435 & -2.172641 \\ \text { C } & -0.775891 & -1.769801 & -2.731485 \\ \text { C } & -2.181966 & -1.760618 & -2.878141 \\ \text { C } & -2.849732 & -0.609716 & -3.457081 \\ \text { C } & -0.003411 & -0.618611 & -3.139968 \\ \text { C } & 3.526679 & 0.616886 & -2.718671 \\ \text { C } & 2.111751 & 0.618973 & -2.890608 \\ \text { C } & 1.359411 & 1.778616 & -2.537426 \\ \text { C } & -0.049192 & 1.779262 & -2.686445 \\ \text { C } & 3.380249 & 2.740143 & -1.499315 \\ \text { C } & 1.989542 & 2.711788 & -1.626751 \\ \text { C } & 1.154439 & 3.146999 & -0.524467 \\ \text { C } & -0.254819 & 3.119987 & -0.653803 \\ & 3.180078 & 3.128573 & 0.893599\end{array}$




$\begin{array}{rrrr}\text { C } & 1.753216 & 3.105182 & 0.767756 \\ \text { C } & 0.942797 & 2.626571 & 1.851800 \\ \text { C } & -0.461857 & 2.619490 & 1.731380 \\ \text { C } & 2.998841 & 1.714940 & 2.874688 \\ \text { C } & 1.589138 & 1.722739 & 2.775505 \\ \text { C } & 0.838777 & 0.571575 & 3.175026 \\ \text { C } & -0.583829 & 0.579911 & 3.073077 \\ \text { C } & 2.947198 & -0.685176 & 3.363423 \\ \text { C } & 1.539796 & -0.674791 & 3.265942 \\ \text { C } & 0.849661 & -1.836138 & 2.751236 \\ \text { C } & -0.558914 & -1.821665 & 2.632183 \\ \text { C } & 3.055125 & -2.738605 & 2.060219 \\ \text { C } & 1.629254 & -2.712653 & 1.930549 \\ \text { C } & 1.014862 & -3.196447 & 0.734144 \\ \text { C } & -0.391401 & -3.165855 & 0.601666 \\ \text { C } & 3.253497 & -3.230051 & -0.313178 \\ \text { C } & 1.850524 & -3.197166 & -0.447886 \\ \text { C } & 1.255873 & -2.658320 & -1.636521 \\ \text { C } & -0.162455 & -2.640654 & -1.775458 \\ \text { C } & 3.466433 & -1.788665 & -2.274379 \\ \text { C } & 2.059914 & -1.784001 & -2.431856 \\ \text { C } & 1.399264 & -0.623862 & -2.986204 \\ \text { C } & 4.240899 & -0.628281 & -2.660801 \\ \text { C } & 7.751944 & 0.625168 & -2.217787 \\ \text { C } & 6.336547 & 0.610234 & -2.369143 \\ \text { C } & 5.587468 & 1.766427 & -2.056127 \\ \text { C } & 4.183354 & 1.777751 & -2.222591 \\ \text { C } & 7.613551 & 2.935366 & -1.400449 \\ \text { C } & 6.246646 & 2.814773 & -1.303384 \\ \text { C } & 5.409759 & 3.262336 & -0.151456 \\ \text { C } & 3.994589 & 3.231076 & -0.276841 \\ \text { C } & 5.976256 & 3.091809 & 1.121360 \\ \text { C } & 5.202671 & 2.657705 & 2.219168 \\ \text { C } & 3.793248 & 2.647044 & 2.094538 \\ \text { C } & 7.196658 & 1.750953 & 3.530378 \\ \text { C } & 5.842386 & 1.722028 & 3.169835 \\ \text { C } & 5.098297 & 0.534677 & 3.426836 \\ & 3.668571 & 0.543852 & 3.323134 \\ \text { C } & 7.144794 & -0.629246 & 4.016125 \\ \text { C.792529 } & -0.688374 & 3.660950\end{array}$




$\begin{array}{rrrr}\mathrm{C} & 5.109323 & -1.890551 & 3.126285 \\ \mathrm{C} & 3.696453 & -1.871831 & 2.998507 \\ \mathrm{C} & 5.854030 & -2.730276 & 2.280196 \\ \mathrm{C} & 5.268129 & -3.317635 & 1.139178 \\ \mathrm{C} & 3.856427 & -3.280884 & 1.004936 \\ \mathrm{C} & 7.501414 & -3.484109 & -0.079276 \\ \mathrm{C} & 6.102086 & -3.333985 & -0.083016 \\ \mathrm{C} & 5.504643 & -2.679734 & -1.194241 \\ \mathrm{C} & 4.078609 & -2.671527 & -1.341309 \\ \mathrm{C} & 7.724206 & -1.796885 & -1.822913 \\ \mathrm{C} & 6.315268 & -1.792161 & -1.971012 \\ \mathrm{C} & 5.634541 & -0.630283 & -2.496601 \\ \mathrm{C} & 8.492126 & -0.595873 & -2.203225 \\ \mathrm{C} & 10.534931 & 0.722654 & -2.209614 \\ \mathrm{C} & 9.819254 & 1.897738 & -2.007824 \\ \mathrm{C} & 8.408590 & 1.870470 & -1.960707 \\ \mathrm{C} & 7.814321 & 0.599491 & 4.025138 \\ \mathrm{C} & 8.293512 & -2.773202 & -0.974049 \\ \mathrm{C} & 9.887718 & -0.522606 & -2.249219 \\ \mathrm{H} & -9.125953 & 3.732331 & -2.350000 \\ \mathrm{H} & -10.527588 & 3.579528 & -0.318367 \\ \mathrm{H} & -9.585152 & 2.705577 & 1.793060 \\ \mathrm{H} & -9.669075 & -1.526920 & 2.761181 \\ \mathrm{H} & -10.696336 & -3.006282 & 1.057691 \\ \mathrm{H} & -9.360428 & -3.764295 & -0.880671 \\ \mathrm{H} & -6.023433 & 0.610438 & -3.540480 \\ \mathrm{H} & -6.933562 & 2.911005 & -3.431098 \\ \mathrm{H} & -8.700954 & 0.571449 & 2.171179 \\ \mathrm{H} & -8.254459 & -2.732489 & -2.660203 \\ \mathrm{H} & -6.878430 & -1.501491 & -4.265192 \\ \mathrm{H} & 7.049148 & 2.966298 & 1.179456 \\ \mathrm{H} & 6.931463 & -2.636812 & 2.298147 \\ \mathrm{H} & 11.616822 & 0.758095 & -2.264528 \\ \mathrm{H} & 10.339358 & 2.836132 & -1.851581 \\ \mathrm{H} & 8.132091 & 3.742762 & -0.893481 \\ \mathrm{H} & 7.771417 & 2.660155 & 3.398252 \\ \mathrm{H} & 7.682282 & -1.540494 & 4.251440 \\ \mathrm{H} & 9.974544 & -4.068724 & 0.701805 \\ \mathrm{H} & & -2.834901 & -0.882228\end{array}$

S128 


$\begin{array}{lrrr}\text { H } & 10.478654 & -1.430255 & -2.283242 \\ & & & \\ \text { (8,0) } & \text { 5 cells } & & \\ & & & \\ \text { 182 } & & & \\ & & & \\ \text { C } & -11.596277 & 3.385378 & -0.019798 \\ \text { C } & -11.708855 & -2.841344 & 1.219568 \\ \text { C } & -7.194274 & 0.663876 & -3.518247 \\ \text { C } & -7.313110 & 2.774364 & -2.239716 \\ \text { C } & -8.658736 & 3.051116 & -2.337925 \\ \text { C } & -9.451611 & 3.283532 & -1.157140 \\ \text { C } & -10.846977 & 3.510288 & -1.182706 \\ \text { C } & -7.425288 & 2.984036 & 0.202928 \\ \text { C } & -8.843149 & 3.012902 & 0.108569 \\ \text { C } & -9.646369 & 2.662930 & 1.234886 \\ \text { C } & -11.017416 & 2.907986 & 1.170944 \\ \text { C } & -7.569665 & 1.738253 & 2.290573 \\ \text { C } & -8.988926 & 1.741349 & 2.195357 \\ \text { C } & -9.688590 & 0.579284 & 2.549643 \\ \text { C } & -7.605673 & -0.653979 & 2.788112 \\ \text { C } & -9.019019 & -0.650675 & 2.711647 \\ \text { C } & -9.712423 & -1.836987 & 2.156358 \\ \text { C } & -11.094685 & -2.047017 & 2.195555 \\ \text { C } & -7.512673 & -2.564293 & 1.289139 \\ \text { C } & -8.942048 & -2.546026 & 1.190618 \\ \text { C } & -9.597347 & -3.102472 & 0.052987 \\ \text { C } & -10.986639 & -3.291891 & 0.112549 \\ \text { C } & -7.393182 & -3.058766 & -1.089030 \\ \text { C } & -8.800650 & -3.086474 & -1.185106 \\ \text { C } & -9.389684 & -2.664194 & -2.404126 \\ \text { C } & -7.256429 & -1.776738 & -3.170796 \\ \text { C } & -8.645117 & -1.962307 & -3.342085 \\ \text { C } & -6.513074 & -0.575255 & -3.598006 \\ \text { C } & -2.958147 & 0.657461 & -3.312471 \\ \text { C } & -4.386986 & 0.664233 & -3.408588 \\ \text { C } & -5.120273 & 1.824436 & -3.006484 \\ \text { C } & -6.540852 & 1.834130 & -3.104867 \\ \text { C } & -3.050094 & 2.680725 & -1.955983\end{array}$

S129 


$\begin{array}{lrrr}\text { C } & -4.448115 & 2.683726 & -2.050178 \\ \text { C } & -5.236486 & 3.048528 & -0.898893 \\ \text { C } & -6.649345 & 3.019031 & -0.975174 \\ \text { C } & -3.185423 & 3.056109 & 0.462403 \\ \text { C } & -4.603744 & 3.030728 & 0.375963 \\ \text { C } & -5.384763 & 2.593526 & 1.503585 \\ \text { C } & -6.784964 & 2.590123 & 1.426294 \\ \text { C } & -3.300237 & 1.719116 & 2.508492 \\ \text { C } & -4.713663 & 1.720132 & 2.439596 \\ \text { C } & -5.456815 & 0.577960 & 2.868863 \\ \text { C } & -6.887912 & 0.585076 & 2.794160 \\ \text { C } & -3.334490 & -0.672589 & 2.986332 \\ \text { C } & -4.745795 & -0.667087 & 2.922145 \\ \text { C } & -5.445173 & -1.807516 & 2.373048 \\ \text { C } & -6.853848 & -1.792732 & 2.291412 \\ \text { C } & -3.264176 & -2.659757 & 1.568906 \\ \text { C } & -4.685702 & -2.642373 & 1.487641 \\ \text { C } & -5.333746 & -3.087317 & 0.292849 \\ \text { C } & -6.741682 & -3.062469 & 0.205818 \\ \text { C } & -3.131185 & -3.096845 & -0.833562 \\ \text { C } & -4.540744 & -3.072659 & -0.914910 \\ \text { C } & -5.178003 & -2.556920 & -2.083080 \\ \text { C } & -6.605712 & -2.546476 & -2.169302 \\ \text { C } & -2.998185 & -1.739120 & -2.863705 \\ \text { C } & -4.408469 & -1.730877 & -2.955521 \\ \text { C } & -5.098625 & -0.577403 & -3.500515 \\ \text { C } & -2.244282 & -0.586923 & -3.295676 \\ \text { C } & 1.300711 & 0.646623 & -3.027084 \\ \text { C } & -0.117840 & 0.649682 & -3.127887 \\ \text { C } & -0.860188 & 1.798506 & -2.706664 \\ \text { C } & -2.273038 & 1.800792 & -2.801183 \\ \text { C } & 1.203920 & 2.693937 & -1.695998 \\ \text { C } & -0.199570 & 2.684864 & -1.779564 \\ \text { C } & -0.990513 & 3.114845 & -0.651625 \\ \text { C } & -2.404652 & 3.099083 & -0.733639 \\ \text { C } & 1.067791 & 3.101273 & 0.708772 \\ \text { C } & -0.351011 & 3.086421 & 0.627219 \\ \text { C } & -1.126738 & 2.607207 & 1.737863 \\ \text { C } & -2.535204 & 2.602573 & 1.660603 \\ & 0.961558 & 1.711577 & 2.717373\end{array}$




$\begin{array}{rrrr}\text { C } & -0.452500 & 1.714474 & 2.649160 \\ \text { C } & -1.191435 & 0.563316 & 3.075362 \\ \text { C } & -2.612368 & 0.568071 & 3.010387 \\ \text { C } & 0.930512 & -0.688287 & 3.180694 \\ \text { C } & -0.481630 & -0.682997 & 3.116113 \\ \text { C } & -1.182312 & -1.830006 & 2.591714 \\ \text { C } & -2.594603 & -1.822057 & 2.518626 \\ \text { C } & 0.991943 & -2.709701 & 1.811308 \\ \text { C } & -0.426907 & -2.692959 & 1.730596 \\ \text { C } & -1.078785 & -3.150106 & 0.538961 \\ \text { C } & -2.489677 & -3.129935 & 0.457230 \\ \text { C } & 1.122240 & -3.159874 & -0.585216 \\ \text { C } & -0.287908 & -3.137961 & -0.667941 \\ \text { C } & -0.926963 & -2.623873 & -1.844643 \\ \text { C } & -2.346562 & -2.610124 & -1.930112 \\ \text { C } & 1.260062 & -1.757547 & -2.582117 \\ \text { C } & -0.152605 & -1.751565 & -2.676588 \\ \text { C } & -0.834568 & -0.592234 & -3.198406 \\ \text { C } & 2.014538 & -0.600200 & -2.999411 \\ \text { C } & 5.553779 & 0.642343 & -2.699782 \\ \text { C } & 4.135320 & 0.642829 & -2.818374 \\ \text { C } & 3.394457 & 1.798479 & -2.424616 \\ \text { C } & 1.980842 & 1.797699 & -2.518842 \\ \text { C } & 5.452238 & 2.757453 & -1.460269 \\ \text { C } & 4.055993 & 2.728769 & -1.536823 \\ \text { C } & 3.262010 & 3.171192 & -0.408974 \\ \text { C } & 1.849666 & 3.150005 & -0.489188 \\ \text { C } & 5.335506 & 3.138469 & 0.937882 \\ \text { C } & 3.906203 & 3.120137 & 0.862675 \\ \text { C } & 3.133379 & 2.622541 & 1.964502 \\ \text { C } & 1.723136 & 2.616647 & 1.890526 \\ \text { C } & 5.222536 & 1.697543 & 2.903125 \\ \text { C } & 3.809984 & 1.704897 & 2.849511 \\ \text { C } & 3.073799 & 0.545757 & 3.257250 \\ \text { C } & 1.651026 & 0.552279 & 3.198928 \\ \text { C } & 5.190573 & -0.709817 & 3.361681 \\ \text { C } & 3.780095 & -0.700934 & 3.307946 \\ & 3.077133 & -1.860263 & 2.811486 \\ \text { C } & 1.665209 & -1.848586 & 2.738680 \\ & & -2.759612 & 2.047706\end{array}$




$\begin{array}{lrrr}\text { C } & 3.829926 & -2.737468 & 1.966376 \\ \text { C } & 3.175757 & -3.220031 & 0.789603 \\ \text { C } & 1.764921 & -3.194696 & 0.705416 \\ \text { C } & 5.376570 & -3.238044 & -0.333080 \\ \text { C } & 3.969821 & -3.210659 & -0.418908 \\ \text { C } & 3.330646 & -2.662745 & -1.581854 \\ \text { C } & 1.910705 & -2.650522 & -1.670922 \\ \text { C } & 5.515835 & -1.769345 & -2.280241 \\ \text { C } & 4.104033 & -1.767074 & -2.386698 \\ \text { C } & 3.422129 & -0.602652 & -2.897766 \\ \text { C } & 6.272365 & -0.602401 & -2.679531 \\ \text { C } & 9.795336 & 0.654449 & -2.355284 \\ \text { C } & 8.375631 & 0.638213 & -2.453752 \\ \text { C } & 7.637156 & 1.790024 & -2.102127 \\ \text { C } & 6.227441 & 1.800488 & -2.216336 \\ \text { C } & 9.684926 & 2.957699 & -1.514474 \\ \text { C } & 8.322506 & 2.834205 & -1.367591 \\ \text { C } & 7.527657 & 3.276025 & -0.184502 \\ \text { C } & 6.109335 & 3.246944 & -0.260479 \\ \text { C } & 8.138007 & 3.095142 & 1.067060 \\ \text { C } & 7.402895 & 2.650603 & 2.186529 \\ \text { C } & 5.989621 & 2.640642 & 2.110280 \\ \text { C } & 9.439302 & 1.732209 & 3.421430 \\ \text { C } & 8.074332 & 1.704984 & 3.104593 \\ \text { C } & 7.340202 & 0.513198 & 3.371341 \\ \text { C } & 5.908274 & 0.521168 & 3.313988 \\ \text { C } & 9.406643 & -0.653547 & 3.881270 \\ \text { C } & 8.043713 & -0.711300 & 3.568729 \\ \text { C } & 7.345369 & -1.909677 & 3.046768 \\ \text { C } & 5.928783 & -1.892227 & 2.965635 \\ \text { C } & 8.062818 & -2.743527 & 2.171632 \\ \text { C } & 7.440260 & -3.326670 & 1.047904 \\ \text { C } & 6.024633 & -3.294315 & 0.962494 \\ \text { C } & 9.630190 & -3.477178 & -0.250012 \\ \text { C } & 8.231517 & -3.331479 & -0.202508 \\ \text { C } & 7.593079 & -2.667876 & -1.285883 \\ \text { C } & 6.163704 & -2.664067 & -1.383400 \\ & 9.786502 & -1.771312 & -1.983096 \\ \text { C.372895 } & -1.768134 & -2.079852 \\ \text { C.671179 } & -0.602814 & -2.567376\end{array}$




$\begin{array}{rrrr}\text { C } & 10.537696 & -0.565375 & -2.380438 \\ \mathrm{C} & 12.576411 & 0.757384 & -2.453558 \\ \mathrm{C} & 11.867402 & 1.929049 & -2.213309 \\ \mathrm{C} & 10.459475 & 1.898725 & -2.112161 \\ \mathrm{C} & 10.074179 & 0.576157 & 3.882872 \\ \mathrm{C} & 10.387975 & -2.754735 & -1.165804 \\ \mathrm{C} & 11.930121 & -0.488952 & -2.479708 \\ \mathrm{H} & -11.329811 & 3.754192 & -2.122277 \\ \mathrm{H} & -12.661110 & 3.585834 & -0.045319 \\ \mathrm{H} & -11.648592 & 2.691340 & 2.025043 \\ \mathrm{H} & -11.694580 & -1.560272 & 2.955851 \\ \mathrm{H} & -12.774689 & -3.028790 & 1.275736 \\ \mathrm{H} & -11.503731 & -3.765361 & -0.713663 \\ \mathrm{H} & -8.273943 & 0.640464 & -3.451096 \\ \mathrm{H} & -9.175868 & 2.942603 & -3.285671 \\ \mathrm{H} & -10.751673 & 0.548477 & 2.352001 \\ \mathrm{H} & -10.465085 & -2.719277 & -2.520745 \\ \mathrm{H} & -9.151851 & -1.472917 & -4.166082 \\ \mathrm{H} & 9.212218 & 2.969023 & 1.086746 \\ \mathrm{H} & 9.140181 & -2.648771 & 2.154525 \\ \mathrm{H} & 13.655275 & 0.795366 & -2.550166 \\ \mathrm{H} & 12.391637 & 2.867038 & -2.069080 \\ \mathrm{H} & 10.220616 & 3.763203 & -1.022613 \\ \mathrm{H} & 10.008165 & 2.643907 & 3.281375 \\ \mathrm{H} & 11.120501 & 0.615665 & 4.161891 \\ \mathrm{H} & 9.952520 & -1.566232 & 4.089983 \\ \mathrm{H} & 10.132815 & -4.067135 & 0.508282 \\ \mathrm{H} & 11.468144 & -2.814557 & -1.113244 \\ \mathrm{H} & 12.520838 & -1.394939 & -2.545500\end{array}$

$(8,0) 6$ cells

214

$\begin{array}{lrrr}\text { C } & -13.726543 & 3.384679 & 0.133770 \\ \text { C } & -13.811463 & -2.858188 & 1.322556 \\ \text { C } & -9.388723 & 0.693775 & -3.466425 \\ \text { C } & -9.483911 & 2.792812 & -2.167362 \\ \text { C } & -10.831208 & 3.070273 & -2.239298\end{array}$




$\begin{array}{rrrr}\text { C } & -11.602747 & 3.292504 & -1.042825 \\ \text { C } & -12.998372 & 3.519570 & -1.041275 \\ \text { C } & -9.552321 & 2.982257 & 0.278173 \\ \text { C } & -10.971522 & 3.011164 & 0.209357 \\ \text { C } & -11.754568 & 2.651252 & 1.346797 \\ \text { C } & -13.126420 & 2.896701 & 1.309751 \\ \text { C } & -9.659068 & 1.719206 & 2.357577 \\ \text { C } & -11.079819 & 1.721528 & 2.287209 \\ \text { C } & -11.771935 & 0.555548 & 2.643375 \\ \text { C } & -9.684025 & -0.677547 & 2.835124 \\ \text { C } & -11.098369 & -0.675155 & 2.783297 \\ \text { C } & -11.799962 & -1.857758 & 2.230797 \\ \text { C } & -13.180971 & -2.070218 & 2.293297 \\ \text { C } & -9.615149 & -2.574694 & 1.318097 \\ \text { C } & -11.046013 & -2.558099 & 1.245782 \\ \text { C } & -11.721100 & -3.106551 & 0.115866 \\ \text { C } & -13.108757 & -3.298960 & 0.199167 \\ \text { C } & -9.538155 & -3.048908 & -1.065698 \\ \text { C } & -10.947223 & -3.078789 & -1.136231 \\ \text { C } & -11.559426 & -2.647654 & -2.340505 \\ \text { C } & -9.442463 & -1.750158 & -3.139472 \\ \text { C } & -10.833685 & -1.936382 & -3.286277 \\ \text { C } & -8.708834 & -0.544235 & -3.570436 \\ \text { C } & -5.150591 & 0.688300 & -3.344909 \\ \text { C } & -6.580211 & 0.695128 & -3.411790 \\ \text { C } & -7.305782 & 1.850899 & -2.982845 \\ \text { C } & -8.727898 & 1.860753 & -3.054752 \\ \text { C } & -5.215349 & 2.693071 & -1.959796 \\ \text { C } & -6.616030 & 2.698815 & -2.029371 \\ \text { C } & -7.382948 & 3.054672 & -0.861992 \\ \text { C } & -8.797335 & 3.026578 & -0.913120 \\ \text { C } & -5.307854 & 3.051855 & 0.463173 \\ \text { C } & -6.727167 & 3.028172 & 0.401643 \\ \text { C } & -7.488890 & 2.582451 & 1.539535 \\ \text { C } & -8.890279 & 2.578760 & 1.486900 \\ \text { C } & -5.387595 & 1.703440 & 2.503211 \\ \text { C } & -6.801784 & 1.703200 & 2.457575 \\ \text { C } & -7.536307 & 0.556674 & 2.890751 \\ \text { C } & -8.967762 & 0.562579 & 2.840090 \\ & -5.411291 & -0.692525 & 2.960867\end{array}$




$\begin{array}{lrrr}\text { C } & -6.823182 & -0.688326 & 2.919836 \\ \text { C } & -7.529674 & -1.823848 & 2.371295 \\ \text { C } & -8.939671 & -1.810706 & 2.314955 \\ \text { C } & -5.361647 & -2.663282 & 1.519757 \\ \text { C } & -6.784034 & -2.649095 & 1.464676 \\ \text { C } & -7.453205 & -3.083896 & 0.277360 \\ \text { C } & -8.862821 & -3.061922 & 0.216581 \\ \text { C } & -5.271092 & -3.078065 & -0.888898 \\ \text { C } & -6.682762 & -3.057440 & -0.944071 \\ \text { C } & -7.343042 & -2.536461 & -2.097108 \\ \text { C } & -8.771821 & -2.527229 & -2.156452 \\ \text { C } & -5.180096 & -1.711432 & -2.915651 \\ \text { C } & -6.591541 & -1.703510 & -2.979050 \\ \text { C } & -7.292793 & -0.546270 & -3.500746 \\ \text { C } & -4.436823 & -0.555893 & -3.354198 \\ \text { C } & -0.888960 & 0.675949 & -3.155514 \\ \text { C } & -2.307457 & 0.680046 & -3.222650 \\ \text { C } & -3.041252 & 1.822240 & -2.764696 \\ \text { C } & -4.455410 & 1.825591 & -2.831540 \\ \text { C } & -0.954822 & 2.688412 & -1.772578 \\ \text { C } & -2.363110 & 2.687274 & -1.832481 \\ \text { C } & -3.131032 & 3.110137 & -0.689188 \\ \text { C } & -4.547340 & 3.099611 & -0.746342 \\ \text { C } & -1.049903 & 3.086765 & 0.637730 \\ \text { C } & -2.468151 & 3.077603 & 0.579946 \\ \text { C } & -3.227160 & 2.594268 & 1.701355 \\ \text { C } & -4.637265 & 2.590742 & 1.647522 \\ \text { C } & -1.125332 & 1.699538 & 2.649530 \\ \text { C } & -2.540007 & 1.701009 & 2.600421 \\ \text { C } & -3.271350 & 0.546632 & 3.033066 \\ \text { C } & -4.691028 & 0.549664 & 2.988380 \\ \text { C } & -1.146002 & -0.702512 & 3.091776 \\ \text { C } & -2.558945 & -0.699527 & 3.046637 \\ \text { C } & -3.263877 & -1.838963 & 2.515791 \\ \text { C } & -4.677454 & -1.834128 & 2.466860 \\ \text { C } & -1.101401 & -2.699227 & 1.685388 \\ \text { C } & -2.519582 & -2.689107 & 1.630685 \\ \text { C } & -3.192251 & -3.132231 & 0.443558 \\ \text { C } & -4.605377 & -3.118173 & 0.388571 \\ & -1.011798 & -3.122893 & -0.720382\end{array}$




$\begin{array}{lrrr}\text { C } & -2.425085 & -3.108348 & -0.776376 \\ \text { C } & -3.088503 & -2.598644 & -1.941632 \\ \text { C } & -4.508529 & -2.587014 & -1.999163 \\ \text { C } & -0.918182 & -1.728315 & -2.725509 \\ \text { C } & -2.332200 & -1.723071 & -2.788414 \\ \text { C } & -3.025127 & -0.561522 & -3.287602 \\ \text { C } & -0.175167 & -0.570580 & -3.153373 \\ \text { C } & 3.371421 & 0.669127 & -2.950400 \\ \text { C } & 1.953102 & 0.670639 & -3.021268 \\ \text { C } & 1.217574 & 1.815750 & -2.572258 \\ \text { C } & -0.197068 & 1.817063 & -2.635361 \\ \text { C } & 3.302422 & 2.707515 & -1.602354 \\ \text { C } & 1.895198 & 2.698042 & -1.657441 \\ \text { C } & 1.127615 & 3.137355 & -0.518856 \\ \text { C } & -0.287028 & 3.127894 & -0.574955 \\ \text { C } & 3.210252 & 3.109881 & 0.804161 \\ \text { C } & 1.791648 & 3.100514 & 0.749526 \\ \text { C } & 1.035518 & 2.601294 & 1.863746 \\ \text { C } & -0.376838 & 2.598640 & 1.809892 \\ \text { C } & 3.139402 & 1.691956 & 2.793582 \\ \text { C } & 1.723982 & 1.695325 & 2.747823 \\ \text { C } & 0.991838 & 0.536743 & 3.171210 \\ \text { C } & -0.427375 & 0.540469 & 3.126154 \\ \text { C } & 3.118119 & -0.714360 & 3.227369 \\ \text { C } & 1.704132 & -0.709735 & 3.183275 \\ \text { C } & 0.998160 & -1.854504 & 2.666453 \\ \text { C } & -0.415392 & -1.848629 & 2.615808 \\ \text { C } & 3.158047 & -2.732892 & 1.851045 \\ \text { C } & 1.739662 & -2.719506 & 1.794816 \\ \text { C } & 1.067383 & -3.174631 & 0.612358 \\ \text { C } & -0.345681 & -3.159503 & 0.555434 \\ \text { C } & 3.247400 & -3.169237 & -0.549266 \\ \text { C } & 1.835832 & -3.152721 & -0.606527 \\ \text { C } & 1.172379 & -2.630760 & -1.767926 \\ \text { C } & -0.245964 & -2.621969 & -1.827046 \\ \text { C } & 3.344642 & -1.740746 & -2.529315 \\ \text { C } & 1.929813 & -1.737001 & -2.595991 \\ \text { C } & 1.236906 & -0.573473 & -3.085228 \\ & 4.087936 & -0.577319 & -2.946371 \\ & 7.631613 & 0.668101 & -2.707394\end{array}$




$\begin{array}{rrrr}\text { C } & 6.211485 & 0.667675 & -2.797869 \\ \text { C } & 5.477135 & 1.819243 & -2.379438 \\ \text { C } & 4.061594 & 1.817507 & -2.444681 \\ \text { C } & 7.553182 & 2.772900 & -1.448672 \\ \text { C } & 6.155156 & 2.743850 & -1.498908 \\ \text { C } & 5.383346 & 3.182227 & -0.354910 \\ \text { C } & 3.970405 & 3.163568 & -0.409100 \\ \text { C } & 7.480737 & 3.137736 & 0.953576 \\ \text { C } & 6.050937 & 3.121500 & 0.904967 \\ \text { C } & 5.298381 & 2.611759 & 2.014989 \\ \text { C } & 3.886378 & 2.607383 & 1.966584 \\ \text { C } & 7.403416 & 1.677783 & 2.906120 \\ \text { C } & 5.990066 & 1.684945 & 2.877188 \\ \text { C } & 5.260842 & 0.520710 & 3.285170 \\ \text { C } & 3.837787 & 0.526727 & 3.249925 \\ \text { C } & 7.380796 & -0.734179 & 3.341034 \\ \text { C } & 5.969101 & -0.725968 & 3.310449 \\ \text { C } & 5.259246 & -1.881757 & 2.817667 \\ \text { C } & 3.845918 & -1.870847 & 2.768158 \\ \text { C } & 7.427467 & -2.774917 & 2.011719 \\ \text { C } & 5.998631 & -2.754582 & 1.955773 \\ \text { C } & 5.324915 & -3.231631 & 0.787606 \\ \text { C } & 3.912819 & -3.210070 & 0.728621 \\ \text { C } & 7.504582 & -3.235652 & -0.374213 \\ \text { C } & 6.096766 & -3.211475 & -0.434462 \\ \text { C } & 5.434963 & -2.654671 & -1.581121 \\ \text { C } & 4.014816 & -2.646049 & -1.644355 \\ \text { C } & 7.605103 & -1.747364 & -2.308948 \\ \text { C } & 6.191286 & -1.746348 & -2.388750 \\ \text { C } & 5.497939 & -0.578357 & -2.873429 \\ \text { C } & 8.352195 & -0.575934 & -2.711587 \\ \text { C } & 11.879637 & 0.682347 & -2.444102 \\ \text { C } & 10.458403 & 0.665320 & -2.515552 \\ \text { C } & 9.725695 & 1.813035 & -2.139557 \\ \text { C } & 8.313872 & 1.822916 & -2.226557 \\ \text { C } & 11.783430 & 2.977862 & -1.581032 \\ \text { C } & 10.424097 & 2.851647 & -1.409438 \\ & 9.651573 & 3.283474 & -0.208305 \\ \text { C.284901 } & 3.255004 & -0.258414 \\ & 3.092129 & 1.030525\end{array}$




\begin{tabular}{|c|c|c|c|}
\hline C & 9.570499 & 2.638198 & 2.159425 \\
\hline C & 8.155981 & 2.628634 & 2.109046 \\
\hline C & 11.628318 & 1.710810 & 3.351081 \\
\hline C & 10.258252 & 1.685201 & 3.057436 \\
\hline C & 9.529424 & 0.490454 & 3.326106 \\
\hline C & 8.096840 & 0.497746 & 3.293571 \\
\hline C & 11.605213 & -0.678966 & 3.790407 \\
\hline $\mathrm{C}$ & 10.237207 & -0.735118 & 3.500278 \\
\hline C & 9.531017 & -1.929353 & 2.980065 \\
\hline $\mathrm{C}$ & 8.113116 & -1.912435 & 2.923465 \\
\hline $\mathrm{C}$ & 10.234037 & -2.755272 & 2.085738 \\
\hline C & 9.592639 & -3.330295 & 0.968473 \\
\hline $\mathrm{C}$ & 8.175695 & -3.300178 & 0.908833 \\
\hline $\mathrm{C}$ & 11.758632 & -3.466676 & -0.370813 \\
\hline $\mathrm{C}$ & 10.361029 & -3.323620 & -0.296103 \\
\hline $\mathrm{C}$ & 9.701657 & -2.651894 & -1.362182 \\
\hline $\mathrm{C}$ & 8.271166 & -2.650111 & -1.433757 \\
\hline C & 11.880458 & -1.746324 & -2.092501 \\
\hline $\mathrm{C}$ & 10.465184 & -1.743929 & -2.162434 \\
\hline $\mathrm{C}$ & 9.753008 & -0.575585 & -2.626483 \\
\hline $\mathrm{C}$ & 12.622677 & -0.536360 & -2.494213 \\
\hline C & 14.658209 & 0.789426 & -2.595434 \\
\hline $\mathrm{C}$ & 13.952897 & 1.958034 & -2.330913 \\
\hline $\mathrm{C}$ & 12.547190 & 1.925160 & -2.202795 \\
\hline $\mathrm{C}$ & 12.271738 & 0.551244 & 3.791674 \\
\hline $\mathrm{C}$ & 12.498227 & -2.735626 & -1.294927 \\
\hline $\mathrm{C}$ & 14.012751 & -0.457452 & -2.619958 \\
\hline $\mathrm{H}$ & -13.497921 & 3.771854 & -1.969816 \\
\hline $\mathrm{H}$ & -14.791593 & 3.585495 & 0.129200 \\
\hline $\mathrm{H}$ & -13.742157 & 2.672533 & 2.173118 \\
\hline $\mathrm{H}$ & -13.767769 & -1.590280 & 3.067987 \\
\hline $\mathrm{H}$ & -14.875779 & -3.047977 & 1.396626 \\
\hline $\mathrm{H}$ & -13.640008 & -3.767069 & -0.621092 \\
\hline $\mathrm{H}$ & -10.466923 & 0.669311 & -3.378970 \\
\hline $\mathrm{H}$ & -11.364816 & 2.970462 & -3.178826 \\
\hline $\mathrm{H}$ & -12.838336 & 0.525306 & 2.464359 \\
\hline $\mathrm{H}$ & -12.636710 & -2.703698 & -2.437497 \\
\hline $\mathrm{H}$ & -11.356569 & -1.440752 & -4.096317 \\
\hline $\mathrm{H}$ & 11.359286 & 2.965986 & 1.029440 \\
\hline $\mathrm{H}$ & 11.310879 & -2.659348 & 2.05100 \\
\hline
\end{tabular}

S138 


$\begin{array}{rrrr}\text { H } & 15.734928 & 0.829496 & -2.712784 \\ \mathrm{H} & 14.478898 & 2.895307 & -2.188580 \\ \mathrm{H} & 12.327561 & 3.779859 & -1.092739 \\ \mathrm{H} & 12.194073 & 2.624168 & 3.209364 \\ \mathrm{H} & 13.322516 & 0.589267 & 4.053587 \\ \mathrm{H} & 12.155103 & -1.592928 & 3.982227 \\ \mathrm{H} & 12.276287 & -4.061886 & 0.373109 \\ \mathrm{H} & 13.579252 & -2.794527 & -1.263081 \\ \mathrm{H} & 14.602996 & -1.362064 & -2.705415\end{array}$

$(5,4) 4$ cells

122

$\begin{array}{llll}\text { C } & 6.723319 & 0.861424 & -2.985442\end{array}$

$\begin{array}{llll}\text { C } & 6.632137 & 2.076344 & -2.370632\end{array}$

$\begin{array}{llll}\text { C } & 5.377667 & 2.514510 & -1.811013\end{array}$

$\begin{array}{llll}\text { C } & 4.198810 & 1.933234 & -2.359516\end{array}$

$\begin{array}{llll}\text { C } & 4.292829 & 0.635361 & -2.971058\end{array}$

$\begin{array}{llll}\text { C } & 5.568311 & -0.001763 & -3.049308\end{array}$

$\begin{array}{llll}\text { C } & 2.915006 & 2.381946 & -1.906847\end{array}$

$\begin{array}{llll}\text { C } & 2.825274 & 3.014228 & -0.637714\end{array}$

$\begin{array}{llll}\text { C } & 4.018814 & 3.104028 & 0.150900\end{array}$

$\begin{array}{llll}\text { C } & 5.289881 & 3.079906 & -0.492463\end{array}$

$\begin{array}{llll}\text { C } & 6.445841 & 3.152170 & 0.362543\end{array}$

$\begin{array}{llll}\text { C } & 6.357625 & 2.762818 & 1.670467\end{array}$

$\begin{array}{llll}\text { C } & 5.105796 & 2.304729 & 2.210440\end{array}$

$\begin{array}{llll}\text { C } & 3.927556 & 2.733377 & 1.537399\end{array}$

$\begin{array}{llll}\text { C } & 2.643121 & 2.374062 & 2.064274\end{array}$

$\begin{array}{llll}\text { C } & 2.552254 & 1.244751 & 2.920927\end{array}$

$\begin{array}{llll}\text { C } & 3.745483 & 0.485861 & 3.157445\end{array}$

C $\quad 5.015502 \quad 1.114980 \quad 3.022030$

$\begin{array}{llll}\text { C } & 1.456962 & 2.814333 & 1.395971\end{array}$

$\begin{array}{llll}\text { C } & 1.546603 & 3.106012 & 0.000919\end{array}$

$\begin{array}{llll}\text { C } & 1.274894 & 0.636653 & 3.132839\end{array}$

$\begin{array}{llll}\text { C } & 0.092768 & 1.391881 & 2.870819\end{array}$

$\begin{array}{llll}\text { C } & 0.182136 & 2.487565 & 1.952711\end{array}$

$\begin{array}{llll}\text { C } & -1.003856 & 2.879359 & 1.258801\end{array}$

$\begin{array}{llll}\text { C } & -0.914763 & 3.095416 & -0.152088\end{array}$ 


\begin{tabular}{lrrr} 
C & 0.362350 & 2.983748 & -0.787873 \\
C & 0.451980 & 2.282080 & -2.032050 \\
C & 1.728400 & 1.800171 & -2.458382 \\
C & -1.185191 & 0.791144 & 3.100001 \\
C & -2.367079 & 1.529087 & 2.791883 \\
C & -2.279792 & 2.573571 & 1.830659 \\
C & -3.474709 & 2.925668 & 1.121325 \\
C & -3.381456 & 3.055377 & -0.298114 \\
C & -2.099076 & 2.917871 & -0.929378 \\
C & -2.009825 & 2.161652 & -2.133503 \\
C & -0.732085 & 1.666261 & -2.544074 \\
C & -3.194820 & 1.517667 & -2.616810 \\
C & -4.476285 & 2.033422 & -2.242904 \\
C & -4.559335 & 2.853227 & -1.070477 \\
C & -5.661155 & 1.387326 & -2.706483 \\
C & -6.924400 & 1.998551 & -2.346265 \\
C & -7.009057 & 2.809215 & -1.256389 \\
C & -5.833033 & 3.031456 & -0.438789 \\
C & -3.102376 & 0.158236 & -3.022607 \\
C & -4.292829 & -0.635510 & -2.971024 \\
C & -5.568311 & 0.001610 & -3.049306 \\
C & -0.639523 & 0.320500 & -3.018723 \\
C & -1.821431 & -0.482698 & -2.996725 \\
C & -1.274895 & -0.636496 & 3.132871 \\
C & -2.552255 & -1.244605 & 2.920989 \\
C & -3.745484 & -0.485703 & 3.157467 \\
C & -3.655340 & 0.946297 & 3.052966 \\
C & -5.015503 & -1.114830 & 3.022084 \\
C & -6.164818 & -0.290837 & 3.270318 \\
C & -6.076084 & 1.070681 & 3.141437 \\
C & -4.833759 & 1.687962 & 2.776362 \\
C & 1.821431 & 0.482547 & -2.996751 \\
C & 0.639523 & -0.320652 & -3.018707 \\
C & 1.185190 & -0.790990 & 3.100042 \\
C & -0.092768 & -1.391737 & 2.870889 \\
C & 3.102376 & -0.158388 & -3.022600 \\
C & 3.655339 & -0.946145 & 3.053016 \\
C & 2.367079 & -1.528947 & 2.791962 \\
& 4.833758 & -1.687824 & 2.776450 \\
\hline
\end{tabular}




$\begin{array}{lrrr}\text { C } & 6.164816 & 0.291000 & 3.270307 \\ \text { C } & -2.643121 & -2.373960 & 2.064395 \\ \text { C } & -3.927556 & -2.733303 & 1.537537 \\ \text { C } & -5.105796 & -2.304620 & 2.210556 \\ \text { C } & -0.182136 & -2.487468 & 1.952837 \\ \text { C } & -1.456962 & -2.814265 & 1.396113 \\ \text { C } & 2.279792 & -2.573479 & 1.830790 \\ \text { C } & 1.003856 & -2.879296 & 1.258947 \\ \text { C } & -4.018814 & -3.104023 & 0.151057 \\ \text { C } & -5.289881 & -3.079933 & -0.492308 \\ \text { C } & -6.445841 & -3.152156 & 0.362702 \\ \text { C } & -6.357625 & -2.762738 & 1.670607 \\ \text { C } & -1.546603 & -3.106013 & 0.001076 \\ \text { C } & -2.825274 & -3.014261 & -0.637562 \\ \text { C } & 0.914763 & -3.095424 & -0.151932 \\ \text { C } & -0.362350 & -2.983787 & -0.787722 \\ \text { C } & 2.099076 & -2.917917 & -0.929231 \\ \text { C } & 3.381456 & -3.055391 & -0.297959 \\ \text { C } & 3.474708 & -2.925611 & 1.121473 \\ \text { C } & -2.915006 & -2.382043 & -1.906727 \\ \text { C } & -4.198810 & -1.933352 & -2.359417 \\ \text { C } & -5.377667 & -2.514601 & -1.810885 \\ \text { C } & -0.451981 & -2.282181 & -2.031934 \\ \text { C } & -1.728400 & -1.800294 & -2.458290 \\ \text { C } & 2.009825 & -2.161759 & -2.133393 \\ \text { C } & 0.732085 & -1.666389 & -2.543989 \\ \text { C } & 3.194819 & -1.517798 & -2.616733 \\ \text { C } & 4.476285 & -2.033534 & -2.242802 \\ \text { C } & 4.559334 & -2.853280 & -1.070333 \\ \text { C } & 5.661155 & -1.387462 & -2.706415 \\ \text { C } & 6.924400 & -1.998668 & -2.346165 \\ \text { C } & 7.009057 & -2.809276 & -1.256247 \\ \text { C } & 5.833033 & -3.031476 & -0.438635 \\ \text { C } & -6.723319 & -0.861575 & -2.985397 \\ \text { C } & -6.632137 & -2.076463 & -2.370526 \\ \text { C } & -4.757195 & 2.694919 & 1.723555 \\ \text { C } & -5.905648 & 3.008935 & 0.956068 \\ \text { C } & 4.757195 & -2.694832 & 1.723691 \\ \text { H } & 5.905647 & -3.008884 & 0.956220 \\ & 7.260407 & 2.673868 & 2.262793\end{array}$




$\begin{array}{rrrr}\text { H } & 7.417239 & 3.364991 & -0.066369 \\ \mathrm{H} & -6.980652 & 1.665967 & 3.177991 \\ \mathrm{H} & -6.887728 & 2.944965 & 1.408873 \\ \mathrm{H} & 7.529285 & 2.657400 & -2.193496 \\ \mathrm{H} & 7.136891 & 0.749489 & 3.404496 \\ \mathrm{H} & 6.980651 & -1.665808 & 3.178080 \\ \mathrm{H} & -7.260407 & -2.673759 & 2.262928 \\ \mathrm{H} & -7.136892 & -0.749319 & 3.404529 \\ \mathrm{H} & 6.887728 & -2.944891 & 1.409021 \\ \mathrm{H} & 7.969575 & -3.174337 & -0.909685 \\ \mathrm{H} & -7.529286 & -2.657511 & -2.193362 \\ \mathrm{H} & -7.417239 & -3.365000 & -0.066199 \\ \mathrm{H} & 7.823116 & -1.714388 & -2.880206 \\ \mathrm{H} & 7.691918 & 0.485800 & -3.291432 \\ \mathrm{H} & -7.823116 & 1.714244 & -2.880292 \\ \mathrm{H} & -7.691918 & -0.485967 & -3.291406 \\ \mathrm{H} & -7.969575 & 3.174295 & -0.909847\end{array}$

$(7,6) 4$ cells

178

$\begin{array}{lllr}\text { C } & 6.305311 & 4.445588 & -1.890453 \\ \text { C } & 6.223837 & 4.846834 & -0.579058 \\ \text { C } & 4.997416 & 4.762449 & 0.143391 \\ \text { C } & 3.809465 & 4.585473 & -0.616176 \\ \text { C } & 3.895526 & 4.148644 & -1.979169 \\ \text { C } & 5.167727 & 3.918351 & -2.570757 \\ \text { C } & 2.535814 & 4.561856 & 0.042045 \\ \text { C } & 2.485830 & 4.352356 & 1.444897 \\ \text { C } & 3.710017 & 4.133858 & 2.157828 \\ \text { C } & 4.950015 & 4.508063 & 1.571127 \\ \text { C } & 6.126776 & 4.282375 & 2.342261 \\ \text { C } & 6.110588 & 3.448945 & 3.435940 \\ \text { C } & 4.914922 & 2.791050 & 3.843681 \\ \text { C } & 3.692822 & 3.279233 & 3.308868 \\ \text { C } & 2.447482 & 2.704917 & 3.729486 \\ \text { C } & 2.451740 & 1.436292 & 4.368660 \\ \text { C } & 3.699680 & 0.753850 & 4.545501\end{array}$




$\begin{array}{lrrr}\text { C } & 4.921141 & 1.478831 & 4.469042 \\ \text { C } & 1.220354 & 3.231943 & 3.237163 \\ \text { C } & 1.238353 & 4.053450 & 2.066636 \\ \text { C } & 1.226690 & 0.728719 & 4.531792 \\ \text { C } & -0.009742 & 1.411187 & 4.349275 \\ \text { C } & -0.014404 & 2.672166 & 3.679752 \\ \text { C } & -1.245547 & 3.178805 & 3.165955 \\ \text { C } & -1.225148 & 3.967324 & 1.974210 \\ \text { C } & 0.026552 & 4.262701 & 1.349826 \\ \text { C } & 0.077580 & 4.438827 & -0.065903 \\ \text { C } & 1.341008 & 4.435773 & -0.724862 \\ \text { C } & -1.241573 & 0.706028 & 4.517611 \\ \text { C } & -2.472703 & 1.382213 & 4.314741 \\ \text { C } & -2.478877 & 2.626793 & 3.621199 \\ \text { C } & -3.713680 & 3.114815 & 3.091741 \\ \text { C } & -3.686432 & 3.859914 & 1.877661 \\ \text { C } & -2.432853 & 4.148192 & 1.248609 \\ \text { C } & -2.382712 & 4.290735 & -0.169856 \\ \text { C } & -1.118911 & 4.278578 & -0.829625 \\ \text { C } & -3.575678 & 4.103840 & -0.931161 \\ \text { C } & -4.849434 & 4.142830 & -0.278821 \\ \text { C } & -4.893314 & 4.041944 & 1.147886 \\ \text { C } & -6.045163 & 3.983302 & -1.032524 \\ \text { C } & -7.291565 & 4.080257 & -0.323893 \\ \text { C } & -7.339419 & 4.003329 & 1.039893 \\ \text { C } & -6.138783 & 3.803930 & 1.803428 \\ \text { C } & -3.486250 & 3.570226 & -2.242425 \\ \text { C } & -4.670296 & 3.054892 & -2.861059 \\ \text { C } & -5.952635 & 3.412188 & -2.353216 \\ \text { C } & -1.030849 & 3.774849 & -2.161696 \\ \text { C } & -2.203255 & 3.265657 & -2.789821 \\ \text { C } & -1.226656 & -0.725805 & 4.532248 \\ \text { C } & -2.451707 & -1.433478 & 4.369549 \\ \text { C } & -3.699646 & -0.750927 & 4.545984 \\ \text { C } & -3.714181 & 0.682252 & 4.498569 \\ \text { C } & -4.921108 & -1.475954 & 4.469975 \\ \text { C } & -6.119962 & -0.744437 & 4.691173 \\ \text { C } & -6.132230 & 0.631943 & 4.631831 \\ & 1.428172 & 3.963582 & -2.071095\end{array}$




$\begin{array}{lrrr}\text { C } & 0.254748 & 3.472654 & -2.711270 \\ \text { C } & 1.241607 & -0.703121 & 4.518041 \\ \text { C } & 0.009774 & -1.408384 & 4.350138 \\ \text { C } & 2.709324 & 3.664056 & -2.621979 \\ \text { C } & 3.714216 & -0.679358 & 4.498971 \\ \text { C } & 2.472736 & -1.379432 & 4.315576 \\ \text { C } & 4.948779 & -1.365643 & 4.358300 \\ \text { C } & 6.132269 & -0.628965 & 4.632162 \\ \text { C } & 6.120000 & 0.747450 & 4.690664 \\ \text { C } & -2.447454 & -2.702491 & 3.731153 \\ \text { C } & -3.692797 & -3.277076 & 3.310912 \\ \text { C } & -4.914894 & -2.788558 & 3.845424 \\ \text { C } & 0.014432 & -2.669771 & 3.681387 \\ \text { C } & -1.220328 & -3.229826 & 3.239160 \\ \text { C } & 2.478905 & -2.624435 & 3.622794 \\ \text { C } & 1.245572 & -3.176730 & 3.167902 \\ \text { C } & -3.709998 & -4.132462 & 2.160439 \\ \text { C } & -4.949999 & -4.507068 & 1.573998 \\ \text { C } & -6.126754 & -4.280873 & 2.344993 \\ \text { C } & -6.110560 & -3.446720 & 3.438122 \\ \text { C } & -1.238332 & -4.052099 & 2.069175 \\ \text { C } & -2.485812 & -4.351422 & 1.447641 \\ \text { C } & 1.225167 & -3.966018 & 1.976669 \\ \text { C } & -0.026538 & -4.261812 & 1.352488 \\ \text { C } & 2.432868 & -4.147353 & 1.251176 \\ \text { C } & 3.686450 & -3.858661 & 1.880032 \\ \text { C } & 3.713705 & -3.112789 & 3.093637 \\ \text { C } & -2.535807 & -4.561828 & 0.044928 \\ \text { C } & -3.809466 & -4.585879 & -0.613267 \\ \text { C } & -4.997410 & -4.762377 & 0.146423 \\ \text { C } & -0.077578 & -4.438854 & -0.063128 \\ \text { C } & -1.341011 & -4.436217 & -0.722074 \\ \text { C } & 2.382715 & -4.290810 & -0.167197 \\ \text { C } & 1.118905 & -4.279099 & -0.826962 \\ \text { C } & 3.575672 & -4.104389 & -0.928632 \\ \text { C } & 4.849430 & -4.142961 & -0.276279 \\ \text { C } & 4.893324 & -4.041153 & 1.150363 \\ \text { C } & 6.045153 & -3.983913 & -1.030096 \\ \text { C } & 7.291563 & -4.080406 & -0.321413 \\ \text { C } & 7.339429 & -4.002601 & 1.042323\end{array}$




$\begin{array}{lrrr}\text { C } & 6.138798 & -3.802717 & 1.805741 \\ \text { C } & -3.895545 & -4.149910 & -1.976530 \\ \text { C } & -5.167753 & -3.920005 & -2.568251 \\ \text { C } & -6.305326 & -4.446826 & -1.887610 \\ \text { C } & -6.223834 & -4.847240 & -0.575959 \\ \text { C } & -1.428193 & -3.964914 & -2.068617 \\ \text { C } & -2.709350 & -3.665739 & -2.619676 \\ \text { C } & 1.030827 & -3.776207 & -2.159348 \\ \text { C } & -0.254776 & -3.474375 & -2.709105 \\ \text { C } & 3.486226 & -3.571651 & -2.240251 \\ \text { C } & 2.203224 & -3.267440 & -2.787832 \\ \text { C } & 5.952607 & -3.413650 & -2.351149 \\ \text { C } & 4.670265 & -3.056687 & -2.859211 \\ \text { C } & -2.827307 & -2.644209 & -3.596806 \\ \text { C } & -4.129543 & -2.150294 & -3.936674 \\ \text { C } & -5.284931 & -2.903815 & -3.594612 \\ \text { C } & -0.374566 & -2.424386 & -3.668233 \\ \text { C } & -1.665726 & -1.913533 & -3.985429 \\ \text { C } & 2.081796 & -2.193553 & -3.721400 \\ \text { C } & 0.790061 & -1.677080 & -4.028440 \\ \text { C } & 4.546466 & -1.956849 & -3.770953 \\ \text { C } & 3.242206 & -1.432778 & -4.053213 \\ \text { C } & 5.702250 & -1.220007 & -4.147283 \\ \text { C } & 6.971219 & -1.828570 & -3.899258 \\ \text { C } & 7.091693 & -2.888585 & -3.038209 \\ \text { C } & -4.268532 & -0.782219 & -4.342855 \\ \text { C } & -5.561387 & -0.195732 & -4.422789 \\ \text { C } & -6.678875 & -1.084792 & -4.427181 \\ \text { C } & -6.545946 & -2.389599 & -4.022486 \\ \text { C } & -1.804650 & -0.539992 & -4.355273 \\ \text { C } & -3.102966 & 0.051545 & -4.357977 \\ \text { C } & 0.651067 & -0.297442 & -4.364824 \\ \text { C } & -0.651120 & 0.294681 & -4.364995 \\ \text { C } & 3.102910 & -0.054298 & -4.358003 \\ \text { C } & 1.804595 & 0.537240 & -4.355630 \\ \text { C } & 5.561332 & 0.192938 & -4.422997 \\ \text { C } & 4.268477 & 0.779473 & -4.343410 \\ \text { C } & -3.242255 & 1.430214 & -4.054046 \\ \text { C } & -4.546512 & 1.954461 & -3.772085 \\ & -5.702300 & 1.217388 & -4.147943\end{array}$




\begin{tabular}{|c|c|c|c|}
\hline C & -0.790107 & 1.674525 & -4.029448 \\
\hline C & -2.081837 & 2.191193 & -3.722721 \\
\hline C & 1.665678 & 1.911007 & -3.986631 \\
\hline $\mathrm{C}$ & 0.374525 & 2.422054 & -3.669728 \\
\hline C & 4.129495 & 2.147799 & -3.938062 \\
\hline $\mathrm{C}$ & 2.827266 & 2.641922 & -3.598478 \\
\hline C & 5.284889 & 2.901532 & -3.596484 \\
\hline C & 6.545899 & 2.387052 & -4.024063 \\
\hline C & 6.678822 & 1.081997 & -4.427954 \\
\hline C & -7.091728 & 2.886679 & -3.039921 \\
\hline $\mathrm{C}$ & -6.971263 & 1.826106 & -3.900287 \\
\hline $\mathrm{C}$ & -4.964704 & 2.620909 & 3.596750 \\
\hline C & -6.146727 & 3.130236 & 3.037810 \\
\hline $\mathrm{C}$ & 4.964732 & -2.618572 & 3.598331 \\
\hline $\mathrm{C}$ & 6.146751 & -3.128251 & 3.039700 \\
\hline $\mathrm{H}$ & 7.046996 & 3.207785 & 3.922977 \\
\hline $\mathrm{H}$ & 7.075531 & 4.673424 & 1.997721 \\
\hline $\mathrm{H}$ & -7.083891 & 1.146132 & 4.681081 \\
\hline $\mathrm{H}$ & -7.107252 & 2.828814 & 3.437382 \\
\hline $\mathrm{H}$ & 7.131294 & 5.129834 & -0.060719 \\
\hline $\mathrm{H}$ & 7.061477 & 1.273845 & 4.782518 \\
\hline $\mathrm{H}$ & 7.083931 & -1.143123 & 4.681706 \\
\hline $\mathrm{H}$ & -7.046966 & -3.205245 & 3.925008 \\
\hline $\mathrm{H}$ & -7.061438 & -1.270773 & 4.783367 \\
\hline $\mathrm{H}$ & 7.107280 & -2.826586 & 3.439080 \\
\hline $\mathrm{H}$ & 8.294569 & -3.977856 & 1.555354 \\
\hline $\mathrm{H}$ & -7.131282 & -5.129928 & -0.057433 \\
\hline $\mathrm{H}$ & -7.075512 & -4.672151 & 2.000720 \\
\hline $\mathrm{H}$ & 8.217245 & -4.121347 & -0.881329 \\
\hline $\mathrm{H}$ & 8.079740 & -3.256629 & -2.793407 \\
\hline $\mathrm{H}$ & -7.433581 & -3.001988 & -3.926016 \\
\hline $\mathrm{H}$ & -7.275066 & -4.422418 & -2.368019 \\
\hline $\mathrm{H}$ & 7.867102 & -1.384536 & -4.314545 \\
\hline $\mathrm{H}$ & 7.668181 & 0.696675 & -4.638691 \\
\hline $\mathrm{H}$ & -7.867156 & 1.381797 & -4.315257 \\
\hline $\mathrm{H}$ & -7.668238 & -0.699609 & -4.638151 \\
\hline $\mathrm{H}$ & 7.433534 & 2.999504 & -3.927987 \\
\hline $\mathrm{H}$ & 7.275049 & 4.420872 & -2.370852 \\
\hline $\mathrm{H}$ & -8.217253 & 4.120840 & -0.883826 \\
\hline $\mathrm{H}$ & -8.079775 & 3.254878 & -2.79534 \\
\hline
\end{tabular}




$\begin{array}{lrrr}\text { H } & -8.294555 & 3.978921 & 1.552950 \\ & & & \\ \text { (8,7) } & \text { 4 cells } & & \\ & & & \\ & & & \\ & & & \\ \text { C } & 5.040750 & -0.478883 & 5.163322 \\ \text { C } & 3.756080 & 0.123932 & 5.211987 \\ \text { C } & 3.632273 & 1.547615 & 5.108971 \\ \text { C } & 4.794905 & 2.356179 & 4.975251 \\ \text { C } & 6.044524 & 1.742621 & 5.246419 \\ \text { C } & 6.162275 & 0.370847 & 5.332905 \\ \text { C } & 2.334932 & 2.117992 & 4.894427 \\ \text { C } & 2.228545 & 3.357224 & 4.207083 \\ \text { C } & 3.421479 & 4.020882 & 3.765810 \\ \text { C } & 4.683732 & 3.637387 & 4.292450 \\ \text { C } & 0.959823 & 3.784191 & 3.729640 \\ \text { C } & 0.894807 & 4.633892 & 2.580455 \\ \text { C } & 2.101784 & 5.056260 & 1.954331 \\ \text { C } & 3.354540 & 4.894592 & 2.632317 \\ \text { C } & -0.345403 & 4.792839 & 1.902193 \\ \text { C } & -0.346468 & 5.094895 & 0.508635 \\ \text { C } & 0.893061 & 5.257526 & -0.173678 \\ \text { C } & 2.098647 & 5.381729 & 0.572754 \\ \text { C } & -1.554088 & 4.943468 & -0.239256 \\ \text { C } & -1.481625 & 4.657320 & -1.634211 \\ \text { C } & -0.201257 & 4.548697 & -2.263024 \\ \text { C } & 0.963436 & 4.993614 & -1.577455 \\ \text { C } & -2.644123 & 4.198465 & -2.313939 \\ \text { C } & -2.499769 & 3.369027 & -3.468254 \\ \text { C } & -1.196586 & 3.034522 & -3.932714 \\ \text { C } & -0.059728 & 3.740577 & -3.428787 \\ \text { C } & -3.629624 & 2.647789 & -3.952331 \\ \text { C } & -3.431514 & 1.430380 & -4.652322 \\ \text { C } & -2.106691 & 0.957008 & -4.880496 \\ \text { C } & -0.999855 & 1.822140 & -4.655940 \\ \text { C } & -4.550728 & 0.563322 & -4.877629 \\ \text { C } & -4.322314 & -0.846439 & -4.994371 \\ \text { C } & -2.980396 & -1.344549 & -4.912254\end{array}$




$\begin{array}{lrrr}\text { C } & -1.879566 & -0.447302 & -5.025401 \\ \text { C } & -5.418953 & -1.748302 & -4.942649 \\ \text { C } & -5.193053 & -3.091575 & -4.442482 \\ \text { C } & -3.878806 & -3.466962 & -4.053401 \\ \text { C } & -2.757309 & -2.667444 & -4.452044 \\ \text { C } & -6.259861 & -3.944486 & -4.040491 \\ \text { C } & -6.077737 & -4.908040 & -3.076746 \\ \text { C } & -4.813700 & -5.097086 & -2.449934 \\ \text { C } & -3.687621 & -4.481427 & -3.059460 \\ \text { C } & -2.376291 & -4.688360 & -2.516948 \\ \text { C } & -2.240783 & -5.221770 & -1.209388 \\ \text { C } & -3.419927 & -5.517479 & -0.448952 \\ \text { C } & -4.679782 & -5.615170 & -1.099845 \\ \text { C } & -0.967115 & -5.205117 & -0.571362 \\ \text { C } & -0.898418 & -5.181840 & 0.856884 \\ \text { C } & -2.104711 & -5.150166 & 1.611857 \\ \text { C } & -3.353725 & -5.466418 & 0.981552 \\ \text { C } & 0.199309 & -4.910879 & -1.331141 \\ \text { C } & 1.478909 & -4.893689 & -0.691943 \\ \text { C } & 1.549769 & -4.895131 & 0.732156 \\ \text { C } & 0.341333 & -4.889176 & 1.493884 \\ \text { C } & 2.642955 & -4.583105 & -1.448496 \\ \text { C } & 3.918303 & -4.565175 & -0.809909 \\ \text { C } & 3.992069 & -4.592662 & 0.605815 \\ \text { C } & 2.789383 & -4.607602 & 1.372266 \\ \text { C } & 2.788771 & -4.054282 & 2.687792 \\ \text { C } & 4.003331 & -3.521343 & 3.225157 \\ \text { C } & 5.238660 & -3.805410 & 2.579802 \\ \text { C } & 5.244315 & -4.329258 & 1.248812 \\ \text { C } & 6.452887 & -4.347607 & 0.500628 \\ \text { C } & 7.676802 & -4.117886 & 1.212047 \\ \text { C } & 7.677749 & -3.629032 & 2.489903 \\ \text { C } & 6.447906 & -3.316695 & 3.157066 \\ \text { C } & 5.094908 & -4.250588 & -1.563382 \\ \text { C } & 6.375044 & -4.299521 & -0.941090 \\ \text { C } & 0.341311 & -4.315276 & 2.799049 \\ \text { C } & 1.555238 & -3.780389 & 3.332284 \\ \text { C } & 1.496573 & -2.743693 & 4.313338 \\ & 2.678803 & -2.024493 & 4.650092 \\ & 3.953134 & -2.513625 & 4.229564\end{array}$

S148 


$\begin{array}{lrrr}\text { C } & -2.106334 & -4.557753 & 2.901706 \\ \text { C } & -0.898141 & -4.023882 & 3.433013 \\ \text { C } & -0.960413 & -2.967639 & 4.395959 \\ \text { C } & 0.223925 & -2.243378 & 4.720348 \\ \text { C } & -4.549495 & -5.495331 & 1.748631 \\ \text { C } & -4.555312 & -4.864500 & 3.057913 \\ \text { C } & -3.357996 & -4.265763 & 3.536604 \\ \text { C } & -3.421908 & -3.191278 & 4.482081 \\ \text { C } & -2.227841 & -2.455840 & 4.785040 \\ \text { C } & -5.805699 & -5.942303 & -0.294047 \\ \text { C } & -5.743655 & -5.880400 & 1.078794 \\ \text { C } & -4.682752 & -2.713454 & 4.928889 \\ \text { C } & -5.819267 & -3.520969 & 4.653546 \\ \text { C } & -5.757198 & -4.561088 & 3.753509 \\ \text { C } & -2.333241 & -1.107025 & 5.219747 \\ \text { C } & -3.630158 & -0.505435 & 5.321960 \\ \text { C } & -4.792898 & -1.324535 & 5.351121 \\ \text { C } & 0.118575 & -0.897499 & 5.178784 \\ \text { C } & -1.167116 & -0.295281 & 5.281500 \\ \text { C } & 0.060462 & -4.351737 & -2.635501 \\ \text { C } & -1.240734 & -4.121335 & -3.163712 \\ \text { C } & 2.572035 & -0.685952 & 5.129201 \\ \text { C } & 1.293550 & -0.086458 & 5.246306 \\ \text { C } & 2.500910 & -3.997753 & -2.744448 \\ \text { C } & 1.198704 & -3.759617 & -3.267313 \\ \text { C } & 4.949211 & -3.640771 & -2.852363 \\ \text { C } & 3.631954 & -3.385212 & -3.358409 \\ \text { C } & 6.080196 & -3.076436 & -3.501489 \\ \text { C } & 7.365623 & -3.422759 & -2.990820 \\ \text { C } & 7.507718 & -4.014653 & -1.760637 \\ \text { C } & -1.433893 & -3.087663 & -4.133370 \\ \text { C } & 1.003878 & -2.710332 & -4.212658 \\ \text { C } & -0.325617 & -2.289313 & -4.530973 \\ \text { C } & 3.435468 & -2.325242 & -4.280296 \\ \text { C } & 2.111301 & -1.904536 & -4.597300 \\ \text { C } & 5.878725 & -1.975379 & -4.421711 \\ \text { C } & 4.555300 & -1.517550 & -4.665384 \\ \text { C } & -0.550311 & -0.951549 & -4.969695 \\ \text { C } & 1.885183 & -0.554496 & -5.010845 \\ & 0.555893 & -0.049171 & -5.056003\end{array}$




$\begin{array}{lrrr}\text { C } & 4.328104 & -0.156631 & -5.051718 \\ \text { C } & 2.986029 & 0.348034 & -5.069877 \\ \text { C } & 5.424983 & 0.738419 & -5.172165 \\ \text { C } & 6.729439 & 0.168015 & -5.215431 \\ \text { C } & 6.947717 & -1.140656 & -4.857886 \\ \text { C } & -5.874590 & 1.058607 & -4.728023 \\ \text { C } & -6.942602 & 0.155268 & -4.999290 \\ \text { C } & -6.723224 & -1.197625 & -5.098137 \\ \text { C } & 0.330356 & 1.347978 & -4.884629 \\ \text { C } & 2.762259 & 1.734800 & -4.874983 \\ \text { C } & 1.438034 & 2.208491 & -4.646614 \\ \text { C } & 5.198427 & 2.153135 & -4.942747 \\ \text { C } & 3.883136 & 2.597012 & -4.637303 \\ \text { C } & -4.947697 & 2.995280 & -3.506888 \\ \text { C } & -6.077654 & 2.315402 & -4.036146 \\ \text { C } & 1.242597 & 3.411611 & -3.898941 \\ \text { C } & 3.689273 & 3.787942 & -3.864815 \\ \text { C } & 2.376604 & 4.097560 & -3.376978 \\ \text { C } & 4.813540 & 4.515509 & -3.390039 \\ \text { C } & 6.079435 & 4.205020 & -3.962021 \\ \text { C } & 6.264373 & 3.068815 & -4.713576 \\ \text { C } & -5.095362 & 3.844693 & -2.362062 \\ \text { C } & -6.376092 & 4.012265 & -1.762126 \\ \text { C } & -7.507701 & 3.570764 & -2.510577 \\ \text { C } & -7.363779 & 2.751629 & -3.602421 \\ \text { C } & -3.920099 & 4.305064 & -1.685192 \\ \text { C } & 2.238002 & 4.883592 & -2.204623 \\ \text { C } & 4.675741 & 5.298036 & -2.175008 \\ \text { C } & 3.415085 & 5.331485 & -1.519084 \\ \text { C } & -3.995377 & 4.613759 & -0.303307 \\ \text { C } & -5.247567 & 4.480988 & 0.378756 \\ \text { C } & -6.455370 & 4.343976 & -0.358263 \\ \text { C } & -2.793575 & 4.786744 & 0.444970 \\ \text { C } & 3.347223 & 5.569661 & -0.107844 \\ \text { C } & 4.542133 & 5.755141 & 0.638155 \\ \text { C } & 5.735211 & 6.005173 & -0.095163 \\ \text { C } & 5.798786 & 5.788716 & -1.452167 \\ \text { C } & -5.241622 & 4.236334 & 1.788294 \\ & -6.450026 & 3.870367 & 2.451751 \\ \text { - } 7.680062 & 4.035662 & 1.734397\end{array}$




$\begin{array}{rrrr}\text { C } & -7.679107 & 4.255562 & 0.383974 \\ \mathrm{C} & -2.792331 & 4.508827 & 1.844975 \\ \mathrm{C} & -4.005936 & 4.090763 & 2.477803 \\ \mathrm{C} & -1.558284 & 4.370984 & 2.530886 \\ \mathrm{C} & 4.550317 & 5.391434 & 2.045330 \\ \mathrm{C} & -1.497273 & 3.547260 & 3.696365 \\ \mathrm{C} & -2.678410 & 2.907415 & 4.169433 \\ \mathrm{C} & -3.953812 & 3.303401 & 3.662730 \\ \mathrm{C} & -0.223403 & 3.136198 & 4.190477 \\ \mathrm{C} & 5.819157 & 4.376906 & 3.864570 \\ \mathrm{C} & 5.754090 & 5.226543 & 2.782908 \\ \mathrm{C} & -0.117010 & 1.905205 & 4.901764 \\ \mathrm{C} & -1.291532 & 1.123507 & 5.130030 \\ \mathrm{C} & -2.570517 & 1.688558 & 4.901088 \\ \mathrm{C} & 1.169168 & 1.334489 & 5.116809 \\ \mathrm{C} & -3.754058 & 0.910864 & 5.144292 \\ \mathrm{C} & -6.041980 & -0.669431 & 5.500296 \\ \mathrm{C} & -6.159836 & 0.692762 & 5.317194 \\ \mathrm{C} & -5.039007 & 1.492412 & 4.980864 \\ \mathrm{C} & 6.381260 & -2.364060 & 4.192435 \\ \mathrm{C} & 5.158578 & -1.838522 & 4.625978 \\ \mathrm{C} & -6.381737 & 3.145974 & 3.657749 \\ \mathrm{C} & -5.158096 & 2.719147 & 4.186382 \\ \mathrm{H} & -6.650656 & -6.035951 & 1.648613 \\ \mathrm{H} & -6.670311 & -5.083806 & 3.499694 \\ \mathrm{H} & -6.779220 & -3.258010 & 5.079193 \\ \mathrm{H} & -6.759971 & -6.143152 & -0.763582 \\ \mathrm{H} & 8.504182 & -4.174791 & -1.369893 \\ \mathrm{H} & 8.620899 & -4.253880 & 0.700576 \\ \mathrm{H} & -6.937847 & -5.463122 & -2.724989 \\ \mathrm{H} & -7.258386 & -3.767452 & -4.418652 \\ \mathrm{H} & 7.965524 & -1.505505 & -4.809526 \\ \mathrm{H} & 8.253875 & -3.132029 & -3.536872 \\ \mathrm{H} & -7.574352 & -1.858700 & -5.199901 \\ \mathrm{H} & -7.960594 & 0.521911 & -5.025277 \\ & 7.264100 & 2.820560 & -5.045783 \\ \mathrm{H} & 7.581303 & 0.796786 & -5.440562 \\ \mathrm{H} & -8.551144 & 2.358668 & -4.081823 \\ \mathrm{H} & 6.752332 & 5.896706 & -1.952648\end{array}$




$\begin{array}{rrrr}\mathrm{H} & 6.938804 & 4.819197 & -3.725552 \\ \mathrm{H} & -8.622699 & 4.279200 & -0.145575 \\ \mathrm{H} & -8.615579 & 3.883624 & 2.261513 \\ \mathrm{H} & 6.666253 & 5.690151 & 2.430168 \\ \mathrm{H} & 6.640376 & 6.278201 & 0.432052 \\ \mathrm{H} & -7.310381 & 2.766127 & 4.065419 \\ \mathrm{H} & -7.148641 & 1.133425 & 5.329759 \\ \mathrm{H} & 6.944016 & 2.344033 & 5.275997 \\ \mathrm{H} & 6.780365 & 4.199010 & 4.329501 \\ \mathrm{H} & -6.941205 & -1.253098 & 5.649236 \\ \mathrm{H} & 7.311022 & -1.912764 & 4.516102 \\ \mathrm{H} & 7.151175 & -0.059125 & 5.428824 \\ \mathrm{H} & 8.613601 & -3.378622 & 2.977390\end{array}$

$(9,8) 4$ cells

234

$\begin{array}{llll}\text { C } & -8.566259 & -2.209934 & -2.205812 \\ \text { C } & -7.284673 & -2.789910 & -2.424011 \\ \text { C } & -6.855322 & -4.005839 & -1.759786 \\ \text { C } & -7.676555 & -4.698536 & -0.827483 \\ \text { C } & -5.487197 & -4.383740 & -1.830690 \\ \text { C } & -4.616842 & -3.752540 & -2.779205 \\ \text { C } & -5.031819 & -2.554687 & -3.415050 \\ \text { C } & -6.320892 & -2.003739 & -3.110658 \\ \text { C } & -3.266796 & -4.187682 & -2.906847 \\ \text { C } & -2.409290 & -3.564163 & -3.853994 \\ \text { C } & -2.819918 & -2.352323 & -4.479911 \\ \text { C } & -4.088019 & -1.792142 & -4.160764 \\ \text { C } & -1.052538 & -3.999305 & -3.981985 \\ \text { C } & -0.192041 & -3.369322 & -4.922319 \\ \text { C } & -0.597926 & -2.142238 & -5.535636 \\ \text { C } & -1.863711 & -1.580124 & -5.211044 \\ \text { C } & 1.158158 & -3.802735 & -5.047388 \\ \text { C } & 2.028420 & -3.174987 & -5.999024 \\ \text { C } & 1.628913 & -1.936016 & -6.596468 \\ \text { C } & 0.360559 & -1.365333 & -6.245043 \\ \text { C } & 3.350619 & -3.661779 & -6.182896\end{array}$




$\begin{array}{lrrr}\text { C } & 4.150532 & -3.022240 & -7.168237 \\ \text { C } & 3.770269 & -1.827401 & -7.734740 \\ \text { C } & 2.558575 & -1.184083 & -7.363788 \\ \text { C } & 2.357653 & 0.248743 & -7.503801 \\ \text { C } & 3.365898 & 1.116011 & -8.002769 \\ \text { C } & 3.904694 & -4.583437 & -5.205812 \\ \text { C } & 5.282301 & -4.932483 & -5.176449 \\ \text { C } & 0.155396 & 0.029837 & -6.399807 \\ \text { C } & 1.226204 & 0.849335 & -6.888141 \\ \text { C } & 1.704918 & -4.685231 & -4.080988 \\ \text { C } & 3.114332 & -4.950721 & -4.083870 \\ \text { C } & -2.076582 & -0.182013 & -5.382037 \\ \text { C } & -1.014601 & 0.634443 & -5.859526 \\ \text { C } & -0.499418 & -4.871357 & -3.000815 \\ \text { C } & 0.901479 & -5.113849 & -2.986925 \\ \text { C } & -4.308885 & -0.392672 & -4.349287 \\ \text { C } & -3.252464 & 0.423873 & -4.837405 \\ \text { C } & -2.706919 & -5.047292 & -1.910126 \\ \text { C } & -1.304710 & -5.281970 & -1.892355 \\ \text { C } & -6.549197 & -0.603861 & -3.313746 \\ \text { C } & -5.478687 & 0.212328 & -3.803659 \\ \text { C } & -4.922171 & -5.227824 & -0.820891 \\ \text { C } & -3.503776 & -5.437453 & -0.796744 \\ \text { C } & -8.788465 & -0.869097 & -2.403865 \\ \text { C } & -7.745032 & 0.000851 & -2.832065 \\ \text { C } & -7.132093 & -5.501133 & 0.147267 \\ \text { C } & -5.725613 & -5.677997 & 0.260797 \\ \text { C } & 3.745464 & -5.391592 & -2.875973 \\ \text { C } & 5.161778 & -5.476824 & -2.801743 \\ \text { C } & 5.887275 & -5.366098 & -4.019482 \\ \text { C } & 1.533649 & -5.532411 & -1.773683 \\ \text { C } & 2.954489 & -5.533288 & -1.687999 \\ \text { C } & -0.673653 & -5.678041 & -0.678160 \\ \text { C } & 0.754189 & -5.678733 & -0.593592 \\ \text { C } & -2.874115 & -5.813089 & 0.417253 \\ \text { C } & -1.453236 & -5.813970 & 0.503089 \\ \text { C } & -5.080544 & -6.038530 & 1.510987 \\ \text { C } & -3.665266 & -5.954968 & 1.605101 \\ \text { C } & -5.806031 & -6.215055 & 2.720926 \\ & 5.804175 & -5.401317 & -1.501296\end{array}$




$\begin{array}{lrrr}\text { C } & 7.208297 & -5.235929 & -1.348747 \\ \text { C } & 3.581110 & -5.436029 & -0.419445 \\ \text { C } & 4.996751 & -5.218870 & -0.346598 \\ \text { C } & 1.381786 & -5.561427 & 0.679812 \\ \text { C } & 2.781008 & -5.318839 & 0.752394 \\ \text { C } & -0.825002 & -5.673708 & 1.780640 \\ \text { C } & 0.572772 & -5.422348 & 1.851270 \\ \text { C } & -3.038595 & -5.790390 & 2.882409 \\ \text { C } & -1.632614 & -5.512704 & 2.941830 \\ \text { C } & -5.205534 & -6.045897 & 3.946907 \\ \text { C } & -3.832399 & -5.694548 & 4.056785 \\ \text { C } & 5.552002 & -4.617529 & 0.828861 \\ \text { C } & 6.914916 & -4.215300 & 0.847270 \\ \text { C } & 7.743657 & -4.668049 & -0.216668 \\ \text { C } & 3.330442 & -4.697716 & 1.917884 \\ \text { C } & 4.674301 & -4.226794 & 1.893336 \\ \text { C } & 1.114863 & -4.783973 & 3.003626 \\ \text { C } & 2.465273 & -4.312433 & 2.978454 \\ \text { C } & -1.097387 & -4.859530 & 4.081356 \\ \text { C } & 0.246260 & -4.389884 & 4.058269 \\ \text { C } & -3.290564 & -5.004430 & 5.215161 \\ \text { C } & -1.976001 & -4.469428 & 5.145871 \\ \text { C } & -4.098919 & -4.608924 & 6.315182 \\ \text { C } & 7.328930 & -3.173720 & 1.768142 \\ \text { C } & 8.603395 & -2.544500 & 1.690270 \\ \text { C } & 5.073143 & -3.194202 & 2.780083 \\ \text { C } & 6.354531 & -2.572610 & 2.609212 \\ \text { C } & 2.859009 & -3.262842 & 3.857442 \\ \text { C } & 4.118896 & -2.628695 & 3.673321 \\ \text { C } & 0.634402 & -3.321561 & 4.927126 \\ \text { C } & 1.891703 & -2.684056 & 4.737564 \\ \text { C } & -1.595090 & -3.385113 & 6.000693 \\ \text { C } & -0.335710 & -2.732808 & 5.786165 \\ \text { C } & -3.736689 & -3.560809 & 7.129902 \\ \text { C } & -2.536116 & -2.832887 & 6.910628 \\ \text { C } & 6.563802 & -1.250156 & 3.119001 \\ \text { C } & 7.751679 & -0.538245 & 2.787281 \\ \text { C } & 8.807745 & -1.278641 & 2.182613 \\ \text { C } & 4.320145 & -1.302774 & 4.167353 \\ & 5.481514 & -0.576480 & 3.772347\end{array}$




$\begin{array}{lrrr}\text { C } & 2.084317 & -1.355074 & 5.212712 \\ \text { C } & 3.251580 & -0.628004 & 4.818437 \\ \text { C } & -0.151315 & -1.402730 & 6.243604 \\ \text { C } & 1.009960 & -0.677963 & 5.852890 \\ \text { C } & -2.357515 & -1.462045 & 7.359975 \\ \text { C } & -1.234712 & -0.725155 & 6.894845 \\ \text { C } & -3.379327 & -0.739322 & 8.031759 \\ \text { C } & 7.745945 & 0.907190 & 2.842299 \\ \text { C } & 8.801331 & 1.701574 & 2.288952 \\ \text { C } & 5.470348 & 0.840435 & 3.814989 \\ \text { C } & 6.548875 & 1.572411 & 3.221096 \\ \text { C } & 3.231638 & 0.796677 & 4.842284 \\ \text { C } & 4.290596 & 1.524278 & 4.229719 \\ \text { C } & 0.982672 & 0.752252 & 5.859369 \\ \text { C } & 2.041116 & 1.477177 & 5.242286 \\ \text { C } & -1.270133 & 0.706710 & 6.881726 \\ \text { C } & -0.209987 & 1.427737 & 6.238325 \\ \text { C } & -3.417376 & 0.636648 & 8.010219 \\ \text { C } & -2.433331 & 1.394175 & 7.321292 \\ \text { C } & 6.325276 & 2.926054 & 2.817285 \\ \text { C } & 7.307880 & 3.611064 & 2.044185 \\ \text { C } & 8.595869 & 3.001014 & 1.910202 \\ \text { C } & 4.065139 & 2.866742 & 3.799123 \\ \text { C } & 5.040133 & 3.515026 & 2.977387 \\ \text { C } & 1.812697 & 2.810468 & 4.795674 \\ \text { C } & 2.787556 & 3.454938 & 3.971957 \\ \text { C } & -0.443346 & 2.750108 & 5.777512 \\ \text { C } & 0.525358 & 3.391818 & 4.956866 \\ \text { C } & -2.681234 & 2.741428 & 6.831249 \\ \text { C } & -1.740924 & 3.335932 & 5.945874 \\ \text { C } & -3.933016 & 3.392312 & 6.985026 \\ \text { C } & 6.924863 & 4.727639 & 1.273317 \\ \text { C } & 4.659349 & 4.609577 & 2.151295 \\ \text { C } & 5.594898 & 5.150128 & 1.202754 \\ \text { C } & 2.391784 & 4.531906 & 3.121507 \\ \text { C } & 3.291679 & 5.017949 & 2.132050 \\ \text { C } & 0.121734 & 4.457021 & 4.090535 \\ \text { C } & -2.022694 & 4.931557 & 3.093302 \\ & -1.243063 & 4.845589 & 4.051114\end{array}$




\begin{tabular}{|c|c|c|c|}
\hline C & -4.327605 & 4.400357 & 6.132410 \\
\hline $\mathrm{C}$ & -3.497594 & 4.835699 & 5.067260 \\
\hline C & 5.063243 & 5.874872 & 0.043196 \\
\hline C & 5.870872 & 6.242393 & -1.058961 \\
\hline C & 2.777469 & 5.687961 & 0.982286 \\
\hline $\mathrm{C}$ & 3.655544 & 5.967537 & -0.120083 \\
\hline $\mathrm{C}$ & 0.509394 & 5.585624 & 1.936909 \\
\hline C & 1.379273 & 5.849383 & 0.834023 \\
\hline C & -1.757479 & 5.482549 & 2.888884 \\
\hline $\mathrm{C}$ & -0.897405 & 5.739132 & 1.787438 \\
\hline $\mathrm{C}$ & -4.028096 & 5.472823 & 3.869027 \\
\hline $\mathrm{C}$ & -3.174495 & 5.641196 & 2.743480 \\
\hline C & -5.412655 & 5.694302 & 3.671905 \\
\hline $\mathrm{C}$ & 5.334515 & 6.424376 & -2.317875 \\
\hline $\mathrm{C}$ & 3.097716 & 6.144868 & -1.427271 \\
\hline $\mathrm{C}$ & 3.951399 & 6.242753 & -2.561184 \\
\hline $\mathrm{C}$ & 0.820742 & 6.005324 & -0.475897 \\
\hline $\mathrm{C}$ & 1.681858 & 6.011386 & -1.606064 \\
\hline $\mathrm{C}$ & -1.455874 & 5.878351 & 0.475569 \\
\hline $\mathrm{C}$ & -0.584866 & 5.877510 & -0.657613 \\
\hline C & -3.732043 & 5.758738 & 1.429427 \\
\hline $\mathrm{C}$ & -2.852699 & 5.742080 & 0.293266 \\
\hline $\mathrm{C}$ & -5.948667 & 5.796893 & 2.403749 \\
\hline $\mathrm{C}$ & -5.138998 & 5.692601 & 1.247958 \\
\hline $\mathrm{C}$ & 3.424962 & 5.887925 & -3.872773 \\
\hline C & 4.257383 & 5.711482 & -5.008135 \\
\hline $\mathrm{C}$ & 1.171846 & 5.647546 & -2.882264 \\
\hline $\mathrm{C}$ & 2.080858 & 5.439988 & -3.972781 \\
\hline C & -1.093400 & 5.494439 & -1.931733 \\
\hline $\mathrm{C}$ & -0.189201 & 5.264153 & -3.009034 \\
\hline $\mathrm{C}$ & -3.361765 & 5.340455 & -0.977576 \\
\hline $\mathrm{C}$ & -2.458273 & 5.096291 & -2.049480 \\
\hline $\mathrm{C}$ & -5.664729 & 5.236868 & -0.043922 \\
\hline C & -4.724715 & 4.930341 & -1.087746 \\
\hline $\mathrm{C}$ & -6.989269 & 4.822454 & -0.206336 \\
\hline $\mathrm{C}$ & 3.871625 & 4.916564 & -6.065514 \\
\hline $\mathrm{C}$ & 1.682165 & 4.606365 & -5.067054 \\
\hline $\mathrm{C}$ & 2.626869 & 4.234972 & -6.062393 \\
\hline C & -0.582228 & 4.414005 & -4.091244 \\
\hline $\mathrm{C}$ & 0.391923 & 3.982368 & -5.03370 \\
\hline
\end{tabular}




\begin{tabular}{|c|c|c|c|}
\hline $\mathrm{C}$ & -2.842319 & 4.228783 & -3.117183 \\
\hline C & -1.861612 & 3.794579 & -4.062592 \\
\hline $\mathrm{C}$ & -5.092579 & 4.038340 & -2.134039 \\
\hline $\mathrm{C}$ & -4.111333 & 3.599334 & -3.077697 \\
\hline C & -7.358465 & 3.895602 & -1.202621 \\
\hline $\mathrm{C}$ & -6.368686 & 3.409925 & -2.106339 \\
\hline C & 2.393663 & 3.027261 & -6.839717 \\
\hline C & 3.384859 & 2.454214 & -7.680112 \\
\hline C & 0.174097 & 2.790846 & -5.774655 \\
\hline $\mathrm{C}$ & 1.241485 & 2.243908 & -6.561595 \\
\hline $\mathrm{C}$ & -2.073538 & 2.588223 & -4.790605 \\
\hline $\mathrm{C}$ & -1.007521 & 2.031689 & -5.552415 \\
\hline C & -4.319365 & 2.379586 & -3.790686 \\
\hline $\mathrm{C}$ & -3.252676 & 1.819402 & -4.548450 \\
\hline $\mathrm{C}$ & -6.573986 & 2.172747 & -2.794448 \\
\hline $\mathrm{C}$ & -5.487400 & 1.604222 & -3.534427 \\
\hline $\mathrm{C}$ & -7.759602 & 1.423178 & -2.568798 \\
\hline $\mathrm{C}$ & -8.824441 & 2.062116 & -1.855507 \\
\hline $\mathrm{C}$ & -8.636894 & 3.251657 & -1.204069 \\
\hline $\mathrm{H}$ & -8.744351 & -4.523142 & -0.820444 \\
\hline $\mathrm{H}$ & -9.364220 & -2.815113 & -1.795616 \\
\hline $\mathrm{H}$ & 4.190891 & 0.707622 & -8.571766 \\
\hline $\mathrm{H}$ & 4.454456 & -1.331635 & -8.411007 \\
\hline $\mathrm{H}$ & 5.893748 & -4.773959 & -6.055308 \\
\hline $\mathrm{H}$ & 5.122422 & -3.428748 & -7.415687 \\
\hline $\mathrm{H}$ & -6.872847 & -6.393005 & 2.684828 \\
\hline $\mathrm{H}$ & -7.787912 & -5.933950 & 0.891474 \\
\hline $\mathrm{H}$ & 7.868597 & -5.479642 & -2.170880 \\
\hline $\mathrm{H}$ & 6.956270 & -5.534345 & -4.023351 \\
\hline $\mathrm{H}$ & -5.064213 & -5.074385 & 6.465543 \\
\hline $\mathrm{H}$ & -5.818041 & -6.097016 & 4.837678 \\
\hline $\mathrm{H}$ & 9.409962 & -3.033840 & 1.159961 \\
\hline $\mathrm{H}$ & 8.808979 & -4.480951 & -0.182685 \\
\hline $\mathrm{H}$ & -4.198568 & -1.274126 & 8.494144 \\
\hline $\mathrm{H}$ & -4.427801 & -3.235879 & 7.896786 \\
\hline $\mathrm{H}$ & 9.762801 & 1.244850 & 2.094113 \\
\hline $\mathrm{H}$ & 9.769519 & -0.808094 & 2.026255 \\
\hline $\mathrm{H}$ & -4.637532 & 3.033260 & 7.723928 \\
\hline $\mathrm{H}$ & -4.264694 & 1.139908 & 8.457229 \\
\hline $\mathrm{H}$ & 7.664685 & 5.149403 & 0.604416 \\
\hline
\end{tabular}




$\begin{array}{lrrr}\mathrm{H} & 9.387282 & 3.556999 & 1.419600 \\ \mathrm{H} & 6.945914 & 6.293243 & -0.943226 \\ \mathrm{H} & -6.085570 & 5.683011 & 4.519421 \\ \mathrm{H} & -5.329078 & 4.799242 & 6.228986 \\ \mathrm{H} & 6.006867 & 6.610468 & -3.145286 \\ \mathrm{H} & 5.254323 & 6.132661 & -5.012511 \\ \mathrm{H} & -7.733395 & 5.076231 & 0.538397 \\ \mathrm{H} & -7.024176 & 5.863522 & 2.301021 \\ \mathrm{H} & 4.578270 & 4.738140 & -6.865374 \\ \mathrm{H} & 4.223812 & 3.055120 & -8.006519 \\ \mathrm{H} & -9.755225 & -0.457694 & -2.144916 \\ \mathrm{H} & -9.778470 & 1.559567 & -1.764429 \\ \mathrm{H} & -9.434586 & 3.675839 & -0.604110\end{array}$

$(5,3) 4$ cells

122

$\begin{array}{lrrr}\text { C } & -7.676472 & -2.092218 & -2.763700 \\ \text { C } & -6.429355 & -2.008383 & -2.163813 \\ \text { C } & -6.288487 & -2.349584 & -0.781319 \\ \text { C } & -7.452519 & -2.386373 & 0.041528 \\ \text { C } & -8.703810 & -2.545681 & -0.608372 \\ \text { C } & -8.796218 & -2.464100 & -1.988743 \\ \text { C } & -4.985927 & -2.398315 & -0.194801 \\ \text { C } & -4.838331 & -2.066044 & 1.167681 \\ \text { C } & -5.999643 & -1.514045 & 1.831372 \\ \text { C } & -7.298473 & -1.841877 & 1.386349 \\ \text { C } & -5.786285 & -0.275812 & 2.533541 \\ \text { C } & -6.880519 & 0.643416 & 2.612175 \\ \text { C } & -8.207451 & 0.077741 & 2.579201 \\ \text { C } & -8.404288 & -1.142100 & 1.996103 \\ \text { C } & -3.530519 & -1.806523 & 1.680205 \\ \text { C } & -3.343192 & -0.663991 & 2.519655 \\ \text { C } & -4.468273 & 0.231560 & 2.649846 \\ \text { C } & -5.270331 & -1.238465 & -2.682004 \\ \text { C } & -3.962625 & -1.653648 & -2.275725 \\ \text { C } & -3.819008 & -2.373938 & -1.040962 \\ \text { C } & -2.534604 & -2.490882 & -0.455832\end{array}$




$\begin{array}{rrrr}\text { C } & -2.386083 & -2.287588 & 0.958811 \\ \text { C } & -2.034656 & -0.157669 & 2.712597 \\ \text { C } & -0.907897 & -1.013000 & 2.456897 \\ \text { C } & -1.083482 & -2.052285 & 1.486438 \\ \text { C } & 0.072242 & -2.424315 & 0.712317 \\ \text { C } & -0.072241 & -2.424323 & -0.712292 \\ \text { C } & -1.369243 & -2.243862 & -1.271160 \\ \text { C } & -1.530991 & -1.331902 & -2.358767 \\ \text { C } & -2.842408 & -0.878185 & -2.694039 \\ \text { C } & 0.401588 & -0.524000 & 2.715836 \\ \text { C } & 1.530992 & -1.331876 & 2.358780 \\ \text { C } & 1.369244 & -2.243848 & 1.271183 \\ \text { C } & 2.534605 & -2.490876 & 0.455858 \\ \text { C } & 2.386084 & -2.287598 & -0.958787 \\ \text { C } & 1.083483 & -2.052301 & -1.486416 \\ \text { C } & 0.907897 & -1.013026 & -2.456887 \\ \text { C } & -0.401588 & -0.524029 & -2.715831 \\ \text { C } & -1.812346 & 1.256890 & 2.581464 \\ \text { C } & -0.485468 & 1.729204 & 2.386192 \\ \text { C } & 0.617207 & 0.893413 & 2.768532 \\ \text { C } & 1.943156 & 1.391616 & 2.632601 \\ \text { C } & 3.058781 & 0.524922 & 2.922502 \\ \text { C } & 2.842408 & -0.878156 & 2.694048 \\ \text { C } & 3.962626 & -1.653623 & 2.275742 \\ \text { C } & 3.819009 & -2.373926 & 1.040986 \\ \text { C } & 2.183428 & 2.471799 & 1.733385 \\ \text { C } & 1.090742 & 2.919988 & 0.919314 \\ \text { C } & -0.241052 & 2.711651 & 1.368400 \\ \text { C } & -4.242836 & 1.607361 & 2.349296 \\ \text { C } & -2.907969 & 2.043199 & 2.097421 \\ \text { C } & 5.270332 & -1.238435 & 2.682017 \\ \text { C } & 5.458147 & 0.099416 & 3.011703 \\ \text { C } & 4.385441 & 1.037658 & 2.878582 \\ \text { C } & 4.614999 & 2.262131 & 2.110357 \\ \text { C } & 3.528138 & 2.734548 & 1.318259 \\ \text { C } & 3.779905 & 3.065374 & -0.064214 \\ \text { C } & 5.102572 & 3.042546 & -0.562362 \\ \text { C } & 6.151672 & 3.088273 & 0.411873 \\ & 5.918353 & 2.686729 & 1.706611 \\ \text { C.985928 } & -2.398311 & 0.194826\end{array}$




$\begin{array}{lrrr}\text { C } & 6.288488 & -2.349574 & 0.781344 \\ \text { C } & 6.429356 & -2.008358 & 2.163834 \\ \text { C } & 7.452520 & -2.386371 & -0.041503 \\ \text { C } & 8.703811 & -2.545672 & 0.608399 \\ \text { C } & 8.796219 & -2.464075 & 1.988769 \\ \text { C } & 7.676472 & -2.092186 & 2.763722 \\ \text { C } & 3.530520 & -1.806540 & -1.680186 \\ \text { C } & 4.838332 & -2.066055 & -1.167659 \\ \text { C } & 7.298474 & -1.841889 & -1.386330 \\ \text { C } & 5.999644 & -1.514063 & -1.831356 \\ \text { C } & 5.786285 & -0.275838 & -2.533538 \\ \text { C } & 4.468273 & 0.231533 & -2.649849 \\ \text { C } & 3.343193 & -0.664017 & -2.519648 \\ \text { C } & 2.034657 & -0.157698 & -2.712596 \\ \text { C } & 6.880520 & 0.643390 & -2.612183 \\ \text { C } & 8.207452 & 0.077716 & -2.579203 \\ \text { C } & 8.404289 & -1.142119 & -1.996092 \\ \text { C } & 1.812346 & 1.256863 & -2.581478 \\ \text { C } & 2.907969 & 2.043177 & -2.097444 \\ \text { C } & 4.242836 & 1.607337 & -2.349314 \\ \text { C } & 0.485468 & 1.729179 & -2.386211 \\ \text { C } & -0.617207 & 0.893383 & -2.768543 \\ \text { C } & -3.058780 & 0.524890 & -2.922508 \\ \text { C } & -1.943156 & 1.391588 & -2.632617 \\ \text { C } & -2.183428 & 2.471780 & -1.733412 \\ \text { C } & -1.090743 & 2.919978 & -0.919346 \\ \text { C } & 0.241052 & 2.711636 & -1.368430 \\ \text { C } & -5.458147 & 0.099382 & -3.011705 \\ \text { C } & -4.385441 & 1.037626 & -2.878594 \\ \text { C } & -4.614999 & 2.262107 & -2.110382 \\ \text { C } & -3.528139 & 2.734533 & -1.318289 \\ \text { C } & -3.779906 & 3.065374 & 0.064180 \\ \text { C } & -5.102572 & 3.042551 & 0.562328 \\ \text { C } & -6.151672 & 3.088267 & -0.411908 \\ \text { C } & -5.918353 & 2.686709 & -1.706641 \\ \text { C } & -6.638963 & 1.987962 & 2.265338 \\ \text { C } & -5.351879 & 2.381039 & 1.855953 \\ \text { C } & -2.664690 & 2.884508 & 0.970541 \\ & 1.339482 & 3.030403 & 0.494337 \\ \text { (1.3981 } & 3.030398 & -0.494371\end{array}$




$\begin{array}{rrrr}\text { C } & 2.664689 & 2.884498 & -0.970573 \\ \mathrm{C} & 5.351878 & 2.381020 & -1.855980 \\ \mathrm{C} & 6.638963 & 1.987939 & -2.265361 \\ \mathrm{H} & 6.475951 & 0.463207 & 3.067959 \\ \mathrm{H} & 6.759832 & 2.552795 & 2.376163 \\ \mathrm{H} & 7.173060 & 3.254554 & 0.092336 \\ \mathrm{H} & 7.795069 & -1.841491 & 3.811162 \\ \mathrm{H} & 7.496272 & 2.614970 & -2.046686 \\ \mathrm{H} & 9.758979 & -2.590845 & 2.469959 \\ \mathrm{H} & 9.603483 & -2.673643 & 0.018999 \\ \mathrm{H} & 9.413504 & -1.503655 & -1.842292 \\ \mathrm{H} & 9.052359 & 0.687272 & -2.879990 \\ \mathrm{H} & -6.475951 & 0.463173 & -3.067964 \\ \mathrm{H} & -6.759832 & 2.552768 & -2.376191 \\ \mathrm{H} & -7.795069 & -1.841534 & -3.811143 \\ \mathrm{H} & -7.173060 & 3.254551 & -0.092372 \\ \mathrm{H} & -9.758978 & -2.590875 & -2.469932 \\ \mathrm{H} & -9.603482 & -2.673646 & -0.018971 \\ \mathrm{H} & -9.413503 & -1.503638 & 1.842307 \\ \mathrm{H} & -9.052359 & 0.687300 & 2.879981 \\ \mathrm{H} & -7.496272 & 2.614989 & 2.046657\end{array}$

$(7,5) 4$ cells

178

$\begin{array}{lllr}\text { C } & 5.836237 & 4.349982 & 1.989919 \\ \text { C } & 4.518506 & 4.031669 & 2.410599 \\ \text { C } & 3.467741 & 4.281080 & 1.483152 \\ \text { C } & 3.775479 & 4.452637 & 0.092348 \\ \text { C } & 5.125574 & 4.441691 & -0.342101 \\ \text { C } & 6.127043 & 4.561073 & 0.657974 \\ \text { C } & 2.105799 & 4.082950 & 1.879900 \\ \text { C } & 1.824193 & 3.311376 & 3.041410 \\ \text { C } & 2.916712 & 2.681194 & 3.730576 \\ \text { C } & 4.239899 & 3.159925 & 3.545033 \\ \text { C } & 2.693319 & 1.401237 & 4.340402 \\ \text { C } & 3.806480 & 0.591680 & 4.702912 \\ \text { C } & 5.067530 & 1.241588 & 4.803777\end{array}$

S161 


$\begin{array}{lrrr}\text { C } & 5.275555 & 2.486874 & 4.252220 \\ \text { C } & 0.490300 & 2.901867 & 3.304351 \\ \text { C } & 0.258254 & 1.660868 & 3.982653 \\ \text { C } & 1.375180 & 0.837719 & 4.308696 \\ \text { C } & 1.228206 & -0.576044 & 4.263724 \\ \text { C } & 2.410252 & -1.385458 & 4.181940 \\ \text { C } & 3.674885 & -0.858538 & 4.579470 \\ \text { C } & -1.050107 & 1.101173 & 3.980626 \\ \text { C } & -1.205334 & -0.317411 & 3.984049 \\ \text { C } & -0.037477 & -1.136746 & 3.931099 \\ \text { C } & -0.091075 & -2.357576 & 3.184383 \\ \text { C } & 1.133847 & -2.932170 & 2.734376 \\ \text { C } & 2.361822 & -2.560212 & 3.369204 \\ \text { C } & 3.580190 & -3.127175 & 2.910021 \\ \text { C } & 4.794105 & -2.802067 & 3.587888 \\ \text { C } & 4.816007 & -1.687337 & 4.423044 \\ \text { C } & 1.169001 & -3.581200 & 1.467348 \\ \text { C } & 2.438290 & -3.746056 & 0.816735 \\ \text { C } & 3.629943 & -3.651795 & 1.578060 \\ \text { C } & 4.896510 & -3.687715 & 0.916640 \\ \text { C } & 6.104291 & -3.660940 & 1.687530 \\ \text { C } & 6.046068 & -3.400259 & 3.089912 \\ \text { C } & -0.031640 & -3.715739 & 0.714969 \\ \text { C } & -1.290281 & -3.477935 & 1.349983 \\ \text { C } & -1.316661 & -2.756497 & 2.580376 \\ \text { C } & -2.542473 & -2.138128 & 2.993788 \\ \text { C } & -2.479100 & -0.882962 & 3.674511 \\ \text { C } & -3.640058 & -0.054941 & 3.696816 \\ \text { C } & -3.472833 & 1.362093 & 3.626775 \\ \text { C } & -2.167891 & 1.914113 & 3.605765 \\ \text { C } & -1.928796 & 3.113703 & 2.862736 \\ \text { C } & -0.586689 & 3.504876 & 2.585138 \\ \text { C } & -0.299278 & 4.208737 & 1.376449 \\ \text { C } & 1.051968 & 4.364756 & 0.963094 \\ \text { C } & -4.915054 & -0.622472 & 3.401789 \\ \text { C } & -4.985813 & -1.891892 & 2.776636 \\ \text { C } & -3.770658 & -2.555842 & 2.415190 \\ \text { C } & -3.751547 & -3.346066 & 1.223195 \\ & -2.438289 & -3.746009 & -0.816955\end{array}$




\begin{tabular}{|c|c|c|c|}
\hline C & -1.169000 & -3.581116 & -1.467558 \\
\hline C & 0.031640 & -3.715698 & -0.715187 \\
\hline C & 1.290281 & -3.477856 & -1.350188 \\
\hline C & 2.499272 & -3.636811 & -0.606571 \\
\hline C & 3.751548 & -3.345995 & -1.223391 \\
\hline C & 4.956076 & -3.508418 & -0.480785 \\
\hline C & -6.233817 & -2.325803 & 2.224731 \\
\hline $\mathrm{C}$ & -6.226293 & -3.186747 & 1.079084 \\
\hline $\mathrm{C}$ & -4.956075 & -3.508446 & 0.480578 \\
\hline $\mathrm{C}$ & -4.896509 & -3.687664 & -0.916856 \\
\hline C & -3.629943 & -3.651706 & -1.578275 \\
\hline $\mathrm{C}$ & -3.580189 & -3.127009 & -2.910205 \\
\hline $\mathrm{C}$ & -2.361822 & -2.560019 & -3.369356 \\
\hline $\mathrm{C}$ & -1.133846 & -2.932013 & -2.734549 \\
\hline C & 0.091076 & -2.357392 & -3.184523 \\
\hline $\mathrm{C}$ & 1.316662 & -2.756348 & -2.580539 \\
\hline $\mathrm{C}$ & 2.542473 & -2.137954 & -2.993915 \\
\hline $\mathrm{C}$ & 3.770659 & -2.555701 & -2.415340 \\
\hline C & -4.584549 & 2.160431 & 3.200265 \\
\hline C & -5.898500 & 1.625367 & 3.268107 \\
\hline $\mathrm{C}$ & -6.084192 & 0.211200 & 3.398376 \\
\hline $\mathrm{C}$ & -7.365800 & -0.352399 & 3.173298 \\
\hline $\mathrm{C}$ & -7.445910 & -1.681732 & 2.604801 \\
\hline C & -8.657924 & -2.222361 & 2.085646 \\
\hline $\mathrm{C}$ & -8.648399 & -3.091297 & 1.020037 \\
\hline $\mathrm{C}$ & -7.428721 & -3.459448 & 0.384585 \\
\hline C & -7.368958 & -3.782952 & -1.039840 \\
\hline C & -6.104291 & -3.660844 & -1.687745 \\
\hline C & -6.046068 & -3.400083 & -3.090112 \\
\hline $\mathrm{C}$ & -4.794105 & -2.801862 & -3.588053 \\
\hline $\mathrm{C}$ & -6.995575 & 2.443501 & 2.863749 \\
\hline C & -8.314121 & 1.891631 & 2.997858 \\
\hline $\mathrm{C}$ & -8.488892 & 0.543343 & 3.152267 \\
\hline $\mathrm{C}$ & -7.204821 & -3.527701 & -3.854020 \\
\hline C & -8.417889 & -3.864831 & -3.235911 \\
\hline C & -8.512143 & -3.944268 & -1.852166 \\
\hline C & -2.410252 & -1.385217 & -4.182023 \\
\hline $\mathrm{C}$ & -3.674885 & -0.858274 & -4.579521 \\
\hline C & -4.816007 & -1.687082 & -4.423143 \\
\hline $\mathrm{C}$ & -2.997649 & 3.682919 & 2.109729 \\
\hline
\end{tabular}

S163 


$\begin{array}{lrrr}\text { C } & -4.344569 & 3.314768 & 2.403954 \\ \text { C } & -1.228206 & -0.575798 & -4.263760 \\ \text { C } & 0.037477 & -1.136520 & -3.931168 \\ \text { C } & -1.375180 & 0.837967 & -4.308650 \\ \text { C } & -2.693320 & 1.401487 & -4.340322 \\ \text { C } & -3.806481 & 0.591951 & -4.702879 \\ \text { C } & 1.205334 & -0.317181 & -3.984071 \\ \text { C } & 2.479100 & -0.882750 & -3.674566 \\ \text { C } & 1.050106 & 1.101403 & -3.980565 \\ \text { C } & -0.258255 & 1.661098 & -3.982559 \\ \text { C } & 3.640058 & -0.054727 & -3.696824 \\ \text { C } & 4.915054 & -0.622274 & -3.401827 \\ \text { C } & 4.985814 & -1.891729 & -2.776748 \\ \text { C } & 6.233818 & -2.325672 & -2.224868 \\ \text { C } & 6.226294 & -3.186683 & -1.079272 \\ \text { C } & 7.428722 & -3.459425 & -0.384789 \\ \text { C } & 7.368959 & -3.783011 & 1.039618 \\ \text { C } & 8.512144 & -3.944374 & 1.851935 \\ \text { C } & 8.417889 & -3.865016 & 3.235685 \\ \text { C } & 7.204821 & -3.527922 & 3.853812 \\ \text { C } & 3.472832 & 1.362303 & -3.626700 \\ \text { C } & 2.167890 & 1.914322 & -3.605658 \\ \text { C } & 6.084192 & 0.211398 & -3.398367 \\ \text { C } & 7.365800 & -0.352213 & -3.173321 \\ \text { C } & 7.445910 & -1.681578 & -2.604900 \\ \text { C } & 8.657924 & -2.222237 & -2.085776 \\ \text { C } & 8.648399 & -3.091236 & -1.020219 \\ \text { C } & 5.898499 & 1.625557 & -3.268017 \\ \text { C } & 4.584548 & 2.160617 & -3.200145 \\ \text { C } & 6.995573 & 2.443670 & -2.863613 \\ \text { C } & 8.314120 & 1.891808 & -2.997753 \\ \text { C } & 8.488891 & 0.543528 & -3.152239 \\ \text { C } & -2.916712 & 2.681409 & -3.730423 \\ \text { C } & -4.239900 & 3.160130 & -3.544854 \\ \text { C } & -5.275556 & 2.487119 & -4.252079 \\ \text { C } & -5.067531 & 1.241864 & -4.803708 \\ \text { C } & -0.490301 & 2.902057 & -3.304186 \\ & -1.824194 & 3.311551 & -3.041221 \\ \text { C } & 1.928795 & 3.113868 & -2.862559 \\ \text { - } & & 3.505025 & -2.584938\end{array}$




$\begin{array}{lrrr}\mathrm{C} & 4.344568 & 3.314908 & -2.403766 \\ \mathrm{C} & 2.997647 & 3.683041 & -2.109520 \\ \mathrm{C} & -2.105800 & 4.083058 & -1.879667 \\ \mathrm{C} & -3.467742 & 4.281166 & -1.482908 \\ \mathrm{C} & -4.518506 & 4.031809 & -2.410369 \\ \mathrm{C} & 0.299277 & 4.208817 & -1.376208 \\ \mathrm{C} & -1.051969 & 4.364811 & -0.962844 \\ \mathrm{C} & -3.775480 & 4.452642 & -0.092094 \\ \mathrm{C} & -5.125575 & 4.441671 & 0.342354 \\ \mathrm{C} & -6.127044 & 4.561111 & -0.657714 \\ \mathrm{C} & -5.836238 & 4.350097 & -1.989671 \\ \mathrm{C} & -6.737613 & 3.586558 & 2.078690 \\ \mathrm{C} & -5.434763 & 3.905450 & 1.675159 \\ \mathrm{C} & -2.704786 & 4.306290 & 0.860343 \\ \mathrm{C} & -1.359890 & 4.424368 & 0.437514 \\ \mathrm{C} & 6.737611 & 3.586681 & -2.078488 \\ \mathrm{C} & 5.434761 & 3.905549 & -1.674937 \\ \mathrm{C} & 2.704785 & 4.306339 & -0.860097 \\ \mathrm{C} & 1.359889 & 4.424393 & -0.437261 \\ \mathrm{H} & -9.491941 & 0.136594 & 3.136263 \\ \mathrm{H} & -9.607968 & -1.865020 & 2.462294 \\ \mathrm{H} & -9.591958 & -3.396195 & 0.585784 \\ \mathrm{H} & -9.481361 & -4.100718 & -1.396052 \\ \mathrm{H} & -9.305170 & -4.006298 & -3.841721 \\ \mathrm{H} & -7.165087 & -3.365695 & -4.924774 \\ \mathrm{H} & -5.779745 & -1.334345 & -4.765497 \\ \mathrm{H} & -5.913758 & 0.708907 & -5.218855 \\ \mathrm{H} & -6.279120 & 2.893117 & -4.247584 \\ \mathrm{H} & -6.651699 & 4.311641 & -2.701205 \\ \mathrm{H} & -7.163375 & 4.676469 & -0.366620 \\ \mathrm{H} & -7.585420 & 4.084898 & 1.623498 \\ \mathrm{H} & -9.171317 & 2.540792 & 2.856635 \\ \mathrm{H} & 7.165087 & -3.365977 & 4.924576 \\ \mathrm{H} & 5.779745 & -1.334620 & 4.765419 \\ & 9.591959 & -3.396160 & -0.585984 \\ \mathrm{H} & 9.481362 & -4.100798 & 1.395812 \\ \mathrm{H} & 9.491940 & 0.136778 & -3.136259 \\ \mathrm{H} & 7.585419 & 4.084996 & -1.623268 \\ \mathrm{H} & & 2.540961 & -2.856493\end{array}$




$\begin{array}{rrrr}\mathrm{H} & 7.163373 & 4.676447 & 0.366886 \\ \mathrm{H} & 6.651698 & 4.311484 & 2.701451 \\ \mathrm{H} & 6.279119 & 2.892872 & 4.247748 \\ \mathrm{H} & 5.913757 & 0.708606 & 5.218893 \\ \mathrm{H} & 9.305171 & -4.006518 & 3.841486\end{array}$

$(8,6) 4$ cells

206

$\begin{array}{llll}\text { C } & -6.234508 & 5.394039 & 0.098983\end{array}$

$\begin{array}{llll}\text { C } & -4.882815 & 5.359691 & -0.324838\end{array}$

$\begin{array}{llll}\text { C } & -3.897977 & 5.101660 & 0.669678\end{array}$

$\begin{array}{llll}\text { C } & -4.289709 & 4.556495 & 1.935842\end{array}$

$\begin{array}{llll}\text { C } & -5.661287 & 4.323470 & 2.214371\end{array}$

$\begin{array}{llll}\text { C } & -6.609007 & 4.900388 & 1.332395\end{array}$

$\begin{array}{llll}\text { C } & -2.507575 & 5.155521 & 0.329134\end{array}$

$\begin{array}{llll}\text { C } & -2.122734 & 5.138701 & -1.039782\end{array}$

C $\quad-3.137703 \quad 4.993496 \quad-2.045622$

$\begin{array}{llll}\text { C } & -4.495773 & 5.255486 & -1.726640\end{array}$

$\begin{array}{llll}\text { C } & -0.755828 & 4.974835 & -1.383230\end{array}$

$\begin{array}{llll}\text { C } & -0.409794 & 4.385958 & -2.642546\end{array}$

$\begin{array}{llll}\text { C } & -1.448826 & 3.915136 & -3.494862\end{array}$

$\begin{array}{llll}\text { C } & -2.799901 & 4.338443 & -3.274728\end{array}$

$\begin{array}{llll}\text { C } & -1.190501 & 2.828970 & -4.373699\end{array}$

$\begin{array}{llll}\text { C } & 0.110970 & 2.259604 & -4.425021\end{array}$

$\begin{array}{llll}\text { C } & 1.202549 & 2.936426 & -3.806754\end{array}$

$\begin{array}{llll}\text { C } & 0.933741 & 3.992203 & -2.886304\end{array}$

$\begin{array}{llll}\text { C } & -2.298353 & 2.143618 & -4.977618\end{array}$

$\begin{array}{llll}\text { C } & -2.157727 & 0.753628 & -5.300770\end{array}$

$\begin{array}{llll}\text { C } & -0.899972 & 0.106096 & -5.058891\end{array}$

$\begin{array}{llll}\text { C } & 0.263093 & 0.884499 & -4.796074\end{array}$

$\begin{array}{llll}\text { C } & -3.310045 & -0.018833 & -5.613930\end{array}$

$\begin{array}{llll}\text { C } & -3.307893 & -1.441370 & -5.281806\end{array}$

$\begin{array}{llll}\text { C } & -2.121617 & -2.000313 & -4.719776\end{array}$

$\begin{array}{llll}\text { C } & -0.878184 & -1.289079 & -4.790952\end{array}$

$\begin{array}{llll}\text { C } & -4.513984 & -2.170816 & -5.147654\end{array}$

C $\quad-4.637467 \quad-3.219274 \quad-4.237489$

$\begin{array}{llll}\text { C } & -3.506084 & -3.578238 & -3.445289\end{array}$ 


$\begin{array}{lrrr}\text { C } & -2.221773 & -3.101768 & -3.817525 \\ \text { C } & -1.074499 & -3.509498 & -3.063173 \\ \text { C } & -1.251702 & -4.134721 & -1.797153 \\ \text { C } & -2.578114 & -4.258265 & -1.265704 \\ \text { C } & -3.695005 & -4.094382 & -2.122668 \\ \text { C } & -0.128469 & -4.335406 & -0.947003 \\ \text { C } & -0.318718 & -4.403247 & 0.470542 \\ \text { C } & -1.622650 & -4.184151 & 1.008539 \\ \text { C } & -2.762978 & -4.236716 & 0.148967 \\ \text { C } & 0.812368 & -4.365588 & 1.332850 \\ \text { C } & 0.672311 & -3.864979 & 2.657798 \\ \text { C } & -0.585923 & -3.349802 & 3.079852 \\ \text { C } & -1.752834 & -3.625313 & 2.312851 \\ \text { C } & 2.129497 & -4.520036 & 0.786710 \\ \text { C } & 3.252303 & -4.518610 & 1.651928 \\ \text { C } & 3.093859 & -4.127892 & 3.021018 \\ \text { C } & 1.841498 & -3.611290 & 3.445575 \\ \text { C } & 4.568318 & -4.567496 & 1.103817 \\ \text { C } & 5.704020 & -4.637344 & 1.976900 \\ \text { C } & 5.528307 & -4.480787 & 3.384612 \\ \text { C } & 4.243433 & -3.925514 & 3.840805 \\ \text { C } & 7.015046 & -4.783787 & 1.432793 \\ \text { C } & 8.077086 & -5.030633 & 2.326200 \\ \text { C } & 7.866483 & -5.032328 & 3.700275 \\ \text { C } & 6.614072 & -4.704203 & 4.232993 \\ \text { C } & 4.757258 & -4.354746 & -0.278163 \\ \text { C } & 6.087476 & -4.111100 & -0.770445 \\ \text { C } & 7.212092 & -4.442740 & 0.023410 \\ \text { C } & 1.808678 & -2.609566 & 4.461654 \\ \text { C } & 3.026153 & -2.190418 & 5.077464 \\ \text { C } & 4.184206 & -2.973386 & 4.858383 \\ \text { C } & 2.319768 & -4.364528 & -0.618677 \\ \text { C } & 3.631993 & -4.135808 & -1.120844 \\ \text { C } & 0.609493 & -1.839532 & 4.621550 \\ \text { C } & -0.611621 & -2.303844 & 4.057172 \\ \text { C } & 1.188215 & -4.147346 & -1.464016 \\ \text { C } & -1.797150 & -1.524263 & 4.202913 \\ \text { C } & -3.027208 & -1.994353 & 3.650042 \\ & -4.011736 & -3.071246 & 2.713139 \\ & & -3.361326 & 1.961869\end{array}$




$\begin{array}{lrrr}\text { C } & -4.059550 & -3.974493 & 0.676174 \\ \text { C } & -4.205697 & -1.204729 & 3.779196 \\ \text { C } & -5.435184 & -1.676819 & 3.233134 \\ \text { C } & -5.427490 & -2.767989 & 2.330722 \\ \text { C } & -6.618238 & -3.077763 & 1.597252 \\ \text { C } & -6.508110 & -3.748427 & 0.336896 \\ \text { C } & -5.194490 & -4.027933 & -0.181508 \\ \text { C } & -5.014260 & -4.110267 & -1.578298 \\ \text { C } & -5.957122 & -3.734793 & -3.837160 \\ \text { C } & -6.148192 & -4.016726 & -2.450914 \\ \text { C } & -7.468314 & -4.127580 & -1.920965 \\ \text { C } & -7.648097 & -3.917501 & -0.485348 \\ \text { C } & -8.541078 & -4.215148 & -2.832314 \\ \text { C } & -8.325175 & -4.097679 & -4.199908 \\ \text { C } & -7.050887 & -3.802947 & -4.700878 \\ \text { C } & 0.215700 & -3.032665 & -3.431269 \\ \text { C } & 0.311087 & -1.887506 & -4.285633 \\ \text { C } & 1.540265 & -1.168042 & -4.340291 \\ \text { C } & 1.512116 & 0.236665 & -4.579763 \\ \text { C } & -3.579394 & 2.756653 & -5.009218 \\ \text { C } & -4.628392 & 2.033916 & -5.640240 \\ \text { C } & -4.499670 & 0.692852 & -5.926545 \\ \text { C } & -3.831343 & 3.907722 & -4.154220 \\ \text { C } & 1.358997 & -3.462423 & -2.701738 \\ \text { C } & 2.651811 & -2.946995 & -3.041772 \\ \text { C } & 2.738577 & -1.772645 & -3.847631 \\ \text { C } & 3.962711 & -1.046741 & -3.884253 \\ \text { C } & 3.925957 & 0.369889 & -4.080867 \\ \text { C } & 2.676082 & 1.016046 & -4.280370 \\ \text { C } & 2.513262 & 2.372235 & -3.866235 \\ \text { C } & -7.867521 & -2.519732 & 1.992292 \\ \text { C } & -9.021905 & -2.935042 & 1.272469 \\ \text { C } & -8.915617 & -3.617603 & 0.082230 \\ \text { C } & -6.623399 & -0.881332 & 3.353125 \\ \text { C } & -7.865850 & -1.368182 & 2.872578 \\ \text { C } & 3.797932 & -3.394284 & -2.332955 \\ \text { C } & 6.245035 & -3.315527 & -1.949459 \\ \text { C } & 5.078696 & -2.842841 & -2.636168 \\ \text { C } & 5.157639 & -1.652612 & -3.400138 \\ & 8.496554 & -4.171188 & -0.516786\end{array}$

S168 


$\begin{array}{lrrr}\text { C } & 8.650109 & -3.372836 & -1.628951 \\ \text { C } & 7.527712 & -2.805980 & -2.290143 \\ \text { C } & 7.600371 & -1.554900 & -3.025943 \\ \text { C } & 6.394364 & -0.921865 & -3.421251 \\ \text { C } & 6.345799 & 0.503963 & -3.563331 \\ \text { C } & 5.076453 & 1.143044 & -3.737865 \\ \text { C } & 4.906343 & 2.476439 & -3.288200 \\ \text { C } & 3.596760 & 3.035157 & -3.220964 \\ \text { C } & 7.499436 & 1.280101 & -3.257779 \\ \text { C } & 8.745155 & 0.590747 & -3.184258 \\ \text { C } & 8.794217 & -0.777862 & -3.080856 \\ \text { C } & 7.316423 & 2.618330 & -2.738617 \\ \text { C } & 5.997320 & 3.129731 & -2.624633 \\ \text { C } & 5.696547 & 4.109349 & -1.626047 \\ \text { C } & 6.715446 & 4.540021 & -0.725708 \\ \text { C } & 8.072985 & 4.229547 & -1.063896 \\ \text { C } & 8.358974 & 3.308193 & -2.035277 \\ \text { C } & 3.313770 & 4.050405 & -2.256302 \\ \text { C } & 4.344705 & 4.444857 & -1.344186 \\ \text { C } & 1.972271 & 4.425224 & -2.001527 \\ \text { C } & 0.712610 & -0.489059 & 5.054498 \\ \text { C } & 2.004853 & 0.051221 & 5.364737 \\ \text { C } & 3.111699 & -0.817940 & 5.574523 \\ \text { C } & -1.686281 & -0.162925 & 4.610431 \\ \text { C } & -0.402856 & 0.380409 & 4.898030 \\ \text { C } & -4.082210 & 0.169803 & 4.147848 \\ \text { C } & -2.802721 & 0.712247 & 4.420960 \\ \text { C } & -6.482721 & 0.502034 & 3.690848 \\ \text { C } & -5.191081 & 1.047819 & 3.923226 \\ \text { C } & -7.584160 & 1.389690 & 3.511699 \\ \text { C } & -8.880054 & 0.808846 & 3.322348 \\ \text { C } & -9.012024 & -0.519382 & 3.015947 \\ \text { C } & 2.223382 & 1.460817 & 5.217767 \\ \text { C } & 3.535184 & 1.994249 & 5.322304 \\ \text { C } & 4.541556 & 1.140736 & 5.846688 \\ \text { C } & 4.338182 & -0.218081 & 5.962798 \\ \text { C } & -0.173349 & 1.781253 & 4.700789 \\ & 1.155700 & 2.278104 & 4.712559 \\ \text { C } & -1.565209 & 2.101653 & 4.177678 \\ & & 2.590772 & 4.177369\end{array}$




\begin{tabular}{|c|c|c|c|}
\hline C & -4.952286 & 2.421315 & 3.642989 \\
\hline $\mathrm{C}$ & -3.608307 & 2.900705 & 3.628293 \\
\hline C & 1.475881 & 3.448352 & 3.969116 \\
\hline C & 2.849230 & 3.817496 & 3.793994 \\
\hline $\mathrm{C}$ & 3.851407 & 3.231548 & 4.617354 \\
\hline $\mathrm{C}$ & -0.897670 & 3.731129 & 3.386488 \\
\hline $\mathrm{C}$ & 0.467896 & 4.072213 & 3.182831 \\
\hline $\mathrm{C}$ & 3.228319 & 4.588773 & 2.646803 \\
\hline C & 4.600749 & 4.810079 & 2.360029 \\
\hline $\mathrm{C}$ & 5.535279 & 4.480564 & 3.372990 \\
\hline C & 5.175826 & 3.710056 & 4.461136 \\
\hline $\mathrm{C}$ & 1.620627 & 4.946000 & -0.717401 \\
\hline $\mathrm{C}$ & 2.614611 & 5.022491 & 0.299905 \\
\hline $\mathrm{C}$ & 3.993505 & 4.907785 & -0.045815 \\
\hline C & 0.244968 & 5.088319 & -0.372507 \\
\hline $\mathrm{C}$ & -1.521940 & 4.944076 & 1.333079 \\
\hline C & -0.143373 & 5.037655 & 0.998490 \\
\hline $\mathrm{C}$ & -5.132866 & 4.430971 & -3.932704 \\
\hline $\mathrm{C}$ & -5.451492 & 5.089999 & -2.765017 \\
\hline $\mathrm{C}$ & -7.328692 & 2.753451 & 3.253593 \\
\hline $\mathrm{C}$ & -6.022444 & 3.237387 & 3.135220 \\
\hline $\mathrm{C}$ & -3.270438 & 4.003833 & 2.788536 \\
\hline $\mathrm{C}$ & -1.910777 & 4.321241 & 2.565262 \\
\hline $\mathrm{C}$ & 0.852155 & 4.774224 & 1.992707 \\
\hline C & 2.222220 & 4.898937 & 1.666223 \\
\hline $\mathrm{C}$ & 5.010055 & 5.024240 & 0.965406 \\
\hline $\mathrm{C}$ & 6.346735 & 5.002623 & 0.555352 \\
\hline $\mathrm{H}$ & 8.693498 & -5.242371 & 4.368217 \\
\hline $\mathrm{H}$ & 9.076339 & -5.198181 & 1.945554 \\
\hline $\mathrm{H}$ & 9.381157 & -4.501702 & 0.011972 \\
\hline $\mathrm{H}$ & 9.650066 & -3.098589 & -1.939640 \\
\hline $\mathrm{H}$ & 9.752657 & -1.256431 & -2.926050 \\
\hline $\mathrm{H}$ & 9.665756 & 1.155365 & -3.110353 \\
\hline $\mathrm{H}$ & 9.389330 & 3.020029 & -2.198789 \\
\hline $\mathrm{H}$ & 6.482643 & -4.630468 & 5.306044 \\
\hline $\mathrm{H}$ & 5.109807 & -2.700962 & 5.347281 \\
\hline $\mathrm{H}$ & 5.170631 & -0.842943 & 6.260024 \\
\hline $\mathrm{H}$ & 5.527497 & 1.537181 & 6.052610 \\
\hline $\mathrm{H}$ & 5.949754 & 3.382925 & 5.143832 \\
\hline $\mathrm{H}$ & 6.580589 & 4.727525 & 3.23862 \\
\hline
\end{tabular}




$\begin{array}{rrrr}\text { H } & 7.139291 & 5.170597 & 1.274641 \\ \mathrm{H} & 8.871266 & 4.658550 & -0.468176 \\ \mathrm{H} & -6.910303 & -3.633940 & -5.761901 \\ \mathrm{H} & -5.417606 & -1.787618 & -5.601976 \\ \mathrm{H} & -9.817126 & -3.832158 & -0.476898 \\ \mathrm{H} & -9.550539 & -4.353282 & -2.467230 \\ \mathrm{H} & -9.993414 & -0.908185 & 2.777143 \\ \mathrm{H} & -10.003323 & -2.632668 & 1.614382 \\ \mathrm{H} & -8.167407 & 3.372741 & 2.959123 \\ \mathrm{H} & -9.749018 & 1.457739 & 3.319611 \\ \mathrm{H} & -7.664241 & 4.842512 & 1.566631 \\ \mathrm{H} & -7.006610 & 5.711632 & -0.590346 \\ \mathrm{H} & -6.480578 & 5.380237 & -2.597036 \\ \mathrm{H} & -5.921083 & 4.226803 & -4.646089 \\ \mathrm{H} & -5.587806 & 2.509298 & -5.798580 \\ \mathrm{H} & -5.361853 & 0.156932 & -6.302779 \\ \mathrm{H} & -9.161081 & -4.186971 & -4.883649\end{array}$

$(9,7) 4$ cells

234

$\begin{array}{lrrr}\text { C } & 4.326591 & 4.438207 & 5.437005 \\ \text { C } & 3.475992 & 4.931502 & 4.414414 \\ \text { C } & 2.119577 & 4.512516 & 4.435601 \\ \text { C } & 1.706058 & 3.453093 & 5.306501 \\ \text { C } & 2.661208 & 2.794688 & 6.129002 \\ \text { C } & 3.935832 & 3.402954 & 6.259851 \\ \text { C } & 3.991724 & 5.598694 & 3.224265 \\ \text { C } & 3.134517 & 5.743553 & 2.097458 \\ \text { C } & 1.719119 & 5.580783 & 2.249906 \\ \text { C } & 1.204824 & 4.988180 & 3.436361 \\ \text { C } & 3.692600 & 5.848970 & 0.782380 \\ \text { C } & 5.101265 & 5.850845 & 0.604612 \\ \text { C } & 5.901786 & 5.994946 & 1.762590 \\ \text { C } & 5.367552 & 5.866658 & 3.029908 \\ \text { C } & -0.169735 & 4.647817 & 3.513317 \\ \text { C } & -1.071107 & 5.109310 & 2.509001 \\ \text { C } & -0.549749 & 5.655925 & 1.301406\end{array}$

S171 


$\begin{array}{lrrr}\text { C } & 0.857181 & 5.781235 & 1.137792 \\ \text { C } & -0.595525 & 3.623652 & 4.419633 \\ \text { C } & 0.376102 & 2.930780 & 5.193824 \\ \text { C } & -2.456622 & 4.783859 & 2.592265 \\ \text { C } & -2.891312 & 3.798191 & 3.531074 \\ \text { C } & -1.921823 & 3.120500 & 4.335982 \\ \text { C } & -2.212095 & 1.814498 & 4.825811 \\ \text { C } & -1.158150 & 1.018571 & 5.359537 \\ \text { C } & 0.097828 & 1.614867 & 5.651737 \\ \text { C } & 1.165836 & 0.816699 & 6.183945 \\ \text { C } & 2.389949 & 1.430601 & 6.562274 \\ \text { C } & 1.065496 & -0.611588 & 6.119100 \\ \text { C } & -0.115575 & -1.204539 & 5.558384 \\ \text { C } & -1.271874 & -0.408909 & 5.327388 \\ \text { C } & -2.446428 & -1.006176 & 4.789138 \\ \text { C } & -3.602797 & -0.201818 & 4.532651 \\ \text { C } & -3.477725 & 1.218947 & 4.536552 \\ \text { C } & -4.522815 & 2.012414 & 3.985105 \\ \text { C } & -4.216121 & 3.305189 & 3.459930 \\ \text { C } & 3.393220 & 0.592383 & 7.114728 \\ \text { C } & 3.304040 & -0.780521 & 7.035123 \\ \text { C } & 2.202569 & -1.415997 & 6.405775 \\ \text { C } & 2.300493 & -2.739803 & 5.794013 \\ \text { C } & 1.219435 & -3.189617 & 4.978421 \\ \text { C } & -0.042641 & -2.509772 & 5.001717 \\ \text { C } & -1.131687 & -3.007604 & 4.231991 \\ \text { C } & -2.379784 & -2.321564 & 4.247413 \\ \text { C } & -0.893474 & -4.000295 & 3.227877 \\ \text { C } & 0.439240 & -4.436268 & 2.989203 \\ \text { C } & 1.465750 & -4.139252 & 3.943524 \\ \text { C } & 2.792548 & -4.582175 & 3.703836 \\ \text { C } & 3.797108 & -4.339761 & 4.686136 \\ \text { C } & 3.528786 & -3.434033 & 5.712987 \\ \text { C } & -4.778209 & -0.800074 & 4.004825 \\ \text { C } & -4.720650 & -2.132232 & 3.486718 \\ \text { C } & -3.478193 & -2.824930 & 3.482236 \\ \text { C } & -3.251205 & -3.844139 & 2.511294 \\ \text { C } & -1.917505 & -4.317239 & 2.292644 \\ & -0.1970151 & -4.864705 & 1.024952 \\ & & -5.040662 & 0.690212\end{array}$




$\begin{array}{lrrr}\text { C } & 0.794510 & -4.934142 & 1.705268 \\ \text { C } & 2.180946 & -5.055080 & 1.363113 \\ \text { C } & 3.165397 & -4.982363 & 2.380187 \\ \text { C } & 4.547001 & -5.016378 & 2.032759 \\ \text { C } & 5.544374 & -5.018911 & 3.064244 \\ \text { C } & 5.158867 & -4.831522 & 4.425893 \\ \text { C } & 0.197069 & -5.041158 & -0.686347 \\ \text { C } & 1.571226 & -4.865114 & -1.021225 \\ \text { C } & 2.570500 & -4.981324 & -0.005844 \\ \text { C } & 3.938949 & -4.771194 & -0.331067 \\ \text { C } & 4.931943 & -4.891055 & 0.680233 \\ \text { C } & 6.317846 & -4.674504 & 0.360790 \\ \text { C } & 7.318472 & -4.912392 & 1.334900 \\ \text { C } & 6.923340 & -5.155623 & 2.723018 \\ \text { C } & 7.849960 & -5.332371 & 3.769475 \\ \text { C } & 7.442202 & -5.290782 & 5.097867 \\ \text { C } & 6.116221 & -4.994611 & 5.429980 \\ \text { C } & -0.793415 & -4.935703 & -1.701489 \\ \text { C } & -2.179820 & -5.056739 & -1.359238 \\ \text { C } & -2.569394 & -4.981991 & 0.009663 \\ \text { C } & -3.937894 & -4.771936 & 0.334717 \\ \text { C } & -4.279140 & -4.175805 & 1.589694 \\ \text { C } & -5.597730 & -3.670500 & 1.784593 \\ \text { C } & -5.815029 & -2.635513 & 2.727261 \\ \text { C } & -7.071313 & -1.939465 & 2.726110 \\ \text { C } & -7.116297 & -0.591681 & 3.210645 \\ \text { C } & -5.918864 & 0.007651 & 3.719177 \\ \text { C } & -5.786085 & 1.418259 & 3.699731 \\ \text { C } & -8.187510 & -2.488142 & 2.043648 \\ \text { C } & -7.975242 & -3.579915 & 1.107091 \\ \text { C } & -6.647404 & -4.031654 & 0.876563 \\ \text { C } & -6.316817 & -4.676380 & -0.357210 \\ \text { C } & -4.930861 & -4.892852 & -0.676486 \\ \text { C } & -4.545890 & -5.019165 & -2.028911 \\ \text { C } & -3.164291 & -4.985079 & -2.376368 \\ \text { C } & -2.791545 & -4.585838 & -3.700333 \\ \text { C } & -1.464860 & -4.142770 & -3.940376 \\ \text { C } & -0.438273 & -4.438762 & -2.985818 \\ & 0.894333 & -4.002647 & -3.224844 \\ & 1.918445 & -4.318582 & -2.289358\end{array}$

S173 


$\begin{array}{lrrr}\text { C } & 3.252030 & -3.845337 & -2.508396 \\ \text { C } & 4.280051 & -4.175994 & -1.586528 \\ \text { C } & 5.598522 & -3.670540 & -1.781838 \\ \text { C } & 6.648279 & -4.030690 & -0.873502 \\ \text { C } & -8.982825 & -4.034359 & 0.217261 \\ \text { C } & -8.665195 & -4.685887 & -0.954947 \\ \text { C } & -7.317393 & -4.915302 & -1.331120 \\ \text { C } & -6.922204 & -5.159495 & -2.719050 \\ \text { C } & -5.543268 & -5.022746 & -3.060388 \\ \text { C } & -5.157812 & -4.836326 & -4.422185 \\ \text { C } & -3.796171 & -4.344441 & -4.682821 \\ \text { C } & -3.528079 & -3.439454 & -5.710381 \\ \text { C } & -2.299956 & -2.744984 & -5.791961 \\ \text { C } & -1.218783 & -3.193890 & -4.976022 \\ \text { C } & 0.043126 & -2.513745 & -4.999867 \\ \text { C } & 1.132307 & -3.010705 & -4.229759 \\ \text { C } & 2.380241 & -2.324397 & -4.245754 \\ \text { C } & 3.478766 & -2.826861 & -3.480163 \\ \text { C } & 4.721076 & -2.133867 & -3.485232 \\ \text { C } & 5.815583 & -2.636266 & -2.725352 \\ \text { C } & -6.840435 & 2.212820 & 3.140568 \\ \text { C } & -8.121618 & 1.647158 & 2.910335 \\ \text { C } & -8.269551 & 0.207996 & 2.972451 \\ \text { C } & -9.449467 & -0.462407 & 2.542480 \\ \text { C } & -9.410668 & -1.763157 & 2.100693 \\ \text { C } & -6.115135 & -5.000397 & -5.426140 \\ \text { C } & -7.441059 & -5.296566 & -5.093791 \\ \text { C } & -7.848798 & -5.337211 & -3.765368 \\ \text { C } & -6.515978 & 3.493345 & 2.592278 \\ \text { C } & -7.471493 & 4.189345 & 1.795720 \\ \text { C } & -8.821960 & 3.715268 & 1.811544 \\ \text { C } & -9.131205 & 2.493976 & 2.349070 \\ \text { C } & -5.175488 & 3.965748 & 2.628811 \\ \text { C } & 0.115740 & -1.208952 & -5.557585 \\ \text { C } & -1.065476 & -0.616726 & -6.118765 \\ \text { C } & -2.202361 & -1.421635 & -6.404769 \\ \text { C } & -3.349201 & 5.225508 & 1.575463 \\ \text { C } & -4.739089 & 4.919210 & 1.668079 \\ \text { C } & -1.166143 & 0.811483 & -6.184781 \\ & -2.390400 & 1.424795 & -6.563595\end{array}$




$\begin{array}{rrrr}\text { C } & -3.393497 & 0.585892 & -7.115327 \\ \text { C } & -3.303997 & -0.786924 & -7.034605 \\ \text { C } & 1.271862 & -0.412867 & -5.327238 \\ \text { C } & 2.446567 & -1.009409 & -4.788522 \\ \text { C } & 1.157809 & 1.014564 & -5.360572 \\ \text { C } & -0.098309 & 1.610330 & -5.653244 \\ \text { C } & 3.602744 & -0.204569 & -4.532758 \\ \text { C } & 4.778302 & -0.802139 & -4.004426 \\ \text { C } & 3.477343 & 1.216146 & -4.537779 \\ \text { C } & 2.211576 & 1.811180 & -4.827530 \\ \text { C } & 5.918784 & 0.006072 & -3.719449 \\ \text { C } & 7.116359 & -0.592509 & -3.210415 \\ \text { C } & 7.071691 & -1.939927 & -2.724790 \\ \text { C } & 8.188018 & -2.487753 & -2.041858 \\ \text { C } & 7.976000 & -3.578793 & -1.104371 \\ \text { C } & 8.983688 & -4.032200 & -0.214137 \\ \text { C } & 8.666213 & -4.682867 & 0.958594 \\ \text { C } & 5.785659 & 1.416689 & -3.701161 \\ \text { C } & 4.522271 & 2.010304 & -3.986999 \\ \text { C } & 8.269417 & 0.207651 & -2.972966 \\ \text { C } & 9.449463 & -0.462117 & -2.542346 \\ \text { C } & 9.410997 & -1.762483 & -2.099422 \\ \text { C } & 8.121192 & 1.646812 & -2.912081 \\ \text { C } & 6.839830 & 2.211968 & -3.142706 \\ \text { C } & -0.376881 & 2.926561 & -5.196422 \\ \text { C } & -1.706955 & 3.448482 & -5.309515 \\ \text { C } & -2.661961 & 2.789184 & -6.131463 \\ \text { C } & 1.921006 & 3.117513 & -4.338766 \\ \text { C } & 0.594595 & 3.620295 & -4.422812 \\ \text { C } & 4.215265 & 3.303440 & -3.462875 \\ \text { C } & 2.890344 & 3.796074 & -3.534405 \\ \text { C } & 6.515090 & 3.492842 & -2.595431 \\ \text { C } & 5.174473 & 3.964892 & -2.632298 \\ \text { C } & 7.470459 & 4.189706 & -1.799455 \\ \text { C } & 8.821063 & 3.716038 & -1.815100 \\ \text { C } & 9.130608 & 2.494395 & -2.351667 \\ \text { C } & -2.120707 & 4.508522 & -4.439473 \\ \text { C } & -3.477215 & 4.927226 & -4.418627 \\ & -3.936714 & 3.397075 & -6.262826\end{array}$




$\begin{array}{rrrr}\text { C } & 0.168578 & 4.645086 & -3.517309 \\ \mathrm{C} & -1.206060 & 4.985192 & -3.440619 \\ \mathrm{C} & 2.455436 & 4.782384 & -2.596374 \\ \mathrm{C} & 1.069844 & 5.107579 & -2.513362 \\ \mathrm{C} & 4.737867 & 4.918996 & -1.672308 \\ \mathrm{C} & 3.347914 & 5.225041 & -1.579922 \\ \mathrm{C} & -1.720484 & 5.578627 & -2.254638 \\ \mathrm{C} & -3.135917 & 5.741203 & -2.102322 \\ \mathrm{C} & -3.993089 & 5.595257 & -3.229012 \\ \mathrm{C} & 0.548365 & 5.655026 & -1.306198 \\ \mathrm{C} & -0.858591 & 5.780149 & -1.142680 \\ \mathrm{C} & -3.694023 & 5.847528 & -0.787326 \\ \mathrm{C} & -5.102685 & 5.849227 & -0.609557 \\ \mathrm{C} & -5.903240 & 5.992249 & -1.767651 \\ \mathrm{C} & -5.368978 & 5.863075 & -3.034864 \\ \mathrm{C} & 2.817060 & 5.721308 & -0.351457 \\ \mathrm{C} & 1.417395 & 5.818465 & -0.181446 \\ \mathrm{C} & 5.658738 & 5.401673 & -0.677999 \\ \mathrm{C} & 7.019189 & 5.145089 & -0.863084 \\ \mathrm{C} & -7.020448 & 5.144127 & 0.858640 \\ \mathrm{C} & -5.660049 & 5.400916 & 0.673393 \\ \mathrm{C} & -1.418813 & 5.818285 & 0.176530 \\ \mathrm{C} & -2.818459 & 5.720940 & 0.346614 \\ \mathrm{H} & -10.313696 & -2.203750 & 1.698681 \\ \mathrm{H} & -10.019711 & -3.794692 & 0.413776 \\ \mathrm{H} & -9.463542 & -4.937932 & -1.640645 \\ \mathrm{H} & -8.895979 & -5.492006 & -3.540742 \\ \mathrm{H} & -10.381761 & 0.083409 & 2.477108 \\ \mathrm{H} & -8.167394 & -5.456741 & -5.881808 \\ \mathrm{H} & -5.824867 & -4.910038 & -6.466008 \\ \mathrm{H} & -10.144849 & 2.125142 & 2.262830 \\ \mathrm{H} & -4.349750 & -3.137017 & -6.345090 \\ \mathrm{H} & -4.139786 & -1.381320 & -7.380584 \\ \mathrm{H} & -4.297042 & 1.023513 & -7.519302 \\ \mathrm{H} & -4.657397 & 2.987152 & -6.958581 \\ \mathrm{H} & -5.342994 & 4.799693 & -5.517362 \\ & -6.040366 & 5.872872 & -3.883840 \\ \mathrm{H} & -6.976242 & 6.093778 & -1.668606 \\ \mathrm{H} & -9.585405 & 4.296732 & 1.306390\end{array}$




$\begin{array}{rrrr}\text { H } & 5.825929 & -4.903504 & 6.469777 \\ \mathrm{H} & 4.350380 & -3.130886 & 6.347454 \\ \mathrm{H} & 9.464610 & -4.934070 & 1.644542 \\ \mathrm{H} & 8.897168 & -5.487165 & 3.544977 \\ \mathrm{H} & 10.314126 & -2.202481 & -1.697001 \\ \mathrm{H} & 10.020504 & -3.792350 & -0.410785 \\ \mathrm{H} & 10.144404 & 2.125985 & -2.265390 \\ \mathrm{H} & 10.381606 & 0.084006 & -2.477310 \\ \mathrm{H} & 7.748921 & 5.554490 & -0.175115 \\ \mathrm{H} & 9.584422 & 4.298162 & -1.310575 \\ \mathrm{H} & 6.974767 & 6.096618 & 1.663464 \\ \mathrm{H} & 6.038940 & 5.877268 & 3.878876 \\ \mathrm{H} & 5.341815 & 4.805242 & 5.513211 \\ \mathrm{H} & 4.656620 & 2.993754 & 6.955925 \\ \mathrm{H} & 4.296643 & 1.030541 & 7.518387 \\ \mathrm{H} & 4.139958 & -1.374446 & 7.381606 \\ \mathrm{H} & 8.168562 & -5.450223 & 5.886009\end{array}$

